Universidad de Lima

) DFXOMAGHIngeniería!, QQXWMDO

\&DUHDde Ingeniería Industrial

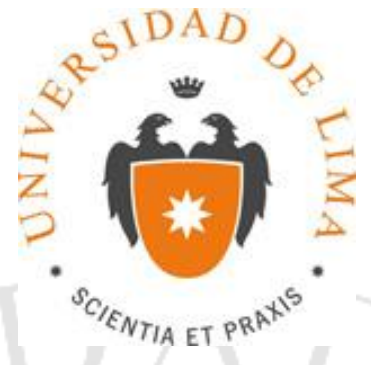

\title{
ESTUDIO DE PREFACTIBILIDAD PARA LA INSTALACIÓN DE UNA PLANTA PRODUCTORA DE LICOR A BASE DE HIGO FERMENTADO PARA EL MERCADO LOCAL
}

Trabajo de investigación para optar el Título Profesional de Ingeniero Industrial

Víctor Oscar Véliz Rueda

Código 20072653

Asesor

Alex Vidal Paredes

Lima - Perú

Abril de 2016 


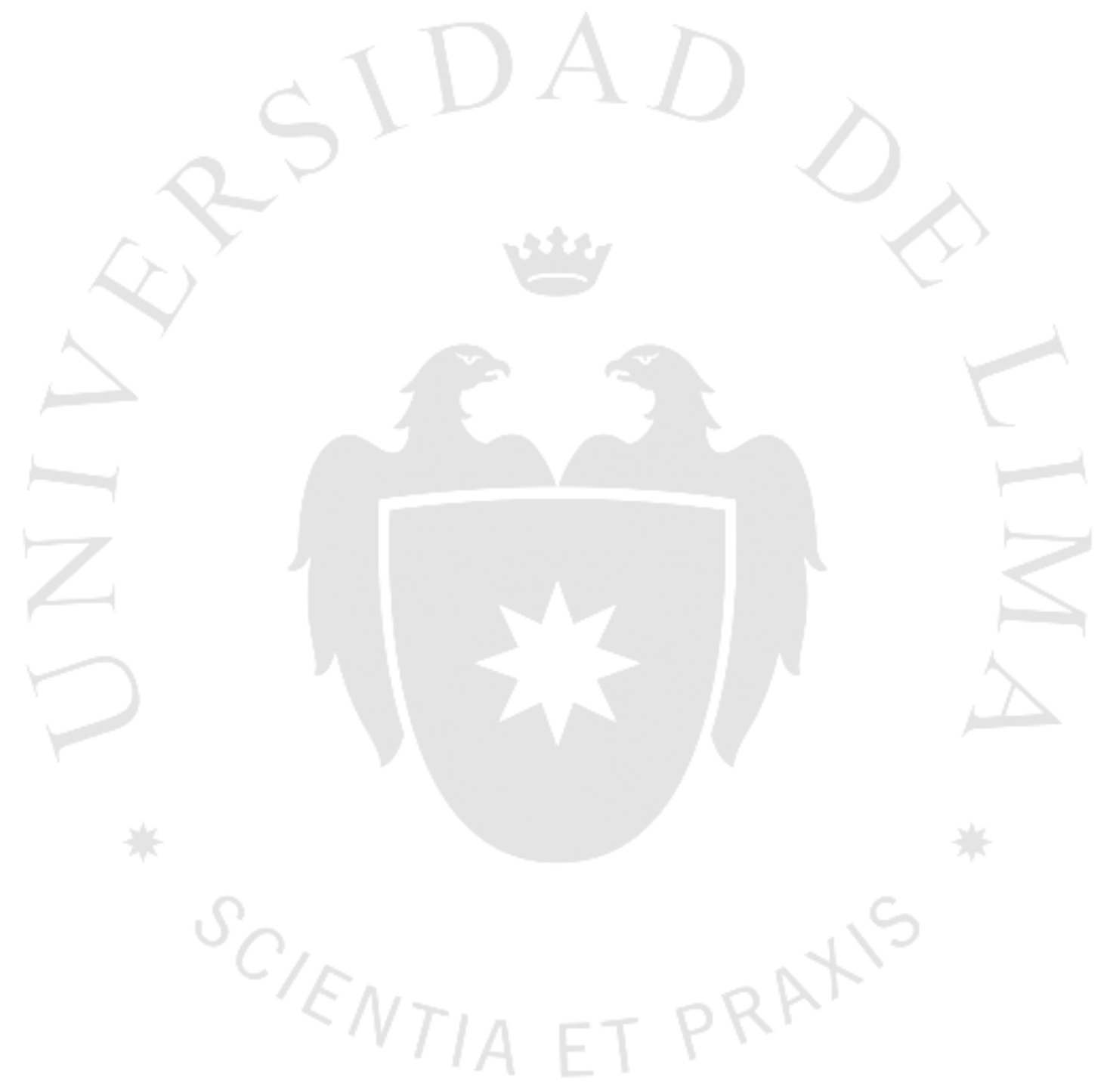


"ESTUDIO DE PREFACTIBILIDAD PARA LA INSTALACIÓN DE UNA PLANTA PRODUCTORA DE LICOR A BASE DE HIGO FERMENTADO PARA EL MERCADO LOCAL" 


\section{TABLA DE CONTENIDO}

\section{CAPÍTULO I: ASPECTOS GENERALES.}

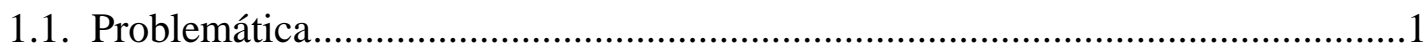

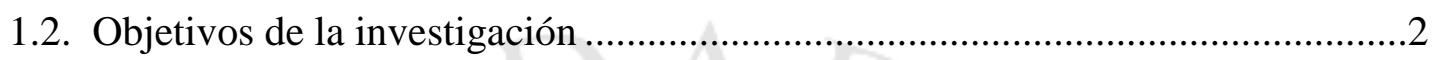

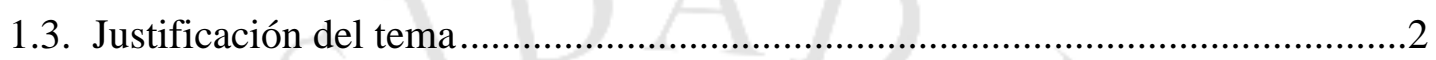

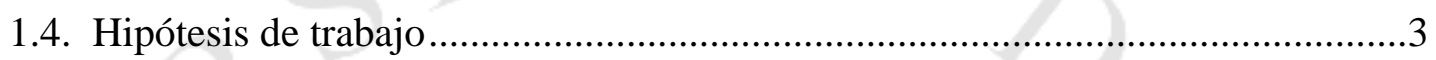

1.5. Marco referencial de la investigación .............................................................

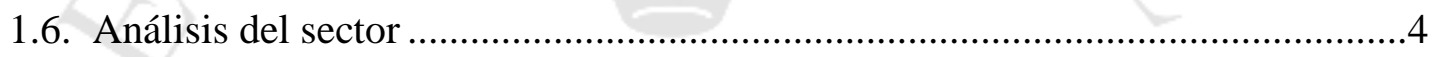

CAPÍTULO II: ESTUDIO DE MERCADO ......................................................

2.1. Aspectos generales del estudio de mercado ......................................................

2.1.1. Definición comercial del producto...........................................................

2.1.2. Principales características del producto .............................................. 9

2.1.3. Determinación del área geográfica que abarcará el estudio.......................10

2.1.4. Determinación de la metodología que se empleará en la investigación de

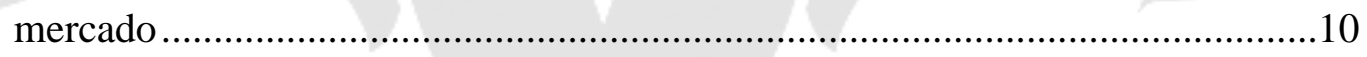

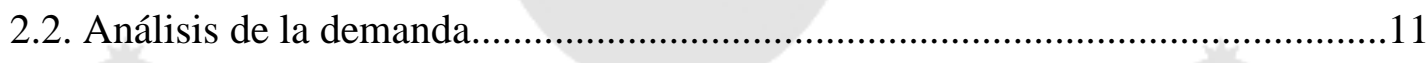

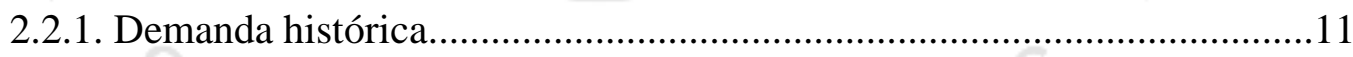

2.2.2. Demanda potencial.......................................................................... 14

2.2.3. Proyección de la demanda y metodología del análisis.............................15

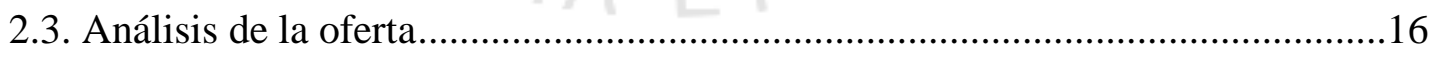

2.3.1. Análisis de la competencia............................................................... 16

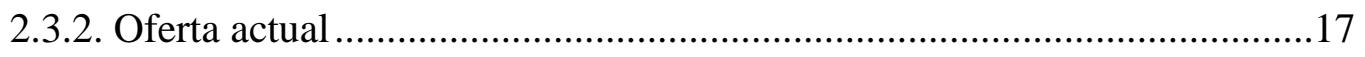

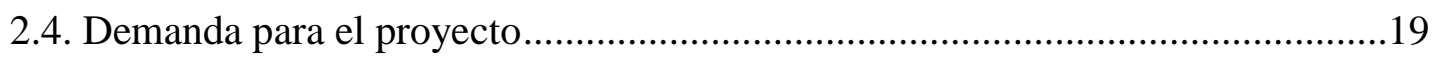

2.4.1. Segmentación del mercado ....................................................................19

2.4.3. Determinación de la demanda para el proyecto .......................................21 
2.5. Comercialización.

2.5.1. Políticas de comercialización y distribución............................................23

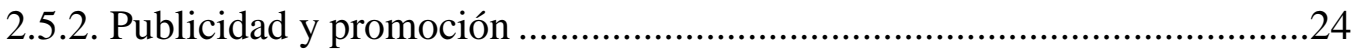

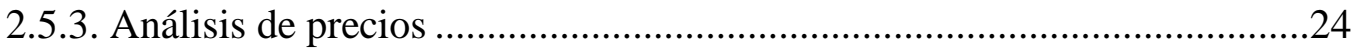

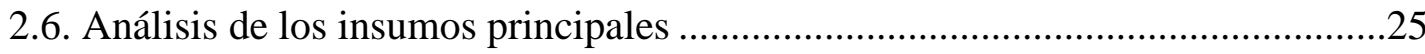

2.6.1. Características principales de la materia prima......................................25

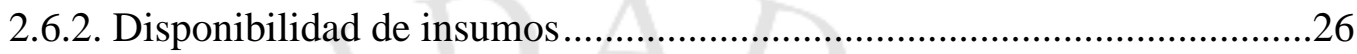

2.6.3. Costos de la materia prima .................................................................28

CAPÍTULO III: LOCALIZACIÓN DE PLANTA ............................................2

3.1. Análisis de los factores de localización .........................................................29

3.2. Identificación y descripción de las alternativas de localización ...........................30

3.3. Evaluación y selección de localización..................................................................35

3.3.1. Evaluación y selección de la macro localización ..............................................35

3.3.2. Evaluación y selección de la micro localización .......................................37

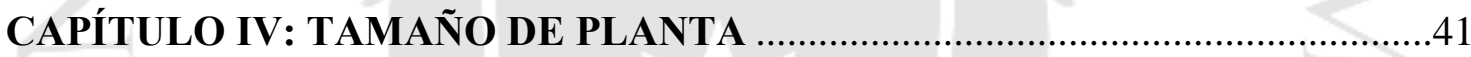

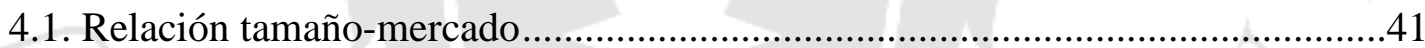

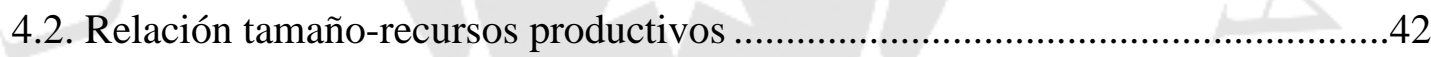

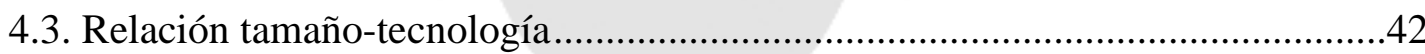

4.4. Relación Tamaño- Punto de Equilibrio...............................................................43

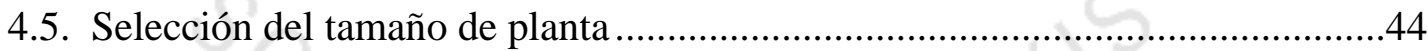

CAPÍTULO V: INGENIERÍA DEL PROYECTO.............................................46

5.1. Definición del producto basada en sus características de fabricación ................46

5.1.1. Especificaciones técnicas del producto ................................................46

5.2. Tecnologías existentes y procesos de producción...............................................47

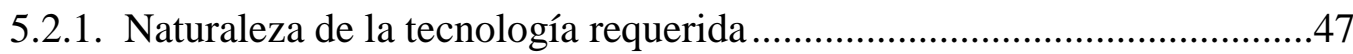

5.2.2. Proceso de producción .......................................................................49

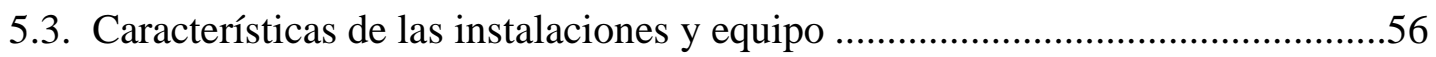


5.3.1. Selección de la maquinaria y equipo.......................................................56

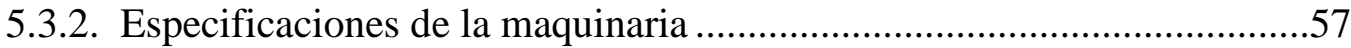

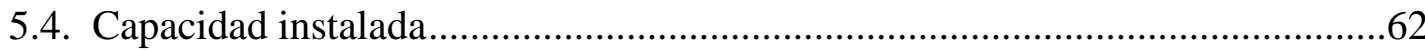

5.4.1. Cálculo de la capacidad instalada .......................................................62

5.4.2. Cálculo detallado del número de máquinas requeridas...........................63

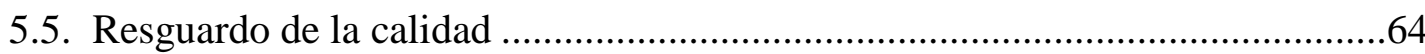

5.5.1. Calidad de la materia prima, de los insumos, del proceso y del

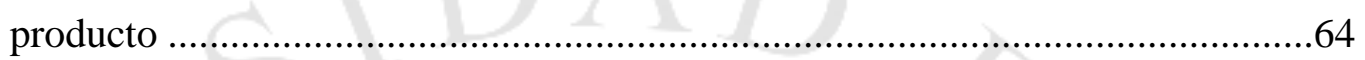

5.5.2. Medidas de resguardo de la calidad en la producción .............................66

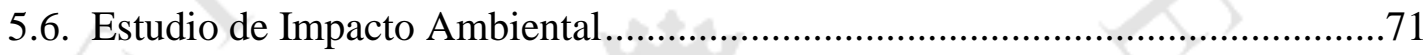

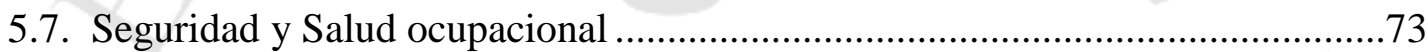

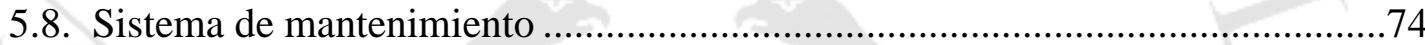

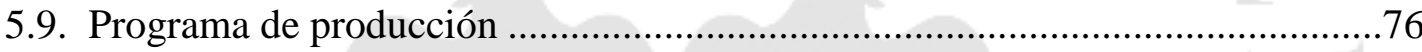

5.9.1. Consideraciones sobre la vida útil del proyecto.....................................76

5.9.2. Programa de producción para la vida útil del proyecto ...........................76

5.10.3. Determinación del número de operarios y trabajadores indirectos .........83

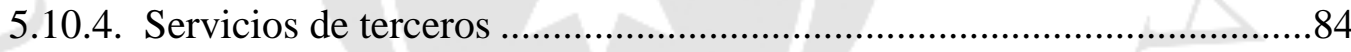

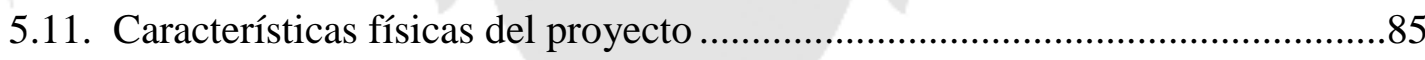

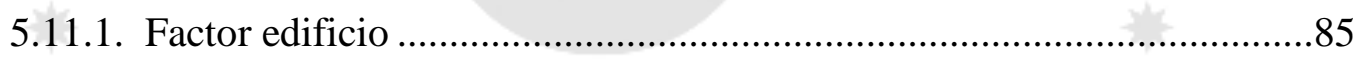

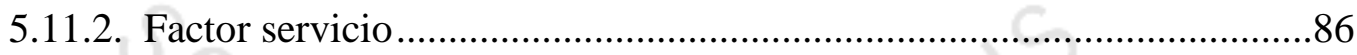

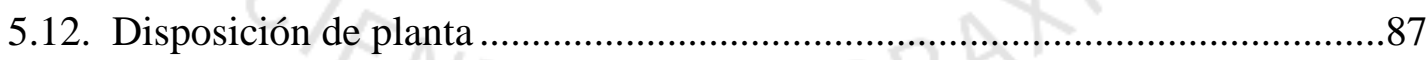

5.12.1. Determinación de las zonas físicas requeridas.....................................87

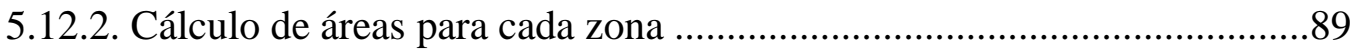

5.12.3. Dispositivos de seguridad industrial y señalización ...............................89

5.12.4. Disposición general........................................................................91

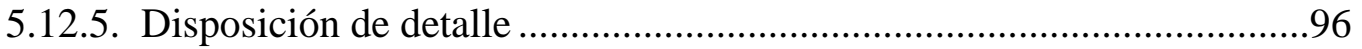

5.13. Cronograma de implementación del proyecto ..............................................100 


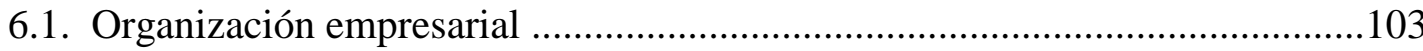

6.2. Requerimientos de personal directivo, administrativo y de servicios ...............105

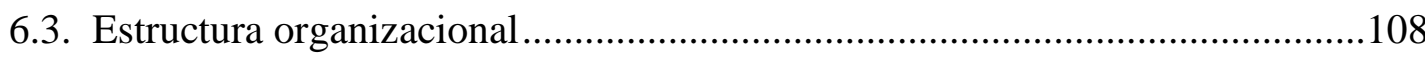

CAPÍTULO VII: ASPECTOS ECONÓMICOS Y FINANCIEROS .....................111

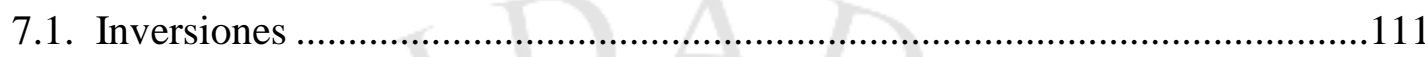

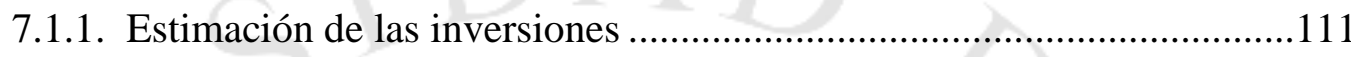

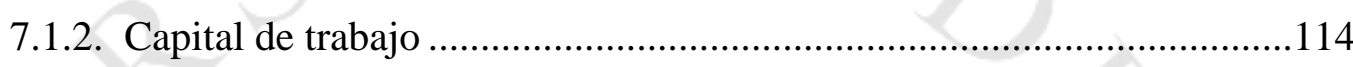

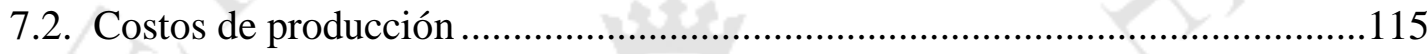

7.2.1. Costos de materias primas, insumos y otros materiales........................115

7.2.2. Costo de los servicios (energía eléctrica, agua, combustible, etc.) ........119

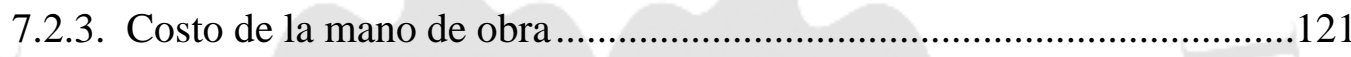

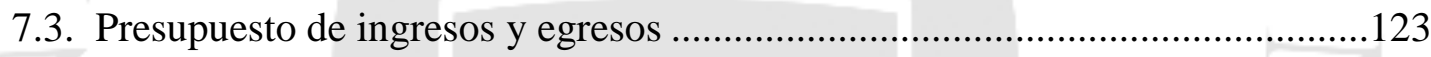

7.3.1. Presupuesto de ingreso por ventas ................................................... 123

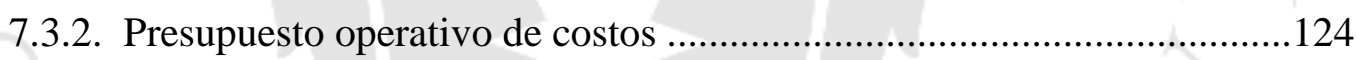

7.3.3. Presupuesto operativo de gastos administrativos................................126

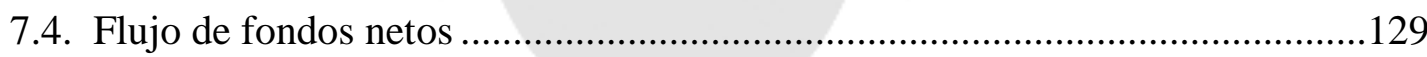

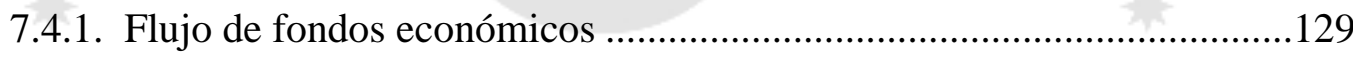

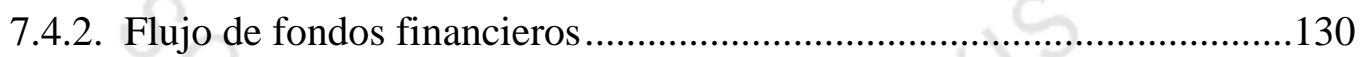

\section{CAPÍTULO VIII: EVALUACIÓN ECONÓMICA Y FINANCIERA DEL}

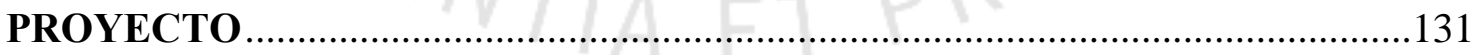

8.1. Evaluación económica: VAN, TIR, B/C, PR ................................................131

8.2. Evaluación financiera: VAN, TIR, B/C, PR ................................................132

8.3. Análisis de los resultados económicos y financieros del proyecto ...................133

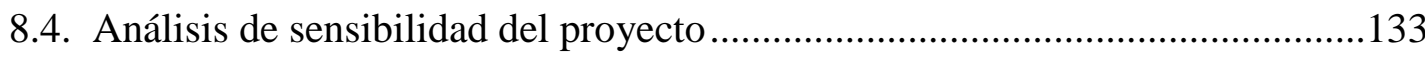


9.1. Identificación de las zonas y comunidades de influencia del proyecto

9.2. Impacto en la zona de influencia del proyecto

9.3. Impacto social del proyecto

CONCLUSIONES. .141

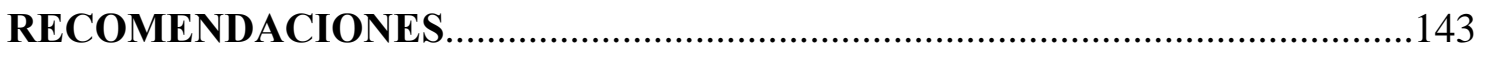

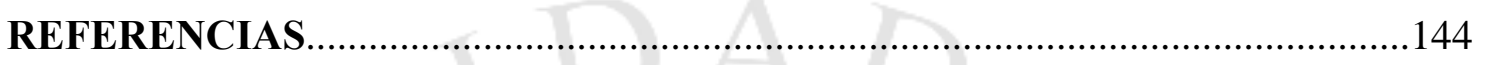

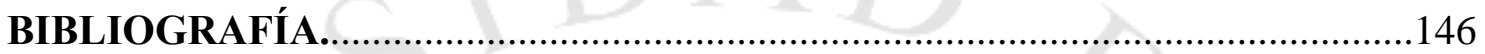

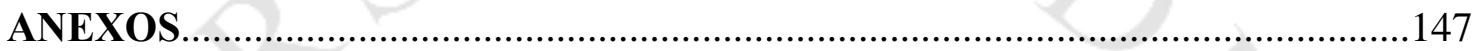




\section{ÍNDICE DE FIGURAS}

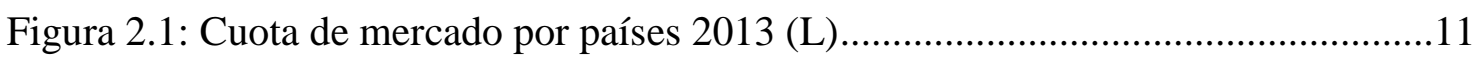

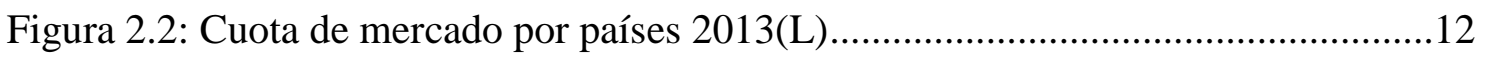

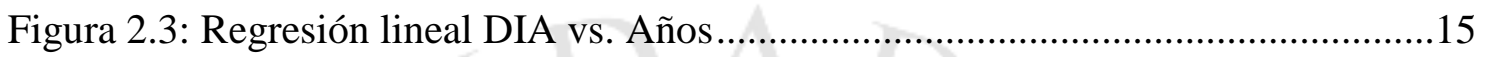

Figura 2.4: Frecuencia de consumo por rango de edades ...............................................20

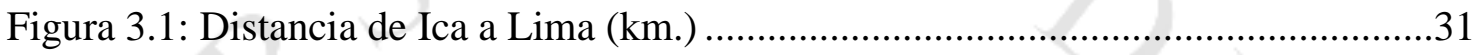

Figura 3.2: Distancia de Arequipa a Lima (km.) .....................................................

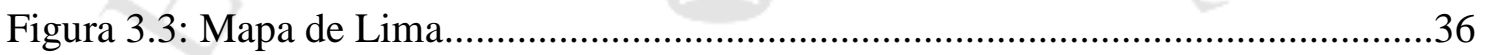

Figura 5.1: Diagrama de operaciones y procesos para la producción de licor de higo

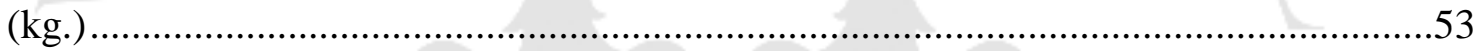

Figura 5.2: Balance de materia en la elaboración de licor de higo (kg.) ........................55

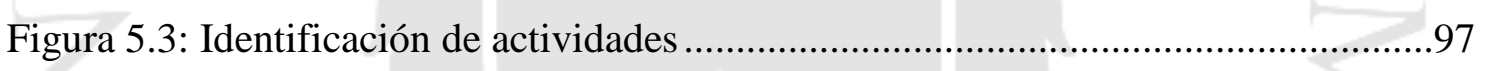

Figura 5.4: Diagrama relacional de actividades......................................................98

Figura 5.5: Plano de distribución de la planta procesadora de licor de higo .................99

Figura 5.6: Diagrama de Gantt para la implementación del proyecto ..........................101

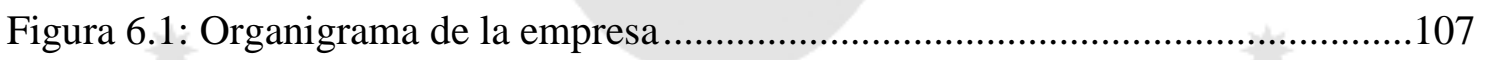




\section{ÍNDICE DE TABLAS}

Tabla 1.1: Fuerza existente en el sector en orden de poder de afectación ........................7

Tabla 2.1: Partida arancelaria de vinos con capacidad menor a 2 litros .........................9

Tabla 2.2: Clasificación Industrial Internacional Uniforme del vino .............................9

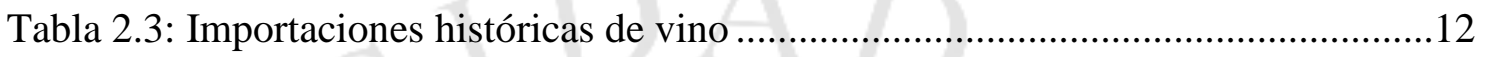

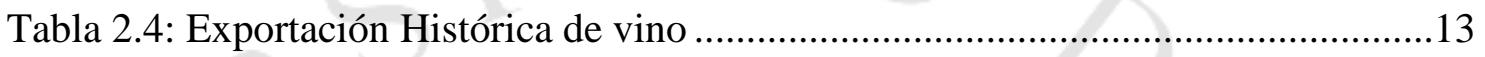

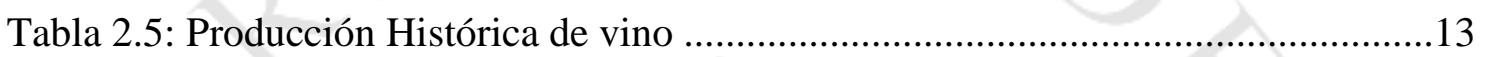

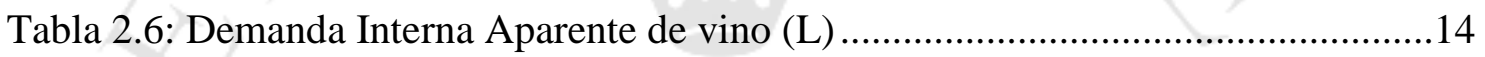

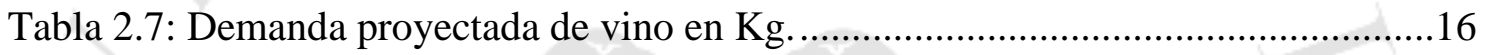

Tabla 2.8: Participación histórica de marcado por empresa (\%) . ..................................17

Tabla 2.9: Vinos nacionales e importados más consumidos en el Perú ........................18

Tabla 2.10: Demanda proyectada del proyecto ........................................................22

Tabla 2.11: Precios históricos de vinos de 750ml. (S/.) ..................................................24

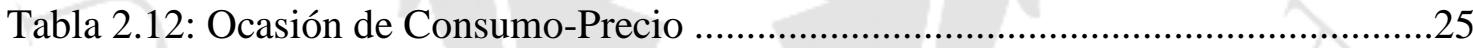

Tabla 2.13: Cantidad de nutrientes por cada 100gr. de higo seco ................................26

Tabla 2.14: Regiones con mayor producción de higo 2013 (T) ...................................26

Tabla 2.15: Producción Histórica de Higo (T) ...........................................................27

Tabla 2.16: Cantidad proyectada disponible de higo para los próximos 10 años $(\mathrm{kg})$...27

Tabla 2.17: Precio promedio histórico del higo en chacra (S/.) ...................................28

Tabla 3.1: Producción de los cultivos de higo en los departamentos de Ica, Arequipa y

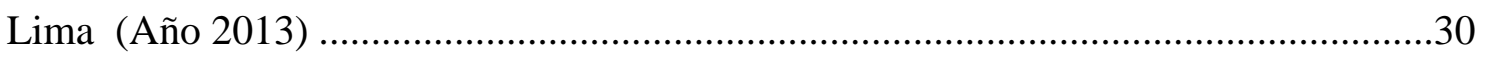

Tabla 3.2: PEA ocupada y PEA desocupada del departamento de Ica, Arequipa y Lima

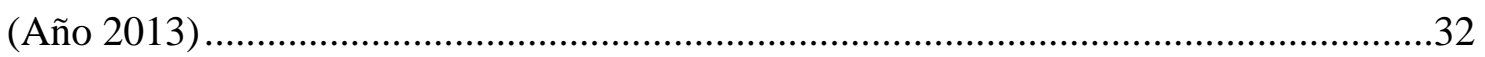

Tabla 3.3: Grado de electrificación, Potencia instalada y producción de energía eléctrica por departamentos año 2013 
Tabla 3.4: $\mathrm{N}^{\circ}$ de clientes, venta de energía y precio medio de energía por sector año 2013

Tabla 3.5: Conexiones de agua potable y alcantarilla, tarifa media (S/./m3) ................33

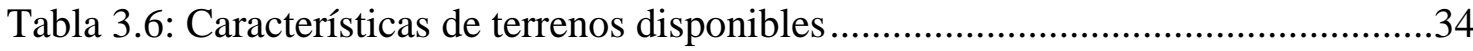

Tabla 3.7: Matriz de enfrentamiento-Macro localización ............................................35

Tabla 3.8: Ranking de factores -Macro localización ......................................................36

Tabla 3.9: Costo de transporte de una tonelada de materia prima(S/.) ..........................38

Tabla 3.10: Matriz de enfrentamiento-Micro localización .............................................39

Tabla 3.11: Ranking de factores -Micro localización ..............................................40

Tabla 4.1: Relación Tamaño-Mercado (Kg.) ...............................................................

Tabla 4.2: Relación tamaño-recursos productivos (Kg.) ..............................................42

Tabla 4.3: Relación tamaño-tecnología. (Kg.) .............................................................43

Tabla 4.4: Análisis de restricciones de tamaño de planta (kg/día.) ................................45

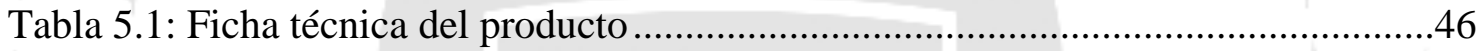

Tabla 5.2: Especificaciones técnicas de la lavadora industrial ...................................57

Tabla 5.3: Especificaciones técnicas de la mesa de selección ........................................57

Tabla 5.4: Especificaciones técnicas de la licuadora industrial ...................................58

Tabla 5.5: Especificaciones técnicas del filtro de placas ..........................................58

Tabla 5.6: Especificaciones técnicas del tanque fermentador ....................................59

Tabla 5.7: Especificaciones técnicas de la lavadora de botellas ...................................59

Tabla 5.8: Especificaciones técnicas de la encorchadora ...........................................60

Tabla 5.9: Especificaciones técnicas de la llenadora de botellas..................................60

Tabla 5.10: Especificaciones técnicas de la etiquetadora ..........................................61

Tabla 5.11: Especificaciones técnicas del tanque de almacenamiento .........................61

Tabla 5.12: Especificaciones técnicas de la pistola de calor ......................................62

Tabla 5.13: Cálculo de la capacidad instalada para el décimo año del proyecto (Kg.) ..62

Tabla 5.14: Cálculo del número de máquinas para el décimo año del proyecto (Kg.)...63 


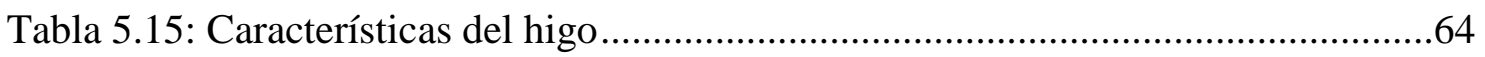

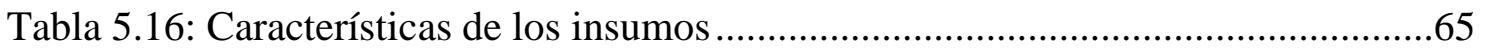

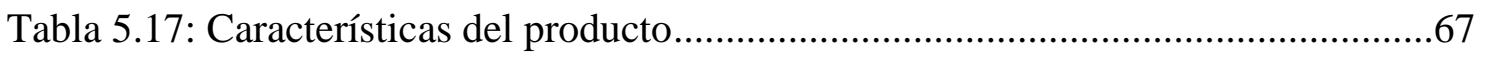

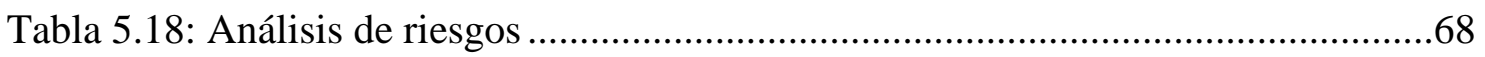

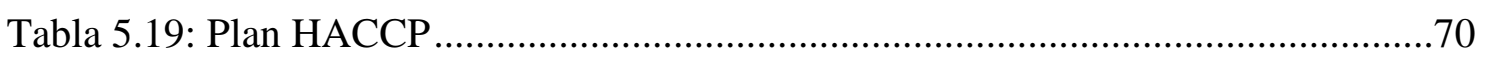

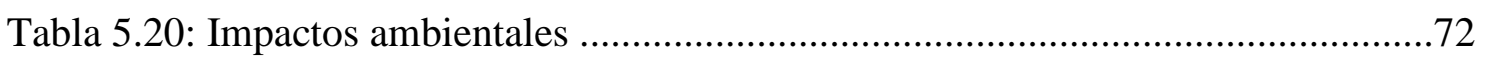

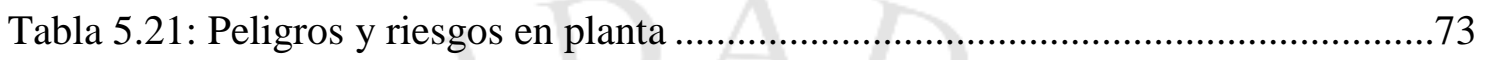

Tabla 5.22: Programa de mantenimiento de las máquinas .........................................75

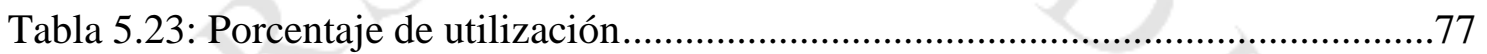

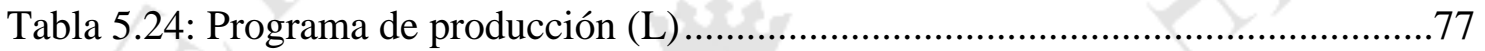

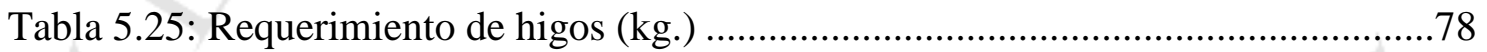

Tabla 5.26: Requerimiento de azúcar, sulfito y levaduras $(\mathrm{kg})$...................................79

Tabla 5.27: Requerimiento de botellas, corchos, cápsulas, etiquetas y cajas (Unid.) ....79

Tabla 5.28: Consumo de energía eléctrica en planta por hora ..................................... 80

Tabla 5.29: Consumo de energía eléctrica en oficinas, baños y vestuarios $(\mathrm{kW})$..........80

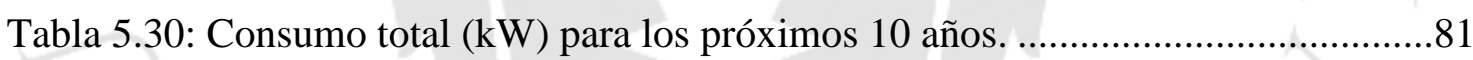

Tabla 5.31: Consumo total de agua para producción en planta .....................................82

Tabla 5.32: Consumo total de agua en baños y vestuarios .........................................83

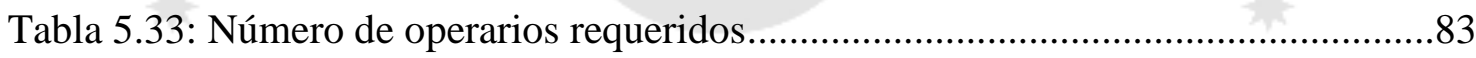

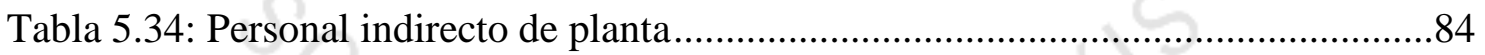

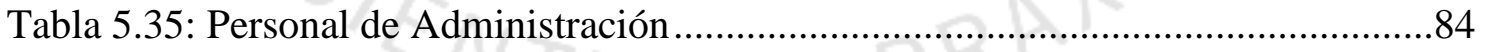

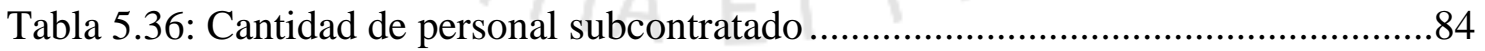

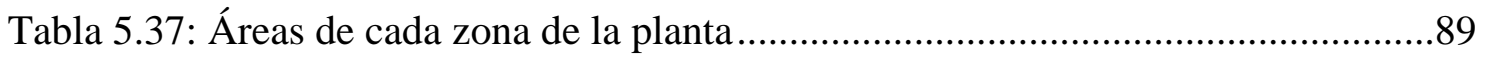

Tabla 5.38: Principales señaléticas a utilizar ............................................................90

Tabla 5.39: Cálculo de espacios para elementos fijos ................................................93

Tabla 5.40: Cálculo de espacios para elementos móviles..........................................93

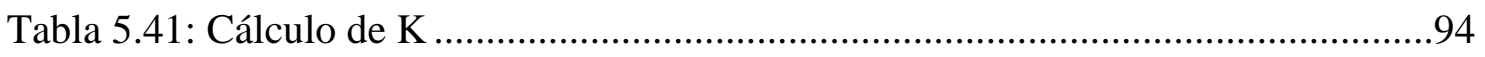


Tabla 5.42: Determinación del área requerida $\left(\mathrm{m}^{2}\right)$ .94

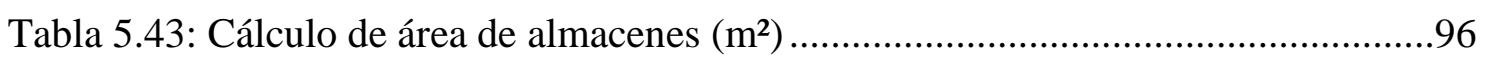

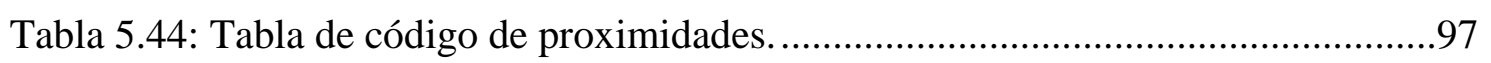

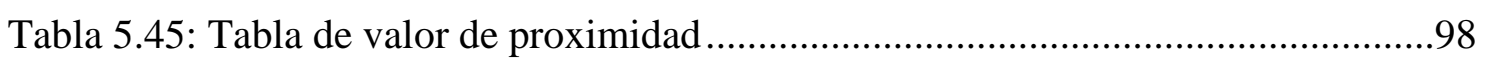

Tabla 7.1: Inversión para maquinarias y equipos .................................................111

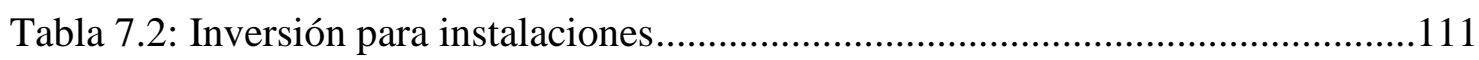

Tabla 7.3: Inversión para equipos de cómputo y mobiliario ......................................112

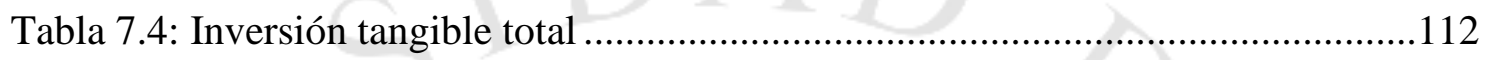

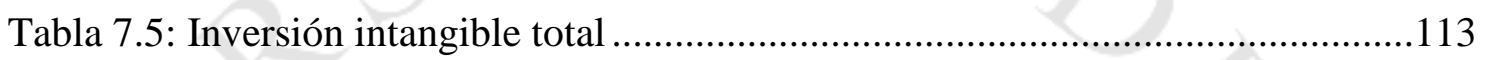

Tabla 7.6: Datos requeridos para calcular el capital de trabajo ..................................113

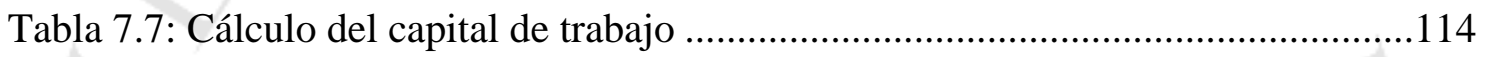

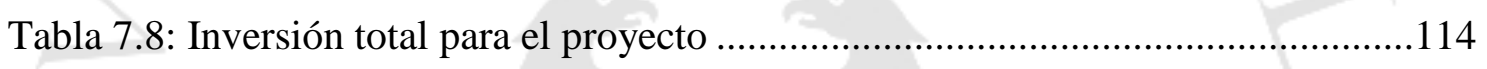

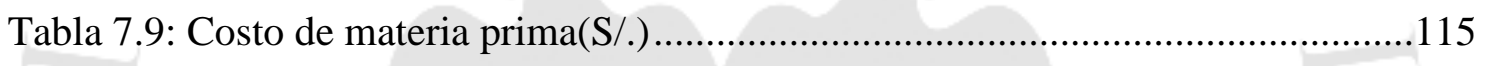

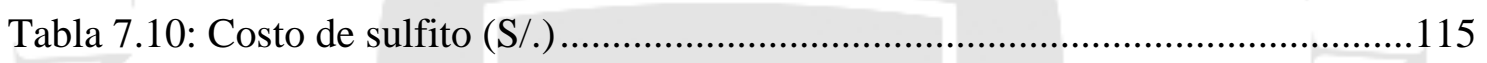

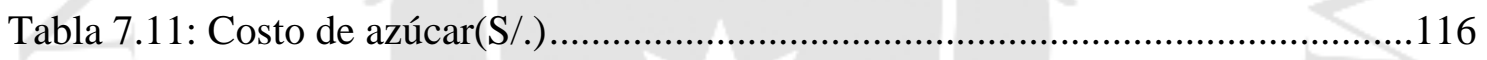

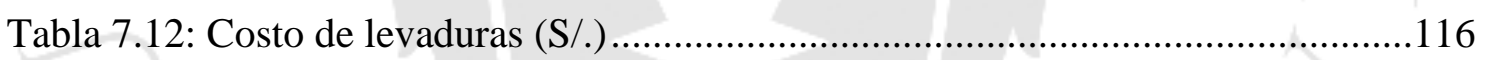

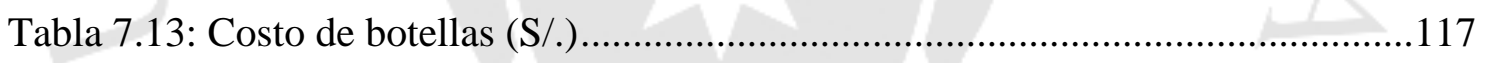

Tabla 7.14: Costo decorchos, cápsulas termoencogibles y etiquetas (S/.) ..................117

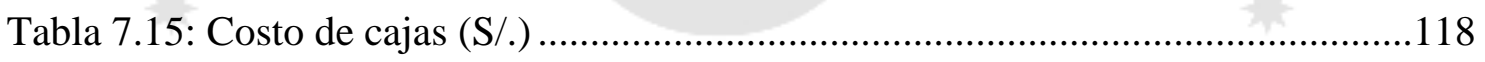

Tabla 7.16: Costo de la energía eléctrica consumida por año (S/.) ............................119

Tabla 7.17: Costo del agua consumida por las máquinas(S/.) ..................................119

Tabla 7.18: Salarios anuales de la mano de operarios y supervisores (S/.) ..................120

Tabla 7.19: Salarios anuales de la mano de obra indirecta(S/.) ...............................121

Tabla 7.20: Salarios anuales del personal administrativo (S/.) ...............................121

Tabla 7.21: Gasto en pago de servicios para los próximos 10 años (S/.) .....................122

Tabla 7.22: Presupuesto de ingreso por ventas (S/.) ............................................... 122

Tabla 7.23: Presupuesto operativo de los costos de producción(S/.)..........................123 
Tabla 7.24: Depreciación de activos tangibles anualizada (S/.)

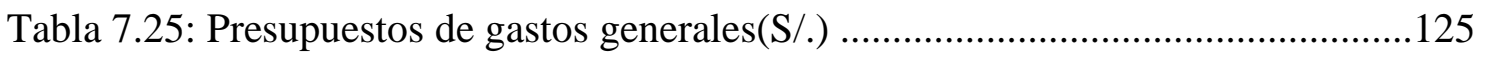

Tabla 7.26: Amortización de activos intangibles(S/.).............................................126

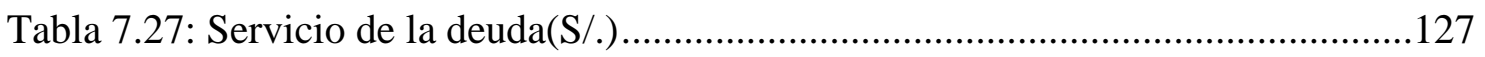

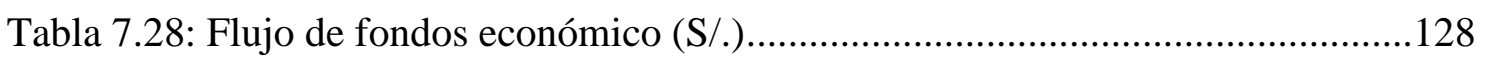

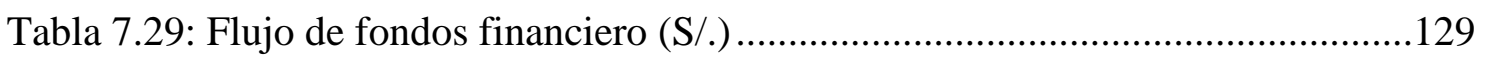

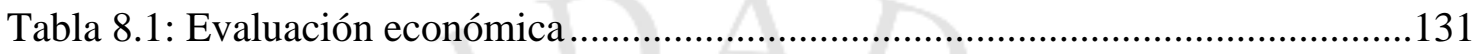

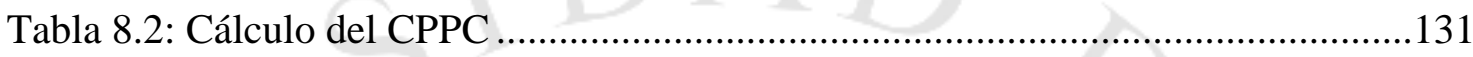

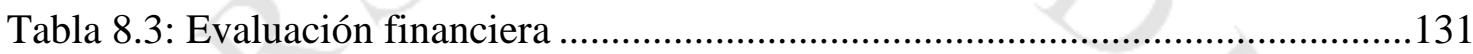

Tabla 8.4: Evaluación económica cuando el precio baja ............................................132

Tabla 8.5: Evaluación financiera cuando el precio baja .............................................133

Tabla 8.6: Evaluación económica cuando el precio sube .........................................133

Tabla 8.7: Evaluación financiera cuando el precio sube............................................133

Tabla 8.8: Evaluación económica cuando la demanda baja .......................................134

Tabla 8.9: Evaluación financiera cuando la demanda baja.......................................134

Tabla 8.10: Evaluación económica cuando la demanda sube.....................................135

Tabla 8.11: Evaluación financiera cuando la demanda sube ......................................135

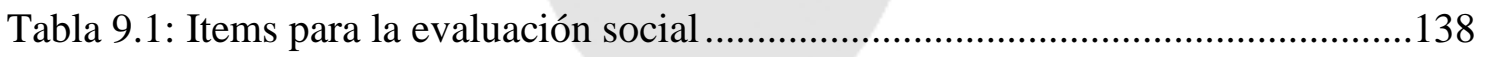




\section{ÍNDICE DE ANEXOS}

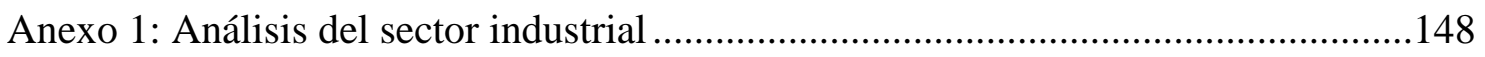

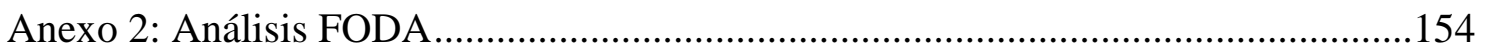

Anexo 3: Cuestionario de estudio de mercado ...............................................................159

Anexo 4: Cuestionario de estudio de mercado (con los datos obtenidos) .....................163

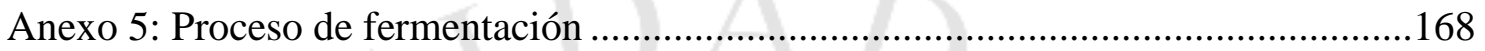

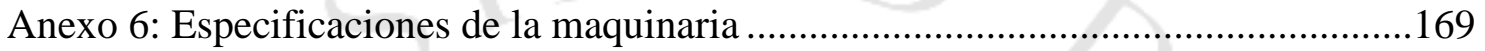

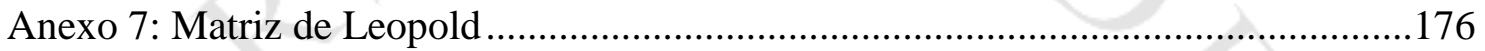

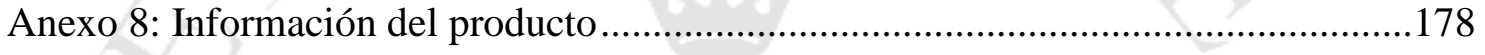

Anexo 9: Contrato de constitución de la empresa ante registros públicos ....................179 


\section{RESUMEN EJECUTIVO}

El tema del presente trabajo es la instalación de una planta productora de licor de higo fermentado para el mercado limeño, dicho producto busca ser considerado como una nueva opción para el consumo de bebidas alcohólicas, se puede tomar en toda ocasión, principalmente como acompañamiento en las comidas. El licor tiene un sabor dulce afrutado, es de color marrón y su concentración alcohólica es similar a la de un vino tradicional (12\%). El mercado objetivo será Lima Metropolitana, especificamente los distritos del nivel socioeconómico B de Lima Moderna. El producto se comercializará principalmente en autoservicios y licorerías. La presentación será en botellas de $750 \mathrm{ml}$. y será vendida a los mayoristas a un precio de S/. 15,875; llegando al consumidor final a un precio de S/. 22 aproximadamente. La constitución de la empresa es una Sociedad Anónima Cerrada, se ubicará en la provincia de Cañete, en el departamento de Lima y contará con una capacidad anual de producción de 308.330 botellas de licor. El proceso de producción implicará las actividades de selección, lavado, obtención y corrección del jugo, fermentación, filtrado, encorchado, encapsulado y etiquetado; considerando un plan HACCP que garantice la inocuidad del producto. El área total de la planta será de $720 \mathrm{~m}^{2}$. La inversión total será de S/. 1.485.596, conformada por un financiamiento bancario de $60 \%$ y un aporte propio de $40 \%$ de la inversión; obteniendo finalmente un VAN económico y financiero de S/. 2.714.780 y S/. 2.838.192 respectivamente y una TIR de $48 \%$ y $78 \%$ respectivamente. 


\section{EXECUTIVE SUMMARY}

The theme of this project is the installation of a fig liqueur plant for the Lima market, this product is intended to be considered as a new option for consumption of alcoholic drinks, it can be drunk at all times, mainly as accompaniment in foods. The liquor has a sweet fruity taste, is brown and its alcohol concentration is similar to a traditional wine (12\%). The target market is Lima Metropolitana, specifically the districts of socioeconomic level B from Lima Moderna. The product will be mainly sold in supermarkets and liquor stores. The presentation will be in $750 \mathrm{ml}$. bottles and it will be sold to wholesalers at a price of S /. 15.875, reaching un approximate price of S/. 22 for the final consumers. The constitution of the company is a private limited company, it will be located in the province of Cañete, department of Lima, and will have an annual production capacity of 308.330 bottles of liquor. The production process involves the activities of selection, washing, preparation and correction of the juice, fermentation, filtering, corking, encapsulation and labeling, considering a HACCP plan to ensure product safety. The plant area will be $720 \mathrm{~m}^{2}$. The total investment will be $\mathrm{S} / .1 .485 .596$, made by a bank contribution of $60 \%$ and an own contribution of $40 \%$ of the investment; finally obtaining an economic and financial NPV of S /. 2.714.780 and S /. 2.838.192 respectively and an IRR of $48 \%$ and $78 \%$ respectively. 


\section{CAPÍTULO I: ASPECTOS GENERALES}

\subsection{Problemática}

Los licores de frutas son ingeridos principalmente como acompañamiento en las comidas y como aperitivo en reuniones sociales y como bebida alcohólica tienen que ser consumidos por personas adultas con la debida moderación. En el mercado nacional existen licores de diversos tipos de frutas, tales como uvas, naranjas, manzanas, entre otros y en una amplia gama de presentaciones, que van desde productos en presentaciones personales hasta tamaños mayores a 2 litros. El producto presentado es un tipo de licor preparado a base de higo fermentado, que es un tipo de bebida no muy consumida aún en el país, pero con grandes posibilidades de crecimiento si se cumple con los requerimientos para su aceptación por el público objetivo.

El presente plan de investigación para la instalación de una planta procesadora de licor a base de higo fermentado para el mercado local, parte de dos motivos principales; el primero de ellos es la creciente demanda en el consumo de vinos y demás licores y el segundo es aprovechar comercialmente el higo.

Las tendencias actuales muestran un aumento en el consumo de vinos en el país, influenciado por el crecimiento económico, turístico y gastronómico que se ha tenido los últimos años. Justamente en este último aspecto es en donde el Perú ha tenido un gran desarrollo y difusión, debido a que su amplia variedad de platos permite que estos puedan ser acompañados con diversos tipos de bebidas, incluyendo bebidas con alcohol. Desarrollándose así una mayor cultura vitivinícola y haciendo de esto una oportunidad para la industria del vino. Visto el crecimiento que tiene la industria de bebidas alcohólicas de casi $3 \%$ anual y el poco desarrollo industrial que tienen muchos de los frutos que se cosechan en el Perú. Los licores de fruta son una alternativa viable para el desarrollo agroindustrial, ya que dan un valor agregado a la fruta y abren un nuevo mercado, otorgando beneficios tanto económicos como sociales. 


\subsection{Objetivos de la investigación}

\section{Objetivo general:}

- Determinar la viabilidad técnica, económica, social, financiera y de mercado para la instalación de una planta para la elaboración de licor a partir del higo fermentado, determinando los costos del proyecto.

\section{Objetivos específicos:}

- Realizar un estudio de mercado del consumo del higo, estableciendo si es viable su consumo en vinos.

- Identificar y analizar las empresas que actualmente comercializan vino en el mercado nacional.

- $\quad$ Evaluar la viabilidad tecnológica del proyecto.

- Evaluar la rentabilidad económica y financiera del proyecto.

- $\quad$ Evaluar los costos asociados a la instalación de este proyecto.

\subsection{Justificación del tema}

\section{Justificación técnica:}

El proceso de elaboración del licor de fruta es muy similar al del vino tradicional, obteniéndose a partir de la fermentación alcohólica del zumo de las frutas. Diferenciándose en la utilización de mayores cantidades de agua y azúcar. La instalación de la planta permitirá que se le otorgue un mejor uso a la materia prima principal, en este caso, el higo.

\section{Justificación económica:}

En el país ha habido un incremento en el PBI en los últimos años y un “boom" en la gastronomía y con ello el crecimiento en la producción de vinos y licores nacionales se ha incrementado en los últimos años, al igual que las importaciones, esto debido a que el consumidor peruano está buscando opciones mucho más sofisticadas que, en muchas ocasiones, tienen precios más elevados. Lo cual permite que exista un creciente mercado dispuesto a pagar un buen precio por el producto y con mayor razón si este es de buena calidad. 


\section{Justificación social:}

La instalación de una planta productora de vino significará una fuente de empleo, no solo generará trabajo directo a los que laboren en la planta, sino también a los diferentes participantes de la cadena de suministro, principalmente de los agricultores, que tendrán un mercado nuevo donde vender su producto.

\subsection{Hipótesis de trabajo}

Existen las condiciones técnicas y económicas favorables para la instalación de una planta productora de licor a partir del higo, para poder aprovechar la disponibilidad de materia prima existente en el país, usar una tecnología apropiada y ubicar un mercado local para el producto.

\subsection{Marco referencial de la investigación}

Chue, A. (2011) Estudio de prefactibilidad para la implementación de una planta productora de sidra a partir de manzana delicia (Pyrus Malus D) (Tesis para optar el Título de Ingeniero Industrial). Universidad de Lima. Perú.

El estudio está orientado a producción y comercialización de sidra a base de la manzana delicia, cuyo mercado objetivo es Lima Metropolitana y dentro de esta zona las personas menores de 30 años son las seleccionadas para tenerlas como público meta, ya que según su estudio de mercado la mayoría de ellas buscan un sustituto a la cerveza. El proceso principal de la elaboración del producto es la fermentación de la fruta junto con una gasificación posterior. El producto es presentado en botellas de vidrio de $450 \mathrm{ml}$. en una novedosa presentación que incluye una la tapa rosca que brinda facilidad al momento de abrir el producto.

\section{Glosario de términos:}

- Cuba de fermentación: También llamado tanque de fermentación, es un recipiente destinado a operaciones o trasiegos de diversa índole, en dicho recipiente ocurre la fermentación del mosto. 
- Encubado: Trasiego del mosto y los hollejos a un depósito adecuado para su fermentación.

- Descube: Consiste en la separación del licor, fermentado o en proceso de fermentación, de sus hollejos.

- Fermentación: Proceso mediante el cual una sustancia se transforma en otra u otras distintas como consecuencia de la actividad de algunos microorganismos.

- Mosto: Es el jugo proveniente del estrujado, triturado o licuado de una fruta, generalmente la uva, que será el lugar de cultivo de las levaduras, por definición éste debe tener azúcares fermentables, es decir que sean capaces de alimentar levaduras para que estas generen alcohol etílico y gas carbónico.

- Trasiego: Operación consistente en separar el licor de las materias sólidas depositadas en el fondo de los recipientes, tanto durante la fermentación como durante las diferentes etapas de la crianza.

\subsection{Análisis del sector}

\section{Amenaza de entrada de nuevos competidores:}

Por las características del producto, este se encontraría compitiendo en el sector vitivinícola, y entre las barreras de entrada se tendría:

-Una inversión inicial alta principalmente en la adquisición de tanques de fermentación.

-En lo concerniente a licencias y trámites se tiene que cumplir con registros de sanidad por ser un producto comestible, y sobre las normas técnicas peruanas estas solo han centrado sus estudios en el vino de uva, por lo que se tendría que recurrir a normas de otros países o elaborar una en forma particular.

-Los principales productores de vino en el país se han ganado la confianza de sus clientes haciendo hincapié en su trayectoria y tradición, es por eso que la diferenciación es un punto clave para ingreso al mercado al ser un producto nuevo con características poco conocidas. Teniéndose que hacer una inversión alta en publicidad para crear una aceptación y una lealtad hacia la marca. 
-Las empresas establecidas en el mercado, tienen ventajas en cuanto a los costos porque ya manejan economías de escalas.

Por tanto no es tan fácil ingresar al mercado produciendo a gran escala, en este caso el poder de la fuerza es bajo.

\section{Poder de negociación de los clientes:}

El consumidor promedio peruano no tiene una gran lealtad a las marcas de vino:

De las personas que consumen vino un $35 \%$ es leal a la marca, mientras que el $55 \%$ compraría otra marca de no encontrar una de su preferencia y $10 \%$ no precisa respuesta. ${ }^{1}$

Debido a ello su poder de negociación podría establecerse como alto.

Por otra parte un gran número de consumidores realiza sus compras en supermercados, por lo cual estos últimos estarían en ventaja al momento de realizar las negociaciones.

\section{Poder de negociación de los proveedores:}

El insumo principal en la elaboración del producto es el higo. Fruto que no se le ha dado mucha importancia, por lo que mucho de los agricultores no poseen buenas técnicas de sembrío y cosecha. Esto explica que se tenga una oferta no uniforme, ni de calidad. Dándole al proveedor un nivel de negociación medio, pero que se atenuaría dando capacitación a los agricultores o en última instancia hacer una integración vertical con cosechas propias.

Sin embargo, el higo es un cultivo con producción permanente, con cosechas anuales, principalmente entre los meses de diciembre y abril. Y cuya venta se hace principalmente como higo fresco, no existiendo mucha industrialización. Además solamente se exporta el entre el 8 y $10 \%$ de la producción; por lo que no se tendría mucha competencia a la hora de adquirirlo.

\footnotetext{
1 Oficina Comercial de ProChile en Lima Perú. (abril, 2013). Estudio de Mercado de vinos en el Perú. Recuperado de http://www.lamolina.edu.pe/FACULTAD/ciencias/dquimica/CIV/PMP_VINOS_2012.pdf
} 
En el caso de los envases de vidrio no existe una industria concentrada, por lo cual dificulta que estos puedan tener un poder de negociación alto.

Entre las principales empresas tenemos a:

- $\quad$ Owens-illinois Perú S.A.

- $\quad$ Amfa vitrum SA

- $\quad$ Vtecni S.A.

- $\quad$ Envases de vidrio SAC.

\section{Amenaza de productos sustitutos:}

Entre los productos sustitutos tenemos a la cerveza nacional como principal competidor, después le siguen el wisky, el pisco y el ron como lo demuestra una encuesta:

En relación al Perú, la OMS determinó que el licor que más se consume en nuestro país es la cerveza $(46,8 \%$ del total de alcohol que se consume anualmente), seguido de diversas bebidas espirituosas $(47,1 \%)$ y del vino $(6,1 \%){ }^{2}$

Se concluye que la fuerza es alta, ya que en el país es muy fácil reemplazar al vino por cualquier otra bebida alcohólica.

\section{Rivalidad entre los competidores:}

El mercado peruano está cuantitativamente dominado por los competidores locales, que copan cerca del $80 \%$ del mercado. ${ }^{3}$

Entre los principales competidores se tendría a las empresas Santiago Queirolo, Tacama y Tabernero.

Aunque existe una relación directa entre el conocimiento del producto y la compra, casi el $64 \%$ de los consumidores no tiene una marca en especial a la hora de su compra. Por tanto la rivalidad entre competidores no resultaría tan alta.

Finalmente utilizando la tabla de atractibilidad del sector industrial (ver anexo1), se obtuvieron los siguientes resultados:

\footnotetext{
2 Perú 21. (13 de Mayo de 2014). Peruanos beben 8,1 litros de licor al año..Recuperado de http://peru21.pe/opinion/peruanos-beben-81-litros-licor-al-ano-2183012

3 Oficina Económica y Comercial de la Embajada de España en Lima. (2013) El mercado de vino en Perú. Recuperado de http://www.exteriores.gob.es/
} 


\section{Tabla 1.1}

Fuerza existente en el sector en orden de poder de afectación al sector

\begin{tabular}{|c|l|c|c|}
\hline \multicolumn{2}{|c|}{$\begin{array}{c}\text { Fuerzas existente en el sector en orden de su poder de afectación } \\
\text { al sector }\end{array}$} & $\begin{array}{c}\text { Valor obtenido en el análisis } \\
\text { previo }\end{array}$ \\
\cline { 3 - 4 } & \multicolumn{1}{|c|}{ PF } & GA \\
\hline 1 & Intensidad de la amenaza de productos sustitutos. & 0,56 & 0,44 \\
\hline 2 & Intensidad de la rivalidad existente en el sector. & 0,38 & 0,63 \\
\hline 3 & Poder de negociación de los compradores. & 0,38 & 0,63 \\
\hline 4 & Ingreso por parte de competidores potenciales. & 0,35 & 0,65 \\
\hline 5 & Poder de negociación de los proveedores. & 0,29 & 0,72 \\
\hline
\end{tabular}

Nota: $\mathrm{PF}=$ Poder de la fuerza, GA=Grado de atractibilidad.

Elaboración propia

Se concluye que la amenaza de los productos sustitutos es la más grande amenaza para el sector, seguida de la rivalidad entre los competidores y del poder de negociación de los compradores.

Las fuerzas con menor poder son las que contemplan la posibilidad de nuevos competidores en el sector y el poder negociación de los proveedores. Dichos resultados sirven para utilizar estrategias en el proyecto (Ver anexo 2). 


\section{CAPÍTULO II: ESTUDIO DE MERCADO}

En el estudio de mercado se determinará la población objetivo a la cual ofrecer el producto, así como también los precios de venta, disponibilidad de recursos y las formas de distribución del producto.

\subsection{Aspectos generales del estudio de mercado}

\subsubsection{Definición comercial del producto}

El producto ofrecido es el vino de higo. Según sus características se define como un bien:

- Tangible: Se puede percibir por los sentidos

- No durable: Se consume por cierto periodo de tiempo.

- De comparación: El consumidor lo adquiere en función de su calidad, precio, etc.

Tomando como base la teoría expuesta por Philip Kotler, se define el producto en los siguientes niveles:

\section{Producto Básico}

El producto en estudio es un sustituto del vino de uvas, es elaborado a partir de una fruta diferente, en este caso el higo. Dicho producto satisfará la necesidad de bebida alcohólica como acompañamiento en las comidas y celebraciones.

\section{Producto Real:}

Vino elaborado a partir del higo, con $12^{\circ}$ de contenido alcohólico, de olor frutado y sabor dulce característico agradable al paladar, en envase de vidrio de $750 \mathrm{ml}$ con un tapón de corcho que facilite su manipulación y conservación. Así mismo, contendrá una etiqueta adherida en la parte frontal, en la que se incluye el nombre, la marca y otras especificaciones técnicas como el peso, insumos utilizados en la elaboración, etc. 


\section{Producto aumentado:}

Servicio Post-Venta: El cliente tendrá acceso a un número telefónico y correo electrónico al cual podrá llamar en caso que tenga cualquier consulta o reclamo acerca del producto adquirido.

Servicio de entrega: Llevar el producto en excelentes condiciones.

Garantía: Aunque se busque tener cero defectos, ante cualquier eventualidad, se repondrá el producto que presente problema.

\subsubsection{Principales características del producto}

\section{Posición arancelaria NANDINA, CIUU}

Debido a que el producto es muy similar en muchos aspectos al vino, el estudio de mercado se realizará en base a este último producto. La partida arancelaria que identifica al vino es la siguiente:

Tabla 2.1

Partida arancelaria de vinos con capacidad menor a 2 litros

\begin{tabular}{|c|c|}
\hline Ítem & Descripción \\
\hline 2204.21 .00 .00 & Demás vinos en recipientes con capacidad $<=$ a 2 litros \\
\hline
\end{tabular}

Fuente: Sunat

La clasificación Industrial Internacional Uniforme es la siguiente:

\section{Tabla 2.2}

\section{Clasificación Industrial Internacional Uniforme del vino}

\begin{tabular}{|c|l|}
\hline CIUU & \multicolumn{1}{|c|}{ Descripción } \\
\hline 1551 & $\begin{array}{l}\text { Destilación, rectificación y mezcla de bebidas alcohólicas; } \\
\text { producción de alcohol etílico a partir de sustancias fermentadas }\end{array}$ \\
\hline
\end{tabular}

Fuente: Ministerio de la Producción (2013) 


\section{EXECUTIVE SUMMARY}

The theme of this project is the installation of a fig liqueur plant for the Lima market, this product is intended to be considered as a new option for consumption of alcoholic drinks, it can be drunk at all times, mainly as accompaniment in foods. The liquor has a sweet fruity taste, is brown and its alcohol concentration is similar to a traditional wine (12\%). The target market is Lima Metropolitana, specifically the districts of socioeconomic level B from Lima Moderna. The product will be mainly sold in supermarkets and liquor stores. The presentation will be in $750 \mathrm{ml}$. bottles and it will be sold to wholesalers at a price of S /. 15.875, reaching un approximate price of S/. 22 for the final consumers. The constitution of the company is a private limited company, it will be located in the province of Cañete, department of Lima, and will have an annual production capacity of 308.330 bottles of liquor. The production process involves the activities of selection, washing, preparation and correction of the juice, fermentation, filtering, corking, encapsulation and labeling, considering a HACCP plan to ensure product safety. The plant area will be $720 \mathrm{~m}^{2}$. The total investment will be $\mathrm{S} / \mathrm{1}$.485.596, made by a bank contribution of $60 \%$ and an own contribution of $40 \%$ of the investment; finally obtaining an economic and financial NPV of S /. 2.714.780 and S /. 2.838.192 respectively and an IRR of $48 \%$ and $78 \%$ respectively. 


\subsection{Análisis de la demanda}

\subsubsection{Demanda histórica}

\section{Importaciones/exportaciones}

Entre los años 2004 y 2013 el valor FOB de las importaciones de vino registró una tasa de crecimiento promedio anual de 12,8\%, habiendo triplicado su valor al pasar de US\$ 11 a 34 millones de dólares en términos FOB; sin embargo, el volumen importado en litros no ha crecido en la misma magnitud ya que se incrementó en 1,5 veces, situación que está relacionada al aumento de los precios unitarios promedio.

El $40 \%$ de los vinos importados que se consumen en el país son argentinos, aproximadamente 3,5 millones de litros el año 2013, compitiendo directamente con los vinos provenientes de Chile que representan el 37,3\% del volumen importado (3,2 millones de litros); pero con precios relativamente menores. Así el vino chileno ingresó a nuestro país el año 2013 a un valor unitario promedio de US\$2,63 el litro mientras que el vino argentino lo hizo a US\$ 3,92. España representa el 12\% de importación en volumen, seguido de Italia y Francia, como se aprecia en la siguiente figura:

\section{Figura 2.1}

\section{Cuota de mercado por países 2013 (L)}

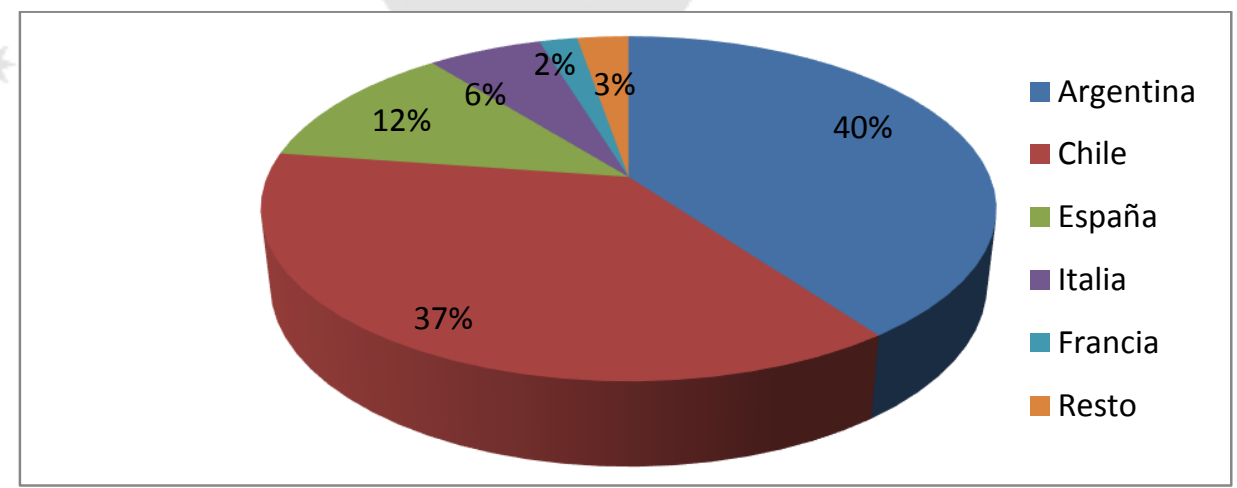

Fuente: Euromonitor Internacional (2013)

Las importaciones de vino han tenido un incremento constante como se puede ver en la tabla 2.3. 
Tabla 2.3

\section{Importaciones históricas de vino}

\begin{tabular}{|c|c|c|}
\hline Año & US \$ CIF & Litros (L) \\
\hline 2004 & 12.623 .060 & 6.010 .981 \\
\hline 2005 & 14.542 .443 & 6.463 .308 \\
\hline 2006 & 16.597 .524 & 6.915 .635 \\
\hline 2007 & 17.410 .986 & 6.962 .211 \\
\hline 2008 & 21.154 .159 & 7.576 .318 \\
\hline 2009 & 19.269 .041 & 6.821 .308 \\
\hline 2010 & 23.224 .020 & 7.963 .189 \\
\hline 2011 & 28.895 .866 & 9.103 .151 \\
\hline 2012 & 32.958 .438 & 8.889 .852 \\
\hline 2013 & 32.279 .632 & 8.494 .640 \\
\hline
\end{tabular}

Fuente: Sunat

Las exportaciones de vino se han incrementado en los últimos años; sin embargo, la cantidad exportada es mucho menor a la cantidad importada, siendo Estados Unidos un país tradicional para las exportaciones; como se puede ver en la figura 2.2:

Figura 2.2.

Cuota de mercado por países 2013 (L)

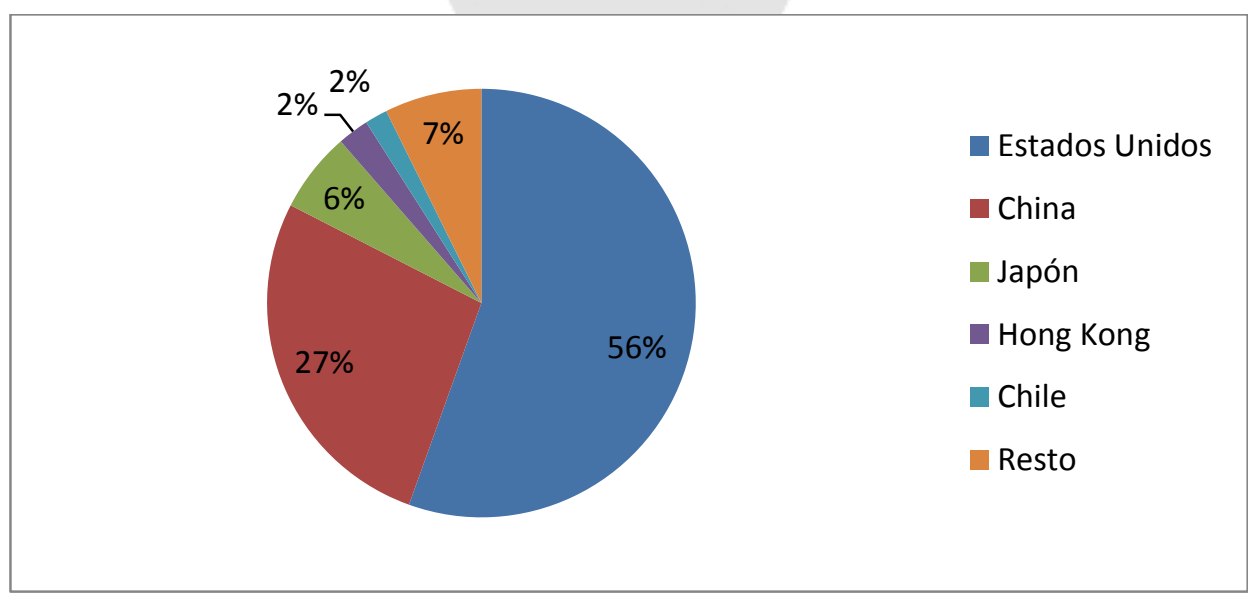

Fuente: Euromonitor Internacional (2013)

La exportación histórica del vino se puede apreciar en la siguiente tabla: 
Tabla 2.4

Exportación Histórica de vino

\begin{tabular}{|c|c|c|}
\hline Año & US \$ FOB & Litros (L) \\
\hline 2004 & 278.700 & 139.300 \\
\hline 2005 & 354.400 & 168.700 \\
\hline 2006 & 355.800 & 155.000 \\
\hline 2007 & 645.900 & 277.600 \\
\hline 2008 & 626.600 & 223.600 \\
\hline 2009 & 457.400 & 175.800 \\
\hline 2010 & 821.000 & 294.600 \\
\hline 2011 & 789.300 & 293.400 \\
\hline 2012 & 901.600 & 342.800 \\
\hline 2013 & 477.000 & 180.000 \\
\hline
\end{tabular}

Fuente: SUNAT

\section{Producción}

La producción nacional de vino, se aprecia en la tabla 2.5:

Tabla 2.5

Producción Histórica de vino

\begin{tabular}{|c|c|c|}
\hline Año & Litros (L) & US\$ \\
\hline 2004 & 15.628 .319 & 237.811 .056 \\
\hline 2005 & 18.684 .692 & 301.378 .025 \\
\hline 2006 & 19.900 .000 & 340.239 .382 \\
\hline 2007 & 22.600 .000 & 409.586 .665 \\
\hline 2008 & 28.100 .000 & 540.666 .461 \\
\hline 2009 & 25.500 .000 & 510.650 .580 \\
\hline 2010 & 32.400 .000 & 675.034 .182 \\
\hline 2011 & 32.000 .000 & 702.141 .247 \\
\hline 2012 & 33.300 .000 & 792.026 .233 \\
\hline 2013 & 34.625 .360 & 872.962 .314 \\
\hline
\end{tabular}

Fuente: SUNAT

\section{Demanda Interna Aparente (DIA)}

El mercado peruano de vinos experimentó durante los últimos años un crecimiento sostenido, con un único año de caída (2009) ligado a la coyuntura económica y un $40 \%$ de aumento acumulado en los últimos cinco años. El mercado de vinos está principalmente conformado por vinos dulces (50\%), ya que 
no existe una cultura vinícola generalizada. La demanda interna aparente (DIA) está constituida por la siguiente fórmula: Producción + Importaciones exportaciones:

Tabla2.6

Demanda interna aparente de vino ( $L)$

\begin{tabular}{|c|c|c|c|c|}
\hline Año & Producción & Importaciones & Exportaciones & DIA \\
\hline 2004 & 15.628 .319 & 6.010 .981 & 139.300 & 21.500 .000 \\
\hline 2005 & 18.684 .692 & 6.463 .308 & 168.700 & 24.979 .300 \\
\hline 2006 & 19.900 .000 & 6.915 .635 & 155.000 & 26.660 .635 \\
\hline 2007 & 22.600 .000 & 6.962 .211 & 277.600 & 29.284 .611 \\
\hline 2008 & 28.100 .000 & 7.576 .318 & 223.600 & 35.452 .718 \\
\hline 2009 & 25.500 .000 & 6.821 .308 & 175.800 & 32.145 .508 \\
\hline 2010 & 32.400 .000 & 7.963 .189 & 294.600 & 40.068 .589 \\
\hline 2011 & 32.000 .000 & 9.103 .151 & 293.400 & 40.809 .751 \\
\hline 2012 & 33.300 .000 & 8.889 .852 & 342.800 & 41.847 .052 \\
\hline 2013 & 34.625 .360 & 8.494 .640 & 180.000 & 42.940 .000 \\
\hline
\end{tabular}

\subsubsection{Demanda potencial}

\section{Patrones de consumo}

El licor de higo fermentado no se comercializa a gran escala en Lima Metropolitana; sin embargo, se puede deducir que las personas que comprarán dicho producto son las asiduas consumidoras de vino, especialmente de los vinos dulces, que son muchas veces consumidos como bajativos y como aperitivos en diversas reuniones.

\section{Determinación de la demanda potencial}

El consumo per-cápita de vino en el Perú es de 1,5 litros, de esta cifra el $50 \%$ corresponde a los vinos dulces; lo que representa una cifra aún baja comparada con el consumo per-cápita de vino en Chile y Argentina que alcanzan los 15 y 20 litros respectivamente. Por lo tanto la demanda potencial serían los 15 litros consumidos por persona en Chile multiplicados por el $50 \%$ que representa el consumo de vino dulce. 
Teniendo como resultado una demanda potencial per cápita de 7,5 litros al año y demanda potencial total de 229 millones de litros al año.

\subsubsection{Proyección de la demanda y metodología del análisis}

Se realizó la proyección de la demanda interna aparente de vino obtenida a través de una regresión lineal, considerando lo siguiente:

$\checkmark \quad$ Variable dependiente: Demanda interna aparente de vinos en el país.

$\checkmark \quad$ Variable independiente: Años.

Obteniendo una correlación de 94\%, como se aprecia en la figura 2.3:

\section{Figura 2.3.}

\section{Regresión lineal DIA vs. Años.}

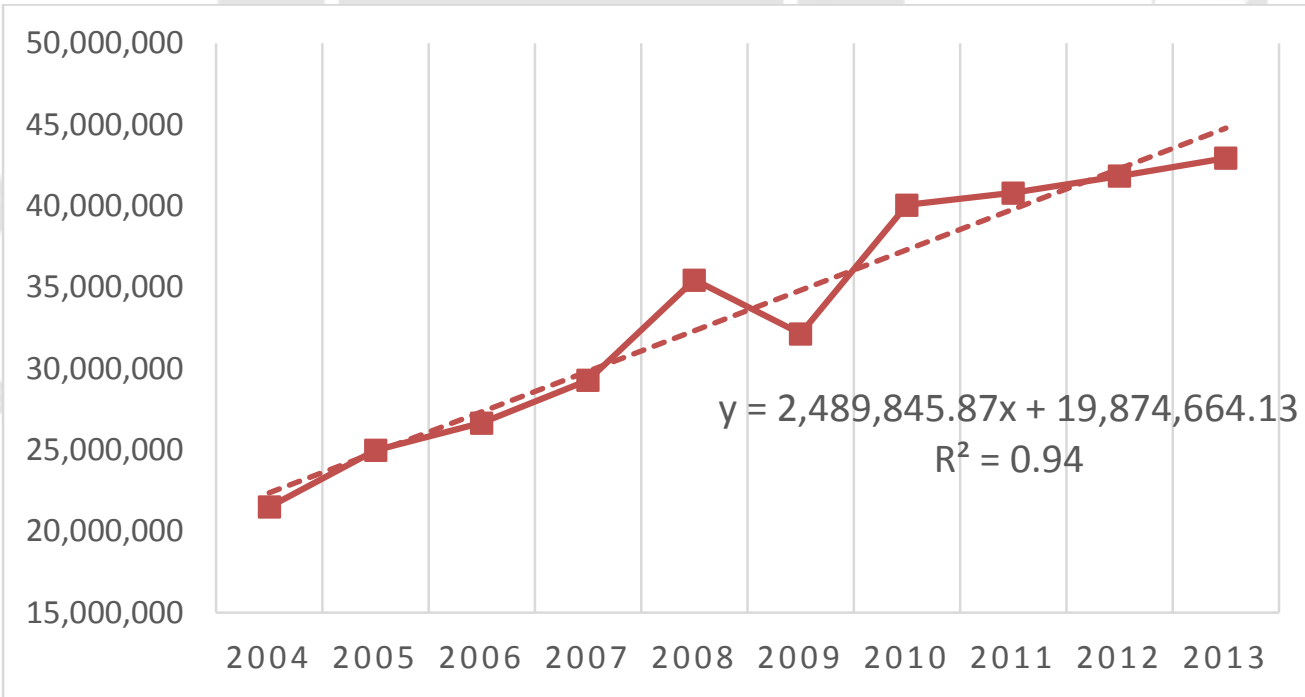

Elaboración propia

Con la fórmula obtenida de la regresión se proyecta la demanda de vino, como se observa en la tabla: 
Tabla 2.7

Demanda proyectada de vino en litros

\begin{tabular}{|c|c|}
\hline Año & Demanda (L) \\
\hline 2015 & 49.752 .815 \\
\hline 2016 & 52.242 .660 \\
\hline 2017 & 54.732 .506 \\
\hline 2018 & 57.222 .352 \\
\hline 2019 & 59.712 .198 \\
\hline 2020 & 62.202 .044 \\
\hline 2021 & 64.691 .890 \\
\hline 2022 & 67.181 .736 \\
\hline 2023 & 69.671 .581 \\
\hline 2024 & 72.161 .427 \\
\hline \multicolumn{2}{|c|}{ Elaboración propia } \\
\hline
\end{tabular}

\subsection{Análisis de la oferta}

\subsubsection{Análisis de la competencia}

La compañías nacionales productoras de vino están lideradas por Santiago Queirolo, Tacama y Tabernero que en conjunto abarcan un 55\% de la producción local en el año 2013; las compañías extranjeras tienen un porcentaje de participación bajo con respecto a estas tres productoras locales, debido principalmente a que sus productos son de gama media alta y tienen un precio más elevado.

En los últimos años la concentración de pocas empresas ocupando la mayor parte de la participación de mercado está disminuyendo, lo que demuestra que nuevas compañías productoras de vino tienen oportunidades de crecimiento en el mercado nacional, como se observa en el rubro otro la siguiente tabla: 
Tabla 2.8

Participación histórica de mercado por empresa (\%)

\begin{tabular}{|c|c|c|c|c|c|c|c|}
\hline Empresa & País & 2008 & 2009 & 2010 & 2011 & 2012 & 2013 \\
\hline Santiago Queirolo SA & Perú & $32,5 \%$ & $33,5 \%$ & $31,3 \%$ & $29,6 \%$ & $27,5 \%$ & $27,1 \%$ \\
\hline Viña Tacama SA & Perú & $28,4 \%$ & $26,9 \%$ & $24,2 \%$ & $21,6 \%$ & $19,5 \%$ & $19,0 \%$ \\
\hline Bodegas y Viñedos Tabernero SA & Perú & $11,2 \%$ & $10,6 \%$ & $9,8 \%$ & $8,9 \%$ & $8,2 \%$ & $8,6 \%$ \\
\hline Viña Concha y Toro SA & Chile & $2,4 \%$ & $2,5 \%$ & $2,7 \%$ & $3,3 \%$ & $3,3 \%$ & $3,2 \%$ \\
\hline Cía Cervecerías Unidas SA & Chile & $0,9 \%$ & $1,0 \%$ & $1,3 \%$ & $1,5 \%$ & $1,6 \%$ & $1,6 \%$ \\
\hline $\begin{array}{c}\text { Cooperativa Vitivinicola San Carlos } \\
\text { Sud Ltda }\end{array}$ & Argentina & $0,3 \%$ & $0,7 \%$ & $0,9 \%$ & $1,3 \%$ & $1,7 \%$ & $1,6 \%$ \\
\hline Campari Milano SpA, Davide & Italia & $0,7 \%$ & $0,8 \%$ & $1,0 \%$ & $1,3 \%$ & $1,5 \%$ & $1,5 \%$ \\
\hline Diageo Plc & Inglaterra & $0,2 \%$ & $0,3 \%$ & $0,4 \%$ & $0,4 \%$ & $0,6 \%$ & $0,6 \%$ \\
\hline $\begin{array}{c}\text { LVMH Moët Hennessy Louis } \\
\text { Vuitton SA }\end{array}$ & Francia & $0,1 \%$ & $0,1 \%$ & $0,2 \%$ & $0,2 \%$ & $0,2 \%$ & $0,2 \%$ \\
\hline Bodega Fecovita Cooperativa Ltda & Argentina & $0,2 \%$ & $0,2 \%$ & $0,2 \%$ & $0,3 \%$ & $0,2 \%$ & $0,2 \%$ \\
\hline Freixenet SA & España & $0,1 \%$ & $0,1 \%$ & $0,1 \%$ & $0,1 \%$ & $0,1 \%$ & $0,1 \%$ \\
\hline Otros & 2 & $23 \%$ & $23 \%$ & $28 \%$ & $31 \%$ & $36 \%$ & $36 \%$ \\
\hline Total & & $100 \%$ & $100 \%$ & $100 \%$ & $100 \%$ & $100 \%$ & $100 \%$ \\
\hline
\end{tabular}

Fuente: Euromonitor Internacional

\subsubsection{Oferta actual}

La oferta de vinos en el Perú está comprendida por la producción local $(78 \%)$ y las importaciones (22\%). Los productores nacionales generalmente ofrecen vinos de menor precio a comparación de los vinos.

En términos cuantitativos, y en línea con la evolución del mercado, se observa una suave tendencia creciente de la producción local, con una brusca interrupción en 2009 y un ligero crecimiento en 2012. 
Los vinos tintos son los que lideran la oferta en el país, seguida de los vinos blancos y rosados, los vinos de los grandes productores nacionales están orientados principalmente a un sector que consume vinos de gama media-baja, con precios que van desde los 10 soles hasta los 60 soles aproximadamente.

En la siguiente tabla se observa una lista de los vinos de gama media más consumidos en el país con sus respectivos precios promedios:

Tabla 2.9

Vinos nacionales e importados más consumidos en el Perú

\begin{tabular}{|c|c|c|c|c|}
\hline $\begin{array}{l}\text { Tipo de } \\
\text { vino }\end{array}$ & $\begin{array}{l}\text { Vinos Nacionales más } \\
\text { consumidos }\end{array}$ & $\begin{array}{c}\text { Precio } \\
\text { por } \\
\text { botella } \\
(\mathrm{S} / .) \\
\end{array}$ & $\begin{array}{c}\text { Vinos Importados más } \\
\text { consumidos }\end{array}$ & $\begin{array}{c}\text { Precio } \\
\text { por } \\
\text { botella } \\
(\mathrm{S} / .) \\
\end{array}$ \\
\hline \multirow{3}{*}{$\begin{array}{l}\text { Vino } \\
\text { rosado }\end{array}$} & Rosé Semi Seco Tacama & 24,50 & Liebfraunmilch Augustus & 16,90 \\
\hline & Gran Rosé Tabernero & 21,00 & Black Tower & 27,90 \\
\hline & Rosé Semi Seco Tabernero & 20,99 & Los árboles Navarro Correas & 28,90 \\
\hline \multirow{6}{*}{$\begin{array}{l}\text { Vino } \\
\text { blanco }\end{array}$} & Gran Blanco Seco Tacama & 21,99 & Marqués de Riscal & 36,90 \\
\hline & Blanco de Blancos Tacama & 43,90 & Canepa & 39,90 \\
\hline & $\begin{array}{l}\text { Blanco de blancos } \\
\text { Tabernero }\end{array}$ & 25.90 & Casillero del Diablo & 23,90 \\
\hline & $\begin{array}{l}\text { Gran Blanco Seco } \\
\text { Tabernero }\end{array}$ & 19,90 & Marqués de Cáceres & 36,90 \\
\hline & Sauvgnon Blanco Queirolo & 21,60 & \multirow{2}{*}{ Rosé Marqués de Caceres } & \multirow{2}{*}{37,90} \\
\hline & Fond de Cave Ocucaje & 29,60 & & \\
\hline \multirow{6}{*}{ Vino } & Gran Tinto Tacama & 21,99 & Canepa & 39,90 \\
\hline & Tinto Secto Tabernero & 20,23 & Santa Carolina & 21,50 \\
\hline & Borgoña Santiago Queirolo & 20,40 & Don Matias Cousiño Macul & 33,90 \\
\hline & Borgoña Tabernero & 20,99 & Tinto Viu Manent & 39,50 \\
\hline & & & Los Arboles Navarro Correas & 28,50 \\
\hline & & & $\begin{array}{l}\text { Caballero de la Cepa, } \\
\text { Cabernet } \\
\text { Sauvignon(+vendido en } \\
\text { Wong) }\end{array}$ & 33,90 \\
\hline
\end{tabular}

Fuente: ProChile (2013). 


\subsection{Demanda para el proyecto}

\subsubsection{Segmentación del mercado}

\section{Segmentación Socioeconómica:}

El consumo de vino varía por niveles socioeconómicos, los niveles socioeconómicos A y B son los sectores que consumen los vinos de mayor precio (vinos de gama alta y media), el consumo en el sector $\mathrm{C}$ se encuentra en un proceso de cambios debido a que recién están desarrollando una cultura vinícola, en este sector predomina la venta de vinos de gama baja. Con respecto a precios, en el mercado peruano los vinos se dividen en tres tipos:

- Vinos de gama baja, con un precio menor a 13 soles, representan un $65 \%$ del mercado.

- Vinos de gama media, cuyos precio van entre 13 y 40 soles, con $25 \%$ de mercado.

- Vinos de gama alta con precios por encima de 40 soles, con solo un $10 \%$ de mercado.

En el país predomina el consumo de vino dulce $(50 \%$ del total consumido), ya que al no existir una cultura vinícola desarrollada este tipo de vinos se hace más agradable al paladar de los no conocedores. A diferencia del promedio peruano en los sectores A y B este porcentaje es mucho menor siendo $17 \%$ y $33 \%$ respectivamente, puesto que según se eleva el nivel social, la cultura vinícola suele ser mayor y se manifiesta más gusto por vinos con escasa o nula azúcar residual, conforme a los parámetros de consumo internacional.

\section{Segmentación Geográfica:}

El consumo de vino se centra en la Costa, especialmente en el departamento de Lima, cuyo consumo es aproximadamente el $70 \%$ del total nacional, seguido de otros departamentos como Ica y Arequipa, que en los últimos años han incrementado su nivel de consumo por el incremento de restaurantes que va de la mano con el boom de la gastronomía.

Las regiones Sierra y Selva no cuentan con cultura vinícola, ya que están acostumbrados a consumir otro tipo de licores como cerveza o bebidas 
propias de su zona; a excepción de Cuzco en donde el consumo de vino peruano está incrementando debido al turismo.

\section{Segmentación Demográfica:}

El consumo de vinos se encuentra más arraigado en personas mayores a 30 años, ya que a partir de esa edad existe mayor costumbre de tomar un vino acompañándolo con las comidas y degustar licores con sabor afrutado y baja cantidad de alcohol. En la siguiente tabla se observa la frecuencia de consumo de vino por rango de edades.

\section{Figura 2.4.}

\section{Frecuencia de consumo por rango de edades}

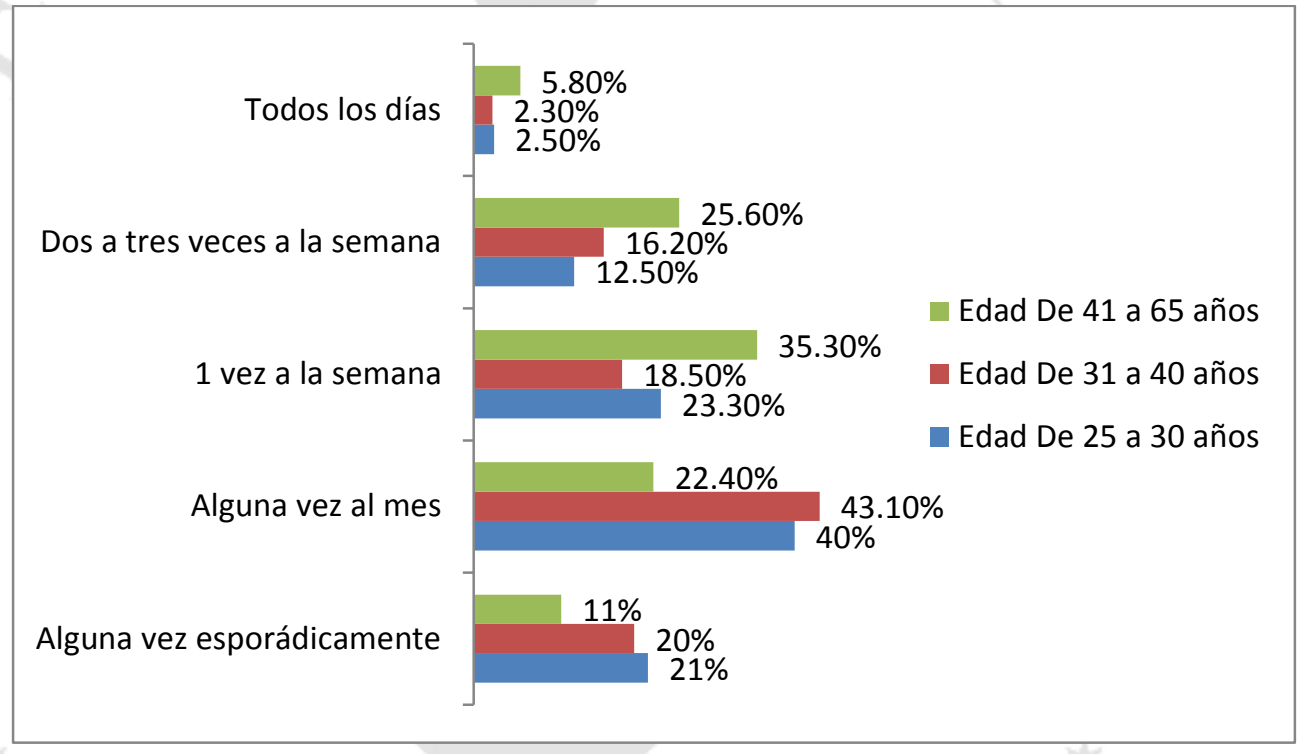

Fuente: Ángeles, I. (2012)

\subsubsection{Selección del mercado meta}

Luego del análisis realizado en el presente capítulo, en donde se observa que los licores como los vinos son consumidos mayoritariamente por los niveles socioeconómicos A y $\mathrm{B}$, y considerando que el precio de venta al consumidor final estará por encima de los 20 nuevos soles, se determina que el producto está dirigido a los distritos de Lima Moderna, en el nivel socioeconómico $\mathrm{B}$, que representan el 9\% de la población de Lima Metropolitana. Esta población está en busca de productos nuevos que satisfagan su paladar y está dispuesta a pagar un buen precio por el producto 
a diferencia de los Niveles Socioeconómicos C, D y E, que en su mayoría no tienen una cultura vinícola desarrollada; además de ello el nivel B tiene un gran potencial de consumo, ya que su capacidad de compra ha aumentado en los últimos años reflejándose en el aumento de centros comerciales, restaurantes y supermercados.

\subsubsection{Determinación de la demanda para el proyecto}

Para determinar la demanda del proyecto es necesario apoyarse de una encuesta dirigida a un determinado número de personas; la fórmula para determinar el número de encuestados en poblaciones infinitas es la siguiente:

$$
n=\frac{Z^{2} * p * q}{e^{2}}
$$

Dónde:

$Z^{2}=$ Nivel de confianza

$\mathrm{p}=$ probabilidad de ocurrencia

$\mathrm{q}=$ probabilidad de no ocurrencia

$e^{2}=$ error de estimación

Resolviendo esta fórmula:

$$
n=\frac{1,96^{2} * 0,5 * 0,5}{0,05^{2}}
$$

Se tiene como resultado un total de 385 personas a encuestar.

Sin embargo para efectos del presente proyecto solo se ha realizado la encuesta a 72 personas (Ver anexo 3), cuyos principales resultados (Ver anexo 4) fueron los siguientes:

A la pregunta: ¿Consume usted bebidas alcohólicas?

- 70 respondieron afirmativamente $(97,2 \%)$

A los que respondieron afirmativamente se les formuló la siguiente pregunta: ¿Consumiría usted un licor de higo fermentado, de sabor afrutado, dulce y muy similar al vino?

- $\quad$ El 52.9\% respondió que si consumiría licor de higo fermentado. 
A las 37 personas que respondieron afirmativamente $(52,9 \%)$, se le realizó la siguiente pregunta: Del 1 al 10 ¿Qué tan decidido estaría usted de comprar el licor de higo?

- $\quad$ El promedio de la intensidad de compra resultó ser $51.7 \%$.

Finalmente, empleando todos los datos recabados en la investigación de mercado se obtiene como resultado la demanda proyectada del proyecto.

Tabla 2.10

Demanda proyectada del proyecto

\begin{tabular}{|c|c|c|c|c|c|c|}
\hline Año & $\begin{array}{c}\text { (1) Consumo de } \\
\text { vino en Lima } \\
\text { (70\% del Perú) } \\
\text { (L) }\end{array}$ & $\begin{array}{l}\text { (2) Lima Moderna } \\
\text { (15\% de Lima } \\
\text { Metropolitana) } \\
\text { (L) }\end{array}$ & $\begin{array}{c}\text { (3) NSE B } \\
\text { ( } 30 \% \text { de Lima } \\
\text { Moderna) } \\
\text { (L) }\end{array}$ & $\begin{array}{c}\text { (4) Vino } \\
\text { dulce } \\
\text { (33\% en } \\
\text { NSE B) } \\
\text { (L) }\end{array}$ & $\begin{array}{c}\text { (5) } \\
\text { Encuesta } \\
(27.3 \%) \\
\text { (L) }\end{array}$ & $\begin{array}{c}\text { (6) } \\
\text { Demanda } \\
\text { Proyecto } \\
\text { (Unid. } \\
\text { 750ml.) }\end{array}$ \\
\hline 2015 & 34.826 .970 & 5.224 .046 & 1.567 .214 & 517.181 & 141.190 & 188.254 \\
\hline 2016 & 36.569 .862 & 5.485 .479 & 1.645 .644 & 543.062 & 148.256 & 197.675 \\
\hline 2017 & 38.312 .754 & 5.746 .913 & 1.724 .074 & 568.944 & 155.322 & 207.096 \\
\hline 2018 & 40.055 .646 & 6.008 .347 & 1.802 .504 & 594.826 & 162.388 & 216.517 \\
\hline 2019 & 41.798 .539 & 6.269 .781 & 1.880 .934 & 620.708 & 169.453 & 225.938 \\
\hline 2020 & 43.541 .431 & 6.531 .215 & 1.959 .364 & 646.590 & 176.519 & 235.359 \\
\hline 2021 & 45.284 .323 & 6.792 .648 & 2.037 .795 & 672.472 & 183.585 & 244.780 \\
\hline 2022 & 47.027 .215 & 7.054 .082 & 2.116 .225 & 698.354 & 190.651 & 254.201 \\
\hline 2023 & 48.770 .107 & 7.315 .516 & 2.194 .655 & 724.236 & 197.716 & 263.622 \\
\hline 2024 & 50.512 .999 & 7.576 .950 & 2.273 .085 & 750.118 & 204.782 & 273.043 \\
\hline
\end{tabular}

Nota: (1) El 70\% del consumo de vino en el país se da en el departamento de Lima. (2) El 15\% de la población de Lima Metropolitana se encuentra en Lima Moderna, que está comprendida por los distritos de: San Miguel, Pueblo Libre, Jesús María, Magdalena, Lince, San Isidro, Miraflores, Surquillo, San Borja, Barranco, Santiago de Surco y La Molina. (3) El NSE B es el 30\% de Lima Moderna. (4) El NSE B consume el 33\% de vino con sabor dulce del mercado nacional. (5) El producto de los resultados de la encuesta: Gente que consumiría licor de higo fermentado (52,9\%) por el promedio de la intensidad de compra (51.7\%), da como resultado 27,3\%. (6) La demanda del proyecto en unidades es la demanda de botellas de licor de $750 \mathrm{ml}$. Elaboración propia 


\subsection{Comercialización}

\subsubsection{Políticas de comercialización y distribución}

El producto se comercializará principalmente en supermercados y licorerías, ya que por un tema de distribución resultaría más complicado abarcar todos los puntos de venta desde un inicio. Sin embargo, también se buscará vender el producto en algunos restaurantes, bodegas y por medio de la página web de la empresa.

Los autoservicios donde será distribuido este producto son Tottus, Metro, Wong y Plaza vea, puesto que el NSE "B” suele adquirir sus productos en dichos autoservicios, cuyas características las veremos a continuación:

\section{Hipermercados Tottus}

Tottus es la cadena de supermercados del grupo de capitales chilenos Falabella, cuenta con 33 locales en el Perú y ha logrado por 6 años consecutivos ubicarse entre las empresas consideradas como mejor lugar para trabajar. Cuenta con 6 tiendas en los distritos de Lima Moderna.

\section{Wong}

Autoservicio del Grupo de Supermercados del mismo nombre, empresa líder en la industria de venta al detalle en el Perú. Es reconocido por ser una tienda con gran variedad de licores, especialmente de gama media y alta, cuenta con 14 tiendas en los distritos de Lima Moderna.

\section{Metro}

Perteneciente al grupo de supermercados Wong, es un autoservicio dirigido a vender productos de gama media, en los distritos de Lima Moderna solo cuenta con 13 tiendas.

\section{Plaza Vea}

Perteneciente a la corporación Supermercados Peruanos, segundo grupo en el país dedicado a la venta minorista, cuenta con 21 tiendas en los distritos de Lima Moderna. 


\subsubsection{Publicidad y promoción}

El presente estudio contempla la creación de una página web en donde se colocarán imágenes del producto, describiendo sus características, precios y descuentos por compras al por mayor.

También se realizará publicidad en los supermercados a través de impulsadoras que se encargarán de mostrar y hacer degustar el producto al público.

Se realizarán ofertas especiales en determinadas temporadas del año, como ofertas 3 × 2 o la venta del producto acompañado de un snack.

\subsubsection{Análisis de precios}

\section{Tendencia histórica de los precios}

Existen diversos precios en el mercado de vinos; sin embargo, los vinos más vendidos son los de gama media-baja, es por ello que el promedio de los precios históricos para el consumidor final no supera los 40 nuevos soles. Como se observa en la tabla 2.11:

Tabla 2.11

Precios históricos de vinos de $750 \mathrm{ml}$. (S/.)

\begin{tabular}{|c|c|}
\hline Año & $\begin{array}{c}\text { Precios Promedio } \\
\text { Históricos de vinos }\end{array}$ \\
\hline 2004 & 26,21 \\
\hline 2005 & 27,13 \\
\hline 2006 & 30,09 \\
\hline 2007 & 31,12 \\
\hline 2008 & 32,24 \\
\hline 2009 & 32,02 \\
\hline 2010 & 34,83 \\
\hline 2011 & 35,94 \\
\hline 2012 & 37,78 \\
\hline 2013 & 39,21 \\
\hline
\end{tabular}

Fuente: Euromonitor Internacional (2013) 


\section{Precio actuales}

El precio de los vinos en el mercado peruano va desde los 6 soles hasta más de 600 soles. La mayoría de veces el precio del vino adquirido está relacionado con la ocasión de consumo, como se verá a continuación:

Tabla 2.12

\section{Ocasión de Consumo-Precio}

\begin{tabular}{|l|l|}
\hline Ocasión de Consumo & Precio(S/.) \\
\hline Elaboración de comidas & $6-10$ \\
\hline Consumo regular(reunión, almuerzo) & $20-40$ \\
\hline Reunión importante (aniversario, cumpleaños) & 60 -más \\
\hline
\end{tabular}

Fuente: Oficina Económica y Comercial de la Embajada de España en Lima

\subsection{Análisis de los insumos principales}

\subsubsection{Características principales de la materia prima}

La materia prima a emplear en la elaboración del producto es el higo, un fruto obtenido de la higuera (Ficus carica). Existen más de 750 especies de higos diferentes entre las que hay comestibles y no comestibles.

Esta fruta proviene de Asia occidental, aunque posteriormente se distribuyó por todo el Mediterráneo. Se sabe que el ser humano ya lo conocía y recolectaba antes del año 9000 a. C.

La producción se concentra en la temporada de verano, es por ello que para asegurar un abastecimiento durante todo el año muchos productores secan el higo, para el presente trabajo se trabajará con el higo fresco de la variedad black misión, cuyas propiedades se aprecian en la siguiente tabla: 
Tabla 2.13

Cantidad de nutrientes por cada 100gr. de higo

\begin{tabular}{|l|l|l|l|}
\hline Calorías & $272,30 \mathrm{kcal}$. & Vitamina A & $8,50 \mathrm{ug}$. \\
\hline Grasa & $1,30 \mathrm{~g}$. & Vitamina B12 & $0 \mathrm{ug}$. \\
\hline Colesterol & $0 \mathrm{mg}$. & Hierro & $3,30 \mathrm{mg}$. \\
\hline Sodio & $40 \mathrm{mg}$. & Vitamina C & $2,50 \mathrm{mg}$. \\
\hline Carbohidratos & $55,10 \mathrm{~g}$. & Calcio & $193 \mathrm{mg}$. \\
\hline Fibra & $12,90 \mathrm{~g}$. & Vitamina B3 & $1,45 \mathrm{mg}$ \\
\hline Azúcares & $55,10 \mathrm{~g}$. & Proteínas & $3,61 \mathrm{~g}$. \\
\hline
\end{tabular}

Fuente: Botánica on-line (2012)

El higo, al ser un alimento rico en potasio, ayuda a una buena circulación, regulando la presión arterial por lo que es un alimento beneficioso para personas que sufren hipertensión. El potasio que contiene esta fruta ayuda a regular los fluidos corporales y a prevenir enfermedades reumáticas o artritis.

Comer higo, al estar entre los alimentos ricos en fibra, ayuda a favorecer el tránsito intestinal. Incluir alimentos con fibra en la dieta, como esta fruta, también ayuda a controlar la obesidad. Ayuda también en el control de la glucemia en personas con diabetes, reducir el colesterol y prevenir el cáncer de colon.

\subsubsection{Disponibilidad de insumos}

La producción del higo se encuentra en los departamentos de Arequipa, Ica, Moquegua, Tacna, Lima y Ancash, durante los meses de diciembre, enero, febrero y marzo; el tipo de higo más producido en Perú es el higo negro, variedad black misión, la producción por departamento se aprecia en la tabla siguiente:

Tabla 2.14

\section{Regiones con mayor producción de}

higo 2013 (T)

\begin{tabular}{|c|c|}
\hline Departamento & Producción \\
\hline Ica & 717 \\
\hline Tacna & 156 \\
\hline Arequipa & 600 \\
\hline Moquegua & 85 \\
\hline Lima & 140 \\
\hline
\end{tabular}

Fuente: Instituto Nacional de Estadística e Informática (2013) 
El crecimiento de la producción histórica de higo se ha mantenido a lo largo de los años como se puede ver en la siguiente tabla:

Tabla 2.15

\section{Producción Histórica de Higo (T)}

\begin{tabular}{|c|c|}
\hline Año & Toneladas \\
\hline 2008 & 3.000 \\
\hline 2009 & 3.200 \\
\hline 2010 & 3.200 \\
\hline 2011 & 3.330 \\
\hline 2012 & 3.350 \\
\hline 2013 & 3.400 \\
\hline
\end{tabular}

Fuente: Instituto Nacional de Estadística e Informática (2013)

En la siguiente tabla se muestra la cantidad de higo producida proyectada para los siguientes años; sin embargo del total de higo producido, actualmente se exporta el $8 \%$, quedando el $92 \%$ disponible.

Tabla 2.16

Cantidad proyectada disponible de higo para los próximos 10 años (kg)

\begin{tabular}{|c|c|c|c|c|}
\hline Año & $\begin{array}{c}\text { Cantidad higo } \\
\text { Producida } \\
\text { (Kg./año) }\end{array}$ & $\begin{array}{c}\text { Cantidad higo } \\
\text { disponible } \\
\text { (Kg./año) }\end{array}$ & $\begin{array}{c}\text { Cantidad de higo } \\
\text { requerida } \\
\text { (kg./año) }\end{array}$ & $\begin{array}{c}\text { \% de } \\
\text { utilización }\end{array}$ \\
\hline 2015 & 3.581 .290 & 3.294 .787 & $244.729,81$ & $7,43 \%$ \\
\hline 2016 & 3.655 .576 & 3.363 .130 & $256.977,15$ & $7,64 \%$ \\
\hline 2017 & 3.729 .862 & 3.431 .473 & $269.224,49$ & $7,85 \%$ \\
\hline 2018 & 3.804 .148 & 3.499 .816 & $281.471,82$ & $8,04 \%$ \\
\hline 2019 & 3.878 .434 & 3.568 .159 & $293.719,16$ & $8,23 \%$ \\
\hline 2020 & 3.952 .720 & 3.636 .502 & $305.966,50$ & $8,41 \%$ \\
\hline 2021 & 4.027 .006 & 3.704 .846 & $318.213,84$ & $8,59 \%$ \\
\hline 2022 & 4.101 .292 & 3.773 .189 & $330.461,17$ & $8,76 \%$ \\
\hline 2023 & 4.175 .578 & 3.841 .532 & $342.708,51$ & $8,92 \%$ \\
\hline 2024 & 4.249 .864 & 3.909 .875 & $354.955,85$ & $9,08 \%$ \\
\hline
\end{tabular}

Fuente: Instituto Nacional de Estadística e Informática (2013) 
2.6.3. Costos de la materia prima

El precio histórico promedio del higo en chacra no ha presentado mucho incremento a lo largo de los años, como se muestra en la siguiente tabla:

Tabla 2.17

Precio promedio histórico del higo

en chacra $(S /$.

\begin{tabular}{|c|c|}
\hline Año & $\begin{array}{c}\text { Precio promedio del } \\
\text { higo en chacra(S/.) }\end{array}$ \\
\hline 2004 & 0,91 \\
\hline 2005 & 0,66 \\
\hline 2006 & 0,95 \\
\hline 2007 & 0,86 \\
\hline 2008 & 1,01 \\
\hline 2009 & 0,97 \\
\hline 2010 & 0,89 \\
\hline 2011 & 085 \\
\hline 2012 & 1,00 \\
\hline 2013 & 1,30 \\
\hline
\end{tabular}

Fuente: Instituto Nacional de Estadística e Informática (2013) 


\section{CAPÍTULO III: LOCALIZACIÓN DE PLANTA}

\subsection{Análisis de los factores de localización}

Debido a diversos factores que serán analizados en los siguientes puntos, se tiene como alternativa de macro localización a los departamentos de Ica, Arequipa y Lima.

\section{Proximidad a las materias primas}

Es uno de los principales factores considerar, puesto que el higo, que es la principal materia prima es un producto perecedero. Por ello se debe considerar tanto la distancia como el tiempo de transporte de la materia prima, ya que a mayor distancia el costo va en aumento y también es mayor el riesgo de vencimiento por parte de la materia prima.

Tal como se vio en el capítulo anterior los departamentos de Ica y Arequipa figuran entre los mayores productores de higo en el país. Basándose en este criterio, estos departamentos se consideran como buenas opciones para localizar la planta procesadora licor de higo.

\section{Cercanía al mercado}

Es el segundo factor a considerar, ya que dependiendo de la cercanía al mercado al que se desea llegar dependerán los costos de transporte del producto terminado, los canales de distribución a utilizar y también la capacidad de respuesta a las necesidades de los clientes.

El departamento de Lima es el que tiene mayor potencial en este factor, ya que el mercado meta de este estudio se encuentra en este departamento. Así mismo, cuenta con facilidades de acceso mediante la carretera Panamericana, por donde ingresarían los insumos, y con facilidades de venta ya que cuenta con numerosos supermercados, minimarkets, licorerías y bodegas donde se puede ofrecer el producto. 


\section{Requerimientos de infraestructura industrial y condiciones socioeconómicas}

Se debe contar con mano de obra especializada y no especializada para realizar las principales tareas dentro de la empresa. Para ello la ciudad elegida deberá contar con centros de instrucción de tal manera que pueda haber una capacitación constante.

Por otro lado la planta deberá estar ubicada en una zona con buen abastecimiento de agua y energía eléctrica para la operación de la maquinaria involucrada en el proceso productivo, además de contar con vías de fácil acceso para lograr una buena distribución del producto.

Por último se deben tener en cuenta las reglamentaciones fiscales, servicios de construcción así como lugares apropiados para la eliminación de desechos.

\subsection{Identificación y descripción de las alternativas de localización}

\section{Disponibilidad de materia prima}

El departamento de Ica es el mayor productor de higo en el país seguido del departamento de Arequipa, El departamento de Lima no se encuentra dentro de los tres primeros productores de higo en el Perú. Su producción es aproximadamente la quinta parte de lo que se produce en el departamento de Ica. Como se aprecia en la tabla 3.1.

\section{Tabla 3.1}

Producción de los cultivos de higo en los

departamentos de Ica, Arequipa y Lima (Año 2013)

\begin{tabular}{|c|c|}
\hline Departamento & Producción (T) \\
\hline Ica & 717 \\
\hline Arequipa & 600 \\
\hline Lima & 140 \\
\hline
\end{tabular}

Fuente: Instituto Nacional de Estadística e Informática (2013) 


\section{Cercanía al mercado:}

Ica

La distancia de Ica a Lima es $303 \mathrm{Km}$, tomando un tiempo aproximado de 4 horas a una velocidad alta, como se aprecia en la figura 3.1:

Figura 3.1.

\section{Distancia de Ica a Lima (km)}

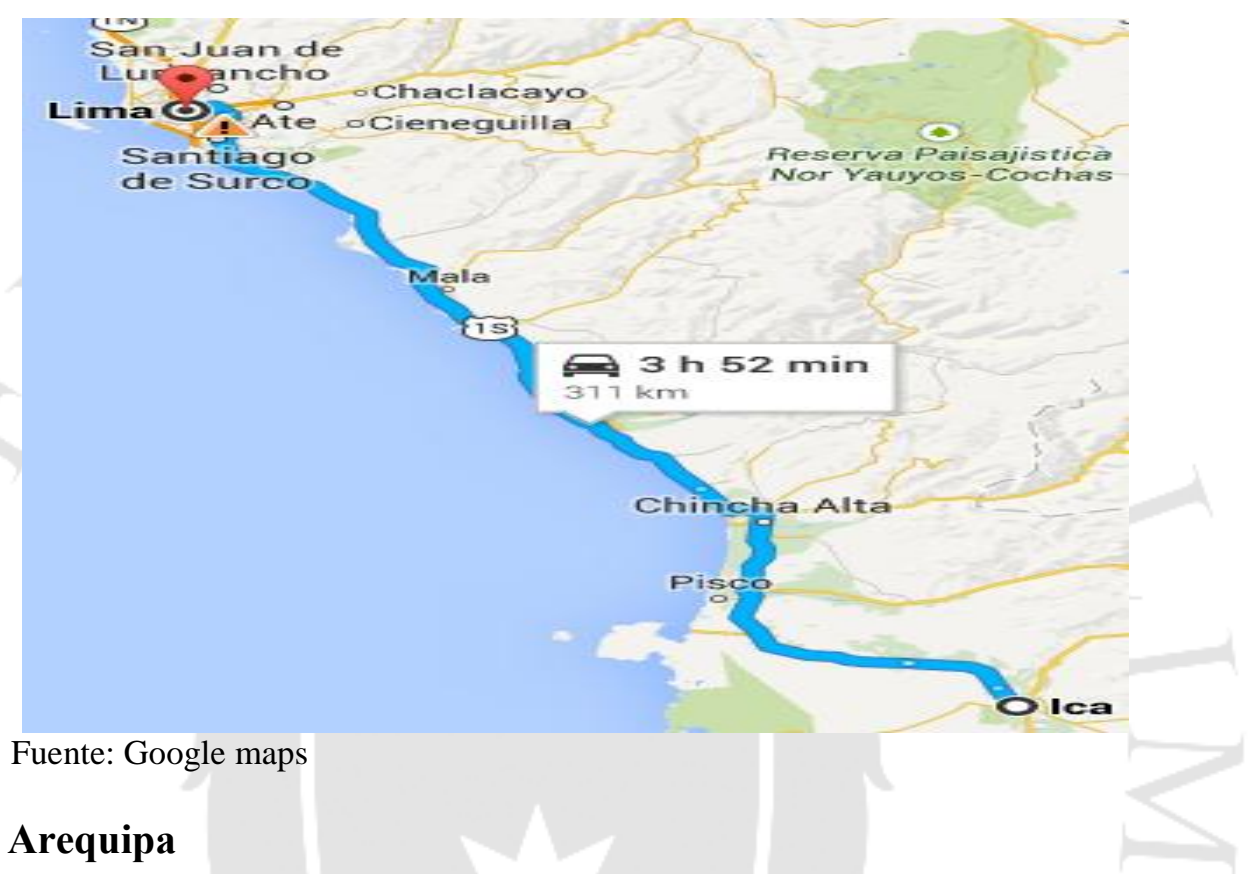

La distancia de Arequipa a Lima es de 1020 km., durando el trayecto por carretera 13 horas 27 minutos, como se aprecia en el siguiente gráfico:

\section{Figura 3.2.}

\section{Distancia de Ica a Lima (km)}

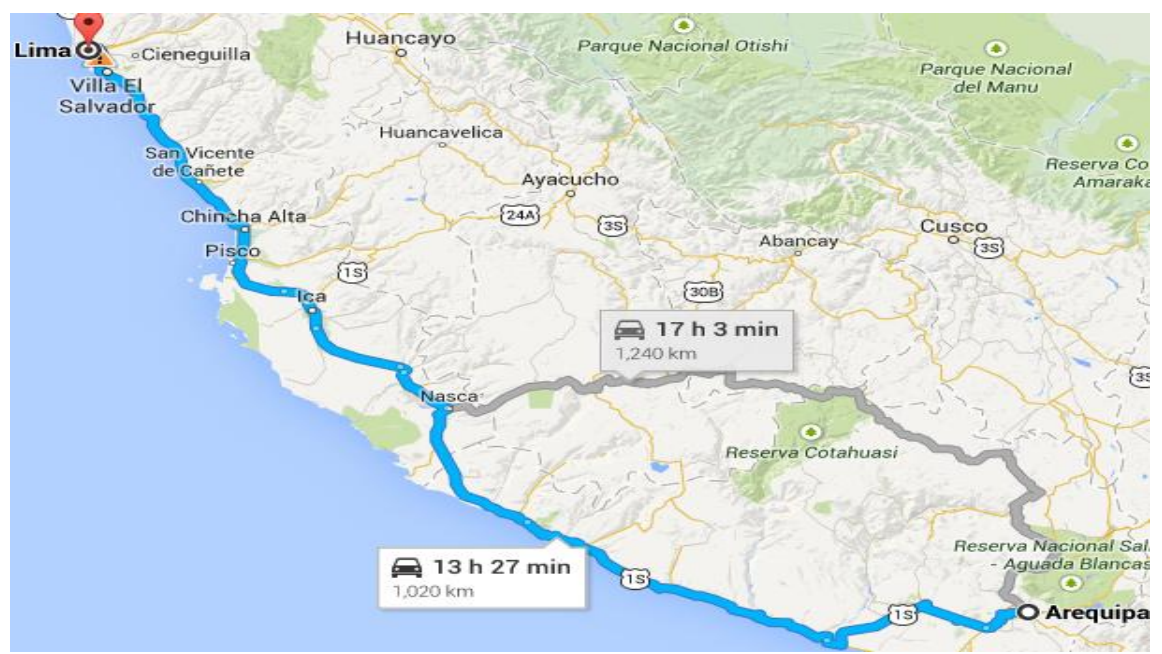

Fuente: Google maps 


\section{Lima}

Bajo este factor el departamento más favorecido es el de Lima, puesto que el mercado meta del proyecto se encuentra dentro de este departamento.

\section{Disponibilidad de mano de obra}

Es muy importante contar con personal capacitado, que sepa manejar las máquinas y equipos con los que se contará para la fabricación del producto y así poder garantizar brindar un producto de calidad.

La oferta laboral en el Perú es alta y la mayoría se encuentra en Lima, dicho departamento es el que posee la población económicamente activa desocupada más alta, Por lo tanto no sería difícil encontrar mano de obra.

Tabla 3.2

PEA ocupada y PEA desocupada del departamento de Ica, Arequipa y Lima (Año 2013)

\begin{tabular}{|c|c|c|}
\hline Departamento & PEA ocupada & PEA desocupada \\
\hline Ica & 394.200 & 21.300 \\
\hline Arequipa & 628.900 & 31.800 \\
\hline Lima & 4.866 .300 & 240.700 \\
\hline
\end{tabular}

Fuente: Instituto Nacional de Estadística e Informática (2013)

\section{Abastecimiento de energía}

La energía es un factor muy importante para el funcionamiento de la planta, esta debe contar con energía durante todo el tiempo de funcionamiento.

Lima es el departamento con el mayor y más barato abastecimiento de energía del Perú, lo que hace posible la instalación de muchas industrias desde las más pequeñas hasta las más grandes. 
Tabla 3.3

Grado de electrificación, Potencia instalada y producción de energía eléctrica por departamentos año 2013

\begin{tabular}{|c|c|c|c|}
\hline Departamento & $\begin{array}{c}\text { Grado de } \\
\text { electrificación }\end{array}$ & $\begin{array}{c}\text { Potencia Instalada } \\
\text { (MW) }\end{array}$ & $\begin{array}{c}\text { Producción de energía } \\
\text { eléctrica(GW.h) }\end{array}$ \\
\hline Ica & $94 \%$ & 236,88 & 643,72 \\
\hline Arequipa & $93 \%$ & 414,53 & $1.367,92$ \\
\hline Lima & $95 \%$ & $4.600,93$ & $18.481,16$ \\
\hline
\end{tabular}

Fuente: Instituto Nacional de Estadística e Informática (2013)

\section{Tabla 3.4}

$\mathrm{N}^{\circ}$ de clientes, venta de energía y precio medio de energía por sector año 2013

\begin{tabular}{|c|c|c|c|}
\hline Departamento & $\begin{array}{c}\mathbf{N}^{\circ} \text { de clientes } \\
\text { finales sector } \\
\text { manufactura }\end{array}$ & $\begin{array}{c}\text { Venta de energía } \\
\text { eléctrica por sectores } \\
\text { (GW.h) Industrial }\end{array}$ & $\begin{array}{c}\text { Precio medio de } \\
\text { energía por sectores } \\
\text { económicos } \\
\text { (cent. US\$/kWh) }\end{array}$ \\
\hline Ica & 934 & 1.830 .9 & 8,17 \\
\hline Arequipa & 1.797 & $1.861,53$ & 6,14 \\
\hline Lima & 6.381 & $5.757,89$ & 13,09 \\
\hline
\end{tabular}

Fuente: Ministerio de Energía y Minas (2013)

\section{Abastecimiento de agua}

El abastecimiento de agua es un factor de gran importancia debido a que es necesario un suministro constante para todo lo concerniente a las actividades industriales y de limpieza que se darán en la planta.

Tabla 3.5

Conexiones de agua potable y alcantarilla, tarifa media $(\mathrm{S} / . / \mathrm{m} 3)$

\begin{tabular}{|c|c|c|c|c|c|}
\hline Departamento & $\begin{array}{c}\text { Conexiones } \\
\text { de agua } \\
\text { potable }\end{array}$ & $\begin{array}{c}\text { Conexiones } \\
\text { de } \\
\text { alcantarillado }\end{array}$ & $\begin{array}{c}\text { Cobertura } \\
\text { de agua } \\
\text { potable }\end{array}$ & $\begin{array}{c}\text { Cobertura de } \\
\text { alcantarillado }\end{array}$ & $\begin{array}{c}\text { Tarifa } \\
\text { media } \\
\text { S/./m3 }\end{array}$ \\
\hline Ica & 48.568 & 42.844 & $86 \%$ & $85 \%$ & 3,18 \\
\hline Arequipa & 272.315 & 230.771 & $88 \%$ & $89 \%$ & 2,03 \\
\hline Lima & 1.412 .305 & 1.313 .443 & $88 \%$ & $84 \%$ & 4,65 \\
\hline
\end{tabular}

Fuente: "SEDAPAR, EMAPICA Y SEDAPAL (2013) 


\section{Servicio de transporte}

El costo del transporte es considerado como un factor importante en este proyecto ya que determina el costo del producto. Si la planta se localiza en Ica o Arequipa se debe transportar el producto terminado hasta Lima a los centros de distribución, por lo que la distancia a recorrer es muy grande.

Si la planta se ubica en Lima se necesitaría transportar la materia prima a la planta, desde el mercado mayorista que sería el proveedor, y luego a los centros de distribución. En este caso la distancia es mucho más corta.

\section{Terrenos}

Para adquirir un terreno donde construir la planta se deben tomar en cuenta diferentes criterios. El terreno se debe encontrar en una zona industrial, sin alejarse mucho del mercado objetivo del proyecto. Además se deben considerar los permisos municipales de construcción sobre el medio ambiente.

En Lima Metropolitana se encuentran la mayor cantidad de parques industriales del Perú, ubicados en diferentes distritos como por ejemplo: Los Olivos, Comas, Independencia, Ate Vitarte, entre otros; sin embargo en otras provincias de Lima también se pueden encontrar terrenos industriales y a un menor precio.

En la siguiente tabla, se muestran los precios promedio por metro cuadrado de los terrenos industriales.

\section{Tabla 3.6}

Características de terrenos disponibles

\begin{tabular}{|c|c|c|c|c|}
\hline $\begin{array}{c}\text { Características } \\
\text { del terreno }\end{array}$ & Ica & Arequipa & Lima & $\begin{array}{c}\text { Otras zonas } \\
\text { de Lima }\end{array}$ \\
\hline $\begin{array}{c}\text { Precio promedio de } \\
\text { venta }(\mathrm{U} \$ \$ / \mathrm{m} 2)\end{array}$ & 180 & 200 & $300-800$ & $80-120$ \\
\hline Tipo de propiedad & $\begin{array}{c}\text { Terreno } \\
\text { industrial }\end{array}$ & $\begin{array}{c}\text { Terreno } \\
\text { industrial }\end{array}$ & $\begin{array}{c}\text { Terreno } \\
\text { industrial }\end{array}$ & $\begin{array}{c}\text { Terreno } \\
\text { industrial }\end{array}$ \\
\hline
\end{tabular}

Fuente: El Comercio (2013) 


\subsection{Evaluación y selección de localización}

\subsubsection{Evaluación y selección de la macro localización}

Mediante el método de ranking de factores, se evaluarán los factores de macro localización:

- $\quad$ Proximidad de las materias primas (A)

- $\quad$ Cercanía al mercado(B)

- $\quad$ Disponibilidad de mano de obra (C)

- Abastecimiento de energía (D)

- $\quad$ Abastecimiento de agua (E)

- $\quad$ Servicio de transporte $(\mathrm{F})$

- $\quad$ Disponibilidad de terrenos $(\mathrm{G})$

Analizando el nivel de importancia relativa de cada uno de los factores y asignando una ponderación relativa se tiene que:

- Se asigna el valor de 1 a los factores más importantes o de igual importancia.

- Se asigna el valor 0 al menos importante.

Para evaluar la importancia relativa de cada factor con respecto a otro, se realiza una matriz de enfrentamiento.

\section{Tabla 3.7}

\section{Matriz de enfrentamiento-Macro localización}

\begin{tabular}{|c|c|c|c|c|c|c|c|c|c|}
\hline Factor & A & B & C & D & E & F & G & Conteo & $\%$ \\
\hline A & $\mathrm{X}$ & 0 & 0 & 1 & 1 & 1 & 1 & 3 & $14 \%$ \\
\hline B & 1 & $\mathrm{X}$ & 1 & 0 & 1 & 0 & 1 & 3 & $14 \%$ \\
\hline $\mathbf{C}$ & 1 & 0 & $\mathrm{X}$ & 1 & 1 & 1 & 1 & 4 & $18 \%$ \\
\hline $\mathbf{D}$ & 1 & 0 & 1 & $\mathrm{X}$ & 1 & 1 & 1 & 4 & $18 \%$ \\
\hline $\mathbf{E}$ & 1 & 1 & 1 & 1 & $\mathrm{X}$ & 1 & 1 & 5 & $23 \%$ \\
\hline F & 1 & 0 & 0 & 0 & 0 & $\mathrm{X}$ & 0 & 1 & $5 \%$ \\
\hline G & 1 & 0 & 0 & 0 & 0 & 1 & $\mathrm{X}$ & 2 & $9 \%$ \\
\hline
\end{tabular}

Elaboración propia 
Una vez terminada la matriz de enfrentamiento se desarrolla el ranking de calificación y posteriormente se efectúa el ranking de factores:

\begin{tabular}{|c|c|}
\hline Puntaje & Calificación \\
\hline Excelente & 10 \\
\hline Muy Bueno & 8 \\
\hline Bueno & 6 \\
\hline Regular & 4 \\
\hline Deficiente & 2 \\
\hline
\end{tabular}

Tabla 3.8

Ranking de factores -Macro localización

\begin{tabular}{|c|c|c|c|c|c|c|c|}
\hline & & \multicolumn{2}{|c|}{ Ica } & \multicolumn{2}{|c|}{ Arequipa } & \multicolumn{2}{|c|}{ Lima } \\
\hline Factor & $\%$ & Calificación & Puntaje & Calificación & Puntaje & Calificación & Puntaje \\
\hline A & $14 \%$ & 10 & 1,36 & 8 & 1,09 & 4 & 0,5 \\
\hline B & $14 \%$ & 8 & 1,09 & 4 & 0,55 & 10 & 1,4 \\
\hline $\mathrm{C}$ & $18 \%$ & 6 & 1,09 & 8 & 1,45 & 10 & 1,8 \\
\hline $\mathrm{D}$ & $18 \%$ & 8 & 1,45 & 8 & 1,45 & 10 & 1,8 \\
\hline $\mathrm{E}$ & $23 \%$ & 6 & 1,36 & 8 & 1,82 & 8 & 1,8 \\
\hline $\mathrm{F}$ & $5 \%$ & 8 & 0,36 & 4 & 0,18 & 6 & 0,3 \\
\hline $\mathrm{G}$ & $9 \%$ & 8 & 0,73 & 8 & 0,73 & 4 & 0,4 \\
\hline Total & 1 & \multicolumn{2}{|c|}{7,45} & \multicolumn{2}{|c|}{7,27} & \multicolumn{2}{|c|}{8,00} \\
\hline
\end{tabular}

Elaboración propia

Analizando los resultados del análisis de la micro localización se obtiene como resultado el departamento de Lima.

Figura 3.1.

Mapa de Lima

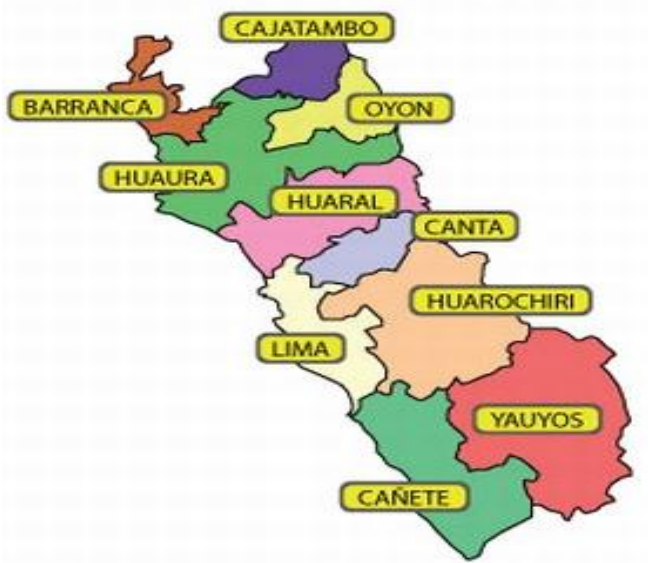

Fuente: Jurado Nacional de Elecciones 
De acuerdo al resultado, se elige por una mínima diferencia al departamento de Lima como el más adecuado para la macro localización de la planta.

\subsubsection{Evaluación y selección de la micro localización}

En esta sección se evaluarán las posibles microlocalizaciones para finalmente ubicar la planta. Estas localizaciones son los distritos de Lurín, Chilca y San Vicente de Cañete.

A continuación se analizarán los diferentes factores más importantes a considerar para escoger al distrito:

\section{Costo del Terreno}

El costo de los terrenos industriales en Lurín fluctúa entre 700 y 900 $\mathrm{S} / . / \mathrm{m}^{2}$, mientras que en Chila y San Vicente de Cañete (ambos distritos de la provincia de Cañete) el costo de los terrenos industriales va desde los 220 hasta los $400 \mathrm{~S} / . / \mathrm{m}^{2}$.

Por lo tanto en este factor los distritos de Chila y San Vicente de Cañete serían los más apropiados.

\section{Abastecimiento de servicios básicos}

El distrito de Lurín se ha convertido en un distrito industrializado, en donde se ubican empresas de manufactura y grandes almacenes, debido a que en otros distritos de Lima ya se observa una carencia de espacio y los costos de los terrenos industriales son muy elevados. Es por ello que en dicho distrito existen terrenos en zonas industriales que cuentan con todos los servicios básicos.

Debido a la expansión el distrito de Chilca, también se está convirtiendo en un distrito industrializado, pues al estar muy cerca de Lurín también es considerado como una buena opción; sin embargo, todavía no está tan industrializado como este último. 
San Vicente de Cañete, por su parte, también cuenta con zonas apropiadas y si bien no está tan industrializado como Lurín, si existen lugares con la infraestructura idónea para instalar una planta de licores, esto se comprueba al observar que en dicho distrito existen otras plantas dedicadas al mismo giro de negocio.

\section{Mano de obra}

En este factor los distritos se encuentran en condiciones similares, sin embargo, San Vicente de Cañete al contar con industrias similares a la propuesta en el presente estudio, podría tener una ligera ventaja, pues se encontraría personal con experiencia, especialmente para el personal de producción.

\section{Obtención de Licencias}

Revisando las páginas web de los 3 distritos se puede observar que los trámites a seguir para obtener una licencia de funcionamiento y una licencia de construcción son similares, incluso en cuestión de costos y de tiempo. Por lo tanto en este factor todos estarían en igualdad de condiciones.

\section{Costo del Transporte}

El costo de transporte está ligado a la distancia de un punto a otro; considerando que el costo de transporte de carga, según el Ministerio de Transportes es de $0,135 \mathrm{~S} / . / \mathrm{T}-\mathrm{km}$, se obtiene que el costo de transporte de una tonelada de materia prima sería el siguiente:

Tabla 3.9

Costo de transporte de una tonelada de materia prima(S/.)

\begin{tabular}{|c|c|c|}
\hline Lugares & Distancia $(\mathbf{K m})$ & Costo por tonelada (S/.) \\
\hline De Ica a Lurín & 258 & 34,8 \\
\hline De Ica a Chilca & 223 & 30,1 \\
\hline $\begin{array}{c}\text { De Ica a San } \\
\text { Vicente de Cañete }\end{array}$ & 144 & 19,4 \\
\hline
\end{tabular}

Fuente: Ministerio de Transportes (2013) 
Con respecto a la accesibilidad todas estas rutas tienen acceso a la carretera Panamericana Sur, por lo tanto estarían en las mismas condiciones.

Para el transporte de productos terminados el distrito de Lurín sería el más conveniente porque está en Lima Metropolitana, y más aun considerando que los grandes autoservicios tienen sus almacenes en este mismo distrito.

Chilca también se encuentra muy cerca, (aproximadamente a $30 \mathrm{~km}$. de Lurín), por lo que resultaría conveniente también. Finalmente San Vicente de Cañete si está a una distancia más considerable del mercado (a 118 km. de Lurín).

Considerando que el transporte de la materia prima se tiene que realizar con mayor rapidez por ser perecible, porque se pueden dañar en el trayecto y por un tema de costos debido al volumen transportado, la mejor opción sería San Vicente de Cañete.

Mediante el método de Ranking de factores, se evaluarán los factores de micro localización:

- $\quad$ Costo de terrenos (A)

- Abastecimiento de servicios básicos (B)

- $\quad$ Mano de obra ( C )

- $\quad$ Obtención de licencias (D)

- $\quad$ Costos del transporte (E)

Tabla 3.10

Matriz de enfrentamiento-Micro localización

\begin{tabular}{|c|c|c|c|c|c|c|c|}
\hline Factor & A & B & C & D & E & Conteo & \% \\
\hline A & X & 1 & 1 & 1 & 1 & 4 & $31 \%$ \\
\hline B & 0 & $\mathrm{X}$ & 1 & 1 & 0 & 2 & $15 \%$ \\
\hline C & 0 & 1 & $\mathrm{X}$ & 1 & 0 & 2 & $15 \%$ \\
\hline $\mathbf{D}$ & 0 & 0 & 1 & $\mathrm{X}$ & 0 & 1 & $8 \%$ \\
\hline E & 1 & 1 & 1 & 1 & $\mathrm{X}$ & 4 & $31 \%$ \\
\hline
\end{tabular}

Elaboración propia 
Tabla 3.11

Ranking de factores -Micro localización

\begin{tabular}{|c|c|c|c|c|c|c|c|}
\hline \multirow[b]{2}{*}{ Factor } & \multirow[b]{2}{*}{$\%$} & \multicolumn{2}{|c|}{ Lurín } & \multicolumn{2}{|c|}{ Chilca } & \multicolumn{2}{|c|}{$\begin{array}{c}\text { San Vicente de } \\
\text { Cañete }\end{array}$} \\
\hline & & Calificación & Puntaje & Calificación & Puntaje & Calificación & Puntaje \\
\hline A & $31 \%$ & 4 & 1,23 & 10 & 3,08 & 10 & 3,1 \\
\hline $\mathrm{B}$ & $15 \%$ & 8 & 1,23 & 6 & 0,92 & 6 & 0,9 \\
\hline $\mathrm{C}$ & $15 \%$ & 8 & 1,23 & 8 & 1,23 & 10 & 1,5 \\
\hline $\mathrm{D}$ & $8 \%$ & 8 & 0,62 & 8 & 0,62 & 8 & 0,6 \\
\hline $\mathrm{E}$ & $31 \%$ & 6 & 1,85 & 6 & 1,85 & 8 & 2,5 \\
\hline Total & $100 \%$ & \multicolumn{2}{|c|}{6,15} & \multicolumn{2}{|c|}{7,69} & \multicolumn{2}{|c|}{8,62} \\
\hline
\end{tabular}

Elaboración propia

De acuerdo al resultado, se elige al distrito de San Vicente de Cañete como el más adecuado para la microlocalización de la planta. 


\section{CAPÍTULO IV: TAMAÑO DE PLANTA}

El tamaño de planta equivale a la capacidad de producción y se define como el volumen que se puede producir en un determinado periodo.

La selección del tamaño de planta depende de diversos factores como: mercado, recursos, productivos, tecnología, entre otros.

\subsection{Relación tamaño-mercado}

Esta relación es un límite para el tamaño de la planta .Es decir la capacidad de producción del proyecto debe estar relacionada con la demanda del proyecto. El tamaño máximo de planta se obtendrá de acuerdo al pronóstico de la demanda, como se observa en el Tabla 4.1.

\section{Tabla 4.1}

\section{Relación Tamaño-Mercado (Kg.)}

\begin{tabular}{|c|c|c|c|c|}
\hline Año & $\begin{array}{c}\text { Demanda del } \\
\text { proyecto } \\
\text { (Unidades) }\end{array}$ & $\begin{array}{c}\text { Demanda del } \\
\text { proyecto (L/Año) }\end{array}$ & $\begin{array}{c}\text { Demanda del } \\
\text { proyecto (L/día) }\end{array}$ & $\begin{array}{c}\text { Demanda del } \\
\text { proyecto (L/h) }{ }^{2}\end{array}$ \\
\hline 2015 & 188.254 & 141.190 & 453 & 28 \\
\hline 2016 & 197.675 & 148.256 & 475 & 30 \\
\hline 2017 & 207.096 & 155.322 & 498 & 31 \\
\hline 2018 & 216.517 & 162.388 & 520 & 33 \\
\hline 2019 & 225.938 & 169.453 & 543 & 34 \\
\hline 2020 & 235.359 & 176.519 & 566 & 35 \\
\hline 2021 & 244.780 & 183.585 & 588 & 37 \\
\hline 2022 & 254.201 & 190.651 & 611 & 40 \\
\hline 2023 & 263.622 & 197.716 & 634 & 41 \\
\hline 2024 & 273.043 & 204.782 & 656 & 37 \\
\hline
\end{tabular}

Nota: L=Litros. $\mathrm{h}=$ horas. $^{1}$ Demanda del proyecto (L/día) considerando 311 días al año. ${ }^{2}$ Demanda del proyecto $(\mathrm{L} / \mathrm{h})$ considerando 16 horas al día.

Elaboración propia 


\subsection{Relación tamaño-recursos productivos}

Se refiere a la disponibilidad de recursos productivos necesarios para la elaboración de los productos. Sin estos recursos no se puede cubrir la demanda del proyecto. La cantidad de higo disponible en el mercado interno se obtiene restando el porcentaje de higo que se exporta, $8 \%$ aproximadamente. Lo ideal es que dicha cantidad sea mucho mayor a la obtenida en el tamaño mercado, como se aprecia en la tabla 4.2.

\section{Tabla 4.2}

Relación tamaño-recursos productivos (Kg.)

\begin{tabular}{|l|c|c|c|c|c|c|}
\hline Año & $\begin{array}{c}\text { Higo } \\
\text { disponible } \\
(\mathbf{K g} / \mathbf{a n ̃ o})\end{array}$ & $\begin{array}{c}\text { Higo } \\
\text { disponible } \\
\mathbf{( K g / d i ́ a )}\end{array}$ & $\begin{array}{c}\text { Higo } \\
\text { disponible } \\
\mathbf{( K g / h )}\end{array}$ & $\begin{array}{c}\text { Higo } \\
\text { requerido } \\
\mathbf{( K g / a n ̃ o )}\end{array}$ & $\begin{array}{c}\text { Higo } \\
\text { requerido } \\
(\mathbf{k g} / \mathbf{d i ́} \mathbf{)})\end{array}$ & $\begin{array}{c}\text { Higo } \\
\text { requerido } \\
(\mathbf{k g} / \mathbf{h})^{\mathbf{2}}\end{array}$ \\
\hline 2015 & 3.294 .787 & 10.560 & 660 & 244.684 & 784 & 49 \\
\hline 2016 & 3.363 .130 & 10.779 & 674 & 256.929 & 824 & 51 \\
\hline 2017 & 3.431 .473 & 10.998 & 687 & 269.174 & 863 & 54 \\
\hline 2018 & 3.499 .816 & 11.217 & 701 & 281.419 & 902 & 56 \\
\hline 2019 & 3.568 .159 & 11.436 & 715 & 293.664 & 941 & 59 \\
\hline 2020 & 3.636 .502 & 11.655 & 728 & 305.909 & 981 & 61 \\
\hline 2021 & 3.704 .846 & 11.875 & 742 & 318.154 & 1020 & 64 \\
\hline 2022 & 3.773 .189 & 12.094 & 756 & 330.399 & 1059 & 66 \\
\hline 2023 & 3.841 .532 & 12.313 & 770 & 342.644 & 1098 & 69 \\
\hline 2024 & 3.909 .875 & 12.532 & 783 & 354.889 & 1138 & 71 \\
\hline
\end{tabular}

Nota: $\mathrm{h}=$ horas. ${ }^{1}$ Higo requerido $(\mathrm{Kg} /$ día $)$ considerando 311 días al año. ${ }^{2}$ Higo requerido $(\mathrm{kg} / \mathrm{h})$ considerando 16 horas al día.

Elaboración propia

Se observa que la cantidad de higos disponibles no es un limitante para la producción del producto.

\subsection{Relación tamaño-tecnología}

Dentro del proyecto se define tecnología como aquellas máquinas y equipos que se usarán para el proceso de producción del licor de higo, tales como: tanques, filtros, llenadoras de botellas, entre otros.

En la tabla 4.3 se muestran las máquinas disponibles que podrían ajustarse para la producción de licor de higo en las cantidades demandadas para el proyecto 
en el décimo año, cabe resaltar que las capacidades finales de las maquinarias adquiridas presentarán variación conforme avance el estudio.

\section{Tabla 4.3}

\section{Relación tamaño-tecnología. (Kg.)}

\begin{tabular}{|c|c|c|c|}
\hline Operación & $\begin{array}{c}\text { Prod./ } \\
\text { hora' }^{1}\end{array}$ & Unid. & $\begin{array}{c}\text { Prod. Terminado/h. } \\
(\mathbf{L})^{\mathbf{2}}\end{array}$ \\
\hline Mesa de selección & 210 & $\mathrm{Kg}$ & 131 \\
\hline Lavadora de frutas por inmersión & 400 & $\mathrm{Kg}$ & 272 \\
\hline Licuadora Industrial & 120 & $\mathrm{Kg}$ & 59 \\
\hline Coladera de acero & 120 & $\mathrm{~L}$ & 59 \\
\hline Tanque fermentador & 41,7 & $\mathrm{~L}$ & 24.5 \\
\hline Tanque de almacenamiento & 125 & $\mathrm{~L}$ & 113 \\
\hline Filtro de 12 placas & 200 & $\mathrm{~L}$ & 180 \\
\hline Llenadora de 2 válvulas & 500 & Unid. & 500 \\
\hline Tapadora manual & 2000 & Unid. & 2000 \\
\hline Etiquetadora & 160 & Unid. & 160 \\
\hline Pistola de calor & 240 & Unid. & 240 \\
\hline Lavadora de botellas & 300 & Unid. & 300 \\
\hline
\end{tabular}

Nota: $\mathrm{L}=$ litros. ${ }^{1}$ Cantidades de salida de cada máquina, es decir todavía no son producto terminado.

${ }^{2}$ Las cantidades de productos terminados se obtuvieron empleando un factor de conversión que se verá a detalle en el capítulo 5 y sin considerar eficiencias.

Elaboración propia

Se observa que operación cuello de botella es el proceso de fermentación, ya que otorga como resultado solo 24,5 litros de producto terminado por hora, esto debido a que el mosto tiene que estar un promedio de 7 días en el tanque, para ello se consideró un tanque que pueda contener 7000 litros de mosto. Es por ello que se utilizarán 3 tanques fermentadores, ya que considerando un factor de utilización de 0,9 y un factor de eficiencia de 0,8 se obtiene una capacidad de $53 \mathrm{~L} / \mathrm{h}$, ligeramente superior al tamaño mercado.

\subsection{Relación Tamaño- Punto de Equilibrio}

Para hallar el punto de equilibrio para este proyecto se han utilizado datos aproximados. El punto de equilibrio nos señalará el tamaño de planta mínimo, en este caso la cantidad mínima de productos que se deben vender para no ganar ni perder dinero, se utiliza la siguiente ecuación: 


$$
P E(Q)=\frac{\text { Costos fijos }}{\text { Precio de venta }- \text { Costos variables }}
$$

El precio establecido en el estudio de mercado de acuerdo a lo que estarían dispuestos a pagar por el producto los posibles cliente, es de S/. 25 por botella de licor de higo; sin embargo, dicho precio es el del vendedor final (autoservicio, licorería, etc.), por lo tanto, considerando un margen de ganancia de $20 \%$ en promedio por parte del vendedor final, adicionalmente a los impuestos respectivos, el precio al que nosotros tendríamos que vender el producto sería S/. 16 aproximadamente, sin incluir IGV.

Con respecto a los costos variables, estos ascienden a S/.11 por botella donde se considera la materia prima, botellas, tapas y otros costos adicionales.

Por otro lado, el costo fijo del proyecto se estima, comparando con otras empresas del sector en S/. 700,000, que se sustenta en el hecho de que hay que hacer varias gestiones administrativas, derivadas del proceso de producción, contactar a proveedores, gastos de alquiler, sueldos, limpieza, entre otros.

Aplicando la fórmula para determinar el punto de equilibrio (PE),

$$
P E(Q)=\frac{700.000}{16-11}
$$

Se obtiene:

$\mathbf{P E}=140.000$ unid/año $<>449$ unid/día $<>28$ unid/h .

Al ser cada botella de $750 \mathrm{ml}$ se obtiene que el punto de equilibrio en litros es 21.

\subsection{Selección del tamaño de planta}

Selección de tamaño óptimo considerando, las relaciones tamaño -mercado, tamaño -recurso productivo, tamaño -tecnología y tamaño punto de equilibrio del décimo año del proyecto. Para el proyecto se considerarán tres tanques fermentadores por lo cual el tamaño de la tecnología aumentaría a $53 \mathrm{~L} / \mathrm{h}$ de producto terminado. En la tabla 4.5 se observa un análisis de las restricciones de tamaño de planta: 
Tabla 4.4

Análisis de restricciones de tamaño de planta (kg/día.)

\begin{tabular}{|c|c|}
\hline Relación & Tamaño \\
\hline Tamaño-Mercado & $41 \mathrm{~L} / \mathrm{h}$ \\
\hline Tamaño-Recursos productivos & $783 \mathrm{Kg} / \mathrm{h}$ \\
\hline Tamaño-Tecnología & $53 \mathrm{~L} / \mathrm{h}$ \\
\hline Tamaño-Punto de equilibrio & $21 \mathrm{~L} / \mathrm{h}$ \\
\hline
\end{tabular}

Elaboración propia

Los datos de la tabla han sido obtenidos de tablas Tamaño mercado (año 10), Tamaño recursos productivos (año 10), tamaño tecnología (3 tanques fermentadores) y tamaño punto de equilibrio

Por lo tanto el tamaño de planta para el presente proyecto estará definido por el tamaño mercado. 


\section{CAPÍTULO V: INGENIERÍA DEL PROYECTO}

\subsection{Definición del producto basada en sus características de fabricación}

\subsubsection{Especificaciones técnicas del producto}

Tabla 5.1

Ficha técnica del producto

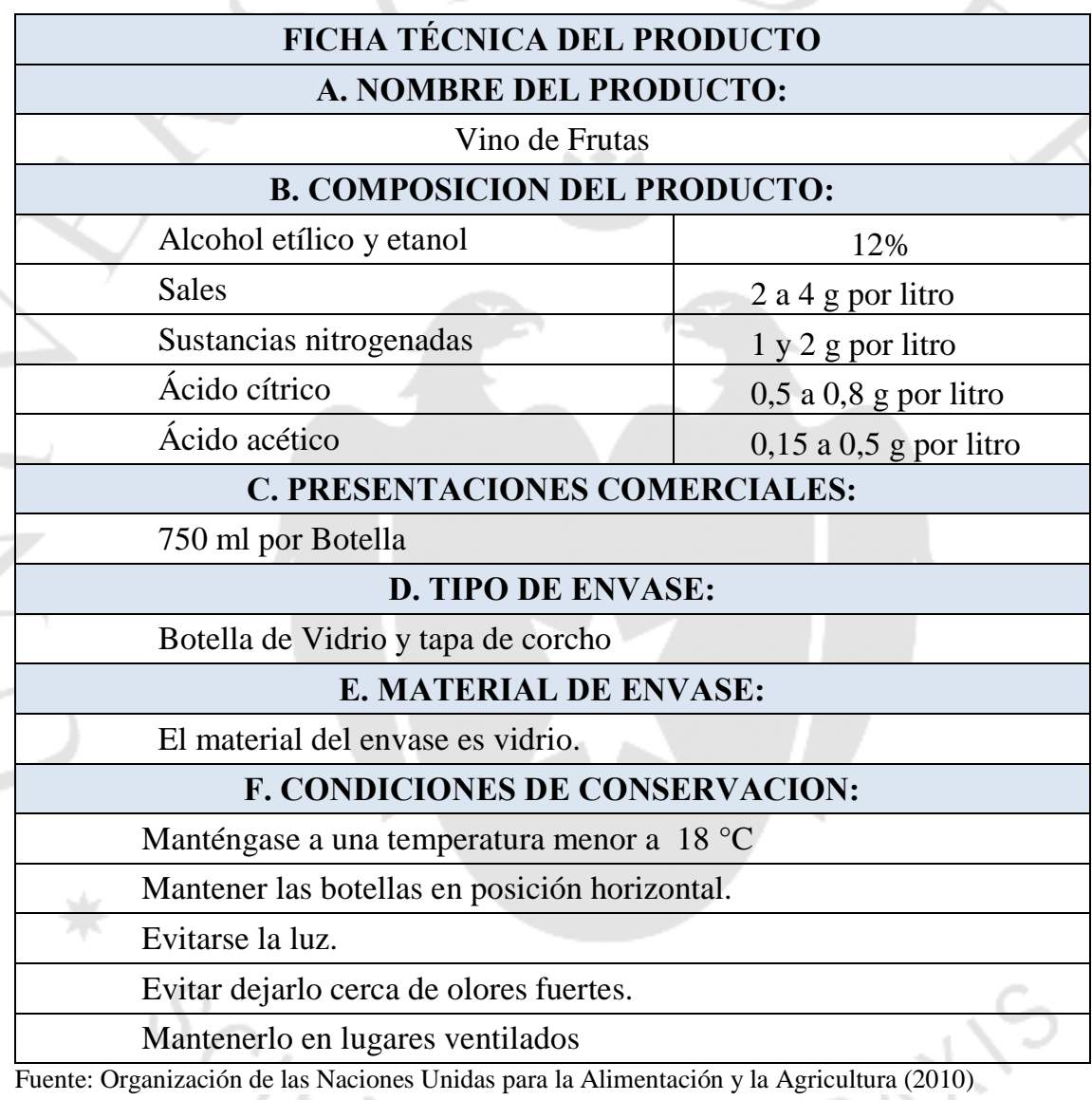

Adicionalmente se considerarán una serie de normas técnicas relacionadas con la producción de vinos:

1. NTP 212.014. 2011. Bebidas Alcohólicas Vitivinícolas. Vinos. Requisitos

2. NTP-CODEX CAC/RCP 63. 2010. Bebidas Alcohólicas Vitivinícolas. Vinos. Código de prácticas para la prevención y reducción de la contaminación por ocratoxina A en el vino. 
3. NTP 212.006: 2009. Bebidas Alcohólicas. Vinos. Determinación de sulfatos

4. NTP 212.008: 2009. Bebidas Alcohólicas. Vinos. Determinación de cloruros.

5. NTP 212.015: 2009. Bebidas Alcohólicas. Vinos. Determinación del anhídrido sulfuroso libre y total

6. NTP 212.030: 2009. Bebidas Alcohólicas. Vinos. Determinación del grado alcohólico.

7. NTP 212.037: 2009. Bebidas Alcohólicas. Vinos. Determinación de la acidez cítrica.

8. NTP 212.038: 2009. Bebidas Alcohólicas. Vinos. Determinación de los azúcares reductores.

9. NTP 212.047: 2009. Bebidas Alcohólicas. Vinos. Determinación de la acidez total.

\subsection{Tecnologías existentes y procesos de producción}

\subsubsection{Naturaleza de la tecnología requerida}

\section{Descripción de las tecnologías existentes}

Las tecnologías existentes para la elaboración de vinos de fruta varían básicamente en los siguientes procesos:

\section{Acondicionamiento del mosto:}

Consiste en la adición de levaduras para una mejor fermentación. Las levaduras utilizadas en el proceso de fermentación pueden ser de 2 tipos:

Fermentación natural: Se realiza mediante la acción espontánea de las propias levaduras existentes en el higo. El jugo del higo, contiene altos niveles de azúcar en forma natural, estos 
azúcares se transforman en alcohol y dióxido de carbono. Dicha fermentación puede producir licores con hasta $16 \%$ de alcohol.

Fermentación mediante levaduras seleccionadas: consiste en eliminar la mayor cantidad de bacterias indeseadas del mosto mediante adición de anhídrido sulfuroso, o mediante la centrifugación e incluso, mediante pasteurización. Luego de realizado esto, se siembran levaduras, además de material alimenticio de estas levaduras como sales de fosfato de amonio y otros. Las levaduras pueden ser:

- Levadura de panadería: Es la levadura de panificación, a bajo costo, tolerancia promedio al alcohol.

- Levadura seleccionada: Mejor desempeño que la levadura de panificación tiene un costo mayor. Como por ejemplo la levadura Saccharomyces cerevisiae.

\section{Filtrado:}

Filtrado con telas: se hace pasar la mezcla fermentada por una tela fina o colador, previamente esterilizado, para eliminar la levadura y la pulpa residual.

Filtro prensa placas y marcos: otorga máxima brillantes al vino, esterilidad $\mathrm{y}$ estabilidad del vino, retiene los microorganismos del mosto.

\section{Selección de la tecnología}

La tecnología seleccionada es la que emplea la levadura seleccionada y utiliza el filtro prensa para la obtención de un licor más limpio en menor tiempo. 


\subsubsection{Proceso de producción}

\section{Descripción del proceso}

Selección: Esta operación consiste en escoger la fruta que se encuentre en buen estado y desechar la que no esté en óptima condiciones, generalmente más de un $90 \%$ de la fruta es admitida para el siguiente proceso. Se realiza de manera manual en una mesa de selección

Lavado: Esta operación consiste en remover toda la suciedad y restos de insecticidas que contenga la fruta, para ello se empleará una máquina de lavado por inmersión.

Obtención del jugo: Esta operación consiste en estrujar, moler o triturar la fruta, para liberar al máximo el jugo. Se realiza mecánicamente en estrujadoras de rodillo y máquinas de cuchillas como licuadoras. En este caso se utilizará una licuadora industrial, a donde ingresará el higo, el agua purificada y el azúcar.

Corrección de la cantidad de azúcar: La cantidad de azúcar se puede medir indirectamente midiendo la densidad, la cual está en relación directa con esta. La densidad se determina mediante el uso de un densímetro especial denominado mostímetro. Conociendo la densidad y mediante una tabla podemos determinar la cantidad de azúcar que tiene el mosto.

Par saber cuántos grados alcohólicos se va a tener con una cantidad de azúcar determinada en el mosto, se puede usar la siguiente relación:

Se necesitan 17 gr azúcar/litros de mosto para obtener un grado A. Por ejemplo si se quiere obtener $12^{\circ} \mathrm{A}$, el mosto debe tener: $17 \times 12=204$ gr. de azúcar por cada litro de mosto.

Colado: Este proceso sirve para eliminar las impurezas y partículas indeseables que pueden encontrarse en el jugo obtenido, para que de esta forma este quede libre de materias sólidas que no favorecen la 
fermentación, se empleará una coladera de acero inoxidable. Luego de ello se pasará el jugo obtenido a las cubas de fermentación.

Sulfitado: Una vez que el mosto se encuentre en el tanque de fermentación se procede a realizar el sulfitado, Esta operación se realiza para eliminar a los microorganismos contaminantes que puedan competir con la levadura y alterar el proceso de fermentación.

El mosto acondicionado se sulfita utilizando metabisulfito de sodio o de potasio, en una cantidad de 50 a $100 \mathrm{mg} / \mathrm{L}$, dependiendo de la temperatura ambiental (a mayor temperatura, mayor sulfitación) y de las condiciones de la fruta (cuanto más madura, más sulfito).

Adición de levaduras: Es conveniente practicar la siembra de levaduras seleccionadas de fuerte capacidad fermentativa y poder alcoholígeno, lo cual a redundar en un comienzo rápido y uniforme de la fermentación y en la obtención de vinos sin azúcares residuales.

Para usar la levadura seca se tienen que tener en cuenta los siguientes pasos:

Reactivación de la levadura seca, lo cual se realiza disolviendo la levadura en un poco de agua hervida entibiada $\left(30{ }^{\circ} \mathrm{C}\right)$ con un poco de azúcar, dejándola por media hora.

Preparación del pie de cuba, que se hace con un poco del mosto a fermentar (aproximadamente el 5\% del total), en el cual se siembra la levadura, dejándola reposar en un sitio abrigado $\left(22-28{ }^{\circ} \mathrm{C}\right)$ hasta que se vea producción de gas (burbujeo).

Una vez, preparado el pie de cuba, se siembra finalmente en la cuba o tanque de fermentación.

Fermentación: Una vez adicionado el pie de cuba o sea las levaduras seleccionadas activadas, empieza la fermentación alcohólica, la cual será controlada mediante la medición de la densidad y de la temperatura. La fermentación se realiza entre 5 y 7 días como mínimo hasta que ya no haya producción de gas. 


\section{Control de la densidad}

Nos indica cómo se va transformando el azúcar en alcohol.

\section{Control de la temperatura:}

Es muy importante que la levadura trabaje en un rango de temperaturas comprendidas entre $20-25{ }^{\circ} \mathrm{C}$. La temperatura tiene una acción selectiva en el desarrollo de otros microorganismos que no son los fermentativos. Si la temperatura sobrepasa $\operatorname{los} 30^{\circ} \mathrm{C}$ puede ocurrir la fermentación por bacterias.

El proceso de fermentación es exotérmico, ya que el proceso absorbe menos energía de la que libera, Por lo tanto para que la temperatura del reactor permanezca constante, la energía neta liberada debe retirarse del tanque fermentador; de lo contrario, su temperatura podría elevarse algunos grados. Para ello se debe realizar un balance de energía que indicará el grado de enfriamiento requerido por el reactor para funcionar en las condiciones deseadas.

Empleando la siguiente fórmula:

\section{$m_{1} C_{\text {Glucosa }} \Delta T+m_{2} C_{H 20} \Delta T=m_{3} \Delta H=($ Calor que se tiene que remover)}

Donde:

- $\mathrm{m}_{1}$ : masa de la glucosa que no reaccionó

- $\mathrm{m}_{2}$ : masa del agua

- $\mathrm{m}_{3}$ : masa de la glucosa que reaccionó

- C : capacidad calorífica

- $\Delta \mathrm{T}^{\circ}$ : variación de la temperatura

- $\Delta \mathrm{H}$ : variación de la entalpia

Aplicado a la ingeniería de procesos, este calor se podría remover de diferentes formas, como: empleando intercambiadores de 
calor, enfriadores o utilizando otros métodos más sencillos como colocar bolsas con agua a baja temperatura en el tanque fermentador.

Trasiego: Consiste en sacar y separar la parte superior del fermento, mediante succión. Durante la fermentación existe una separación de fases, quedando el vino en la parte superior y residuos de fruta o levadura en la parte inferior. La fermentación resultante puede ser entre $65 \%$ a $75 \%$ del mosto.

Filtrado: La parte superior del fermento que está siendo succionada pasa por un filtro de placas y marcos para obtener un vino más limpio, con la menor cantidad de residuos y en poco tiempo.

Envasado: Por lo general se hace en botellas de vidrio. Los envases deben esterilizarse lavándolos con agua, para este caso se empleará una pequeña lavadora de botellas.

Encorchado: Consiste en colocarle el corcho a presión a las botellas una vez que estas han sido llenadas con el producto, para ello se empleará una máquina encorchadora manual.

Encapsulado: Una vez realizado el encorchado se procede a colocar una cápsula termoencogible, para el proyecto se utilizará una pistola de calor que ayudará a la cápsula a adherirse a la botella.

Etiquetado: Consiste en colocar la etiqueta con los datos más importantes del producto, como nombre, ingredientes, fecha de elaboración, Registro Sanitario, entre otros. Se empleará una máquina etiquetadora. 
Diagrama de operaciones y procesos: DOP

\section{Figura 5.1}

Diagrama de operaciones y procesos para la producción de licor de higo (Kg.)

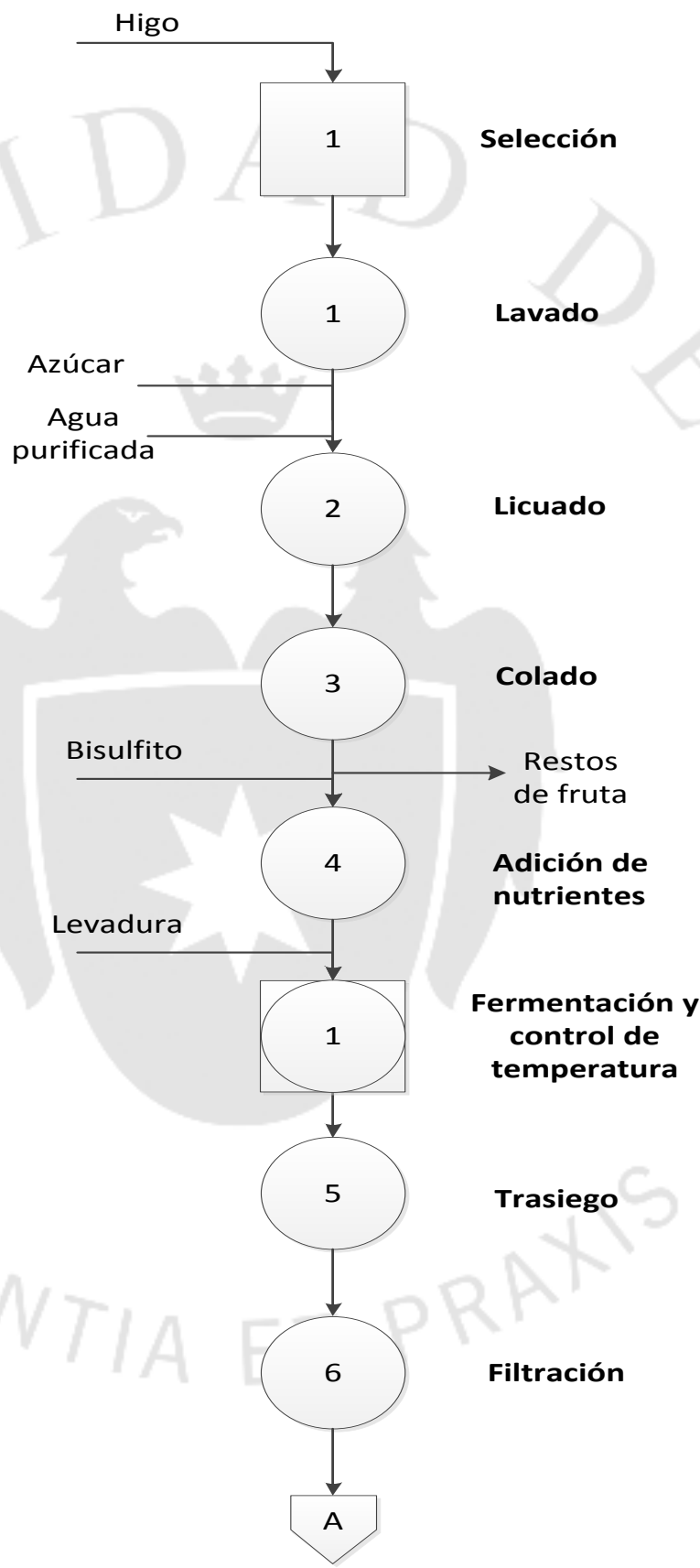




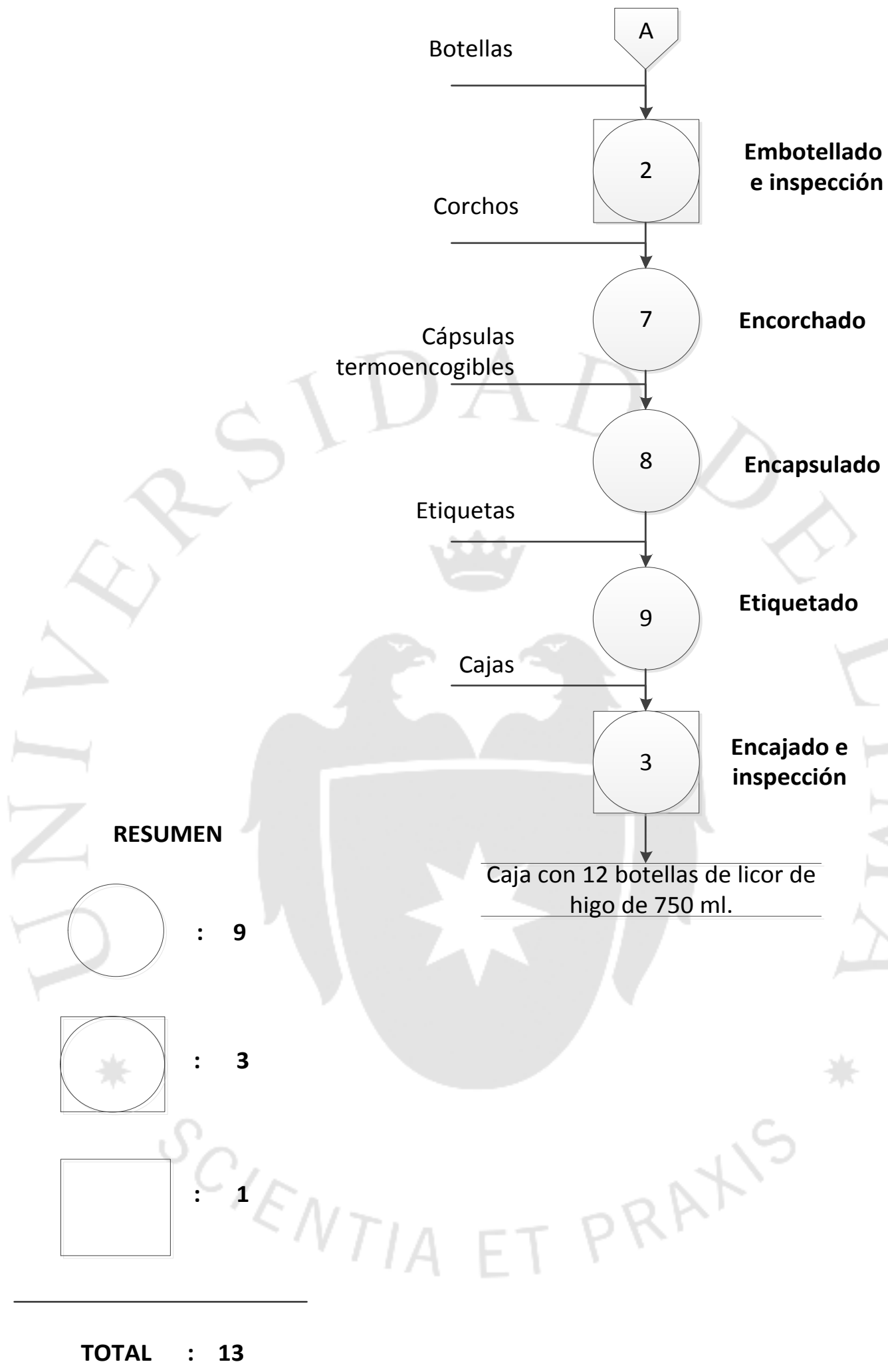

Elaboración propia 


\section{Balance de materia: Diagrama de bloques}

El balance de materia muestra como a partir del higo fresco (80\% de contenido de agua), se obtiene el licor de higo. Cabe resaltar que el presente balance es referencial puesto que está ajustado a la producción de solo una botella de licor de $750 \mathrm{ml}$.

\section{Figura 5.2}

\section{Balance de materia en la elaboración de licor de higo (Kg.)}

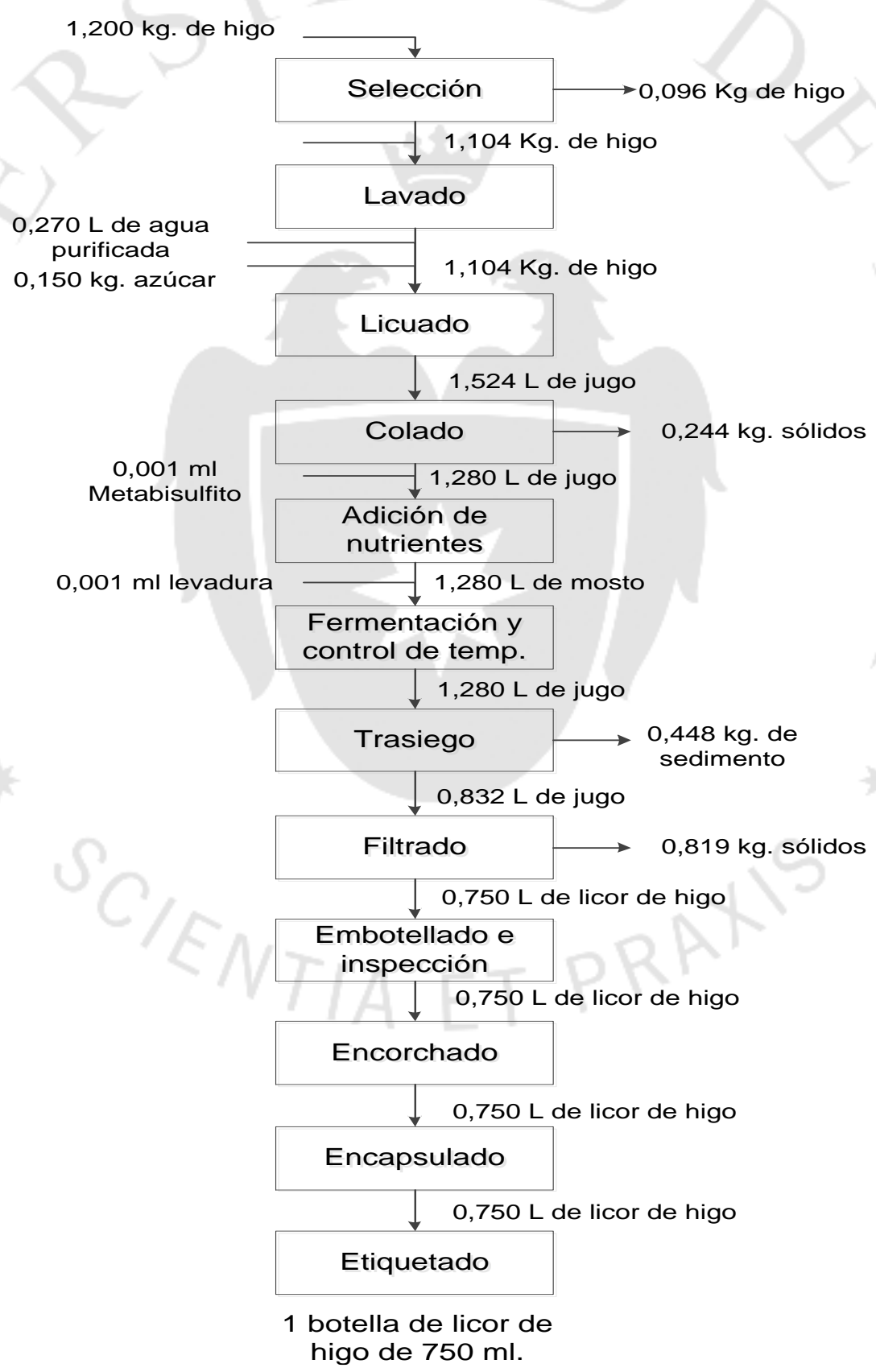

Elaboración propia 


\subsection{Características de las instalaciones y equipo}

\subsubsection{Selección de la maquinaria y equipo}

Para la producción del licor de higo es necesario contar con la maquinaria y los equipos adecuados para garantizar el rendimiento y la calidad del producto. Por tal motivo es importante resaltar que las maquinarias y equipos deben ser de acero inoxidable, ya que es un material resistente a la corrosión e inofensivo para el producto.

Además del material, la selección de equipos se debe hacer en base a su rendimiento de producción, la productividad del equipo y a la calidad de su funcionamiento.

Es así que de acuerdo al proceso descrito anteriormente, se pueden mencionar los principales equipos y máquinas que representan a las principales operaciones del proceso de elaboración del licor de higo.

$\checkmark$ Balanza de plataforma industrial

$\checkmark$ Máquina de lavado

$\checkmark$ Mesa de selección

$\checkmark$ Licuadora de jugo industrial

$\checkmark$ Coladera de acero inoxidable

$\checkmark$ Filtro de placas

$\checkmark$ Tanque de fermentación

$\checkmark$ Tanque de almacenamiento

$\checkmark$ Embotelladora

$\checkmark$ Encorchadora

$\checkmark$ Lavadora de botellas

$\checkmark$ Pistola de aire

$\checkmark$ Etiquetadora

$\checkmark$ Filtro purificador de agua 


\subsubsection{Especificaciones de la maquinaria}

Los selección de equipos para el presente proyecto se ha realizado en base a la demanda del producto, balance de materia, costo y disponibilidad de equipos en el mercado:

\section{Tabla 5.2}

Especificaciones técnicas de la lavadora industrial

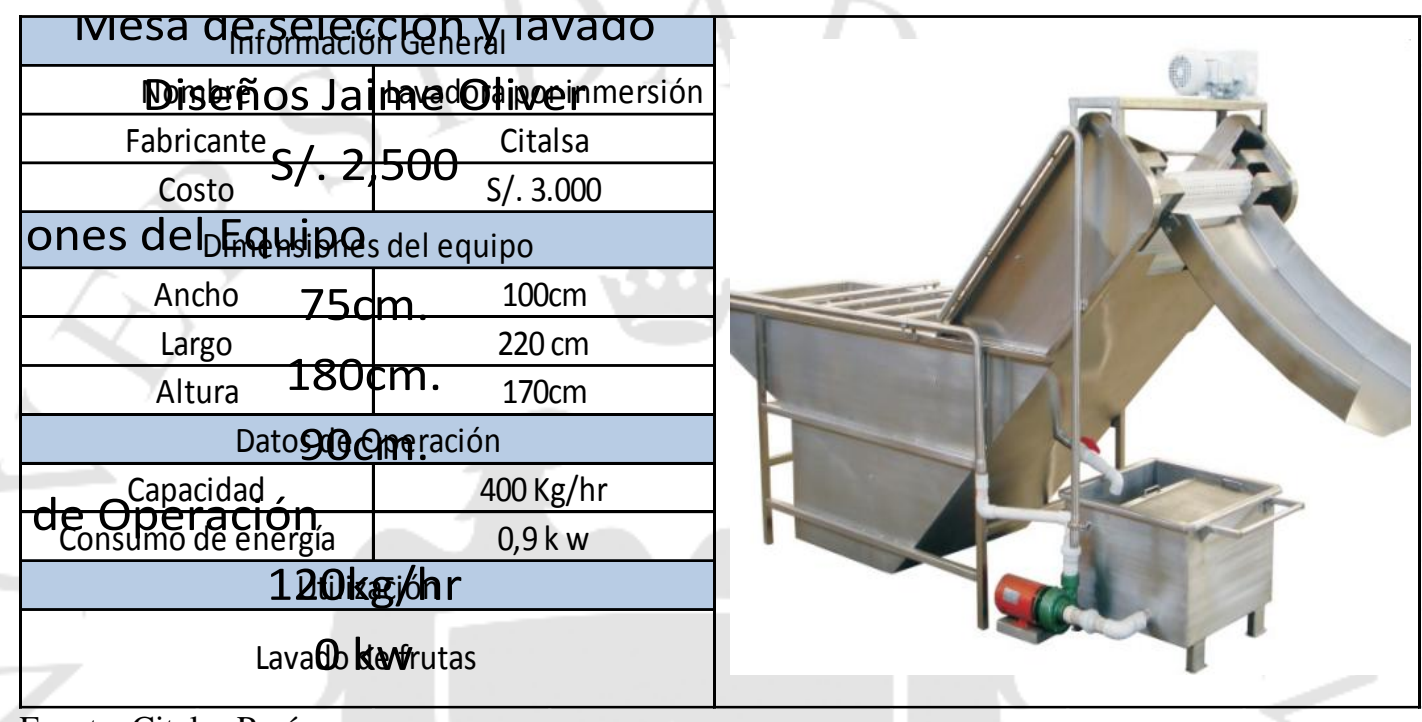

Fuente: Citalsa Perú

Tabla 5.3

Especificaciones técnicas de la mesa de selección

\begin{tabular}{|c|c|}
\hline \multicolumn{2}{|c|}{ Información General } \\
\hline Nombre & Mesa de selección \\
\hline Fabricante & $\begin{array}{c}\text { Shandong Refine Fruit \& Vegetable } \\
\text { Machinery Technology Co., Ltd. }\end{array}$ \\
\hline Costo & $\mathrm{S} / 1.000$ \\
\hline \multicolumn{2}{|c|}{ Dimensiones del equipo } \\
\hline Ancho & $75 \mathrm{~cm}$ \\
\hline Largo & $90 \mathrm{~cm}$ \\
\hline Altura Datos de Operación \\
\hline Capacidad & $210 \mathrm{Kg} / \mathrm{h}$ \\
\hline Consumo de energía & $0 \mathrm{~kW}$ \\
\hline \multicolumn{2}{|c|}{ Utilización } \\
\hline
\end{tabular}

Fuente: Alibaba 
Tabla 5.4

Especificaciones técnicas de la licuadora industrial

\begin{tabular}{|c|c|}
\hline \multicolumn{2}{|c|}{ Información General } \\
\hline Nombre & Licuadora Industrial \\
\hline Fabricante & JPM \\
\hline Costo D/.2.500 & 500 \\
\hline Ancho & 700 \\
\hline Largo & 1000 \\
\hline Altura Datos de Operación & $120 \mathrm{~L} / \mathrm{h}$ \\
\hline Capacidad & $1,5 \mathrm{~kW} / \mathrm{h}$ \\
\hline Consumo de energía & Utilización \\
\hline
\end{tabular}

Fuente: JPM Industrias

Tabla 5.5

Especificaciones técnicas del filtro de placas

\begin{tabular}{|c|c|}
\hline \multicolumn{2}{|c|}{ Información General } \\
\hline Nombre & Filtro de 12 placas \\
\hline Fabricante & AUSAVIL \\
\hline Costo & S/.15.000 \\
\hline \multicolumn{2}{|c|}{ Dimensiones del equipo } \\
\hline Ancho & $50 \mathrm{~cm}$ \\
\hline Largo & $70 \mathrm{~cm}$ \\
\hline Altura & $50 \mathrm{~cm}$ \\
\hline \multicolumn{2}{|c|}{ Datos de Operación } \\
\hline Capacidad & $200 \mathrm{Itr} / \mathrm{hr}$. \\
\hline Consumo de energía & $0.8 \mathrm{Kw} . \mathrm{h} / \mathrm{TM}$ \\
\hline \multicolumn{2}{|c|}{ Utilización } \\
\hline \multicolumn{2}{|c|}{ Para el filtrado de vino en el trasiego. } \\
\hline
\end{tabular}

Fuente: AUSAVIL 
Tabla 5.6

\section{Especificaciones técnicas del tanque fermentador}

\begin{tabular}{|c|c|}
\hline \multicolumn{2}{|c|}{ Información General } \\
\hline Nombre & Tanque fermentador \\
\hline Fabricante & Alca Maquindustrias \\
\hline Costo S/.32.000 \\
\hline \multicolumn{2}{|c|}{ Dimensiones del equipo } \\
\hline Altura & 1500 \\
\hline Diametro Datos de Operación \\
\hline \multicolumn{2}{|c|}{ 2200 } \\
\hline Capacidad & Utilización \\
\hline Consumo de energía & \\
\hline \multicolumn{2}{|c|}{0} \\
\hline
\end{tabular}

Fuente: Ministerio de Agricultura

Tabla 5.7

\section{Especificaciones técnicas de la lavadora de botellas}

\begin{tabular}{|c|c|}
\hline \multicolumn{2}{|c|}{ Información General } \\
\hline Nombre & Lavadora de botellas \\
\hline Fabricante & Enotécnica Pillan \\
\hline Costo S/ 4.500 \\
\hline Dimensiones del equipo \\
\hline Ancho & $30 \mathrm{~cm}$ \\
\hline Largo & $30 \mathrm{~cm}$ \\
\hline Altura & $50 \mathrm{~cm}$ \\
\hline \multicolumn{2}{|c|}{300 Unid. /h } \\
\hline Capacidad de Operación \\
\hline \multicolumn{2}{|c|}{ Utilización } \\
\hline
\end{tabular}

Fuente: Enotécnica Pillan 
Tabla 5.8

\section{Especificaciones técnicas de la encorchadora}

\begin{tabular}{|c|c|}
\hline \multicolumn{2}{|c|}{ Información General } \\
\hline Nombre & Tapadora manual \\
\hline Fabricante & M-MAQ \\
\hline Costo $/ .2 .500$ \\
\hline \multicolumn{2}{|c|}{ Dimensiones del equipo } \\
\hline Ancho & $50 \mathrm{~cm}$ \\
\hline Largo & $120 \mathrm{~cm}$ \\
\hline Altura Datos de Operación \\
\hline Capacidad & 2000 bot/h \\
\hline Consumo de energía & 0 \\
\hline \multicolumn{2}{|c|}{ Utilización } \\
\hline \multicolumn{2}{|c|}{ Coloca corhos en las botellas. } \\
\hline
\end{tabular}

Fuente: Ministerio de Agricultura

\section{Tabla 5.9}

\section{Especificaciones técnicas de la llenadora de botellas}

\begin{tabular}{|c|c|}
\hline \multicolumn{2}{|c|}{ Información General } \\
\hline Nombre & Llenadora de 2 válvulas \\
\hline Fabricante & $\mathrm{M}-\mathrm{MAQ}$ \\
\hline Costo S/.4.000 \\
\hline \multicolumn{2}{|c|}{ Dimensiones del equipo } \\
\hline Ancho & $40 \mathrm{~cm}$ \\
\hline Largo & $50 \mathrm{~cm}$. \\
\hline Altura Datos de Operación \\
\hline \multicolumn{2}{|c|}{500 bot/h } \\
\hline Capacidad & Utilización \\
\hline Lonsumo de energía & \\
\hline
\end{tabular}

Fuente: Ministerio de Agricultura 
Tabla 5.10

\section{Especificaciones técnicas de la etiquetadora}

\begin{tabular}{|c|c|}
\hline \multicolumn{2}{|c|}{ Información General } \\
\hline Nombre & Etiquetadora \\
\hline Fabricante & DLPK \\
\hline Costo & $\mathrm{S} / .2,000$ \\
\hline \multicolumn{2}{|c|}{ Dimensiones del equipo } \\
\hline Largo & 155 \\
\hline Ancho & 220 \\
\hline Altura Datos de Operación & 120 unid. $/ \mathrm{hr}$. \\
\hline Capacidad & $20 \mathrm{Kw}$ \\
\hline Consumo de energía & Utilización \\
\hline \multicolumn{2}{|c|}{ Horno para deshidratar la fruta. } \\
\hline
\end{tabular}

Fuente: Alibaba

Tabla 5.11

Especificaciones técnicas del tanque de almacenamiento

\begin{tabular}{|c|c|}
\hline \multicolumn{2}{|c|}{ Información General } \\
\hline Nombre & Tanque de almacenamiento \\
\hline Fabricante & Alca Maquindustrias \\
\hline Costo & S/.15.000 \\
\hline \multicolumn{2}{|c|}{ Dimensiones del equipo } \\
\hline Altura Datos de Operación \\
\hline Diametro & $62.500 \mathrm{~L} / \mathrm{h}$ \\
\hline \multicolumn{2}{|c|}{0} \\
\hline Capacidad & Utilización \\
\hline Tanque o cubas para almacenamiento del vino. \\
\hline
\end{tabular}

Fuente: Ministerio de Agricultura 
Tabla 5.12

Especificaciones técnicas de la pistola de calor

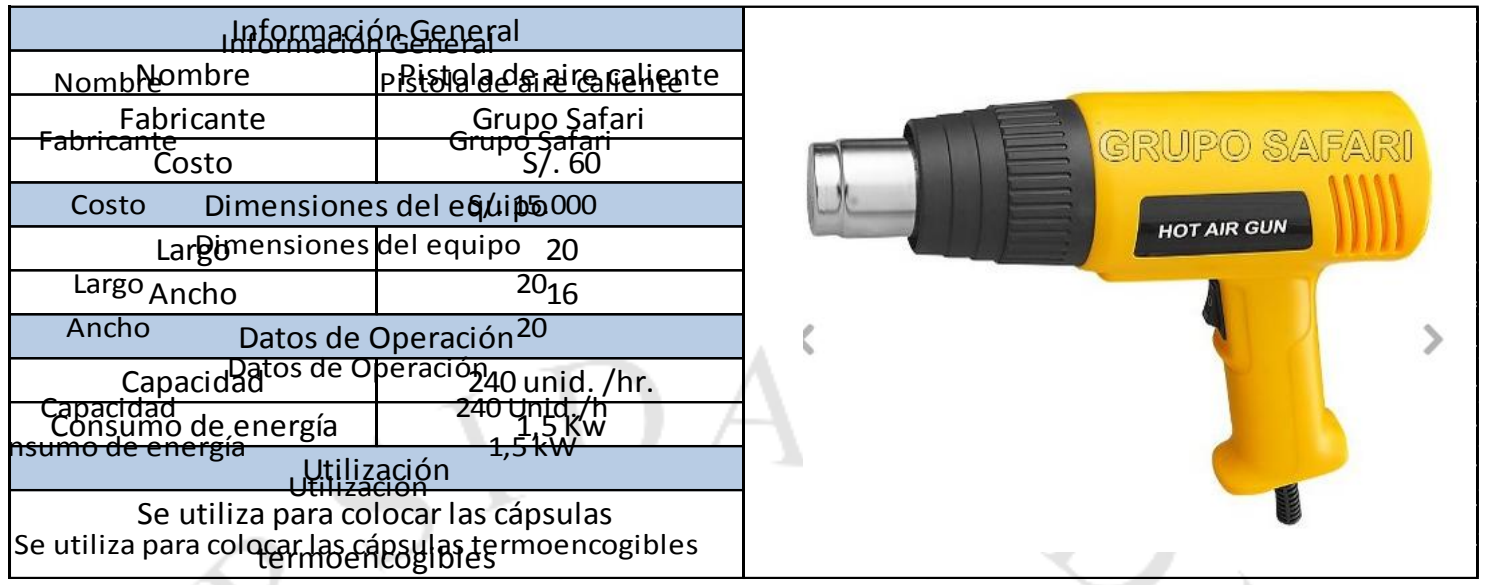

Fuente: Alibaba

\subsection{Capacidad instalada}

\subsubsection{Cálculo de la capacidad instalada}

El cálculo de la capacidad instalada de planta se determina en base a la operación cuello de botella de todo el proceso productivo. En este caso la operación cuello de botella es el fermentado.

Tabla 5.13

Cálculo de la capacidad instalada para el décimo año del proyecto (Kg.)

\begin{tabular}{|c|c|c|c|c|c|c|c|c|c|c|c|c|}
\hline Operación & Unid & $\begin{array}{c}\text { Prod./ } \\
\mathbf{h}\end{array}$ & $\begin{array}{c}\mathbf{N}^{\circ} \\
\text { máq. }\end{array}$ & $\begin{array}{c}\text { Días/ } \\
\text { Sem. }\end{array}$ & $\begin{array}{c}\text { H/ } \\
\text { tur }\end{array}$ & $\begin{array}{c}\text { Tur } \\
/\end{array}$ & $\begin{array}{c}\text { Sem } \\
\text { día }\end{array}$ & Uno & E & $\begin{array}{c}\text { Cap. } \\
\text { prod. } \\
\text { (L) }\end{array}$ & $\begin{array}{c}\text { Factor de } \\
\text { conversión }\end{array}$ & $\begin{array}{c}\text { Cap. } \\
\text { prod } \\
\text { (L) }\end{array}$ \\
\hline Fermentación & $\mathrm{L}$ & 41,67 & 3 & 7 & 8 & 3 & 26 & 0,9 & 0,8 & 393.120 & 0,587 & 231.247 \\
\hline
\end{tabular}

Nota: U= Factor de utilización. E= Factor de eficiencia. Factor de conversión =el cociente de la cantidad de producto final entre la cantidad entrante al proceso de fermentación (ver balance da materia). Elaboración propia

La producción por hora se calculó considerando 7 días de fermentación en un tanque de 7000 litros, teniendo como resultado:

- $\quad$ Prod. $/ \mathrm{hr} .=\frac{7000 \text { litros }}{7 \text { días } \times 24 \text { horas }}=41.67 \mathrm{~L} / \mathrm{h}$. 


\subsubsection{Cálculo detallado del número de máquinas requeridas}

Para el cálculo del número de máquinas se considerarán dos turnos de trabajo de 8 horas cada uno, 6 días a la semana y 26 semanas al año, ya que la planta solo operará medio año:

\section{Tabla 5.14}

\section{Cálculo del número de máquinas para el décimo año del proyecto (Kg.)}

\begin{tabular}{|c|c|c|c|c|c|c|c|c|c|c|c|}
\hline Operación & $\begin{array}{c}\text { Cantidad } \\
\text { Entrada }\end{array}$ & Unid. & $\begin{array}{c}\text { Prod/ } \\
\text { h }\end{array}$ & $\begin{array}{l}\text { Días/ } \\
\text { Sem. }\end{array}$ & $\begin{array}{c}\text { h/ } \\
\text { turno }\end{array}$ & $\begin{array}{c}\text { Turnos/ } \\
\text { día }\end{array}$ & Sem/año & $\mathbf{U}$ & $\mathbf{E}$ & $\begin{array}{c}\mathrm{N}^{\circ} \text { de } \\
\text { máquinas }\end{array}$ & $\begin{array}{c}\mathrm{N}^{\circ} \text { de } \\
\text { máq. real }\end{array}$ \\
\hline Lavadora de frutas & 326.498 & $\mathrm{~kg}$ & 0,003 & 6 & 8 & 2 & 26 & 0,90 & 0,85 & 0,43 & 1 \\
\hline Licuadora Industrial & 450.709 & $\mathrm{~kg}$ & 0,008 & 6 & 8 & 2 & 26 & 0,90 & 0,85 & 1,97 & 2 \\
\hline Tanque fermentador ${ }^{1}$ & 377.141 & $\mathrm{~L}$ & 0,024 & 7 & 8 & 3 & 26 & 0,90 & 0,85 & 2,71 & 3 \\
\hline Tanque de almacenamiento ${ }^{2}$ & 246.087 & $\mathrm{~L}$ & 0,016 & 7 & 8 & 3 & 26 & 0,90 & 0,85 & 1,18 & 2 \\
\hline Filtro de 12 placas & 246.087 & $\mathrm{~L}$ & 0,005 & 6 & 8 & 2 & 26 & 0,90 & 0,85 & 0,64 & 1 \\
\hline Llenadora de 2 válvulas & 295.797 & Bot. & 0,002 & 6 & 8 & 2 & 26 & 0,90 & 0,85 & 0,31 & 1 \\
\hline Lavadora de botellas & 295.797 & Bot. & 0,0033 & 6 & 8 & 2 & 26 & 0,90 & 0,85 & 0,52 & 1 \\
\hline
\end{tabular}

Nota: $U=$ Factor de utilización. E $=$ Factor de eficiencia. ${ }^{1}$ Para los tanques de fermentación y ${ }^{2}$ tanques de almacenamiento se está

considerando 7 días/semana, 8 h/turno y 3 turnos/día, debido a que los tanques pueden almacenar los productos de manera ininterrumpida Elaboración propia 


\subsection{Resguardo de la calidad}

\subsubsection{Calidad de la materia prima, de los insumos, del proceso y del producto}

\section{Calidad de la materia prima}

Para que el higo, materia prima del licor presentado en el presente proyecto, se encuentre apto para el proceso de producción, debe tener ciertas características físicas para ser considerado apropiado para el proceso:

\section{Tabla 5.15}

\section{Características del higo}

\begin{tabular}{|c|l|}
\hline Característica & \multicolumn{1}{|c|}{ Descripción } \\
\hline Forma & La forma del fruto debe ser redonda u oval. \\
\hline Tamaño & De diámetro aproximado de $65 \mathrm{~mm}$. Y de peso aproximado de 25 g. \\
\hline Sabor & El sabor debe ser dulce. \\
\hline Color & $\begin{array}{l}\text { Tanto la piel como la pulpa deben tener un color marrón oscuro } \\
\text { uniforme e intenso. }\end{array}$ \\
\hline
\end{tabular}

Fuente: Botánica on-line

Dichas características deberán ser inspeccionadas por el personal durante la etapa de selección de la fruta. Del cumplimiento de estas, dependerá el pase del fruto a la siguiente estación. Además, se considera óptimo que el fruto se encuentre totalmente maduro para darle mejor sabor al producto final.

\section{Calidad de los insumos}

Al igual que la materia prima, los insumos a utilizar deben cumplir ciertos requerimientos de calidad: 


\section{Tabla 5.16}

\section{Características de los insumos}

\begin{tabular}{|c|c|}
\hline Insumo & Requerimientos \\
\hline Bolsas & Bolsas de polipropileno con capacidad para $10 \mathrm{~kg}$ de higo seco. \\
\hline Azúcar & $\begin{array}{l}\text { El azúcar a añadir debe ser de preferencia blanca, ya que los granos son } \\
\text { más pequeños y se disuelven mejor en el mosto. }\end{array}$ \\
\hline Metabisulfito & $\begin{array}{l}\text { Gránulos finos de color blanco, } \\
\text { Metabisulfito de sodio a } 96 \% \\
\text { Temperatura de descomposición: } 170 \text { C } \\
\text { pH: } 4 \text { a } 5 \\
\text { Apariencia al } 20 \% \text { en solución: Transparente }\end{array}$ \\
\hline Levadura & $\begin{array}{l}\text { Levadura saccharomyces cerevisiae } \\
\text { Aspecto: gránulos de color beige claro. } \\
\text { Olor a levadura } \\
\text { Humedad: }<5 \% \text { Solubilidad (soluble en agua a cualquier proporción) } \\
\text { pH:5-6 } \\
\text { Conservar a temperatura menor a } 20 \mathrm{C}^{\circ} \text {. }\end{array}$ \\
\hline Botella & $\begin{array}{l}\text { Botellas nuevas de color marrón del tipo burdeos, de cuello corto y } \\
\text { hombros bien marcados. Deben ser lavadas previamente con agua fría o } \\
\text { caliente. }\end{array}$ \\
\hline Tapa & $\begin{array}{l}\text { Tapas de corcho recto de forma cilíndrica. } \\
\text { De } 4 \mathrm{~cm} \text { de largo, } 2 \mathrm{~cm} \text { de diámetro. }\end{array}$ \\
\hline $\begin{array}{l}\text { Cápsula } \\
\text { Termoencogible }\end{array}$ & $\begin{array}{l}\text { Largo de falda: } 6 \mathrm{~mm} \text {. } \\
\text { Color guinda } \\
\text { Para contraerse requiere de aire caliente. }\end{array}$ \\
\hline Etiqueta & $\begin{array}{l}\text { La etiqueta será de color blanca con todos los datos del producto y el } \\
\text { contenido reglamentario para bebidas alcohólicas. }\end{array}$ \\
\hline
\end{tabular}

Fuente: Vino de fruta casero

Estos requerimientos de calidad serán verificados por el personal antes de que los insumos sean usados en el proceso de producción.

\section{Calidad en el proceso}

Durante el proceso de producción se realizan varias inspecciones de calidad de la materia prima, del proceso y del producto. Además, para salvaguardar la salubridad del producto, los operarios contarán con material de protección como gorros, guantes y mascarillas en determinadas etapas del proceso de producción. 
Para los procesos de lavado y selección se debe tener ciertas medidas de higiene que permitan tener un producto que no esté contaminado por baterías y/o suciedad que hayan podido ser transmitidas por el ambiente o por las personas que se encuentren en contacto con la materia prima.

Asimismo, a lo largo del proceso de producción los operarios estarán pendientes del funcionamiento correcto de las máquinas y que los resultados vayan acorde a los estándares establecidos para evitar pérdidas.

\section{Producto}

Finalmente se encuentra la última inspección que es producto terminado, que se realiza con la finalidad de cerciorarse de que las botellas estén correctamente selladas, sin el riesgo de que se abran y se contaminen o se derrame el producto. Su almacenaje debe ser en un lugar fresco, para evitar la descomposición del producto. Según la FAO, se tienen que verificar que el producto cumpla con los siguientes parámetros:

- Contenido alcohólico: 12-13\%

- Revisar el sellado: El corcho debe estar bien colocado, al mantener la botella con el pico hacia abajo no debe vaciarse el contenido.

- Altura de llenado: Se debe llenar hasta la mitad del pico de la botella aproximadamente.

Finalmente, se debe contactar a una empresa de transporte que brinde un buen servicio a los clientes, ya que el producto al llegar en buen estado y a tiempo permitirá mantener las buenas relaciones con los compradores.

\subsubsection{Medidas de resguardo de la calidad en la producción}


Tabla 5.17

Características del producto

\begin{tabular}{|l|l|}
\hline \multicolumn{2}{|c|}{ Descripción del producto y uso presunto del licor de Higo } \\
\hline Nombre & Licor de Higo \\
\hline Descripción & Bebida alcohólica \\
\hline Composición & Higo, agua, azúcar, levadura y nutrientes. \\
\hline Características Sensoriales & $\begin{array}{l}\text { Bebida de color marrón con sabor dulce y } \\
\text { olor característico a fruta. }\end{array}$ \\
\hline $\begin{array}{l}\text { Forma de uso y consumidores } \\
\text { potenciales }\end{array}$ & $\begin{array}{l}\text { Como aperitivo y en elaboración de } \\
\text { comidas. }\end{array}$ \\
\hline Empaque, etiquetado y presentaciones & $\begin{array}{l}\text { En envases de vidrio de 750ml. de } \\
\text { capacidad. Unica presentación. }\end{array}$ \\
\hline Vida útil esperada & No tiene fecha de vencimiento. \\
\hline Condiciones de manejo y conservación & Mantener a temperatura menor a $25^{\circ} \mathrm{C}$. \\
\hline
\end{tabular}

Fuente: Vinos de frutas: elaboración artesanal e industrial

\section{Plan HACCP}

Se empleará el sistema Análisis de Peligros y Puntos Críticos de Control (HACCP) para controlar y tratar de eliminar los riesgos existentes en cada etapa del proceso de producción para así garantizar la inocuidad del producto final. El análisis comprende los diferentes tipos de peligros que se podrían presentar a lo largo del proceso:

- $\quad$ Peligros biológicos: Relativo a las bacterias, virus, parásitos en general que pongan en riesgo la producción.

- Peligro químico: Pesticidas, contaminantes tóxicos, contaminación del producto con sustancias químicas.

- $\quad$ Peligro Físico: Algún fragmento de vidrio (botella), metal, madera o algún objeto que pueda causar daño al consumidor.

La tabla 5.20 se observa el análisis de riesgos elaborado a cada etapa y en la tabla 5.21 el plan a seguir para cumplir con el objetivo mencionado. 
Tabla 5.18

Análisis de riesgos

\begin{tabular}{|c|c|c|c|c|c|}
\hline Etapa & Peligros & $\begin{array}{l}\text { ¿El peligro es } \\
\text { significativo? }\end{array}$ & $\begin{array}{l}\text { Justificación su } \\
\text { decisión }\end{array}$ & $\begin{array}{c}\text { ¿Qué medidas } \\
\text { preventivas pueden ser } \\
\text { aplicadas? }\end{array}$ & $\begin{array}{c}\text { ¿Es esta etapa } \\
\text { un Punto } \\
\text { Crítico de } \\
\text { Control (PCC)? }\end{array}$ \\
\hline Seleccionado & $\begin{array}{l}\text { Biológico: } \\
\text { Restos de bacterias } \\
\text { Descomposición } \\
\text { Químico: } \\
\text { Contaminación química }\end{array}$ & SI & $\begin{array}{l}\text {-Las frutas pueden } \\
\text { contener bacterias del } \\
\text { suelo. } \\
\text {-Absorción de químicos } \\
\text { de pesticidas. }\end{array}$ & $\begin{array}{l}\text {-Realizar lavado y } \\
\text { desinfectado de frutas. } \\
\text {-Utilizar a un proveedor } \\
\text { certificado. }\end{array}$ & SI \\
\hline Lavado & $\begin{array}{l}\text { Biológico: } \\
\text { Contaminación } \\
\text { microbiológica } \\
\text { Químico: } \\
\text { Contaminación por } \\
\text { desinfectante }\end{array}$ & NO & $\begin{array}{l}\text {-Agua potable de } \\
\text { calidad } \\
\text {-Desinfectante especial } \\
\text { para alimentos }\end{array}$ & $\begin{array}{l}\text {-Utilizar desinfectante en } \\
\text { cantidades adecuadas. }\end{array}$ & $\mathrm{NO}$ \\
\hline $\begin{array}{l}\text { Obtención } \\
\text { del Mosto(Licuado) }\end{array}$ & $\begin{array}{l}\text { Biológico: } \\
\text { Contaminación por } \\
\text { bacterias en el vaso }\end{array}$ & SI & $\begin{array}{l}\text {-El vaso de la licuadora } \\
\text { puede contener restos } \\
\text { de agua guardada }\end{array}$ & $\begin{array}{lcc}\text {-Lavar } & \text { el } & \text { vaso } \\
\text { constantemente. } & \end{array}$ & $\mathrm{NO}$ \\
\hline Colado & $\begin{array}{l}\text { Biológico: } \\
\text { Restos de bacterias en la } \\
\text { coladera }\end{array}$ & SI & $\begin{array}{l}\text {-Contaminación por } \\
\text { residuos en la coladera. }\end{array}$ & $\begin{array}{l}\text {-Limpieza constante del } \\
\text { utensilio. }\end{array}$ & $\mathrm{NO}$ \\
\hline
\end{tabular}




\begin{tabular}{|c|c|c|c|c|c|}
\hline Fermentado & $\begin{array}{l}\text { Biológico: } \\
\text { Restos de bacterias en la } \\
\text { máquina }\end{array}$ & SI & $\begin{array}{l}\text {-Contaminación por } \\
\text { residuos en el tanque. }\end{array}$ & $\begin{array}{l}\text {-Limpieza en las paredes } \\
\text { internas del tanque. }\end{array}$ & NO \\
\hline Filtrado & $\begin{array}{l}\text { Biológico: } \\
\text { Restos de bacterias en la } \\
\text { máquina }\end{array}$ & 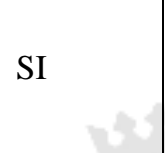 & $\begin{array}{l}\text {-Contaminación por } \\
\text { residuos en el tamiz }\end{array}$ & $\begin{array}{l}\text {-Limpieza constante de } \\
\text { las placas. }\end{array}$ & NO \\
\hline Embotellado & $\begin{array}{l}\text { Biológico: } \\
\text { Recontaminación por } \\
\text { botellas contaminados } \\
\text { Físico: } \\
\text { Botellas en mal estado }\end{array}$ & SI & $\begin{array}{l}\text {-No hay medidas } \\
\text { efectivas de limpieza de } \\
\text { envases }\end{array}$ & $\begin{array}{l}\text {-Lavar y desinfectar } \\
\text { envases adecuadamente }\end{array}$ & SI \\
\hline Encorchado & $\begin{array}{l}\text { Biológico: } \\
\text { Contaminación por } \\
\text { agentes externos }\end{array}$ & SI & -Tapado defectuoso & $\begin{array}{l}\text {-Obtener tapa de un } \\
\text { proveedor confiable }\end{array}$ & NO \\
\hline Encapsulado & $\begin{array}{l}\text { Físico: } \\
\text { Mala presentación }\end{array}$ & SI & - Cápsulas defectuosas & $\begin{array}{l}\text {-Exigir alto nivel de } \\
\text { calidad al proveedor }\end{array}$ & NO \\
\hline Etiquetado & $\begin{array}{l}\text { Físico: } \\
\text { Mala presentación }\end{array}$ & SI & $\begin{array}{l}\text {-Etiquetas defectuosas } \\
\text { (mal impresas) }\end{array}$ & $\begin{array}{l}\text {-Exigir alto nivel de } \\
\text { calidad al proveedor }\end{array}$ & NO \\
\hline
\end{tabular}

Fuente: Vinos de frutas: elaboración artesanal e industrial 


\section{Tabla 5.19}

\section{Plan HACCP}

\begin{tabular}{|c|c|c|c|c|c|c|c|c|c|}
\hline \multirow{2}{*}{ PCC } & \multirow{2}{*}{$\begin{array}{c}\text { Peligros } \\
\text { significativos }\end{array}$} & \multirow{2}{*}{$\begin{array}{c}\text { Límites críticos } \\
\text { para medida } \\
\text { preventiva }\end{array}$} & \multicolumn{4}{|c|}{ Monitoreo } & \multirow{2}{*}{$\begin{array}{l}\text { Acciones } \\
\text { correctoras }\end{array}$} & \multirow{2}{*}{ Registros } & \multirow{2}{*}{ Verificación } \\
\hline & & & Qué & Cómo & Frecuencia & Quién & & & \\
\hline Selección & $\begin{array}{c}\text {-Crecimiento } \\
\text { bacteriano } \\
\text {-Contaminación } \\
\text { química por } \\
\text { pesticidas }\end{array}$ & $\begin{array}{c}\text {-Alteración } \\
\text { del color y/o } \\
\text { sabor de la } \\
\text { fruta }\end{array}$ & $\begin{array}{l}\text {-Apariencia } \\
\text { de la fruta }\end{array}$ & $\begin{array}{l}\text {-Inspección } \\
\text { visual en el } \\
\text { campo y } \\
\text { durante la } \\
\text { selección }\end{array}$ & $\begin{array}{l}\text {-Inspección } \\
\text { mensual en } \\
\text { el campo } \\
\text {-Inspección } \\
\text { por lote } \\
\text { recibido }\end{array}$ & $\begin{array}{l}\text {-Jefe de } \\
\text { Calidad }\end{array}$ & $\begin{array}{c}\text {-Rechazo de } \\
\text { lote de frutas } \\
\text {-Coordinación } \\
\text { con el } \\
\text { proveedor } \\
\text {-Cambio de } \\
\text { proveedor }\end{array}$ & $\begin{array}{l}\text {-Acta de lote } \\
\text { recibido } \\
\text { conforme }\end{array}$ & $\begin{array}{l}\text {-Muestreo } \\
\text { interdiario }\end{array}$ \\
\hline Embotellado & $\begin{array}{c}\text {-Restos de } \\
\text { vidrios en la } \\
\text { botella } \\
\text {-Botellas en mal } \\
\text { estado } \\
\text {-Botella sucias }\end{array}$ & -Ausencia & $\begin{array}{l}\text {-Estado de } \\
\text { las } \\
\text { botellas }\end{array}$ & $\begin{array}{l}\text {-Inspección } \\
\text { visual y } \\
\text { lavado de } \\
\text { botellas }\end{array}$ & $\begin{array}{l}\text {-Por lote } \\
\text { recibido }\end{array}$ & $\begin{array}{l}\text {-Jefe de } \\
\text { Calidad }\end{array}$ & $\begin{array}{c}\text {-Las botellas en } \\
\text { mal estado no se } \\
\text { utilizan } \\
\text {-Revisión de } \\
\text { máquina } \\
\text {-Coordinación } \\
\text { con el } \\
\text { proveedor. } \\
\text {-Cambio de } \\
\text { proveedor }\end{array}$ & $\begin{array}{l}\text {-Acta de lote } \\
\text { recibido } \\
\text { conforme de } \\
\text { botellas } \\
\text {-Registro de } \\
\text { lavado de } \\
\text { botellas } \\
\text {-Registro de } \\
\text { mantenimiento } \\
\text { de máquina }\end{array}$ & $\begin{array}{l}\text {-Muestreo } \\
\text { interdiario }\end{array}$ \\
\hline
\end{tabular}

Elaboración propia 


\subsection{Estudio de Impacto Ambiental}

El estudio el impacto ambiental es una herramienta preventiva mediante la cual se evalúan impactos negativos y positivos que se generan sobre el medio ambiente y se proponen las medidas para ajustarlos a nivel de aceptabilidad. Tiene como objetivo pronosticar los cambios en los factores ambientales y sociales que resultan de un proyecto o actividad propuesta, así como asegurar que los problemas potenciales se hayan señalado y previsto al inicio de la planificación y diseño del proyecto o actividad a realizarse.

El proyecto deberá identificar y evaluar desde sus inicios los posibles impactos que podría causar la operación de la planta al medio ambiente. Se deberán tomar las medidas necesarias desde la concepción del proyecto para disminuir o evitar los impactos negativos.

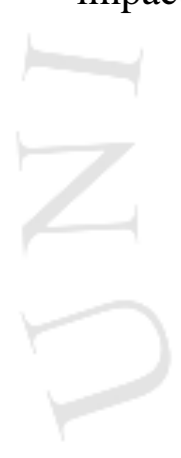


Tabla 5.20

\section{Impactos ambientales}

\begin{tabular}{|c|c|c|c|c|}
\hline Etapa & Salida & Aspecto Ambiental & Impacto Ambiental & Medidas Correctoras \\
\hline Seleccionado & $\begin{array}{l}\text { Frutos no } \\
\text { aptos }\end{array}$ & $\begin{array}{l}\text { Generación de frutas } \\
\text { no aptas }\end{array}$ & $\begin{array}{l}\text { Contaminación por } \\
\text { residuos orgánicos }\end{array}$ & $\begin{array}{l}\text { Venta para elaboración } \\
\text { de comida de animales }\end{array}$ \\
\hline \multirow{2}{*}{ Lavado } & Agua sucia & $\begin{array}{l}\text { Emisión de agua con } \\
\text { residuos de detergente } \\
\text { y partículas sólidas }\end{array}$ & $\begin{array}{l}\text { Contaminación por } \\
\text { emisión de agua sucia }\end{array}$ & Tratar el agua \\
\hline & Ruido & Emisión de ruido & Contaminación sonora & $\begin{array}{c}\text { Protección auricular al } \\
\text { trabajador }\end{array}$ \\
\hline \multirow{2}{*}{$\begin{array}{l}\text { Obtención } \\
\text { del Mosto } \\
\text { (Licuado) }\end{array}$} & $\begin{array}{c}\text { Restos de } \\
\text { fruta }\end{array}$ & $\begin{array}{l}\text { Generación de restos } \\
\text { de fruta. }\end{array}$ & $\begin{array}{l}\text { Contaminación por } \\
\text { residuos orgánicos }\end{array}$ & $\begin{array}{l}\text { Venta para elaboración } \\
\text { de comida de animales }\end{array}$ \\
\hline & Ruido & Emisión de ruido & Contaminación sonora & $\begin{array}{c}\text { Protección auricular al } \\
\text { trabajador }\end{array}$ \\
\hline Colado & $\begin{array}{l}\text { Sólidos de } \\
\text { fruta }\end{array}$ & $\begin{array}{c}\text { Generación de restos } \\
\text { de fruta }\end{array}$ & $\begin{array}{l}\text { Contaminación por } \\
\text { residuos orgánicos }\end{array}$ & $\begin{array}{l}\text { Venta para elaboración } \\
\text { de comida de animales }\end{array}$ \\
\hline \multirow[b]{2}{*}{ Fermentado } & $\begin{array}{l}\text { Sólidos de } \\
\text { mosto }\end{array}$ & $\begin{array}{l}\text { Generación de restos } \\
\text { de mosto }\end{array}$ & $\begin{array}{l}\text { Contaminación por } \\
\text { residuos orgánicos }\end{array}$ & Desechar residuos \\
\hline & Gases & $\begin{array}{l}\text { Emisión de dióxido de } \\
\text { carbono }\end{array}$ & $\begin{array}{l}\text { Contaminación por } \\
\text { emisión de gases }\end{array}$ & Atrapador de gases \\
\hline \multirow[b]{2}{*}{ Filtrado } & $\begin{array}{l}\text { Sólidos de } \\
\text { vino }\end{array}$ & $\begin{array}{l}\text { Generación de restos } \\
\text { de mosto }\end{array}$ & $\begin{array}{l}\text { Contaminación por } \\
\text { residuos orgánicos }\end{array}$ & Desechar residuos \\
\hline & Ruido & Emisión de ruido & Contaminación sonora & $\begin{array}{c}\text { Protección auricular al } \\
\text { trabajador. }\end{array}$ \\
\hline \multirow{2}{*}{ Embotellado } & Ruido & Emisión de ruido & Contaminación sonora & $\begin{array}{l}\text { Protección auricular al } \\
\text { trabajador }\end{array}$ \\
\hline & $\begin{array}{c}\text { Frascos } \\
\text { defectuosos }\end{array}$ & $\begin{array}{c}\text { Emisión de residuos } \\
\text { sólidos }\end{array}$ & $\begin{array}{l}\text { Contaminación por } \\
\text { residuos sólidos }\end{array}$ & Devolución al proveedor \\
\hline Encorchado & Ruido & Emisión de ruido & Contaminación sonora & $\begin{array}{c}\text { Protección auricular al } \\
\text { trabajador }\end{array}$ \\
\hline Encapsulado & Ruido & $\begin{array}{l}\text { Emisión de ruido por } \\
\text { la pistola de aire }\end{array}$ & Contaminación sonora & $\begin{array}{l}\text { Protección auricular al } \\
\text { trabajador }\end{array}$ \\
\hline Etiquetado & $\begin{array}{c}\text { Etiquetas } \\
\text { defectuosas }\end{array}$ & $\begin{array}{c}\text { Emisión de residuos } \\
\text { sólidos }\end{array}$ & $\begin{array}{l}\text { Contaminación por } \\
\text { residuos sólidos }\end{array}$ & $\begin{array}{c}\text { Vender como papel para } \\
\text { reciclaje }\end{array}$ \\
\hline Embalado & $\begin{array}{c}\text { Cajas } \\
\text { defectuosas }\end{array}$ & $\begin{array}{l}\text { Emisión de residuos } \\
\text { sólidos }\end{array}$ & $\begin{array}{l}\text { Contaminación por } \\
\text { residuos sólidos }\end{array}$ & Vender como cartón \\
\hline
\end{tabular}

Elaboración propia 


\subsection{Seguridad y Salud ocupacional}

A continuación, se presentan los principales riesgos de seguridad y salud que pudieran presentarse en la planta y las medidas de control a tomarse en cada caso:

Tabla 5.21

Peligros y riesgos en planta

\begin{tabular}{|c|c|c|c|}
\hline Proceso & Peligro & Riesgo & Control \\
\hline & \multirow{2}{*}{$\begin{array}{c}\text { Trabajo con jabas de } 24 \\
\text { kg. de capacidad }\end{array}$} & $\begin{array}{l}\text { Lesiones por carga } \\
\text { de jabas pesadas }\end{array}$ & Utilización de fajas \\
\hline & & $\begin{array}{l}\text { Aplastamiento de } \\
\text { pies con jabas } \\
\text { pesadas }\end{array}$ & $\begin{array}{l}\text { Utilización de zapatos de punta } \\
\text { de acero }\end{array}$ \\
\hline \multirow{3}{*}{ Lavado } & $\begin{array}{l}\text { Trabajo con jabas de } 24 \\
\text { kg. de capacidad }\end{array}$ & $\begin{array}{l}\text { Lesiones por carga } \\
\text { de jabas pesadas }\end{array}$ & Utilización de fajas \\
\hline & \multirow{2}{*}{$\begin{array}{l}\text { Utilización de } \\
\text { desinfectantes }\end{array}$} & $\begin{array}{l}\text { Intoxicaciones, } \\
\text { daños a la piel }\end{array}$ & Utilización de guantes \\
\hline & & Ingesta & $\begin{array}{l}\text { Etiquetas de desinfectante con } \\
\text { información preventiva }\end{array}$ \\
\hline Licuado & $\begin{array}{l}\text { Trabajo con carga de } \\
\text { más de } 10 \mathrm{~kg} \text {. de } \\
\text { capacidad }\end{array}$ & $\begin{array}{l}\text { Lesiones por carga } \\
\text { pesada }\end{array}$ & Utilización de fajas \\
\hline Colado & $\begin{array}{l}\text { Trabajo con carga de } \\
\text { más de } 10 \mathrm{~kg} . \text { de } \\
\text { capacidad }\end{array}$ & $\begin{array}{c}\text { Lesiones por carga } \\
\text { pesada }\end{array}$ & Utilización de fajas \\
\hline & & Intoxicaciones, & $\begin{array}{c}\text { Utilización de guantes, } \\
\text { mascarilla nasal }\end{array}$ \\
\hline Fermentado & 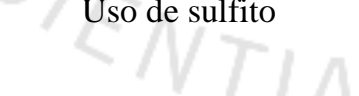 & daños a la piel & $\begin{array}{c}\text { Etiquetas con información } \\
\text { preventiva }\end{array}$ \\
\hline Embotellado & $\begin{array}{c}\text { Trabajo con envases de } \\
\text { vidrio }\end{array}$ & Cortes & Utilización de guantes especiales \\
\hline Encorchado & $\begin{array}{l}\text { Utilización de envases } \\
\text { de vidrio }\end{array}$ & Cortes & Utilización de guantes especiales \\
\hline Etiquetado & $\begin{array}{l}\text { Utilización de envases } \\
\text { de vidrio }\end{array}$ & Cortes & Utilización de guantes especiales \\
\hline Embalado & $\begin{array}{c}\text { Trabajo con envases de } \\
\text { vidrio }\end{array}$ & Cortes & Utilización de guantes especiales \\
\hline
\end{tabular}

Elaboración propia 
Para garantizar la seguridad de la planta se tomarán en cuenta los puntos tratados en el Reglamento de Seguridad y Salud en el Trabajo decretado por el gobierno, por lo que se implementará lo siguiente:

- Comité de salud y seguridad en el trabajo

- Auditorias periódicas

- Registro y control de incidentes y accidentes

- Equipo de protección personal

- Exámenes médicos ocupacionales

- Evaluación de riesgo

- Plan de emergencia

- Mediciones ambientales

- Protección contra incendios

Otros factores a tomar en cuenta en la seguridad de la empresa son la colocación de extintores, implementación de botiquines y servicio de seguridad las 24 horas del día.

\subsection{Sistema de mantenimiento}

Para todas las máquinas se realizará un mantenimiento preventivo programado cada quince días, con la finalidad de corregir cualquier defecto que pudiera más tarde convertirse en una falla. En el caso del tanque fermentador, al ser parte de la estación cuello de botella del proceso de producción, será importante realizar una revisión luego de cada proceso fermentativo para llevar un continuo monitoreo de variables y parámetros y así, poder detectar posibles defectos. A continuación se mostrará la tabla del programa de mantenimiento de las máquinas de producción: 
Tabla 5.22

Programa de mantenimiento de las máquinas

\begin{tabular}{|c|c|c|c|}
\hline Máquina & Frecuencia & Actividad & Tipo de Mantenimiento \\
\hline Lavadora & Quincenal & Calibración de rodamientos & Preventivo \\
\hline Licuadora & Quincenal & Limpieza y cambio de cuchillas. & Preventivo \\
\hline $\begin{array}{c}\text { Tanque } \\
\text { Fermentador }\end{array}$ & Quincenal & $\begin{array}{c}\text { Limpieza del tanque, revisión del } \\
\text { termostato. }\end{array}$ & Preventivo \\
\hline Filtro prensa & Quincenal & Cambio y Limpieza de placas. & Preventivo \\
\hline Llenadora & Quincenal & $\begin{array}{c}\text { Limpieza y calibración de } \\
\text { parámetros de llenado. }\end{array}$ & Preventiv \\
\hline Encorchadora & Quincenal & Regular la presión. & Preventivo \\
\hline$x$ & Mensual & Revisar la temperatura del aire. & Preventivo \\
\hline Etiquetadora & Quincenal & Revisión de regulador de altura. & Preventivo \\
\hline $\begin{array}{c}\text { Lavadora de } \\
\text { botellas }\end{array}$ & Quincenal & Revisión del flujo del agua. & Preventivo \\
\hline
\end{tabular}

Elaboración propia 
Para los procesos de lavado y selección se debe tener ciertas medidas de higiene que permitan tener un producto que no esté contaminado por baterías y/o suciedad que hayan podido ser transmitidas por el ambiente o por las personas que se encuentren en contacto con la materia prima.

Asimismo, a lo largo del proceso de producción los operarios estarán pendientes del funcionamiento correcto de las máquinas y que los resultados vayan acorde a los estándares establecidos para evitar pérdidas.

\section{Producto}

Finalmente se encuentra la última inspección que es producto terminado, que se realiza con la finalidad de cerciorarse de que las botellas estén correctamente selladas, sin el riesgo de que se abran y se contaminen o se derrame el producto. Su almacenaje debe ser en un lugar fresco, para evitar la descomposición del producto. Según la FAO, se tienen que verificar que el producto cumpla con los siguientes parámetros:

- Contenido alcohólico: 12-13\%

- Revisar el sellado: El corcho debe estar bien colocado, al mantener la botella con el pico hacia abajo no debe vaciarse el contenido.

- Altura de llenado: Se debe llenar hasta la mitad del pico de la botella aproximadamente.

Finalmente, se debe contactar a una empresa de transporte que brinde un buen servicio a los clientes, ya que el producto al llegar en buen estado y a tiempo permitirá mantener las buenas relaciones con los compradores.

\subsubsection{Medidas de resguardo de la calidad en la producción}


Tabla 5.23

Porcentaje de utilización

\begin{tabular}{|l|c|c|c|c|}
\hline Año & $\begin{array}{c}\text { Producción } \\
\text { (L/año) }\end{array}$ & $\begin{array}{c}\text { Producción con } \\
\text { stock de } \\
\text { seguridad } \\
\text { (L/año) }\end{array}$ & $\begin{array}{c}\text { Capacidad } \\
\text { instalada } \\
\text { (L/año) }\end{array}$ & Utilización \\
\hline $\mathbf{2 0 1 5}$ & 141.190 & 152.956 & 231.247 & $66 \%$ \\
\hline $\mathbf{2 0 1 6}$ & 148.256 & 160.611 & 231.247 & $69 \%$ \\
\hline $\mathbf{2 0 1 7}$ & 155.322 & 168.265 & 231.247 & $73 \%$ \\
\hline $\mathbf{2 0 1 8}$ & 162.388 & 175.920 & 231.247 & $76 \%$ \\
\hline $\mathbf{2 0 1 9}$ & 169.453 & 183.574 & 231.247 & $79 \%$ \\
\hline $\mathbf{2 0 2 0}$ & 176.519 & 191.229 & 231.247 & $83 \%$ \\
\hline $\mathbf{2 0 2 1}$ & 183.585 & 198.884 & 231.247 & $86 \%$ \\
\hline $\mathbf{2 0 2 2}$ & 190.651 & 206.538 & 231.247 & $89 \%$ \\
\hline $\mathbf{2 0 2 3}$ & 197.716 & 214.193 & 231.247 & $93 \%$ \\
\hline $\mathbf{2 0 2 4}$ & 204.782 & 221.847 & 231.247 & $96 \%$ \\
\hline
\end{tabular}

Elaboración propia

En la tabla 5.24 se muestra el programa de producción para los próximos 10 años.

Tabla 5.24

Programa de producción (L)

\begin{tabular}{|c|c|}
\hline Año & $\begin{array}{c}\text { Producción con } \\
\text { stock de seguridad } \\
\text { (L/año) }\end{array}$ \\
\hline $\mathbf{2 0 1 5}$ & 152.956 \\
\hline $\mathbf{2 0 1 6}$ & 160.611 \\
\hline $\mathbf{2 0 1 7}$ & 168.265 \\
\hline $\mathbf{2 0 1 8}$ & 175.920 \\
\hline $\mathbf{2 0 1 9}$ & 183.574 \\
\hline $\mathbf{2 0 2 0}$ & 191.229 \\
\hline $\mathbf{2 0 2 1}$ & 198.884 \\
\hline $\mathbf{2 0 2 2}$ & 206.538 \\
\hline $\mathbf{2 0 2 3}$ & 214.193 \\
\hline $\mathbf{2 0 2 4}$ & 221.847 \\
\hline
\end{tabular}

Elaboración propia 


\section{Requerimiento de materia prima}

La materia prima para la producción de harina de plátano, es el higo black mission. A continuación se muestra en la tabla 5.25 el requerimiento de higo para cada año de la vida útil del proyecto.

\section{Tabla 5.25}

\section{Requerimiento de higos (kg.)}

\begin{tabular}{|c|c|c|}
\hline Año & $\begin{array}{c}\text { Producción con stock } \\
\text { de seguridad } \\
\text { (L/año) }\end{array}$ & $\begin{array}{c}\text { Requerimiento } \\
\text { de higo } \\
\text { (Kg./año) }\end{array}$ \\
\hline $\mathbf{2 0 1 5}$ & 152.956 & 244.684 \\
\hline $\mathbf{2 0 1 6}$ & 160.611 & 256.929 \\
\hline $\mathbf{2 0 1 7}$ & 168.265 & 269.174 \\
\hline $\mathbf{2 0 1 8}$ & 175.920 & 281.419 \\
\hline $\mathbf{2 0 1 9}$ & 183.574 & 293.664 \\
\hline $\mathbf{2 0 2 0}$ & 191.229 & 305.909 \\
\hline $\mathbf{2 0 2 1}$ & 198.884 & 318.154 \\
\hline $\mathbf{2 0 2 2}$ & 206.538 & 330.399 \\
\hline $\mathbf{2 0 2 3}$ & 214.193 & 342.644 \\
\hline $\mathbf{2 0 2 4}$ & 221.847 & 354.889 \\
\hline
\end{tabular}

Elaboración propia

\section{Requerimientos de insumos y otros materiales para el preparado del licor}

Para el procesado del higo se requiere de azúcar, sulfito y levaduras.

En la tabla 5.26 se pueden apreciar las cantidades requeridas de azúcar, sulfito y levaduras: 
Tabla 5.26

Requerimiento de azúcar, sulfito y levaduras (kg)

\begin{tabular}{|c|c|c|c|}
\hline Año & $\begin{array}{c}\text { Requerimiento } \\
\text { de azúcar } \\
\text { (kg/año) }\end{array}$ & $\begin{array}{c}\text { Requerimiento } \\
\text { de sulfito } \\
\text { (kg/año) }\end{array}$ & $\begin{array}{c}\text { Requerimiento } \\
\text { de levaduras } \\
\text { (kg/año) }\end{array}$ \\
\hline $\mathbf{2 0 1 5}$ & 30.591 & 3,06 & 153 \\
\hline $\mathbf{2 0 1 6}$ & 28.055 & 3,21 & 161 \\
\hline $\mathbf{2 0 1 7}$ & 29.446 & 3,37 & 168 \\
\hline $\mathbf{2 0 1 8}$ & 30.853 & 3,52 & 176 \\
\hline $\mathbf{2 0 1 9}$ & 32.275 & 3,67 & 184 \\
\hline $\mathbf{2 0 2 0}$ & 33.712 & 3,82 & 191 \\
\hline $\mathbf{2 0 2 1}$ & 35.166 & 3,98 & 199 \\
\hline $\mathbf{2 0 2 2}$ & 36.636 & 4,13 & 207 \\
\hline $\mathbf{2 0 2 3}$ & 38.121 & 4,28 & 214 \\
\hline $\mathbf{2 0 2 4}$ & 39.623 & 4,44 & 222 \\
\hline
\end{tabular}

Elaboración propia

Cuando el licor de higo está listo requiere ser envasado, sellado, etiquetado y almacenado. En la tabla 5.27 se pueden apreciar las cantidades requeridas de botellas, corchos, cápsulas, etiquetas y cajas:

\section{Tabla 5.27}

Requerimiento de botellas, corchos, cápsulas, etiquetas y cajas (Unid.)

\begin{tabular}{|c|c|c|c|c|c|}
\hline Año & $\begin{array}{c}\text { Requerimiento } \\
\text { de botellas } \\
\text { (Unid./año) }\end{array}$ & $\begin{array}{c}\text { Requerimiento } \\
\text { de corchos } \\
\text { (Unid./año) }\end{array}$ & $\begin{array}{c}\text { Requerimiento } \\
\text { de cápsulas } \\
\text { (Unid./año) }\end{array}$ & $\begin{array}{c}\text { Requerimiento } \\
\text { de etiquetas } \\
\text { (Unid./año) }\end{array}$ & $\begin{array}{c}\text { Requerimiento } \\
\text { de cajas } \\
\text { (Unid./año) }\end{array}$ \\
\hline $\mathbf{2 0 1 5}$ & 203.942 & 203.942 & 203.942 & 203.942 & 16.995 \\
\hline $\mathbf{2 0 1 6}$ & 214.148 & 214.148 & 214.148 & 214.148 & 17.984 \\
\hline $\mathbf{2 0 1 7}$ & 224.354 & 224.354 & 224.354 & 224.354 & 18.876 \\
\hline $\mathbf{2 0 1 8}$ & 234.560 & 234.560 & 234.560 & 234.560 & 19.778 \\
\hline $\mathbf{2 0 1 9}$ & 244.766 & 244.766 & 244.766 & 244.766 & 20.689 \\
\hline $\mathbf{2 0 2 0}$ & 254.972 & 254.972 & 254.972 & 254.972 & 21.611 \\
\hline $\mathbf{2 0 2 1}$ & 265.178 & 265.178 & 265.178 & 265.178 & 22.543 \\
\hline $\mathbf{2 0 2 2}$ & 275.384 & 275.384 & 275.384 & 275.384 & 23.485 \\
\hline $\mathbf{2 0 2 3}$ & 285.590 & 285.590 & 285.590 & 285.590 & 24.437 \\
\hline $\mathbf{2 0 2 4}$ & 295.797 & 295.797 & 295.797 & 295.797 & 25.400 \\
\hline
\end{tabular}

Elaboración propia 
5.10.2. Servicios: energía eléctrica, agua, vapor, combustible, etc.

En la tabla 5.28 se puede apreciar el consumo de energía eléctrica de cada máquina.

Tabla 5.28

Consumo de energía eléctrica en planta por hora

\begin{tabular}{|l|c|}
\hline \multicolumn{1}{|c|}{ Máquinas } & $\mathbf{k W}$ \\
\hline Lavadora de inmersión & 0,9 \\
\hline Licuadora & 3,0 \\
\hline Filtro de placas & 0,8 \\
\hline Pistola de aire & 1,5 \\
\hline Lavadora de botellas & 0,12 \\
\hline Total & $\mathbf{6 , 3 2}$ \\
\hline
\end{tabular}

Elaboración propia

En la tabla 5.29 se muestra el consumo de energía eléctrica en oficinas, baños y vestuarios.

Tabla 5.29

Consumo de energía eléctrica en oficinas, baños y vestuarios $(\mathrm{kW})$

\begin{tabular}{|c|c|}
\hline Espacio & $\mathbf{k W}$ \\
\hline Oficinas & 2,5 \\
\hline Baños y Vestuarios & 0,09 \\
\hline Total & $\mathbf{2 , 5 9}$ \\
\hline
\end{tabular}

Elaboración propia 
En las tablas 5.30, 5.31 y 5.32 se muestran los consumos totales de energía en planta, de agua en planta y de agua en baños y vestuarios respectivamente.

\section{Tabla 5.30}

Consumo total $(\mathrm{kW})$ para los próximos 10 años

\begin{tabular}{|l|c|c|c|c|c|c|}
\hline Año & Producción(L) & $\begin{array}{c}\text { Capacidad de } \\
\text { prod L/h }\end{array}$ & $\begin{array}{c}\text { Hora } \\
\text { productiva }\end{array}$ & $\begin{array}{c}\text { Consumo } \\
\text { promedio } \\
\text { maq. } \mathbf{k W}\end{array}$ & $\begin{array}{c}\text { Consumo promedio } \\
\text { oficinas y SSHH. kW }\end{array}$ & $\begin{array}{c}\text { Consumo } \\
\text { Total(kW-h) }\end{array}$ \\
\hline $\mathbf{2 0 1 5}$ & 152.956 & 52,94 & 2.889 & 6,3 & 2,6 & 25.743 \\
\hline $\mathbf{2 0 1 6}$ & 160.611 & 52,94 & 3.034 & 6,3 & 2,6 & 27.031 \\
\hline $\mathbf{2 0 1 7}$ & 168.265 & 52,94 & 3.178 & 6,3 & 2,6 & 2,6 \\
\hline $\mathbf{2 0 1 8}$ & 175.920 & 52,94 & 3.323 & 6,3 & 2,6 & 29.607 \\
\hline $\mathbf{2 0 1 9}$ & 183.574 & 52,94 & 3.468 & 6,3 & 3,6 & 30.896 \\
\hline $\mathbf{2 0 2 0}$ & 191.229 & 52,94 & 3.612 & 6,3 & & 32.184 \\
\hline $\mathbf{2 0 2 1}$ & 198.884 & 52,94 & 3.757 & 6,3 & 2,6 & 33.472 \\
\hline $\mathbf{2 0 2 2}$ & 206.538 & 52,94 & 3.901 & 6,3 & 2,6 & 34.760 \\
\hline $\mathbf{2 0 2 3}$ & 214.193 & 52,94 & 4.046 & 6,3 & & 2,6 \\
\hline $\mathbf{2 0 2 4}$ & 221.847 & 52,94 & 4.190 & 6,3 & 2,6 & 36.049 \\
\hline
\end{tabular}

Elaboración propia 
Tabla 5.31

Consumo total de agua para producción en planta $\left(\mathrm{m}^{3}\right)$

\begin{tabular}{|c|c|c|c|c|c|c|c|}
\hline Año & $\begin{array}{c}\text { Producción } \\
\text { (L) }\end{array}$ & \begin{tabular}{|c|} 
Capacidad de \\
producción $\mathrm{L} / \mathrm{h}$
\end{tabular} & Hora productiva & $\begin{array}{c}\mathrm{m} 3 / \text { hora } \\
\text { Lavadora de frutas }\end{array}$ & m3 /hora licuadora & \begin{tabular}{|c|}
$\mathrm{m} 3 /$ hora \\
Lavadora de botellas
\end{tabular} & $\begin{array}{l}\text { Consumo } \\
\text { Total }\left(\mathbf{m}^{3}\right)\end{array}$ \\
\hline 2013 & 152.956 & 52,94 & 2.889 & 0,07 & 0,020 & 0,12 & 607 \\
\hline 2014 & 160.611 & 52,94 & 3.034 & 0,07 & 0,020 & 0,12 & 637 \\
\hline 2015 & 168.265 & 52,94 & 3.178 & 0,07 & 0,020 & 0,12 & 667 \\
\hline 2016 & 175.920 & 52,94 & 3.323 & 0,07 & 0,020 & 0,12 & 698 \\
\hline 2017 & 183.574 & 52,94 & 3.468 & 0,07 & 0,020 & 0,12 & 728 \\
\hline 2018 & 191.229 & 52,94 & 3.612 & 0,07 & 0,020 & 0,12 & 759 \\
\hline 2019 & 198.884 & 52,94 & 3.757 & 0,07 & 0,020 & 0,12 & 789 \\
\hline 2020 & 206.538 & 52,94 & 3.901 & 0,07 & 0,020 & 0,12 & 819 \\
\hline 2021 & 214.193 & 52,94 & 4.046 & 0,07 & 0,020 & 0,12 & 850 \\
\hline 2022 & 221.847 & 52,94 & 4.190 & 0,07 & 0,020 & 0,12 & 880 \\
\hline
\end{tabular}

Elaboración propia 


\section{Tabla 5.32}

Consumo total de agua en baños y vestuarios

\begin{tabular}{|c|c|c|c|c|c|}
\hline Rubro & $\begin{array}{c}\text { Consumo por } \\
\text { hora }\left(\mathbf{m}^{\mathbf{3}}\right)\end{array}$ & Horas & $\begin{array}{c}\text { Consumo diario } \\
\left(\mathbf{m}^{\mathbf{3}}\right)\end{array}$ & Días/año & $\begin{array}{c}\text { Consumo anual } \\
\left(\mathbf{m}^{\mathbf{3}} \mathbf{)}\right.\end{array}$ \\
\hline Baños y Vestuarios & 0,15 & 16 & 2,4 & 156 & 374,4 \\
\hline
\end{tabular}

Elaboración propia

\subsubsection{Determinación del número de operarios y trabajadores indirectos}

Operarios y trabajadores indirectos

En este punto se define la cantidad de trabajadores por puesto de trabajo y por efectos de una clasificación por tipo de puesto, se está dividiendo el personal directo, indirecto, administrativo y subcontratado. Es importante decir que el número de operarios calculados en la tabla 5.33 es por turno de trabajo.

\section{Tabla 5.33}

Número de operarios requeridos

\begin{tabular}{|c|c|}
\hline Operación & No de operarios \\
\hline Selección & 1 \\
\hline Lavado & 1 \\
\hline Obtención del jugo & 1 \\
\hline Colado & 1 \\
\hline Fermentación & 1 \\
\hline Trasiego & 1 \\
\hline Filtrado & \\
\hline Envasado & \\
\hline Encorchado & \\
\hline Encapsulado & 2 \\
\hline Lavado de botellas & \\
\hline Etiquetado & $\mathbf{8}$ \\
\hline Total & \\
\hline
\end{tabular}

Elaboración propia 
Tabla 5.34

Personal indirecto de planta

\begin{tabular}{|c|c|}
\hline Puesto & Cantidad \\
\hline Supervisor de Proceso & 2 \\
\hline Jefe de calidad & 1 \\
\hline Jefe de Mantenimiento & 1 \\
\hline Asistente de Mantenimiento & 1 \\
\hline Montacarguista & 1 \\
\hline Almacenero de materia prima & 2 \\
\hline Almacenero de producto terminado & 2 \\
\hline Total & $\mathbf{1 0}$ \\
\hline
\end{tabular}

Elaboración propia

Tabla 5.35

Personal de Administración

\begin{tabular}{|c|c|}
\hline Puesto & Cantidad \\
\hline Gerente General y de Operaciones & 1 \\
\hline Gerente de Finanzas & 1 \\
\hline Gerente de Marketing y Ventas & 1 \\
\hline Asistente & 1 \\
\hline Total & $\mathbf{4}$ \\
\hline
\end{tabular}

Elaboración propia

\subsubsection{Servicios de terceros}

En la tabla 5.36 se puede apreciar la cantidad de personal subcontratado:

Tabla 5.36

Cantidad de personal subcontratado

\begin{tabular}{|c|c|}
\hline Servicios de terceros & Cantidad \\
\hline Seguridad & 2 \\
\hline Limpieza & 2 \\
\hline Total & $\mathbf{4}$ \\
\hline
\end{tabular}

Elaboración propia 


\subsection{Características físicas del proyecto}

\subsubsection{Factor edificio}

El edificio está dado por las características de infraestructura que posea la planta de producción, que en este caso estará ligada a la zona administrativa de la empresa. De esta forma se buscará darle las comodidades de trabajo al personal de mano de obra como de dirección, siendo el mismo edificio su lugar de labores.

Entre los factores más resaltantes, se tiene:

- $\quad$ Suelos de concreto armado para la zona de producción y patio de maniobras, por el alto tránsito de personas y eventualmente vehículos; y por otro lado, un piso llano, no resbaladizo para la zona de servicios y demás, excepto los pisos de parqué de las oficinas administrativas.

- Las paredes serán de material noble, concreto y acero reforzado, con pequeños desfogues de aire que permitan la liberación de las emisiones de aire.

- $\quad$ En lo que se refiere a los techos, no requieren ningún requisito especial salvo una altura no menor a 4,5 metros de altura para la zona de producción, con la posibilidad de uniformizar toda la planta con la misma medida. La estructura es también de material noble como las paredes exteriores e interiores.

- La planta solamente contará con un solo nivel.

- Las puertas del área de producción y almacén serán las denominadas puertas contra incendios, para permitir la rápida evacuación de personal si fuera necesario.

- Las instalaciones tanto de administración como de producción, tendrán la respectiva toma eléctrica y de iluminación, siendo las primeras trifásicas de ser necesarias, y de esta forma no dificultar las labores de operación. 
- Las áreas contarán con zona de evacuación y seguridad dentro y fuera del local de trabajo.

\subsubsection{Factor servicio}

El factor servicio hace referencia a todo lo necesario para que los empleados de una empresa puedan cumplir sus labores sin limitaciones de recursos, se requiere:

- Oficinas administrativas

Acá se encontrará la oficina del Gerente General con una sala de reuniones anexa a la misma, la gerencia de finanzas y de operaciones.

- Servicios Higiénicos

Los servicios se repartirán de la siguiente manera: uno para la zona administrativa y otros dos baños para la zona de producción.

- Vestuarios

Los vestuarios estarán agregados en los servicios higiénicos de los trabajadores de la planta.

- Secretaría y Sala de Espera

Estas oficinas estarán con las oficinas de los otros gerentes al igual que la sala de espera.

- Zona de vigilancia

Es la zona que cuida el ingreso a la puerta de entrada tanto de personal como de vehículos, siendo lo más próxima a los exteriores de la planta. 


\subsection{Disposición de planta}

\subsubsection{Determinación de las zonas físicas requeridas}

Las zonas físicas requeridas para el funcionamiento de la planta son las siguientes:

- Zona de Producción:

Es una de las zonas que requiere más metros cuadrados en la planta, ya que los tanques ocupan un área considerable y se requiere de espacio para desarrollar todas las actividades del proceso de la mejor manera. Se busca que sea un área iluminada, especialmente, para poder realizar los trabajos de selección de la materia prima.

- Laboratorio:

El laboratorio estará revestido con mayólicas blancas, contará con mesas, lavatorios y los equipos necesarios para poder medir y controlar los parámetros del proceso y cumplir con los estándares requeridos. Se realizará periódicamente el análisis físico-químico del agua.

- Mantenimiento:

El área de mantenimiento estará implementada con las herramientas necesarias para poder realizar frecuentemente el mantenimiento preventivo de los equipos, y en casos excepcionales realizar el mantenimiento correctivo, en la zona de mantenimiento estará el Jefe de Mantenimiento.

- Almacén:

Se contará con tres grandes almacenes:

$\checkmark$ Almacén de materias primas: En este caso es el higo fresco recién llegado de la chacra, que se colocará lo más cerca de la zona de entrada para evitar un excesivo manipuleo. 
$\checkmark \quad$ Almacén de productos terminados: Es el almacén donde se conservará el licor de higo, se debe almacenar en un ambiente seco, limpio y con temperatura menor a $25^{\circ} \mathrm{C}$.

También se tomará en cuenta espacios para los insumos como el azúcar, los nutrientes, levaduras, bolsas, botellas, corchos y demás materiales utilizados en la elaboración del licor, siempre considerando una adecuada separación entre ellos y cumpliendo con las condiciones ambientales necesarias para su conservación.

\section{- Oficinas:}

Con respecto a las oficinas, se requerirá una oficina para el Gerente General, que a su vez es el Gerente de Operaciones, que contará con una sala de reuniones y por ello será relativamente grande; adicionalmente se dispondrá de otra oficina que compartirá el Jefe de Ventas y Finanzas con el Asistente de Gerencia.

\section{- Servicios Higiénicos:}

Se considerará:

$\checkmark \quad 1$ baño para el personal administrativo y mano de obra indirecta varones

$\checkmark \quad 1$ baño para el personal administrativo y mano de obra indirecta damas.

$\checkmark \quad 1$ baño con ducha y vestuario para mano de obra directa masculina.

$\checkmark \quad 1$ baño con ducha y vestuario para mano de obra directa femenina.

\section{- Comedor:}

El comedor contará con un frio bar, un horno microondas y dos mesas cuadradas con cuatro sillas cada una, espacio considerado como suficiente para que los trabajadores puedan almorzar, ya que el personal administrativo y el personal de planta no tienen el mismo turno de refrigerio, además de lo explicado se está considerando que hay colaboradores que optan por comer fuera. 


\subsubsection{Cálculo de áreas para cada zona}

Las áreas para cada zona de la planta serán las siguientes:

\section{Tabla 5.37}

\section{Áreas de cada zona de la planta}

\begin{tabular}{|l|c|}
\hline \multicolumn{1}{|c|}{ Zona } & Área $\mathbf{~ m}^{\mathbf{2}}$ \\
\hline Zona de producción & 150 \\
\hline Almacén de materias primas & 40 \\
\hline Almacén de producto terminado & 60 \\
\hline Almacén de insumos & 20 \\
\hline Área de Mantenimiento & 30 \\
\hline Área de Calidad & 20 \\
\hline Área administrativa & 90 \\
\hline Comedor & 20 \\
\hline SS.HH. Administrativos & 14 \\
\hline Vestuarios & 25 \\
\hline Garita de seguridad & 9 \\
\hline
\end{tabular}

Elaboración propia

\subsubsection{Dispositivos de seguridad industrial y señalización}

Para prevenir las consecuencias de una situación de peligro se buscará emplear los dispositivos de seguridad más adecuados para la planta, en este caso se utilizarán dispositivos para prevenir incendios o mitigarlos, ya que por el tipo de planta no se está expuesto a otra situación de peligro en donde se requieran de diversos dispositivos de seguridad, los dispositivos a instalar serán:

- Extintores

- Dectectores de incendios

Con respecto a la señalización se debe considerar que tienen por objetivo avisar a las personas de que están en una zona peligrosa y deben evitarla o tomar las precauciones y protecciones adecuadas, las señales deben 
ser universales, fáciles de comprender y a su vez se debe concientizar a los trabajadores sobre la importancia de las mismas. Las principal señalética a emplear es la siguiente:

\section{Tabla 5.38}

\section{Principales señaléticas a utilizar}

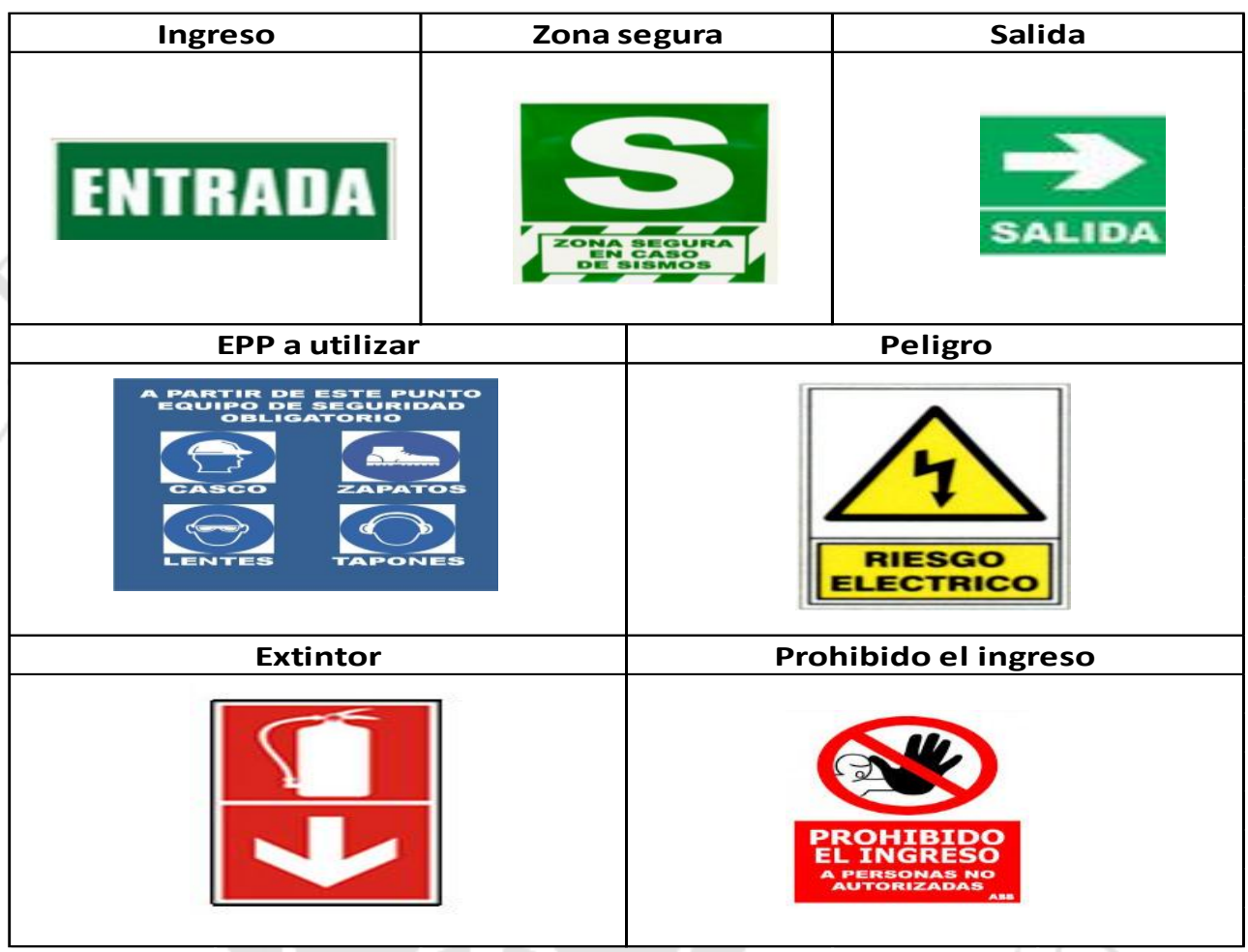

Fuente: Páginas Amarillas

Cabe destacar que cada tipo de señal posee determinados colores, como es el rojo (contra incendio o prohibición), azul (equipos de protección personal), amarillo (advertencia) y verde (evacuación). Así mismo se delimitará la zona de las máquinas con una línea amarilla que solo la podrán cruzar las personas encargadas de la parte productiva y cada área tendrá su nombre en un lugar visible. 


\subsubsection{Disposición general}

Para ubicar adecuadamente los elementos de la producción, se deben analizar sus características, de esta manera a partir de la información del número de máquinas se podrá analizar las necesidades de espacio requerido por cada una de ellas. Existen distintos métodos para la evaluación de espacio físico, en el presente trabajo se hará uso de método de Guerchet.

\section{Método de Guerchet}

Mediante este método se calcularán los espacios físicos que se requerirán para establecer la planta. Para ello se han identificado el número de máquinas, operarios así como equipos de acarreo.

Para cada elemento se calculará la superficie total necesaria partir de la suma de 3 superficies parciales.

$$
\mathrm{St}=\mathrm{n}(\mathrm{Ss}+\mathrm{Sg}+\mathrm{Se})
$$

En dónde:

- $\mathrm{St}=$ Superficie total

- $\mathrm{Ss}=$ Superficie estática

Corresponde a la superficie ocupada por máquinas, equipos y muebles. Para hallar el valor de cada superficie estática se realizó el siguiente cálculo.

Ss=Largo $\mathrm{x}$ Ancho 
- $\mathrm{Sg}=$ Superficie de gravitación

Es la superficie usada por el obrero y por el material acumulador alrededor de cada puesto de trabajo.

\section{$\mathrm{Sg}=\mathrm{S} s \times$ Número de lados}

- $\mathrm{Se}=$ Superficie de evolución

Es la superficie que corresponde a los desplazamientos de personas, medios de transporte, equipo, etc.

$$
\mathrm{Se}=(\mathrm{Ss}+\mathrm{Sg}) \times \mathrm{K}
$$

En la tabla 5.39 y 5.40 se mostrarán los cálculos de espacios para elementos fijos y móviles respectivamente. 


\section{Tabla 5.39}

Cálculo de espacios para elementos fijos

\begin{tabular}{|c|c|c|c|c|c|c|c|c|c|c|c|}
\hline Elementos estáticos & $\mathbf{a}$ & 1 & h & $\mathbf{n}$ & $\mathbf{N}$ & Ss & Sg & Ss $x \mathrm{n} \times \mathbf{h}$ & Ss $\times$ n & Se & St \\
\hline Mesa de selección & 0,75 & 1,8 & 0,9 & 2 & 2 & 1,35 & 2,7 & 2,43 & 2,7 & 1,93 & 11,96 \\
\hline Máquina de lavado & 1,1 & 2,2 & 1,7 & 3,0 & 2,0 & 2,4 & 4,8 & 12,3 & 7,3 & 3,5 & 32 \\
\hline Licuadora & 0,5 & 0,7 & 1,0 & 2,0 & 1,0 & 0,4 & 0,4 & 0,7 & 0,7 & 0,3 & 2,1 \\
\hline Tanque fermentador & 2,2 & 2,2 & 1,5 & 3,0 & 2,0 & 3,8 & 7,6 & 17,1 & 11,4 & 5,4 & 50,5 \\
\hline Filtro & 0,5 & 0,7 & 0,5 & 1,0 & 1,0 & 0,4 & 0,4 & 0,2 & 0,4 & 0,3 & 1,0 \\
\hline Tanque de almacenamiento & 1,6 & 1,6 & 1,2 & 2,0 & 2,0 & 2,0 & 4,0 & 4,8 & 4,0 & 2,9 & 17,8 \\
\hline Llenadora & 0,4 & 0,5 & 0,7 & 1,0 & 1,0 & 0,2 & 0,2 & 0,1 & 0,2 & 0,2 & 0,6 \\
\hline Encorchadora & 0,3 & 0,5 & 1,2 & 1,0 & 1,0 & 0,2 & 0,2 & 0,2 & 0,2 & 0,1 & 0,4 \\
\hline Etiquetadora & 0,5 & 0,8 & 1,1 & 1,0 & 2,0 & 0,4 & 0,8 & 0,4 & 0,4 & 0,6 & 1,8 \\
\hline Lavadora de botellas & 0,3 & 0,3 & 0,5 & 1,0 & 2,0 & 0,1 & 0,2 & 0,05 & 0,1 & 0,1 & 0,4 \\
\hline & & & & & & & & 38,3 & 27,2 & & 118,8 \\
\hline
\end{tabular}

Elaboración propia

\section{Tabla 5.40}

Cálculo de espacios para elementos móviles

\begin{tabular}{|c|c|c|c|c|c|c|c|c|c|c|c|}
\hline Elementos móviles & $\mathbf{a}$ & 1 & $\mathbf{h}$ & $\mathbf{n}$ & $\mathbf{N}$ & Ss & Ss $\times \mathrm{n} \times \mathrm{h}$ & Ss $x$ n & Sg & Se & St \\
\hline Operarios & $-O$ & - & 1,65 & 9 & - & 0,50 & 7,43 & 4,50 & - & - & - \\
\hline Montacarga manual & 0,52 & 1,15 & 0,19 & 2 & - & 0,60 & 0,23 & 1,20 & - & - & - \\
\hline & & & & & \multicolumn{2}{|c|}{ Total } & 7,65 & 5,70 & & & \\
\hline
\end{tabular}

Elaboración propia 


\subsubsection{Cálculo de áreas para cada zona}

Las áreas para cada zona de la planta serán las siguientes:

\section{Tabla 5.37}

Áreas de cada zona de la planta

\begin{tabular}{|l|c|}
\hline \multicolumn{1}{|c|}{ Zona } & Área $\mathbf{~ m}^{\mathbf{2}}$ \\
\hline Zona de producción & 150 \\
\hline Almacén de materias primas & 40 \\
\hline Almacén de producto terminado & 60 \\
\hline Almacén de insumos & 20 \\
\hline Área de Mantenimiento & 30 \\
\hline Área de Calidad & 20 \\
\hline Área administrativa & 90 \\
\hline Comedor & 20 \\
\hline SS.HH. Administrativos & 14 \\
\hline Vestuarios & 25 \\
\hline Garita de seguridad & 9 \\
\hline
\end{tabular}

Elaboración propia

\subsubsection{Dispositivos de seguridad industrial y señalización}

Para prevenir las consecuencias de una situación de peligro se buscará emplear los dispositivos de seguridad más adecuados para la planta, en este caso se utilizarán dispositivos para prevenir incendios o mitigarlos, ya que por el tipo de planta no se está expuesto a otra situación de peligro en donde se requieran de diversos dispositivos de seguridad, los dispositivos a instalar serán:

- Extintores

- Dectectores de incendios

Con respecto a la señalización se debe considerar que tienen por objetivo avisar a las personas de que están en una zona peligrosa y deben evitarla o tomar las precauciones y protecciones adecuadas, las señales deben 
Medidas de la parihuela: $1,2 \times 1 \mathrm{~m}$

Medidas de las bandejas de botellas: 0,45 x 0,40 x 0,32 m (altura)

Cantidad de botellas por bandeja: 33 botellas

Se pueden apilar 4 bandejas una sobre otra.

Cálculos:

En una pallets entran 6 bandejas por nivel

En una pallets entran $6 \times 4 \times 33$ botellas $=792$ botellas

Número de pallets necesarios $(11385,56 / 792)=15$ pallets aprox.

$\checkmark$ Almacenamiento de azúcar

El azúcar tiene una rotación semanal, por lo que se tendrán que almacenar 762 kilos, considerando que cada pallet soporta un peso de 1177 kilos, solo se requerirá de uno para almacenar el azúcar.

$\checkmark$ Demás insumos

Para bolsas y cajas se requerirá 1 pallet, para etiquetas, cápsulas $\mathrm{y}$ corchos se requiere un espacio menor a 1 pallet. Finalmente para el sulfito y levaduras se utilizará un pallet también.

\section{Cálculo del almacén de producto terminado}

Para el cálculo del almacén de producto terminado se tomó en consideración que el tiempo de rotación de producto terminado sería cada 15 días.

Se requieren almacenar: 24.650 botellas llenas (15 días)

Medidas de la parihuela: 1,2 x1 m

Medidas de las cajas de botellas: 0,32 x 0,24 x 0,32 m (altura) 
Cantidad de botellas por caja: 12 botellas

Se pueden apilar 4 cajas una sobre otra.

Cálculos:

En una pallets entran 15 cajas por nivel

En una pallets entran $15 \times 4 \times 12$ botellas $=720$ botellas

Número de pallets necesarias $(24.650 / 720)=35$ pallets aprox .

En resumen se obtiene la siguiente tabla:

\section{Tabla 5.43}

Cálculo de área de almacenes $\left(\mathrm{m}^{2}\right)$

\begin{tabular}{|l|c|c|c|c|}
\hline \multicolumn{1}{|c|}{ Material } & Largo (m) & Ancho (m) & Cantidad & Área $\mathbf{~ m}^{\mathbf{2}}$ \\
\hline Higo fresco & 1,2 & 1 & 15 & 18 \\
\hline Botellas vacías & 1,2 & 1 & 10 & 12 \\
\hline Azúcar & 1,2 & 1 & 1 & 1,2 \\
\hline Demás insumos & 1,2 & 1 & 3 & 3,6 \\
\hline $\begin{array}{l}\text { Producto } \\
\text { terminado }\end{array}$ & 1,2 & 1 & 35 & 42 \\
\hline
\end{tabular}

Elaboración propia

La tabla considera almacenamiento volumétrico sin considerar pasadizos, estos serán determinados en el diseño final del plano.

\subsubsection{Disposición de detalle}

Para realizar la disposición al detalle se realizará el análisis de las relaciones. Este análisis permitirá desarrollar la propuesta de distribución tomando en consideración el grado de importancia que existe entre la cercanía de las áreas. Para realizar el análisis relacional se procederá a elaborar lo siguiente: 


\section{Tabla relacional}

En la figura 5.3 se muestra una tabla con los símbolos y color de cada actividad respectivamente.

\section{Figura 5.3.}

\section{Identificación de actividades}

\begin{tabular}{|c|c|c|}
\hline Símbolo & Color & Actividades \\
\hline & Verde & Operación \\
\hline & Anaranjado & Almacenaje \\
\hline & Azul & Control \\
\hline & Azul & Servicios \\
\hline & Pardo & Administración \\
\hline
\end{tabular}

Fuente: Diaz, B., Jarufe, B., Noriega, MT. (2007)

En la tabla 5.44 se muestra la tabla con el código de proximidades.

Tabla 5.44

Tabla de código de proximidades

\begin{tabular}{|c|c|c|c|}
\hline Código & Proximidad & Color & N $^{\circ}$ de líneas \\
\hline A & Absolutamente necesario & Rojo & 4 rectas \\
\hline E & Especialmente necesario & Amarillo & 3 rectas \\
\hline I & Importante & Verde & 2 rectas \\
\hline O & Normal & Azul & 1 recta \\
\hline U & Sin importancia & Sin color & no se traza \\
\hline X & No deseable & Plomo & 1 zig-zag \\
\hline XX & Altamente no deseable & Negro & 2 zig-zag \\
\hline
\end{tabular}

Fuente: Diaz, B., Jarufe, B., Noriega, MT. (2007)

En la tabla 5.45 se muestra la tabla de valor de proximidades: 


\section{Tabla 5.45}

Tabla de valor de proximidad

\begin{tabular}{|c|c|}
\hline SIMB. & ÁREA \\
\hline (1) & 1. Producción \\
\hline 2 & 2. Almacenes \\
\hline 3 & 3. Oficinas \\
\hline 4 & 4. Baños personal de planta \\
\hline 5 & 5. Baños oficinas \\
\hline 6 & 6. Mantenimiento \\
\hline 7 & 7. Comedor \\
\hline 8 & 8. Patio de maniobras \\
\hline 9 & 9. Control de calidad \\
\hline
\end{tabular}

Elaboración propia

\section{Diagrama relacional de recorrido o actividades}

Una vez realizado estos pasos, se procede a mostrar el diagrama relacional en la figura 5.4:

\section{Figura 5.4.}

\section{Diagrama relacional de actividades}

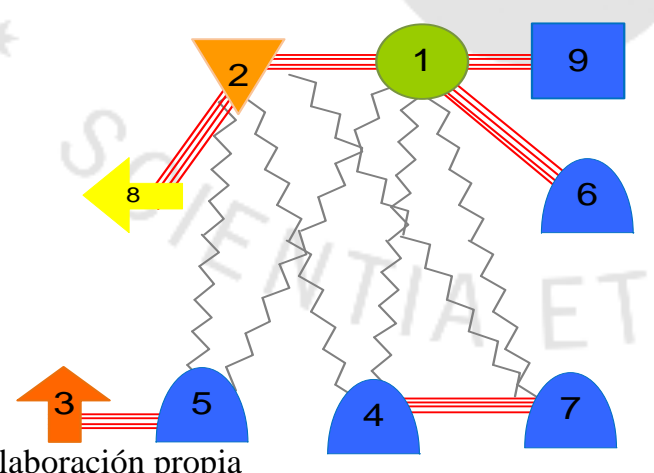

Elaboración propia 


\section{Figura 5.5.}

Plano de distribución de la planta procesadora de licor de higo

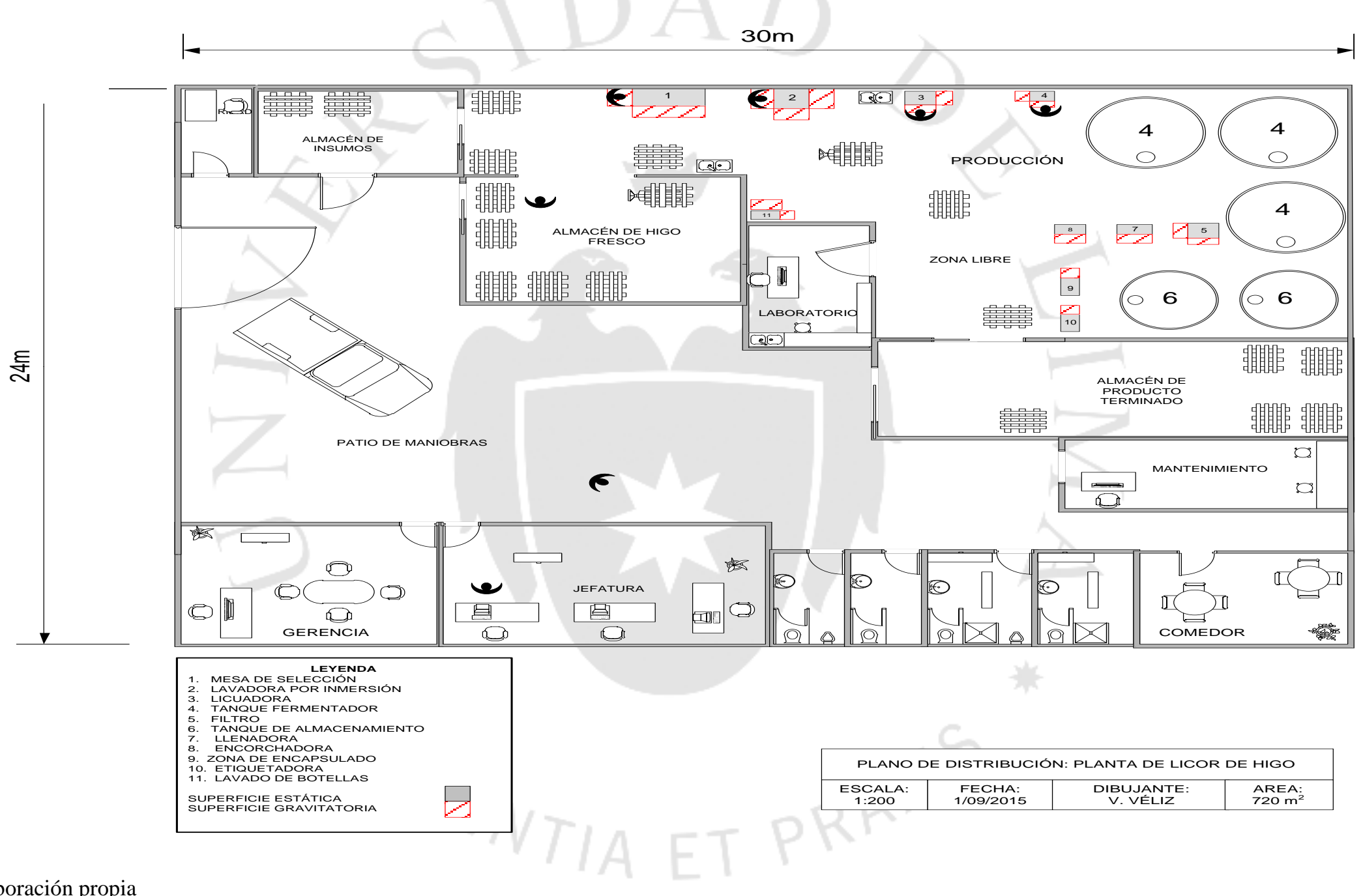

Elaboración propia 


\subsection{Cronograma de implementación del proyecto}

El plan general de implementación consta de dos fases, la fase de pre inversión y la fase de inversión, como se muestra a continuación:

Fase pre inversión:

- $\quad$ Estudio de pre factibilidad: consiste en llevar a cabo una revisión de este estudio para corregir o modificar cualquiera de los puntos importantes del proyecto y así evitar futuros errores por falta de retrospección.

- Estudio de factibilidad: Luego de revisar el estudio de pre-factibilidad, es necesario corroborar que los antecedentes empleados en el estudio sean precisos y además se debe adicionar el análisis económico y financiero empleando fuentes primarias para llevar a cabo este proyecto.

Fase Inversión:

- Ingeniería a detalle: Consiste en la elaboración de planos de arquitectura, obras civiles, estructuras electromecánicas, instrumentación, ingeniería sanitaria, etc.

- Contratos y adquisiciones: Se refiere a todo lo relacionado con la adquisición de: terrenos, maquinaria, equipo, licencias de tecnología, permisos, mobiliario de oficina, etc.

- Gestión financiera: Determina la forma de financiamiento del proyecto.

- Constitución de la empresa: Debe formalizarse el proyecto considerando los asuntos legales para su formalización como empresa.

- Organización de la empresa: Consiste en definir la estructura organizacional de la empresa.

- Instalación y montaje: Requiere de la construcción, instalación, movimiento de tierras, caminos de acceso y montajes.

- $\quad$ Pruebas y puesta en marcha: Se debe probar el funcionamiento de la maquinaria en vacío y en carga. 
- Trabajos complementarios y prueba final: Pueden existir algunos imprevistos que son vistos en la última etapa de la implementación del proyecto.

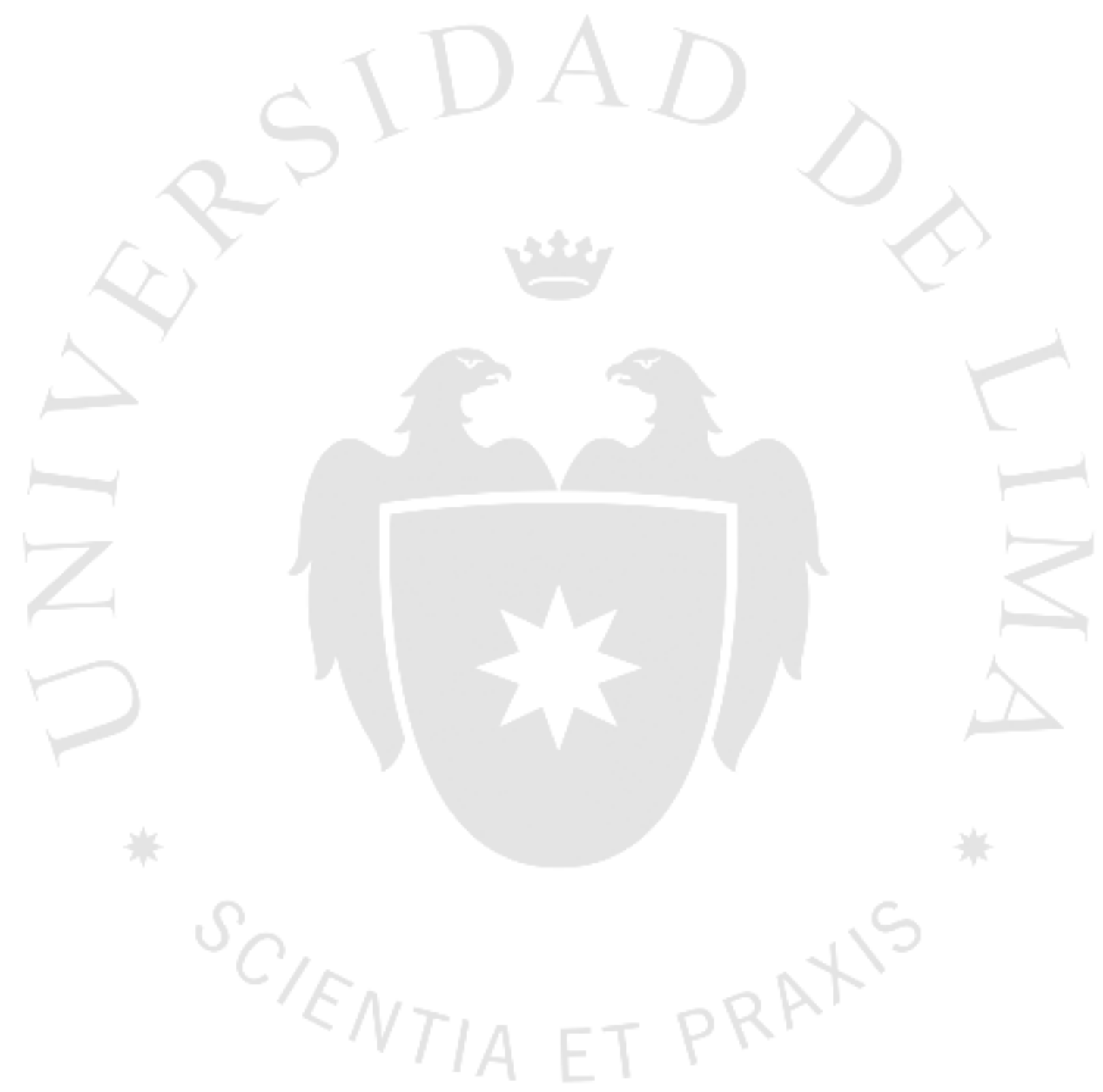


Según las consideraciones anteriores, se obtiene el siguiente cronograma de actividades para la ejecución del proyecto, que tiene una duración de 12 meses. En la figura 5.6 se detallan las actividades requeridas y los tiempos estimados que se emplearán.

\section{Figura 5.6}

Diagrama de Gantt para la implementación del proyecto

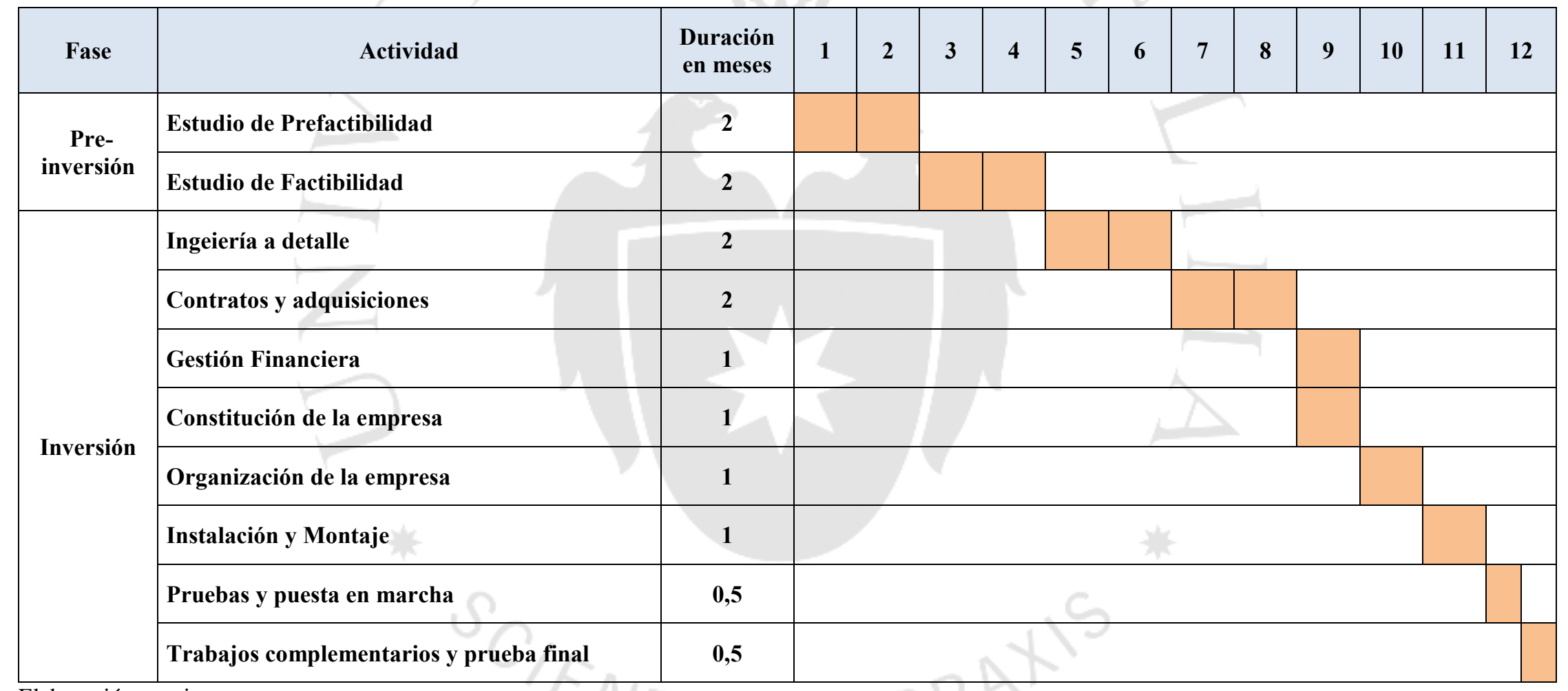

Elaboración propia 


\section{CAPÍTULO VI: ORGANIZACIÓN ADMINISTRATIVA}

\subsection{Organización empresarial}

La organización y administración del proceso de implementación de un proyecto tiene por objetivo lograr un buen manejo y el avance del mismo, a medida que se van desarrollando las etapas previas al funcionamiento de la planta.

Con la finalidad de obtener una correcta administración de los recursos es requerida una adecuada organización que se ajuste a nuestras.

\section{Gestión de la ejecución del proyecto:}

La gestión de la ejecución del proyecto abarcará 2 etapas complementarias, la primera etapa de formulación y la segunda de realización.

\section{Etapa de formulación:}

Formular la razón social, es decir el tipo societario y crear el nombre de la empresa.

Para este proyecto se ha decidido formar una sociedad anónima cerrada y se añade al nombre las siglas S.A.C, ya que la empresa estará formada por pocos socios, el capital a aportar será pequeño y en casos de alguna contingencia nuestros bienes personales no correrían riesgo.

\section{Creación del nombre de la empresa}

Determinar el giro de la actividad, que en nuestro caso es de giro industrial.

$\checkmark \quad$ Acordar el capital. Los aportes del capital pueden ser dinerario (es decir dinero corriente o en efectivo) y también puede constituirse en bienes sean muebles e inmuebles. Por el tipo de razón societario no pueden considerarse aportes de capital a los servicios. 
$\checkmark \quad$ Determinar el plazo de duración que tendrá la empresa, que en este caso es indefinido.

$\checkmark \quad$ Se deberá fijar donde será el domicilio legal de la empresa.

$\checkmark \quad$ Se deberá decidir los proveedores que participarán en la cotización directa de precios de todos los proveedores del efectivo fijo tangible. También las compañías que implementarán las obras civiles del proyecto.

\section{Etapa de realización:}

La etapa de realización comprende los siguientes pasos:

- Elaborar la minuta de constitución social de la empresa firmada por todos los socios y elaborada y firmada por un abogado público.

- Llevar la minuta al notario público para su inscripción en registros públicos para que sea elevada a escritura pública.

- Hacer depósito de dinero en efectivo del capital social en el banco elegido.

- Recabar el registro único del contribuyente (RUC). El representante legal que realice el trámite debe exhibir el documento original que acredite su representación y su documento de identidad original.

- Obtener permiso de impresión de facturas y boletas de una imprenta autorizada por SUNAT.

- Adquirir registro unificado para autorizarlo y obtener la autorización del libro de planillas y tener registro del empleador.

- Obtener registro patronal de ESSALUD.

- Legalizar estos libros contables en la notaria.

- Obtener licencia de funcionamiento municipal.

- Obtener el registro de la marca en INDECOPI 


\subsection{Requerimientos de personal directivo, administrativo y de servicios}

\section{Personal directivo y administrativo:}

Será seleccionado entre profesionales del medio y la capacitación será programada según necesidades de la empresa, para el presente proyecto se requerirán los siguientes puestos:

\section{Gerente General y de Operaciones:}

El perfil de este puesto será un Administrador de empresas o Ingeniero Industrial con una MBA.

Como Gerente General será responsable de la organización y de llevar a cabo la producción, comercialización y distribución a través de sus gerentes de cada área; y como Gerente de Operaciones será responsable del buen funcionamiento de toda la planta usando el diseño de producción más adecuado, asimismo, coordinará con agencia de recursos humanos la capacitación del talento humano, evaluar el rendimiento / aprendizaje / productividad de los colaboradores, evaluar el perfil del colaborador para el ingreso a la empresa, evaluar las gestiones de los colaboradores dentro la organización (puestos claves), gestionar los despidos de los colaboradores, así como sus renuncias voluntarias, analizar el perfil de cada colaborador, así como un diseño de propuestas de crecimiento del organigrama de la empresa, buscar empatía con los colaboradores, búsqueda de capacitaciones entre áreas de trabajo para la comunicación entre colaboradores y conocimiento y experiencia.

\section{Gerente de Finanzas}

El perfil de este puesto será un Administrador, Contador con maestría en Finanzas, responsable de gestionar las liquides de la empresa a través de préstamos, elaborar reportes de ventas, ingresos, egresos, gastos, estados financieros, reportes de optimización de compras, reportes de activos, pasivos, diseño de liquidez en el largo plazo de la empresa, supervisión de tasa de interés con los bancos (contratos), reportes de deudas, pagos a SUNAT, AFP, pagos de impuestos a la Municipalidad. 


\section{Gerente de Marketing y Ventas:}

El perfil de este puesto será un Licenciado en Marketing con una maestría en Administración de negocios, responsable de gestionar la comercialización y distribución a los clientes, responsable de diseñar la publicidad, diseño de la comunicación con los clientes, elaborar planes de ventas, elaborar reportes de ventas, elaborar reportes de la competencia, gestionar planes corporativos, estructurar la forma de pago, mantener la fidelidad del cliente y la supervisión de los retornos de inversión del cliente.

\section{Jefe de Calidad:}

Se requiere una persona con estudios de Ingeniería Química o Alimentaria, cuyas principales funciones serán programar, dirigir, monitorear, supervisar y evaluar los procesos de mejoramiento de calidad; responsable de la inocuidad del producción del producto y de los insumos químicos empleados en el proceso.

\section{Jefe de Mantenimiento:}

Técnico Medio con mención afín al área de Mantenimiento o Bachiller con alguna especialización en Gestión de mantenimiento. Funciones: supervisar el mantenimiento preventivo y/o correctivo en las áreas productivas; coordinando y controlando las tareas del personal a su cargo, así como aplicando los procedimientos establecidos para garantizar el perfecto estado, presentación y uso de edificaciones, equipos, maquinarias y mobiliarios de la organización.

\section{Asistente de Gerencia:}

Persona con estudios de Secretariado o Técnico en Administración o Contabilidad, cuyas principales funciones serán: Apoyar en todos los procesos administrativos y secretariales que garanticen eficientemente el desarrollo de la operación de las Gerencias. 


\section{Personal Operativo y de Servicios:}

\section{Supervisor de Planta:}

Persona con estudios Técnicos en Gestión de la Producción, con experiencia mínima de 5 años en empresas de industrias alimentarias.

Funciones:

- Designar las tareas diarias y asegurar que se cumplan con los tiempos de producción.

- Supervisar a los operarios de la planta.

- Coordinar con los Jefes de Mantenimiento y Calidad para facilitar su trabajo.

- Apoyar en su gestión al Gerente de Operaciones.

- Capacitar a los operarios.

\section{Operarios:}

Estudios secundarios concluidos con experiencia en empresas industriales.

Funciones:

- Realizar las tareas de su puesto de trabajo, siguiendo las indicaciones del supervisor de turno.

\section{Montacarguistas:}

Persona con estudios secundarios completos, con licencia de conducir y con experiencia en manejo de montacargas.

Funciones:

- Realizar las tareas de su puesto de trabajo, siguiendo las indicaciones del supervisor de turno. 


\section{Almaceneros:}

Persona con estudios secundarios completos y con experiencia en almacenes.

Funciones:

- Realizar las tareas de su puesto de trabajo, siguiendo las indicaciones del supervisor de turno.

\subsection{Estructura organizacional}

A continuación se presenta el organigrama de la empresa. Aquí se considera la participación del personal en áreas claves para que la empresa se mantenga a flote y año a año incremente sus ventas.

Figura 6.1:

Organigrama de la empresa

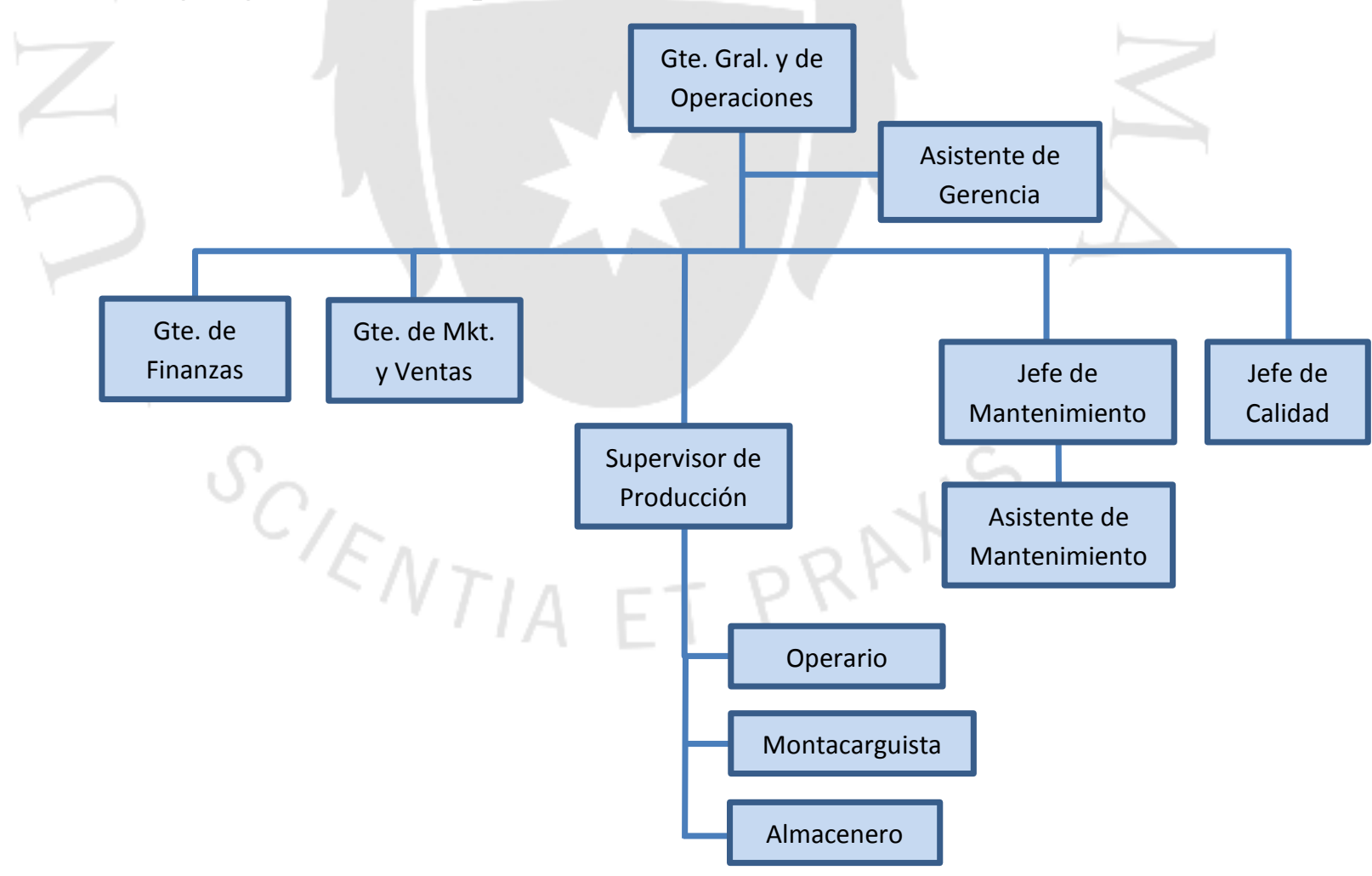

Elaboración propia 


\section{Normas laborales:}

Las principales leyes y decretos aplicables al proyecto según el Ministerio de Trabajo son las siguientes:

- $\quad$ DS N $\mathrm{N}^{\circ}$ 003-97-TR:Ley de productividad y competitividad laboral

- $\quad$ DS N002-97-TR: Ley de formación y promoción laboral

- $\quad$ DS N001-96-TR:Reglamento de Ley de Fomento al empleo

- Ley N²9245: Ley que regula los servicios de tercerización

- Ley N28518: Ley sobre modalidades formativas laborales

- DS $\mathrm{N}^{\circ} 007-2002-\mathrm{TR}:$ Ley de jornada de trabajo, horario y trabajo extra.

- DS: N011-2010-TR: Remuneración Mínima Vital

Fuente: Compendio Normas Laborales. Ministerio de Trabajo www.mintra.gob.pe

La jornada de trabajo para varones y mujeres será de ocho horas diarias o 48 horas semanales como máximo pudiendo establecer jornadas menores por, convenio o decisión unilateral del empleador.

En el proyecto se emplearán dos turnos de trabajo dependiendo si es temporada alta o baja.

La vestimenta es importante porque ayuda a prevenir contaminaciones cruzadas, por lo cual el uniforme completo será:

- Camisa o polo de color blanco

- Pantalón blanco

- Gorro

- Delantales de impermeable

- Cubre boca

- Guantes

- Calzado apropiado 
Además de la vestimenta, se debe considerar el aseo e higiene personal que labora en las salas de proceso, para lo cual se tiene en cuenta lo siguiente el lavado de manos y la limpieza de calzado usando agentes detergentes, desinfectantes y escobillas.

Para garantizar el buen cumplimiento de todas estas normas de limpieza e higiene, la empresa contará con avisos que indican la obligación de lavarse las manos y la presentación pulcra de los uniformes. 


\section{CAPÍTULO VII: ASPECTOS ECONÓMICOS Y FINANCIEROS}

\subsection{Inversiones}

Para el cálculo de la inversión total de nuestro proyecto se considerará la inversión fija, tanto la tangible como la intangible y el capital de trabajo. El 40\% se realizará con capital propio y el $60 \%$ financiado por una entidad bancaria, con una tasa de interés anual de $13 \%$.

\subsubsection{Estimación de las inversiones}

Los gastos de inversión comprenden la inversión en activos tangibles, activos intangibles y capital de trabajo tal y como se muestran en los Tablas 7.1, 7.2, 7.3 y 7.4.

La inversión en activos tangibles está dada por los gastos que se reflejan en bienes fácilmente identificables y son objetivos y reales. 
Tabla 7.1

Inversión para maquinarias y equipos

\begin{tabular}{|c|c|c|c|}
\hline Máquinas y equipos & Cantidad & Precio unitario & Precio total \\
\hline Mesa de selección & 1 & S/. 1.000 & S/. 1.000 \\
\hline Máquina de lavado & 1 & S/. 3.000 & S/. 3.000 \\
\hline Licuadora & 2 & $\mathrm{~S} / .2 .500$ & S/. 5.000 \\
\hline Coladora & 2 & S/. 70 & S/. 140 \\
\hline Tanque fermentador & 3 & $\mathrm{~S} / .31 .500$ & S/. 94.500 \\
\hline Filtro & 1 & S/. 15.000 & S/. 15.000 \\
\hline Tanque de almacenamiento & 2 & S/. 15.000 & S/. 30.000 \\
\hline Llenadora & 1 & S/. 4.000 & S/. 4.000 \\
\hline Encorchadora & 1 & S/. 2.500 & S/. 2.500 \\
\hline Etiquetadora & 1 & S/. 2.000 & S/. 2.000 \\
\hline Lavadora de botellas & 1 & $\mathrm{~S} / .4 .000$ & S/. 4.000 \\
\hline Pallets & 80 & S/. 60 & S/. 4.800 \\
\hline Filtro purificador de agua & 1 & S/. 2.000 & S/. 2000 \\
\hline Rack & 9 & S/. 500 & S/. 4.500 \\
\hline Montacargas & 1 & S/. 6.000 & S/. 6.000 \\
\hline Balanza & 1 & S/. 1.000 & S/. 1.000 \\
\hline Pistola de calor & 1 & S/. 60 & S/.60 \\
\hline Refractometro & 1 & S/. 90 & S/. 90 \\
\hline Termometro & 1 & S/. 40 & S/. 40 \\
\hline Total & & & S/. 179.630 \\
\hline
\end{tabular}

Elaboración propia

Tabla 7.2

\section{Inversión para instalaciones}

\begin{tabular}{|c|c|}
\hline Rubro & $\mathbf{S} /$. \\
\hline Instalación de maquinaria & 35.000 \\
\hline Instalación de tuberías & 30.000 \\
\hline Instalaciones eléctricas & 15.000 \\
\hline Total & $\mathbf{8 0 . 0 0 0}$ \\
\hline
\end{tabular}

Elaboración propia 
Tabla 7.3

Inversión para equipos de cómputo y mobiliario

\begin{tabular}{|l|c|c|c|}
\hline Materiales y Equipos & Cantidad & Precio unitario & Precio total \\
\hline Computadora & 5 & S/. 2.000 & S/. 10.000 \\
\hline Impresora & 2 & S/. 700 & S/. 1.400 \\
\hline Teléfono & 5 & S/. 500 & S/. 2.500 \\
\hline Mobiliario & 5 & S/. 500 & S/. 2.500 \\
\hline \multicolumn{2}{r|}{} & Total & S/. 16.400 \\
\cline { 2 - 4 }
\end{tabular}

Elaboración propia

\section{Obras civiles}

El costo del metro cuadrado construido tiene un promedio de 366, para esto se ha considerado cimientos, pisos, columnas y vigas estructurales de la nave industrial. Como se mencionó anteriormente, el terreno tiene un área de $720 \mathrm{~m}^{2}$, lo que representa un costo total en construcción de S/. 264.000.

\section{Tabla 7.4}

Inversión tangible total

\begin{tabular}{|c|c|}
\hline Rubro & $\mathbf{S} /$. \\
\hline Terreno & 276.480 \\
\hline Construcción de terreno & 264.000 \\
\hline Maquinaria y Equipos & 179.630 \\
\hline Instalaciones al detalle & 80.000 \\
\hline Equipos de cómputo y mobiliario & 16.400 \\
\hline Total & 816.510 \\
\hline
\end{tabular}

Elaboración propia

Los activos intangibles incluyen todos los gastos que se realizan en la fase pre-operativa del proyecto. Como se observa en la tabla 7.5. 
Tabla 7.5

Inversión intangible total

\begin{tabular}{|l|c|}
\hline \multicolumn{1}{|c|}{ Rubro } & S/. \\
\hline Estudios y proyectos de ingeniería & 20.000 \\
\hline Constitución de la empresa & 2.000 \\
\hline Gastos de capacitación & 2.500 \\
\hline Gestiones de marca & 1.500 \\
\hline Publicidad & 10.000 \\
\hline Puesta en marcha & 15.000 \\
\hline Imprevistos Total & 5.000 \\
\hline \multicolumn{2}{|c|}{ T6.000 } \\
\hline
\end{tabular}

Elaboración propia

\subsubsection{Capital de trabajo}

Es la cantidad de dinero necesaria para poder afrontar las necesidades de liquidez de la empresa, para las compras y pagos pertinentes; es decir, cubrir los gastos generados antes de que ingrese dinero por ventas.

En la siguiente tabla se observan los conceptos utilizados para determinar el capital de trabajo:

\section{Tabla 7.6}

Datos requeridos para calcular el capital de trabajo

\begin{tabular}{|l|c|}
\hline \multicolumn{1}{|c|}{$\begin{array}{c}\text { Datos para el Cálculo del Capital de } \\
\text { Trabajo }\end{array}$} & Número de días requeridos \\
\hline Ciclo fabril & 10 \\
\hline $\begin{array}{l}\text { Estadía de productos terminados en el } \\
\text { almacén }\end{array}$ & 15 \\
\hline $\begin{array}{l}\text { Periodo de comercialización y } \\
\text { cobranzas }\end{array}$ & 30 \\
\hline Total de días del ciclo de caja & $\mathbf{5 5}$ \\
\hline
\end{tabular}

Elaboración propia

Obteniéndose así un periodo de ciclo de caja de 55 días.

El cálculo del ciclo de caja se observa en la siguiente tabla: 
Tabla 7.7

Cálculo del capital de trabajo

\begin{tabular}{|l|c|c|}
\hline \multicolumn{1}{|c|}{ Rubro } & Monto anual & Monto 55 días \\
\hline Materia prima e insumos & 922.459 & 278.001 \\
\hline Sueldos y salarios & 1.056 .456 & 318.384 \\
\hline Costo de agua & 3.222 & 971 \\
\hline Costo de energía eléctrica & 8.993 & 2.710 \\
\hline Servicios & 43200 & 13.019 \\
\hline \multicolumn{2}{|c|}{ Capital de trabajo } & $\mathbf{6 1 3 . 0 8 6}$ \\
\hline
\end{tabular}

Elaboración propia

La inversión total para el proyecto se observa en la tabla 7.8:

\section{Tabla 7.8}

Inversión total para el proyecto

\begin{tabular}{|c|c|}
\hline Rubro & Cantidad \\
\hline Inversión tangible & 816.510 \\
\hline Inversión intangible & 56.000 \\
\hline Capital de trabajo & 613.086 \\
\hline Total & 1.485 .596 \\
\hline
\end{tabular}

Elaboración propia

\subsection{Costos de producción}

\subsubsection{Costos de materias primas, insumos y otros materiales}

\section{Costo de materias primas}

El costo del kilo de higo es de S/.1,40 como se aprecia en la tabla 7.9: 
Tabla 7.9

\section{Costo de materia prima(S/.)}

\begin{tabular}{|c|c|}
\hline $\begin{array}{c}\text { Requerimiento de higo } \\
\text { (Kg/año) }\end{array}$ & $\begin{array}{c}\text { Costo total } \\
\text { (S/.) }\end{array}$ \\
\hline 244.684 & 342.557 \\
\hline 256.929 & 359.700 \\
\hline 269.174 & 376.843 \\
\hline 281.419 & 393.986 \\
\hline 293.664 & 411.129 \\
\hline 305.909 & 428.272 \\
\hline 318.154 & 445.415 \\
\hline 330.399 & 462.558 \\
\hline 342.644 & 479.701 \\
\hline 354.889 & 496.844 \\
\hline
\end{tabular}

Elaboración propia

\section{Costo de insumos}

El costo del litro de sulfito es de S/. 0,90:

Tabla 7.10

\section{Costo de sulfito (S/.)}

\begin{tabular}{|c|c|}
\hline $\begin{array}{c}\text { Requerimiento de } \\
\text { Sulfito (kg/año) }\end{array}$ & $\begin{array}{c}\text { Costo total } \\
\text { (S/.) }\end{array}$ \\
\hline 3,06 & 2,75 \\
\hline 3,21 & 2,89 \\
\hline 3,37 & 3,03 \\
\hline 3,52 & 3,17 \\
\hline 3,67 & 3,30 \\
\hline 3,82 & 3,44 \\
\hline 3,98 & 3,58 \\
\hline 4,13 & 3,72 \\
\hline 4,28 & 3,86 \\
\hline 4,44 & 3,99 \\
\hline
\end{tabular}

Elaboración propia

El costo del kilo de azúcar es de S/. 2,0: 
Tabla 7.11

\section{Costo de azúcar(S/.)}

\begin{tabular}{|c|c|}
\hline $\begin{array}{c}\text { Requerimiento de } \\
\text { azúcar (kg/año) }\end{array}$ & $\begin{array}{c}\text { Costo total } \\
\text { (S/.) }\end{array}$ \\
\hline 30.591 & 61.182 \\
\hline 32.122 & 64.244 \\
\hline 33.653 & 67.306 \\
\hline 35.184 & 70.368 \\
\hline 36.715 & 73.430 \\
\hline 38.246 & 76.492 \\
\hline 39.777 & 79.553 \\
\hline 41.308 & 82.615 \\
\hline 42.839 & 85.677 \\
\hline 44.369 & 88.739 \\
\hline
\end{tabular}

Elaboración propia

El costo del kilo de levaduras es de S/. 13,50:

\section{Tabla 7.12}

\section{Costo de levaduras (S/.)}

\begin{tabular}{|c|c|}
\hline $\begin{array}{c}\text { Requerimiento de } \\
\text { levaduras (kg/año) }\end{array}$ & $\begin{array}{c}\text { Costo total } \\
\text { (S/.) }\end{array}$ \\
\hline 153 & 2.065 \\
\hline 161 & 2.168 \\
\hline 168 & 2.272 \\
\hline 176 & 2.375 \\
\hline 184 & 2.478 \\
\hline 191 & 2.582 \\
\hline 199 & 2.685 \\
\hline 207 & 2.788 \\
\hline 214 & 2.892 \\
\hline 222 & 2.995 \\
\hline
\end{tabular}

Elaboración propia 
Costo de botellas, corchos, cápsulas termoencogibles y etiquetas

El costo de cada botella es de S/. 1,80:

Tabla 7.13

Costo de botellas (S/.)

\begin{tabular}{|c|c|}
\hline $\begin{array}{c}\text { Requerimiento de } \\
\text { botellas (kg./año) }\end{array}$ & $\begin{array}{c}\text { Costo total } \\
\text { (S/.) }\end{array}$ \\
\hline 203.942 & 367.095 \\
\hline 214.148 & 385.466 \\
\hline 224.354 & 403.837 \\
\hline 234.560 & 422.208 \\
\hline 244.766 & 440.579 \\
\hline 254.972 & 458.950 \\
\hline 265.178 & 477.321 \\
\hline 275.384 & 495.692 \\
\hline 285.590 & 514.063 \\
\hline 295.797 & 532.434 \\
\hline
\end{tabular}

Elaboración propia

El costo de los corchos, cápsulas termoencogibles y etiquetas y cajas es de $\mathrm{S} / .0,10, \mathrm{~S} / .0,25, \mathrm{~S} / .0,35$ y S/. 0,40 la unidad respectivamente.

Tabla 7.14

Costo de corchos, cápsulas termoencogibles y etiquetas (S/.)

\begin{tabular}{|c|c|c|c|c|c|}
\hline $\begin{array}{c}\text { Requerimiento de } \\
\text { corchos(kg./año) }\end{array}$ & $\begin{array}{c}\text { Costo total } \\
\mathbf{( S / . )}\end{array}$ & $\begin{array}{c}\text { Requerimiento de } \\
\text { cápsulas }\end{array}$ & $\begin{array}{c}\text { Costo total } \\
\mathbf{( S / . )}\end{array}$ & $\begin{array}{c}\text { Requerimiento de } \\
\text { etiquetas (kg./año) }\end{array}$ & $\begin{array}{c}\text { Costo } \\
\text { total (S/.) }\end{array}$ \\
\hline $203.941,51$ & $20.394,15$ & $203.941,51$ & $50.985,38$ & $203.941,51$ & $71.379,53$ \\
\hline $214.147,63$ & $21.414,76$ & $214.147,63$ & $53.536,91$ & $214.147,63$ & $74.951,67$ \\
\hline $224.353,74$ & $22.435,37$ & $224.353,74$ & $56.088,44$ & $224.353,74$ & $78.523,81$ \\
\hline $234.559,86$ & $23.455,99$ & $234.559,86$ & $58.639,96$ & $234.559,86$ & $82.095,95$ \\
\hline $244.765,97$ & $24.476,60$ & $244.765,97$ & $61.191,49$ & $244.765,97$ & $85.668,09$ \\
\hline $254.972,09$ & $25.497,21$ & $254.972,09$ & $63.743,02$ & $254.972,09$ & $89.240,23$ \\
\hline $265.178,20$ & $26.517,82$ & $265.178,20$ & $66.294,55$ & $265.178,20$ & $92.812,37$ \\
\hline $275.384,32$ & $27.538,43$ & $275.384,32$ & $68.846,08$ & $275.384,32$ & $96.384,51$ \\
\hline $285.590,43$ & $28.559,04$ & $285.590,43$ & $71.397,61$ & $285.590,43$ & $99.956,65$ \\
\hline $295.796,55$ & $29.579,65$ & $295.796,55$ & $73.949,14$ & $295.796,55$ & $103.528,79$ \\
\hline
\end{tabular}

Elaboración propia 
El costo de las cajas para 12 botellas es de S/. 0,40 la unidad.

\section{Tabla 7.15}

Costo de cajas (S/.)

\begin{tabular}{|c|c|}
\hline $\begin{array}{c}\text { Requerimiento } \\
\text { de cajas } \\
\text { (kg./año) }\end{array}$ & $\begin{array}{c}\text { Costo total } \\
\text { (S/.) }\end{array}$ \\
\hline $16.995,13$ & $6.798,05$ \\
\hline $17.845,64$ & $7.138,25$ \\
\hline $18.696,15$ & $7.478,46$ \\
\hline $19.546,65$ & $7.818,66$ \\
\hline $20.397,16$ & $8.158,87$ \\
\hline $21.247,67$ & $8.499,07$ \\
\hline $22.098,18$ & $8.839,27$ \\
\hline $22.948,69$ & $9.179,48$ \\
\hline $23.799,20$ & $9.519,68$ \\
\hline $24.649,71$ & $9.859,88$ \\
\hline Elaboración propia &
\end{tabular}

Elaboración propia

7.2.2. Costo de los servicios (energía eléctrica, agua, combustible, etc.)

En los Tablas 7.16 y 7.17 se pueden apreciar los costos de la energía eléctrica y agua consumidas por año respectivamente. 
Tabla 7.16

Costo de la energía eléctrica consumida por año (S/.)

\begin{tabular}{|c|c|c|}
\hline Año & Consumo kW & $\begin{array}{c}\text { Gasto en } \\
\text { energía } \text { S/ }\end{array}$ \\
\hline $\mathbf{2 0 1 5}$ & 21.062 & 7.793 \\
\hline $\mathbf{2 0 1 6}$ & 22.116 & 8.183 \\
\hline $\mathbf{2 0 1 7}$ & 23.170 & 8.573 \\
\hline $\mathbf{2 0 1 8}$ & 24.224 & 8.963 \\
\hline $\mathbf{2 0 1 9}$ & 25.278 & 9.353 \\
\hline $\mathbf{2 0 2 0}$ & 26.332 & 9.743 \\
\hline $\mathbf{2 0 2 1}$ & 27.386 & 10.133 \\
\hline $\mathbf{2 0 2 2}$ & 28.440 & 10.523 \\
\hline $\mathbf{2 0 2 3}$ & 29.494 & 10.913 \\
\hline $\mathbf{2 0 2 4}$ & 30.548 & 11.303 \\
\hline
\end{tabular}

Nota: El consumo de energía en kilowatts $(\mathrm{kW})$, es la suma de consumos obtenida en el capítulo 5. Tarifa Luz del Sur: S/./kW:0,37. Elaboración propia

Tabla 7.17

Costo del agua consumida por las máquinas( $\mathrm{S} /$.

\begin{tabular}{|c|c|c|}
\hline Año & $\begin{array}{c}\text { Consumo } \\
(\mathbf{m 3} / \mathbf{a n ̃ o})\end{array}$ & Costo total S/. \\
\hline $\mathbf{2 0 1 5}$ & 260 & 1.222 \\
\hline $\mathbf{2 0 1 6}$ & 273 & 1.283 \\
\hline $\mathbf{2 0 1 7}$ & 286 & 1.344 \\
\hline $\mathbf{2 0 1 8}$ & 299 & 1.406 \\
\hline $\mathbf{2 0 1 9}$ & 312 & 1.467 \\
\hline $\mathbf{2 0 2 0}$ & 325 & 1.528 \\
\hline $\mathbf{2 0 2 1}$ & 338 & 1.589 \\
\hline $\mathbf{2 0 2 2}$ & 351 & 1.650 \\
\hline $\mathbf{2 0 2 3}$ & 364 & 1.711 \\
\hline $\mathbf{2 0 2 4}$ & 377 & 1.773 \\
\hline
\end{tabular}

Nota: El consumo de agua en metros cúbicos $\left(\mathrm{m}^{3}\right)$, es la sumatoria de consumos obtenido en el capítulo 5. Tarifa Sedapal: S//m³: 4,7. Elaboración propia 
El costo considerado de energía y agua consumida adicionalmente a las máquinas de producción será de S/.1.200 y S/.2.000 anualmente respectivamente.

\subsubsection{Costo de la mano de obra}

Mano de obra directa

En los Tablas 7.18 se muestran los salarios anuales de los operarios y supervisores de planta:

\section{Tabla 7.18}

Salarios anuales de la mano de operarios y supervisores (S/.)

\begin{tabular}{|c|c|c|c|c|c|c|c|}
\hline Puesto & $\mathbf{n}^{\circ}$ & $\begin{array}{c}\text { Salario } \\
\text { Mensual }\end{array}$ & $\begin{array}{c}\text { Salario } \\
\text { Anual }\end{array}$ & $\begin{array}{c}\text { Gratificació } \\
\mathbf{n}\end{array}$ & CTS & $\begin{array}{c}\text { Sist. } \\
\text { Salud }\end{array}$ & $\begin{array}{c}\text { Compensación } \\
\text { Anual }\end{array}$ \\
\hline Operarios & 16 & 800 & 4.800 & 800 & 400 & 432 & 102.912 \\
\hline Supervisor & 2 & 3.800 & 22.800 & 3.800 & 1.900 & 2052 & 61.104 \\
\hline
\end{tabular}

Elaboración propia

Mano de obra indirecta

En los Tablas 7.19 y 7.20 se muestran los salarios anuales de la mano de obra indirecta y del personal administrativo respectivamente: 
Tabla 7.19

Salarios anuales de la mano de obra indirecta(S/.)

\begin{tabular}{|c|c|c|c|c|c|c|c|}
\hline Puesto & $\mathbf{n}^{\circ}$ & $\begin{array}{c}\text { Salario } \\
\text { Mensual }\end{array}$ & $\begin{array}{c}\text { Salario } \\
\text { Anual }\end{array}$ & $\begin{array}{c}\text { Gratifica } \\
\text { ción }\end{array}$ & CTS & $\begin{array}{c}\text { Sist. } \\
\text { Salud }\end{array}$ & $\begin{array}{c}\text { Compensación } \\
\text { Anual }\end{array}$ \\
\hline $\begin{array}{c}\text { Jefe de } \\
\text { calidad }\end{array}$ & 1 & 5.600 & 67.200 & 11.200 & 5.600 & 6.048 & 90.048 \\
\hline $\begin{array}{c}\text { Jefe de } \\
\text { Mantenimiento }\end{array}$ & 1 & 5.600 & 67.200 & 11.200 & 5.600 & 6.048 & 90.048 \\
\hline $\begin{array}{c}\text { Asistente de } \\
\text { Mantenimiento }\end{array}$ & 1 & 1.600 & 19.200 & 3.200 & 1.600 & 1.728 & 25.728 \\
\hline $\begin{array}{c}\text { Montacarguista } \\
\text { Almacenero } \\
\text { de materia } \\
\text { prima }\end{array}$ & 2 & 1.200 & 14.400 & 2.400 & 1.200 & 1.296 & 19.296 \\
\hline $\begin{array}{c}\text { Almacenero } \\
\text { de prod. } \\
\text { terminado }\end{array}$ & 2 & 1.200 & 14.400 & 2.400 & 1.200 & 1.296 & 38.592 \\
\hline
\end{tabular}

Elaboración propia

Tabla 7.20

Salarios anuales del personal administrativo (S/.)

\begin{tabular}{|c|c|c|c|c|c|c|c|}
\hline Puesto & $\mathbf{n}^{\circ}$ & $\begin{array}{c}\text { Salario } \\
\text { Mensual }\end{array}$ & $\begin{array}{c}\text { Salario } \\
\text { Anual }\end{array}$ & Gratificación & CTS & $\begin{array}{c}\text { Sist. } \\
\text { Salud }\end{array}$ & $\begin{array}{c}\text { Compensació } \\
\text { n Anual }\end{array}$ \\
\hline $\begin{array}{c}\text { Gte. General y } \\
\text { de Operaciones }\end{array}$ & 1 & 12.000 & 144.000 & 24.000 & $\begin{array}{c}12.00 \\
0\end{array}$ & 12.960 & 192.960 \\
\hline $\begin{array}{c}\text { Gerente de } \\
\text { Finanzas }\end{array}$ & 1 & 11.000 & 132.000 & 22.000 & $\begin{array}{c}11.00 \\
0\end{array}$ & 11.880 & 176.880 \\
\hline $\begin{array}{c}\text { Gte. de Mkt. y } \\
\text { Ventas }\end{array}$ & 1 & 11.000 & 132.000 & 22.000 & $\begin{array}{c}11.00 \\
0\end{array}$ & 11.880 & 176.880 \\
\hline Asistente & 1 & 2.700 & 32.400 & 5.400 & 2.700 & 2.916 & 43.416 \\
\hline
\end{tabular}

Elaboración propia 
En la tabla 7.21 se muestran los gastos anuales del pago de servicios:

Tabla 7.21

Gasto en pago de servicios para los próximos 10 años (S/.)

\begin{tabular}{|c|c|c|c|c|c|c|c|c|c|c|}
\hline $\begin{array}{c}\text { Gastos de } \\
\text { servicios }\end{array}$ & $\mathbf{2 0 1 5}$ & $\mathbf{2 0 1 6}$ & $\mathbf{2 0 1 7}$ & $\mathbf{2 0 1 8}$ & $\mathbf{2 0 1 9}$ & $\mathbf{2 0 2 0}$ & $\mathbf{2 0 2 1}$ & $\mathbf{2 0 2 2}$ & $\mathbf{2 0 2 3}$ & $\mathbf{2 0 2 4}$ \\
\hline Limpieza & 19.200 & 19.200 & 19.200 & 19.200 & 19.200 & 19.200 & 19.200 & 19.200 & 19.200 & 19.200 \\
\hline Seguridad & 24.000 & 24.000 & 24.000 & 24.000 & 24.000 & 24.000 & 24.000 & 24.000 & 24.000 & 24.000 \\
\hline
\end{tabular}

Elaboración propia

\subsection{Presupuesto de ingresos y egresos}

\subsubsection{Presupuesto de ingreso por ventas}

El precio de venta de cada botella de licor será de S/.15,875:

\section{Tabla 7.22}

Presupuesto de ingreso por ventas (S/.)

\begin{tabular}{|l|c|c|}
\hline Año & Unid. & Precio S/. \\
\hline $\mathbf{2 0 1 5}$ & 205.224 & 3.257 .931 \\
\hline $\mathbf{2 0 1 6}$ & 215.809 & 3.425 .973 \\
\hline $\mathbf{2 0 1 7}$ & 226.512 & 3.595 .878 \\
\hline $\mathbf{2 0 1 8}$ & 237.332 & 3.767 .646 \\
\hline $\mathbf{2 0 1 9}$ & 248.272 & 3.941 .318 \\
\hline $\mathbf{2 0 2 0}$ & 259.332 & 4.116 .896 \\
\hline $\mathbf{2 0 2 1}$ & 270.513 & 4.294 .399 \\
\hline $\mathbf{2 0 2 2}$ & 281.817 & 4.473 .850 \\
\hline $\mathbf{2 0 2 3}$ & 293.247 & 4.655 .291 \\
\hline $\mathbf{2 0 2 4}$ & 304.801 & 4.838 .721 \\
\hline
\end{tabular}

Elaboración propia 


\subsubsection{Presupuesto operativo de costos}

En la tabla 7.23 se muestra el presupuesto operativo de los costos de producción:

Tabla 7.23

Presupuesto operativo de los costos de producción(S/.)

\begin{tabular}{|c|c|c|c|c|c|c|c|c|c|c|}
\hline Rubro & 2015 & 2016 & 2017 & 2018 & 2019 & 2020 & 2021 & 2022 & 2023 & 2024 \\
\hline Materia Prima & 342.557 & 359.700 & 376.843 & 393.986 & 411.129 & 428.272 & 445.415 & 462.558 & 479.701 & 496.844 \\
\hline Azúcar & 61.182 & 64.244 & 67.306 & 70.368 & 73.430 & 76.492 & 79.553 & 82.615 & 85.677 & 88.739 \\
\hline Bisulfito & 2,75 & 2,89 & 3,03 & 3,17 & 3,30 & 3,44 & 3,58 & 3,72 & 3,86 & 3,99 \\
\hline Levaduras & 2.065 & 2.168 & 2.272 & 2.375 & 2.478 & 2.582 & 2.685 & 2.788 & 2.892 & 2.995 \\
\hline Botellas & 367.095 & 385.466 & 403.837 & 422.208 & 440.579 & 458.950 & 477.321 & 495.692 & 514.063 & 532.434 \\
\hline Tapas & 20.394 & 21.415 & 22.435 & 23.456 & 24.477 & 25.497 & 26.518 & 27.538 & 28.559 & 29.580 \\
\hline Cápsulas & 50.985 & 53.537 & 56.088 & 58.640 & 61.191 & 63.743 & 66.295 & 68.846 & 71.398 & 73.949 \\
\hline Etiquetas & 71.380 & 74.952 & 78.524 & 82.096 & 85.668 & 89.240 & 92.812 & 96.385 & 99.957 & 103.529 \\
\hline Cajas & 6.798 & 7.138 & 7.478 & 7.819 & 8.159 & 8.499 & 8.839 & 9.179 & 9.520 & 9.860 \\
\hline Agua & 1.222 & 1.283 & 1.344 & 1.406 & 1.467 & 1.528 & 1.589 & 1.650 & 1.711 & 1.773 \\
\hline Energía & 7.793 & 7.793 & 8.573 & 8.963 & 9.353 & 9.743 & 10.133 & 10.523 & 10.913 & 11.303 \\
\hline Mano de Obra & 466.320 & 466.320 & 466.320 & 466.320 & 466.320 & 466.320 & 466.320 & 466.320 & 466.320 & 466.320 \\
\hline Otros & $2.000,00$ & $2.000,00$ & $2.000,00$ & $2.000,00$ & $2.000,00$ & $2.000,00$ & $2.000,00$ & $2.000,00$ & $2.000,00$ & $2.000,00$ \\
\hline $\begin{array}{l}\text { Costo de } \\
\text { Producción }\end{array}$ & 1.399 .794 & 1.446 .019 & 1.493 .024 & 1.539 .639 & 1.586 .254 & 1.632 .869 & 1.679 .484 & 1.726 .099 & 1.772 .714 & 1.819 .329 \\
\hline Depreciación Fabril & 52.363 & 52.363 & 52.363 & 52.363 & 52.363 & 52.363 & 52.363 & 52.363 & 52.363 & 52.363 \\
\hline Total costo de Prod. & 1.452.157 & 1.498 .382 & 1.545 .387 & 1.592 .002 & 1.638 .617 & 1.685 .232 & 1.731.847 & 1.778 .462 & 1.825.077 & 1.871 .692 \\
\hline
\end{tabular}

Elaboración propia 
En la tabla 7.24 se puede apreciar la depreciación anual de los activos intangibles.

Tabla 7.24

Depreciación de activos tangibles anualizada (S/.)

\begin{tabular}{|c|c|c|c|c|c|c|c|c|c|c|c|c|}
\hline Rubro & Importe & Deprec. & 2015 & 2016 & 2017 & 2018 & 2019 & 2020 & 2021 & 2022 & 2023 & 2024 \\
\hline Terreno & 276.480 & & $y-$ & - & -8 & $0=$ & - & & - & - & - & - \\
\hline $\begin{array}{c}\text { Edificaciones } \\
\text { en planta }\end{array}$ & 264.000 & $10 \%$ & 26.400 & 26.400 & 26.400 & 26.400 & 26.400 & 26.400 & 26.400 & 26.400 & 26.400 & 26.400 \\
\hline $\begin{array}{c}\text { Maquinarias y } \\
\text { Equipos }\end{array}$ & 179.630 & $10 \%$ & 17.963 & 17.963 & 17.963 & 17.963 & 17.963 & 17.963 & 17.963 & 17.963 & 17.963 & 17.963 \\
\hline $\begin{array}{c}\text { Instalación al } \\
\text { detalle }\end{array}$ & 80.000 & $10 \%$ & 8.000 & 8.000 & 8.000 & 8.000 & 8.000 & 8.000 & 8.000 & 8.000 & 8.000 & 8.000 \\
\hline $\begin{array}{l}\text { Equipos de } \\
\text { cómputo y } \\
\text { mobiliario }\end{array}$ & 16.400 & $10 \%$ & 1.640 & 1.640 & 1.640 & 1.640 & 1.640 & 1.640 & 1.640 & 1.640 & 1.640 & 1.640 \\
\hline & & Dep.fabril & 52.363 & 53.363 & 53.363 & 53.363 & 53.363 & 53.363 & 53.363 & 53.363 & 53.363 & 53.363 \\
\hline & & $\begin{array}{c}\text { Dep. no } \\
\text { fabril }\end{array}$ & 1.640 & 1.640 & 1.640 & 1.640 & 1.640 & 1.640 & 1.640 & 1.640 & 1.640 & 1.640 \\
\hline
\end{tabular}

Elaboración propia

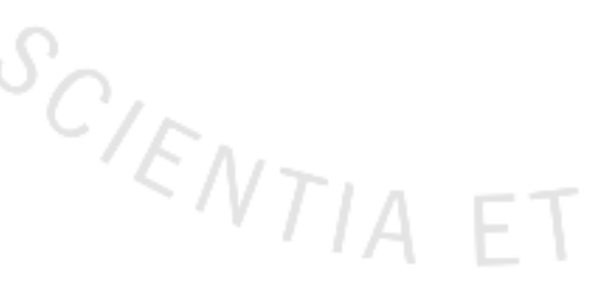




\subsubsection{Presupuesto operativo de gastos administrativos}

En la tabla 7.25 se puede apreciar los presupuestos de los gastos generales anualmente:

\section{Tabla 7.25}

Presupuestos de gastos generales(S/.)

\begin{tabular}{|c|c|c|c|c|c|c|c|c|c|c|}
\hline Rubro & 2015 & 2016 & 2017 & 2018 & 2019 & 2020 & 2021 & 2022 & 2023 & 2024 \\
\hline Sueldos administrativos & 590.136 & 590.136 & 590.136 & 590.136 & 590.136 & 590.136 & 590.136 & 590.136 & 590.136 & 590.136 \\
\hline $\begin{array}{l}\text { Servicio de energía } \\
\text { eléctrica }\end{array}$ & 1.200 & 1.200 & 1.200 & 1.200 & 1.200 & 1.200 & 1.200 & 1.200 & 1.200 & 1.200 \\
\hline Costos de servicio & 43.200 & 43.200 & 43.200 & 43.200 & 43.200 & 43.200 & 43.200 & 43.200 & 43.200 & 43.200 \\
\hline Depreciación no fabril & 1.640 & 1.640 & 1.640 & 1.640 & 1.640 & 1.640 & 1.640 & 1.640 & 1.640 & 1.640 \\
\hline Amortización Intang. & 5.600 & 5.600 & 5.600 & 5.600 & 5.600 & 5.600 & 5.600 & 5.600 & 5.600 & 5.600 \\
\hline Gastos Generales & 641.776 & 641.776 & 641.776 & 641.776 & 641.776 & 641.776 & 641.776 & 641.776 & 641.776 & 641.776 \\
\hline
\end{tabular}

Elaboración propia 
En la tabla 7.26 se puede apreciar la amortización de activos intangibles anualmente.

Tabla 7.26

Amortización de activos intangibles(S/.)

\begin{tabular}{|c|c|c|c|c|c|c|c|c|c|c|c|c|}
\hline Rubro & Importe & Depr. & 2015 & 2016 & 2017 & 2018 & 2019 & 2020 & 2021 & 2022 & 2023 & 2024 \\
\hline $\begin{array}{l}\text { Estudios y } \\
\text { proyectos de } \\
\text { ingeniería }\end{array}$ & 20.000 & $10 \%$ & 2.000 & 2.000 & 2.000 & 2.000 & 2.000 & 2.000 & 2.000 & 2.000 & 2.000 & 2.000 \\
\hline $\begin{array}{l}\text { Constitución de la } \\
\text { empresa }\end{array}$ & 2.000 & $10 \%$ & 200 & 200 & 200 & 200 & 200 & 200 & 200 & 200 & 200 & 200 \\
\hline $\begin{array}{l}\text { Gastos de } \\
\text { capacitación }\end{array}$ & 2.500 & $10 \%$ & 250 & 250 & 250 & 250 & 250 & 250 & 250 & 250 & 250 & 250 \\
\hline Gestiones de marca & 1.500 & $10 \%$ & 150 & 150 & 150 & 150 & 150 & 150 & 150 & 150 & 150 & 150 \\
\hline Publicidad & 10.000 & $10 \%$ & 1.000 & 1.000 & 1.000 & 1.000 & 1.000 & 1.000 & 1.000 & 1.000 & 1.000 & 1.000 \\
\hline Puesta en marcha & 15.000 & $10 \%$ & 1.500 & 1.500 & 1.500 & 1.500 & 1.500 & 1.500 & 1.500 & 1.500 & 1.500 & 1.500 \\
\hline Imprevistos & 5.000 & $10 \%$ & 500 & 500 & 500 & 500 & 500 & 500 & 500 & 500 & 500 & 500 \\
\hline Total & 56.000 & $7 x$ & 5.600 & 5.600 & 5.600 & 5.600 & 5.600 & 5.600 & 5.600 & 5.600 & 5.600 & 5.600 \\
\hline
\end{tabular}

Elaboración propia 


\section{Préstamo bancario}

La deuda se pagará en cuotas constantes, con periodo de gracia parcial, a una tasa de interés anual de 13\%. En la tabla 7.27 se puede apreciar el servicio de la deuda:

\section{Tabla 7.27}

Servicio de la deuda(S/.)

\begin{tabular}{|c|c|c|c|c|c|}
\hline Año & Deuda & Amortización & Intereses & Cuota & Saldo \\
\hline $\mathbf{0}$ & 891.357 & - & 115.876 & 115.876 & 891.357 \\
\hline $\mathbf{1}$ & 891.357 & 137.549 & 115.876 & 253.426 & 753.808 \\
\hline $\mathbf{2}$ & 753.808 & 155.431 & 97.995 & 253.426 & 598.377 \\
\hline $\mathbf{3}$ & 598.377 & 175.637 & 77.789 & 253.426 & 422.740 \\
\hline $\mathbf{4}$ & 422.740 & 198.470 & 54.956 & 253.426 & 224.271 \\
\hline $\mathbf{5}$ & 224.271 & 224.271 & 29.155 & 253.426 & - \\
\hline
\end{tabular}

Elaboración propia 


\subsection{Flujo de fondos netos}

\subsubsection{Flujo de fondos económicos}

\section{Tabla 7.28}

\section{Flujo de fondos económico (S/.)}

\begin{tabular}{|c|c|c|c|c|c|c|c|c|c|c|c|}
\hline Rubro & $\mathbf{0}$ & 1 & 2 & 3 & 4 & 5 & 6 & 7 & 8 & 9 & 10 \\
\hline Inversión total & $(1.485 .596)$ & $=1$ & & & & & & & & & \\
\hline Ingresos & & 3.257 .931 & 3.425 .973 & 3.595 .878 & 3.767 .646 & 3.941 .318 & 4.116.896 & 4.294.399 & 4.473 .850 & 4.655.291 & 4.838 .721 \\
\hline C Prod. & f & 1.452 .157 & 1.498 .382 & 1.545 .387 & 1.592 .002 & 1.638 .617 & 1.685 .232 & 1.731 .847 & 1.778 .462 & 1.825 .077 & 1.871 .692 \\
\hline U. Bruta & & 1.805 .774 & 1.927 .591 & 2.050 .491 & 2.175 .644 & 2.302 .701 & 2.431 .664 & 2.562 .552 & 2.695 .388 & 2.830 .214 & 2.967 .029 \\
\hline G. Generales & & 641.776 & 641.776 & 641.776 & 641.776 & 641.776 & 641.776 & 641.776 & 641.776 & 641.776 & 641.776 \\
\hline G. Financieros & & 115.876 & 97.995 & 77.789 & 54.956 & 29.155 & - & - & - & - & - \\
\hline$U$ ant $P$ e $I$ & & 1.048 .121 & 1.187 .820 & 1.330 .926 & 1.478 .911 & 1.631 .770 & 1.789 .888 & 1.920 .776 & 2.053.612 & 2.188 .438 & 2.325 .253 \\
\hline IR & & 314.436 & 356.346 & 399.278 & 443.673 & 489.531 & 536.966 & 576.233 & 616.084 & 656.531 & 697.576 \\
\hline ISC & & 286.793 & 301.145 & 315.497 & 329.850 & 344.202 & 358.554 & 372.907 & 387.259 & 401.612 & 415.964 \\
\hline $\begin{array}{l}\text { UtiL. antes de la } \\
\text { R.L. }\end{array}$ & & 446.892 & 530.329 & 616.151 & 705.388 & 798.037 & 894.367 & 971.637 & 1.050 .269 & 1.130 .295 & 1.211 .713 \\
\hline Amort intang & & 5.600 & 5.600 & 5.600 & 5.600 & 5.600 & 5.600 & 5.600 & 5.600 & 5.600 & 5.600 \\
\hline Dep fabril & & 52.363 & 52.363 & 52.363 & 52.363 & 52.363 & 52.363 & 52.363 & 52.363 & 52.363 & 52.363 \\
\hline Dep no fabril & & 1.640 & 1.640 & 1.640 & 1.640 & 1.640 & 1.640 & 1.640 & 1.640 & 1.640 & 1.640 \\
\hline G. Financieros(1-t) & & 81.114 & 68.597 & 54.452 & 38.469 & 20.409 & & - & - & - & - \\
\hline Flujo Económico & (1.485.596) & 587.609 & 658.528 & 730.206 & 803.460 & 878.048 & 953.970 & 1.031 .240 & 1.109 .872 & 1.189 .898 & 1.271 .316 \\
\hline
\end{tabular}

Elaboración propia 


\subsubsection{Flujo de fondos financieros}

\section{Tabla 7.29}

\section{Flujo de fondos financiero (S/.)}

\begin{tabular}{|c|c|c|c|c|c|c|c|c|c|c|c|}
\hline Rubro & $\mathbf{0}$ & 1 & 2 & 3 & 4 & 5 & 6 & 7 & 8 & 9 & 10 \\
\hline Aporte propio & $(594.238)$ & & & & & & & & & & \\
\hline Ingresos & & 3.257 .931 & 3.425 .973 & 3.595 .878 & 3.767 .646 & 3.941 .318 & 4.116 .896 & 4.294.399 & 4.473 .850 & 4.655.291 & 4.838.721 \\
\hline C Prod. & & 1.452 .157 & 1.498 .382 & 1.545 .387 & 1.592 .002 & 1.638 .617 & 1.685 .232 & 1.731 .847 & 1.778 .462 & 1.825 .077 & 1.871 .692 \\
\hline U. Bruta & & 1.805 .774 & 1.927 .591 & 2.050 .491 & 2.175 .644 & 2.302 .701 & 2.431 .664 & 2.562 .552 & 2.695 .388 & 2.830 .214 & 2.967 .029 \\
\hline G. Generales & & 641.776 & 641.776 & 641.776 & 641.776 & 641.776 & 641.776 & 641.776 & 641.776 & 641.776 & 641.776 \\
\hline G. Financieros & & 115.876 & 97.995 & 77.789 & 54.956 & 29.155 & - & - & - & - & - \\
\hline $\mathrm{U}$ ant $\mathrm{P}$ e $\mathrm{I}$ & & 1.048 .121 & 1.187 .820 & 1.330 .926 & 1.478 .911 & 1.631 .770 & 1.789 .888 & 1.920 .776 & 2.053 .612 & 2.188 .438 & 2.325 .253 \\
\hline IR & & 314.436 & 356.346 & 399.278 & 443.673 & 489.531 & 536.966 & 576.233 & 616.084 & 656.531 & 697.576 \\
\hline ISC & & 286.793 & 301.145 & 315.497 & 329.850 & 344.202 & 358.554 & 372.907 & 387.259 & 401.612 & 415.964 \\
\hline $\begin{array}{l}\text { Util. antes de } \\
\text { R.L. }\end{array}$ & & 446.892 & 530.329 & 616.151 & 705.388 & 798.037 & 894.367 & 971.637 & 1.050 .269 & 1.130 .295 & 1.211 .713 \\
\hline Amort intang & & 5.600 & 5.600 & 5.600 & 5.600 & 5.600 & 5.600 & 5.600 & 5.600 & 5.600 & 5.600 \\
\hline Dep fabril & & 52.363 & 52.363 & 52.363 & 52.363 & 52.363 & 52.363 & 52.363 & 52.363 & 52.363 & 52.363 \\
\hline Dep no fabril & & 1.640 & 1.640 & 1.640 & 1.640 & 1.640 & 1.640 & 1.640 & 1.640 & 1.640 & 1.640 \\
\hline Amort. Prést. & & $137.549^{-}$ & $155.431^{-}$ & $175.637^{-}$ & $198.470^{-}$ & $224.271^{-}$ & & & & & \\
\hline $\begin{array}{l}\text { Flujo } \\
\text { Financiero } \\
\end{array}$ & (594.238) & 368.946 & 434.501 & 500.117 & 566.521 & 633.369 & 953.970 & 1.031.240 & $\mathbf{1 . 1 0 9 . 8 7 2}$ & $\mathbf{1 . 1 8 9 . 8 9 8}$ & 1.271.316 \\
\hline
\end{tabular}

Elaboración propia 


\section{CAPÍTULO VIII: EVALUACIÓN ECONÓMICA Y FINANCIERA DEL PROYECTO}

\subsection{Evaluación económica: VAN, TIR, B/C, PR}

Se identifican los méritos intrínsecos de un proyecto, sin considerar las formas en que se paga los recursos financieros del proyecto.

Por ello, en esta evaluación se asume que todo el capital viene de manos de los accionistas, se evalúa bajo el costo de oportunidad de los accionistas (COK), que se determinará utilizando la metodología CAMP (Modelo de fijación de precios de activos de capital), El COK de un proyecto tiene la siguiente fórmula:

$$
C O K=r f+\beta *(r m-r f)+r p
$$

- $r f=$ tasa de libre riesgo

- $\beta=$ sensibilidad del mercado

- $r m-r f=$ prima por riesgo de mercado

- $r p=$ riesgo país

Resolviendo la ecuación con los datos obtenidos de Damodaran, se obtiene:

$$
\mathrm{COK}=6.84 \%+1.1 \% *(11.61 \%-6.84 \%)+2.88 \%=15 \%
$$

Así, la ecuación muestra los valores aproximados de cada uno de los factores de estimación, lo cual resulta en una tasa de descuento equivalente a $15 \%$. 
Tabla 8.1

\section{Evaluación económica}

\begin{tabular}{|l|r|}
\hline VANE & 2.714 .780 \\
\hline Relación B / C = & 2,80 \\
\hline TIRE & $47,82 \%$ \\
\hline Periodo de recupero & 2,9 años \\
\hline
\end{tabular}

Elaboración propia

\subsection{Evaluación financiera: VAN, TIR, B/C, PR}

Examina el proyecto bajo la óptica del accionista y su capital propio, independizándose de otras fuentes de financiamiento, se considera el financiamiento externo como flujos del proyecto, incluyendo los préstamos bancarios y por lo tanto, pago de intereses y amortizaciones. Este flujo se evalúa con el Costo promedio ponderado de capital (CPPC) y expresa la rentabilidad real del proyecto, para su evaluación se considera la siguiente tasa de descuento.

Tabla 8.2

Cálculo del CPPC

\begin{tabular}{|c|c|c|c|c|}
\hline Rubro & Importe & \%participación & Tasa & CPPC \\
\hline Accionistas & 594.238 & $40 \%$ & $15 \%$ & $6,0 \%$ \\
\hline Préstamo & 891.357 & $60 \%$ & $13 \%$ & $7,8 \%$ \\
\hline Total & 1.485 .596 & $100 \%$ & & $13,8 \%$ \\
\hline
\end{tabular}

Elaboración propia

Tabla 8.3

\section{Evaluación financiera}

\begin{tabular}{|l|c|}
\hline VANF $=$ & 2.838 .192 \\
\hline Relación B / C = & 5,7 \\
\hline TIRF & $78 \%$ \\
\hline Periodo de recupero & 1,8 años \\
\hline
\end{tabular}

Elaboración propia 


\subsection{Análisis de los resultados económicos y financieros del proyecto}

El proyecto tiene un valor actual neto positivo y alto, por lo tanto es factible, esto también se ve reflejado en el TIR Económica que es mayor que el COK y en la TIR Financiera que es mayor que el CPPC.

La relación beneficio costo es mayor a 1, lo cual es un buen indicador; con respecto al periodo de recupero, estos durarán en promedio no más de 3 años, tiempo sumamente aceptable considerando que el proyecto tiene una vida útil de 10 años.

\subsection{Análisis de sensibilidad del proyecto}

El análisis de sensibilidad muestra los cambios que ocurren cuando varían algunas de las variables involucradas en el proyecto, para el análisis se ha considerado la variación del precio venta en $+/$ - $10 \%$ y la variación de la demanda en $+/-10 \%$, cifra escogida teniendo en cuenta que el promedio de la variación de la demanda histórica del vino es de $10 \%$. A continuación se presentará el análisis cuando hay una variación en el precio:

- $\quad$ Cuando el precio baja $10 \%$, de S/.15,87 a S/.14,30 se obtienen los siguientes resultados:

\section{Tabla 8.4}

Evaluación económica cuando el precio baja

\begin{tabular}{|l|c|}
\hline VANE & 2.179 .583 \\
\hline Relación B / C = & 1,846 \\
\hline TIRE & $30,38 \%$ \\
\hline Periodo de recupero & 5,11 años \\
\hline
\end{tabular}

Elaboración propia 
Tabla 8.5

Evaluación financiera cuando el precio baja

\begin{tabular}{|l|c|}
\hline VANF $=$ & 2.295 .375 \\
\hline Relación B / C = & 3,323 \\
\hline TIRF & $42,18 \%$ \\
\hline Periodo de recupero & 5,15 años \\
\hline
\end{tabular}

Elaboración propia

Se observa que al bajar el precio del producto en un $10 \%$ los indicadores se ven ligeramente afectados, sin embargo todavía son buenos lo cual indica que se puede llevar a cabo el proyecto.

- Cuando el precio sube $10 \%$, de S/.14 a S/.17,5 se obtienen los siguientes resultados:

Tabla 8.6

Evaluación económica cuando el precio sube

\begin{tabular}{|l|c|}
\hline VANE & 3.199 .714 \\
\hline Relación B / C = & 3,798 \\
\hline TIRE & $62,78 \%$ \\
\hline Periodo de recupero & 2,19 años \\
\hline
\end{tabular}

Elaboración propia

\section{Tabla 8.7}

Evaluación financiera cuando el precio sube

\begin{tabular}{|l|c|}
\hline VANF $=$ & 3.215 .507 \\
\hline Relación B / C = & 8,202 \\
\hline TIRF & $101,75 \%$ \\
\hline Periodo de recupero & 1,22 años \\
\hline
\end{tabular}

Elaboración propia 
Cuando hay un aumento en el precio los indicadores también suben, sin embargo al ser este un producto nuevo no se podría subir el precio constantemente, a menos que suba el precio de los licores en todo el mercado.

A continuación se presentará el análisis cuando hay una variación en la demanda:

- Cuando la demanda baja 10\%, se obtienen los siguientes resultados:

Tabla 8.8

Evaluación económica cuando la demanda baja

\begin{tabular}{|l|c|}
\hline VANE & 2.168 .957 \\
\hline Relación B / C = & 1,83 \\
\hline TIRE & $30,25 \%$ \\
\hline Periodo de recupero & 5,13 años \\
\hline
\end{tabular}

Elaboración propia

\section{Tabla 8.9}

\section{Evaluación financiera cuando la demanda baja}

\begin{tabular}{|l|c|}
\hline VANF $=$ & 2.284 .750 \\
\hline Relación B / C = & 3,304 \\
\hline TIRF & $41,94 \%$ \\
\hline Periodo de recupero & 5,21 años \\
\hline
\end{tabular}

Elaboración propia

Con una ligera caída de la demanda, el proyecto todavía sería muy factible como se observa en los indicadores.

- Cuando la demanda sube $10 \%$, se obtienen los siguientes resultados: 
Tabla 8.10

Evaluación económica cuando la demanda sube

\begin{tabular}{|l|c|}
\hline VANE & 3.167 .838 \\
\hline Relación B / C = & 3,775 \\
\hline TIRE & $62,41 \%$ \\
\hline Periodo de recupero & 2,206 años \\
\hline
\end{tabular}

Elaboración propia

\section{Tabla 8.11}

\section{Evaluación financiera cuando la demanda sube}

\begin{tabular}{|l|c|}
\hline VANF = & 3.383 .630 \\
\hline Relación B / C = & 8,145 \\
\hline TIRF & $109,88 \%$ \\
\hline Periodo de recupero & 1,23 años \\
\hline
\end{tabular}

Elaboración propia

Un aumento en la demanda sería beneficioso para el proyecto y se recuperaría la inversión en menor tiempo; sin embargo, si este aumento es muy alto se tendría que considerar un aumento en la capacidad de la planta. 


\section{CAPÍTULO IX: EVALUACIÓN SOCIAL DEL PROYECTO}

\subsection{Identificación de las zonas y comunidades de influencia del proyecto}

La evaluación social nos permite medir el verdadero impacto en el crecimiento económico de la región. Esta evaluación es de suma importancia para los socios puesto que sirve para mejorar el impacto social del producto que se genera en este proyecto.

Además de la rentabilidad que se puede observar en la evaluación económica y financiera, este también ofrece beneficios a todas las personas involucradas en el proceso productivo, desde proveedores hasta el consumidor final.

En concreto, el proyecto beneficiará al distrito de San Vicente de Cañete, ya que la planta operará en dicha zona y también a los distritos de Lima Moderna al comercializar en este lugar los productos.

\subsection{Impacto en la zona de influencia del proyecto}

La demanda considerada en el proyecto de aproximadamente 200.000 litros de licor por año, generará 30 puestos de trabajo directo; sin embargo, la cantidad de personas beneficiadas es mucho más grande si se toman en cuenta los empleos indirectos necesarios para el funcionamiento de la empresa.

\subsection{Impacto social del proyecto}

El pago de impuestos al Estado, para su posterior administración por parte de este, es uno de los principales impactos sociales del proyecto. 
Adicionalmente, en los empleos directos e indirectos saldrán beneficiadas las familias de los empleados, lo cual les dará una mejor calidad de vida y podrán tener un ingreso seguro.

Por último los consumidores finales saldrán beneficiados al tener otra alternativa cuando deseen consumir licor, así sus opciones serán más amplias.

\section{Definición e interpretación de indicadores sociales}

Estos indicadores muestran la evaluación social económica que genera un proyecto al país. Un proyecto rentable debe poder generar beneficio a la comunidad. 
De la siguiente tabla se obtendrán los indicadores a analizar:

\section{Tabla 9.1}

Items para la evaluación social

\begin{tabular}{|c|c|c|c|c|c|c|c|c|c|c|}
\hline Items & 1 & 2 & 3 & 4 & 5 & 6 & 7 & 8 & 9 & 10 \\
\hline Sueldos y salarios & 1.056 .456 & 1.056 .456 & 1.056 .456 & 1.056 .456 & 1.056 .456 & 1.056 .456 & 1.056 .456 & 1.056 .456 & 1.056 .456 & 1.056 .456 \\
\hline Depreciación & 52.363 & 52.363 & 52.363 & 52.363 & 52.363 & 52.363 & 52.363 & 52.363 & 52.363 & 52.363 \\
\hline Gastos financieros & 115.876 & 97.995 & 77.789 & 54.956 & 29.155 & 0 & 0 & $\ldots$ & 0 & 0 \\
\hline $\begin{array}{l}\text { Renta neta antes } \\
\text { de IR }\end{array}$ & 1.048 .121 & 1.187 .820 & 1.330 .926 & 1.478 .911 & 1.631 .770 & 1.789 .888 & 1.920 .776 & 2.053 .612 & 2.188 .438 & 2.325 .253 \\
\hline Valor agregado & 2.272 .817 & 2.394 .634 & 2.517 .534 & 2.642 .687 & 2.769 .744 & 2.898 .707 & 3.029 .595 & 3.162 .431 & 3.297 .257 & 3.434 .072 \\
\hline $\begin{array}{l}\text { Valor agregado } \\
\text { actual al } 15 \%\end{array}$ & 1.976 .363 & 1.810 .687 & 1.655 .319 & 1.363 .068 & 1.377 .052 & 1.253 .191 & 1.138 .937 & 1.033 .804 & 937.286 & 848.850 \\
\hline $\begin{array}{l}\text { Valor agreg. } \\
\text { acum. }\end{array}$ & 1.976 .363 & 3.787 .050 & 5.442 .369 & 6.805 .438 & 8.182 .490 & 9.435 .681 & 10.574 .618 & 11.608.422 & 12.545.709 & 13.394.559 \\
\hline
\end{tabular}

Elaboración propia

Inversión total: S/. 1.485.596 


\section{- Relación Producto Capital}

Mide la relación entre el valor agregado del proyecto versus el monto de la inversión total.

Relación producto capital $=\frac{\text { Valor agregado } \text { acum. }}{\text { Inversión total }}=\frac{13.394 .559}{1.485 .596}=9.01$

- Densidad de capital

Es la relación entre la inversión versus el empleo generado, indica la cantidad de dinero invertido para generar un empleo.

Densidad de capital $=\frac{\text { Inversión total }}{\mathrm{N}^{\circ} \text { de empleos }}=\frac{1.485 .596}{30}=49.519 \mathrm{~S} /$. $/$ hab.- año

- Intensidad de capital

Nos muestra la relación de la inversión total versus el valor agregado del proyecto, nos permite medir cual es el grado de aporte del proyecto a través del nivel de la inversión, para generar valor agregado sobre los insumos.

Intensidad de capital $=\frac{\text { Inversión total }}{\text { Valor agregado acum. }}=\frac{1.485 .596}{13.394 .559}=0.11$ 


\section{CONCLUSIONES}

A continuación detallaremos las conclusiones a las que hemos llegado a partir de nuestra investigación:

- El incremento del poder adquisitivo del consumidor, así como un mayor conocimiento de la gastronomía, han propiciado un aumento en el número de empresas comercializadoras de bebidas alcohólicas hechas en base a frutas.

- Lima Metropolitana representa el mayor mercado de bebidas alcohólicas del Perú, con un gran potencial para el desarrollo de todo tipo de licores,

- Lima Metropolitana es un mercado en donde la población está dispuesta a pagar un buen precio por adquirir un producto de calidad que satisfaga sus necesidades.

- El proyecto absorberá una demanda máxima de 295.797 botellas de licor de 750 ml. para el año 2024.

- Luego del análisis de los factores de macrolocalización y microlocalización se determinó que el mejor lugar para instalar la planta es el distrito de San Vicente de Cañete, provincia de Cañete, departamento de Lima.

- El tamaño de planta estará determinado por el tamaño del mercado: $42 \mathrm{~L} / \mathrm{h}$. trabajando dos turnos diarios, en este caso el tamaño de la planta no debería ser mucho mayor a lo que el mercado está dispuesto a adquirir, porque se generaría una capacidad ociosa.

- El área de la planta será de $720 \mathrm{~m}^{2}$, en donde están comprendidas la zona de producción, almacenes, mantenimiento, calidad, $\mathrm{SSHH}$, zonas administrativas y patio de maniobras.

- Se contará con un plan de calidad, mantenimiento, salud y seguridad laboral.

- El lapso de tiempo para poner en marcha el proyecto será un año, incluyendo desde el estudio de prefactibilidad hasta las pruebas finales.

- El proyecto será una sociedad económica cerrada, debido a que estará formada por un solo socio, el capital a aportar será pequeño y en casos de alguna contingencia nuestros bienes personales no correrían riesgo.

- El proyecto contará con un Gerente General que desempeñará las funciones de Gerente de Operaciones a la vez, debido a que al ser una empresa pequeña le resultará manejable cumplir con ambas labores. 
- Como toda organización, el presente proyecto se adecuará a las normas peruanas pertinentes, que permitan un buen funcionamiento de la misma, así como el bienestar de sus colaboradores.

- La inversión total es de S/. 1.485.596, conformada por un aporte del bancario del $60 \%$ la inversión (S/. 891.358 nuevos soles) y el aporte de los socios de $40 \%$ (S/. $594.238)$.

- El proyecto es viable, el VAN es mayor a la inversión inicial, la tasa interna de retorno de la inversión se encuentra mayor a cualquier otro negocio que podrían invertir los socios.

- El periodo de recupero es menor a tres años y el beneficio/costo es mayor a uno, indicadores muy auspiciosos para el proyecto.

- El proyecto beneficiará a gran parte de la comunidad principalmente a través del pago de impuestos y generación de puestos de trabajo. 


\section{RECOMENDACIONES}

A continuación detallaremos nuestras recomendaciones:

- Invertir en el negocio, siendo que el concepto de producto sustituto al vino es importante para diversificar la cartera de bebidas alcohólicas.

- Lanzar el producto en otras presentaciones que vayan acorde a las necesidades de cada tipo de cliente.

- En el mediano plazo lanzar al mercado bebidas alcohólicas elaboradas a base de otras frutas cosechadas en el país.

- Analizar la posibilidad de realizar una integración hacia atrás, es decir comprar hectáreas de terreno en donde poder cosechar higo y otros frutos. 


\section{REFERENCIAS}

Alca Maquindustrias (agosto, 2013). Tanque fermentador. Recuperado de http://www.corkperu.com/maquinariasprincipal/index.html\#

Alibaba. (marzo, 2015). Etiquetadora manual DLPK. Recuperado de http://spanish.alibaba.com/p-detail/Econ\%C3\%B3mico-simple-Manual-pr\% C3\%A1ctico-de-la-botella-redonda-m\%C3\%A1quina-de-etiquetado300000219995. html

Alibaba. (marzo, 2015). Mesa de selección. Recuperado de http://spanish.alibaba.com/product-gs/stainless-steel-work-table-forworkshop-540818451.html

Alibaba. (agosto, 2015). Pistola de aire caliente. Recuperado de http://es.aliexpress.com/category/204003503/heatgun.html?spm=2114.10010 408.100004.6.2xRTji

Ángeles, I.(noviembre, 2012). Estudio cuantitativo para conocer el perfil del consumidor de vino de Lima Metropolitana. Recuperado de https://prezi.com/bfbx_i31no4i/estudio-cuantitativo-para-conocer-el-perfildel-consumidor-de-vinos-de-lima-metropolitana/

Aqua Pureza Perú. (enero, 2015). Filtros y sistemas purificadores de agua. Recuperado de http://www.aguapureza.pe/osmosis-inversa-en-peru-100gpd/

Ausavil. (febrero, 2014). Filtro de 12 placas. Recuperado de http://www.ausavil.com/web/productos.php?lan=es\&product=pstagnLzyIG

Chue, A. (2011). Estudio de prefactibilidad para la implementación de una planta productora de sidra a partir de manzana delicia (Pyrus Malus D) (Tesis para optar el título de Ingeniero Industrial) Universidad de Lima.

Citalsa Perú. (enero, 2015). Lavadora por inmersión. Recuperado de http://www.citalsa.com/ciproducts/5/338\#firstproduct

Enotecnica Pillan. (setiembre, 2015). Llenadora de botellas. Recuperado de http://www.enotecnicapillan.it/index.php?option=com_zoo\&view=category\& layout=category $\&$ Itemid $=186 \&$ lang $=$ it

Euromonitor Internacional. (julio, 2013). Bebidas alcohólicas: Vino en Perú. Recuperado de http://www.portal.euromonitor.com/portal/analysis/tab 
Google maps. (agosto, 2014). Ubicación geográfica. Recuperado de https://www.google.com.pe/maps?ion=1\&espv=2\&q=google+maps\&bav=on. 2,or.r_cp. $\&$ biw $=752 \& b i h=582 \& d p r=1 \& u m=1 \& i e=u t f-8 \& s a=x \& v e d=0$ ahuke wj-_jxz-r7kahud6yykhqckdxuq_auibigb

Instituto Nacional de Estadística e Informática. (julio, 2014). Sistema de indicadores demográficos, sociales y económicos a nivel distrital. Recuperado de http://www.inei.gob.pe/inicio.htm

JPM industrias. (julio, 2013). Licuadora industrial. Recuperado de http://jpm-industrias.blogspot.pe/p/licuadora-industrial-4-velocidades.html

Jurado Nacional de Elecciones (junio, 2010). Mapa de Lima. Recuperado de http://portal.jne.gob.pe/procesoselectorales/Informacion\%20Electoral/Inscrip cion_listas/mapas/LIMA.jpg

Kolb, E. (2002). Vinos de frutas: elaboración artesanal e industrial. (3a ed.). Zaragoza: Acribia.

M-MAQ fabricantes. (agosto, 2013). Llenadora de 2 válvulas. Recuperado de http://mgbottlingsac.com/g-2-llenadora-por-gravedad/

M-MAQ fabricantes (agosto, 2013). Tapadora manual Recuperado de http://mgbottlingsac.com/encorchadora-manual/

Ministerio de la Producción. (abril, 2014). Anuario Estadístico Industrial, Mipyme y $\begin{array}{llll}\text { Comercio } & \text { Interno } & 2013 . & \text { Recuperado de }\end{array}$ http://www.produce.gob.pe/images/stories/Repositorio/estadistica/anuario/a nuario-estadistico-mype-2013.pdf

Ministerio de Transporte y Comunicaciones. (abril, 2012). Plan estratégico sectorial multianual sector transportes y comunicaciones 2012-2016. Recuperado de http://www.mtc.gob.pe/portaL/home/transparencia/PESEM.pdf

Oficina Económica y Comercial de la Embajada de España en Lima. (setiembre, 2013) El mercado de vino en Perú. Recuperado de http://www3.icex.es/icex/cma/contentTypes/common/records/mostrarDocu mento/?doc $=4705049$

Perú 21. (2013). Peruanos beben 8,1 litros de licor al año. Recuperado de http://peru21.pe/opinion/peruanos-beben-81-litros-licor-al-ano-2183012

SUNAT. (12 de setiembre de 2014). Operatividad aduanera. Recuperado de http://www.sunat.gob.pe/operatividadaduanera/ 


\section{BIBLIOGRAFÍA}

Compañía Peruana de Estudios de Mercado y Opinión Pública. (5 de noviembre de 2013). Market Report 2013. Recuperado de http://cpi.pe/images/upload/paginaweb/archivo/26/MR_201311_01.pdf.

Creus, A. (2011). Seguridad e higiene en el trabajo: un enfoque integral. Buenos Aires: Alfaomega.

Díaz, B., Jarufe, B. y Noriega, M. (2007). Disposición de planta (2a ed.). Lima: Fondo Editorial de la Universidad de Lima.

Stoner, F., Freeman, R. y Gilbert, R. (1996). Administración (6a ed.). México: Prentice Hall-Pearson.

Nuñez, C. (12 de junio de 2014). Profesor Principal de la Universidad Nacional Agraria. Asignatura: Investigación y Desarrollo de Alimentos.

Oficina Comercial de ProChile en Lima Perú. (abril, 2012). Estudio de Mercado de vinos en el Perú. Recuperado de http://www.lamolina.edu.pe/FACULTAD/ciencias/dquimica/CIV/PMP_VIN OS_2012.pdf

Olguín, L. (11 de abril de 2015). Profesor de la Universidad de Lima. Asignatura: Administración Financiera

Organización de las Naciones Unidas para la Alimentación y la Agricultura. (julio, 2012) Procesado de frutas. Recuperado de http://www.fao.org/fileadmin/templates/inpho/documents/PROCESADOSFRUTAS.pdf

Malca, O. (2011). Perfiles de productos con potencial agroexportador (1a ed.). Lima: Centro de Investigación de la universidad del Pacifico.

Benassini, M. (2009). Introducción a la investigación de mercados: enfoque para América Latina (2a ed.). México: Pearson.

Páginas Amarillas. (mayo, 2014). Señalética y mapa de riesgos. Recuperado de http://www.paginasamarillas.com.pe/fichas/riesgo-cero peru_405516/catal ogo/iperc-y-mapa-de-riesgos_13/

Rouzet, E. (2005). El marketing del vino. Madrid: Mundi Prensa.

Suñé, A., Gil, F. y Arcusa, I. (2004). Manual práctico de diseño de sistemas productivos ( $1^{\mathrm{a}}$ ed.). Madrid: Díaz de Santos. 


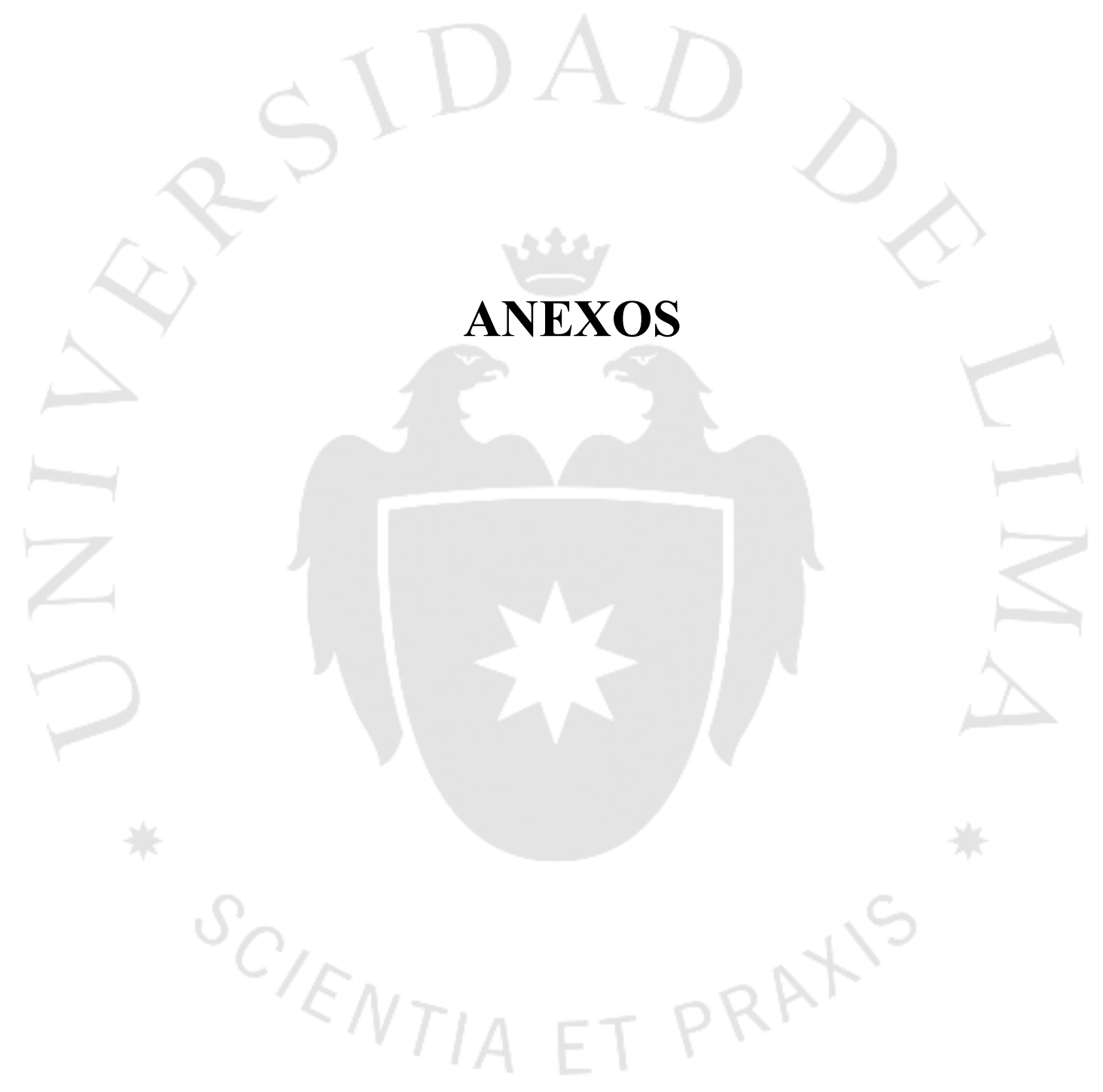




\section{ANEXO 1: ANÁLISIS DEL SECTOR INDUSTRIAL}

\begin{tabular}{|c|c|c|c|c|c|c|c|c|}
\hline \multirow{3}{*}{$\begin{array}{l}\text { Amenaza de ingresos por parte de nuevos } \\
\text { competidores potenciales }\end{array}$} & Sector muy poco atractivo & & & & & \multicolumn{2}{|c|}{ Sector muy atractivo } \\
\hline & Alta amenaza de ingreso & & & & $\overline{c e}$ & & \multicolumn{2}{|c|}{ Baja amenaza de ingreso } \\
\hline & Barreras bajas & & & & & & \multicolumn{2}{|c|}{ Barreras altas } \\
\hline Barreras & Dimensión & 1 & 2 & 3 & 4 & 5 & \multicolumn{2}{|l|}{ Dimensión } \\
\hline Economías de escala & Pequeñas & & & & $\mathrm{x}$ & & \multicolumn{2}{|l|}{ Grandes } \\
\hline Diferenciación del producto & Baja & & 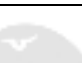 & $\mathrm{x}$ & & $\infty$ & \multicolumn{2}{|l|}{ Alta } \\
\hline Identificación de marca & Baja & & 2 & $\mathrm{x}$ & & & \multicolumn{2}{|l|}{ Alta } \\
\hline Costos de cambio & Bajo & & & $\mathrm{x}$ & & & \multicolumn{2}{|l|}{ Alto } \\
\hline Requisito de capital & Bajo & & 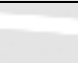 & & $\mathrm{x}$ & & \multicolumn{2}{|l|}{ Alto } \\
\hline Acceso a canales de distribución & Amplio & & $\mathrm{x}$ & & & & \multicolumn{2}{|l|}{ Restringido } \\
\hline Imitación del proceso & Fácil & & & $\mathrm{x}$ & & ta & \multicolumn{2}{|l|}{ Difícil } \\
\hline Regulación gubernamental restrictiva & Baja & & & $\mathrm{x}$ & & A & \multicolumn{2}{|l|}{ Alta } \\
\hline Acceso privilegiado a Materias Primas & No & & & $\mathrm{x}$ & & $1 /$ & \multicolumn{2}{|l|}{$\mathrm{Si}$} \\
\hline Efecto de experiencia & No importante & & & & $\mathrm{x}$ & & \multicolumn{2}{|c|}{ Muy importante } \\
\hline Expectativas de reacción & Bajas & & & & $\mathrm{x}$ & & \multicolumn{2}{|l|}{ Altas } \\
\hline Tecnología de fabricación & Simple y artesanal & & & $\mathrm{x}$ & & sin & \multicolumn{2}{|c|}{ Compleja y alta } \\
\hline \multicolumn{2}{|c|}{ Sumatoria total por columna } & 0 & 2 & 21 & 16 & 0 & Suma Total & 39 \\
\hline \multirow{2}{*}{\multicolumn{2}{|c|}{$\begin{array}{l}\text { Un sector será más vulnerable al ingreso de competidores si las barreras de } \\
\text { ingreso son bajas, un sector con una amenaza alta de ingresos de } \\
\text { competidores será menos atractivo. }\end{array}$}} & \multicolumn{7}{|c|}{\begin{tabular}{l|l} 
Grado de atractividad (GA) =Suma total $/($ número de barreras x 5) & 0.65 \\
Poder de la fuerza (PF) $=\mathbf{0}$ - GA) & 0.35
\end{tabular}} \\
\hline & & Poder d & la fue & F) $=$ & - GA) & & & 0.35 \\
\hline
\end{tabular}




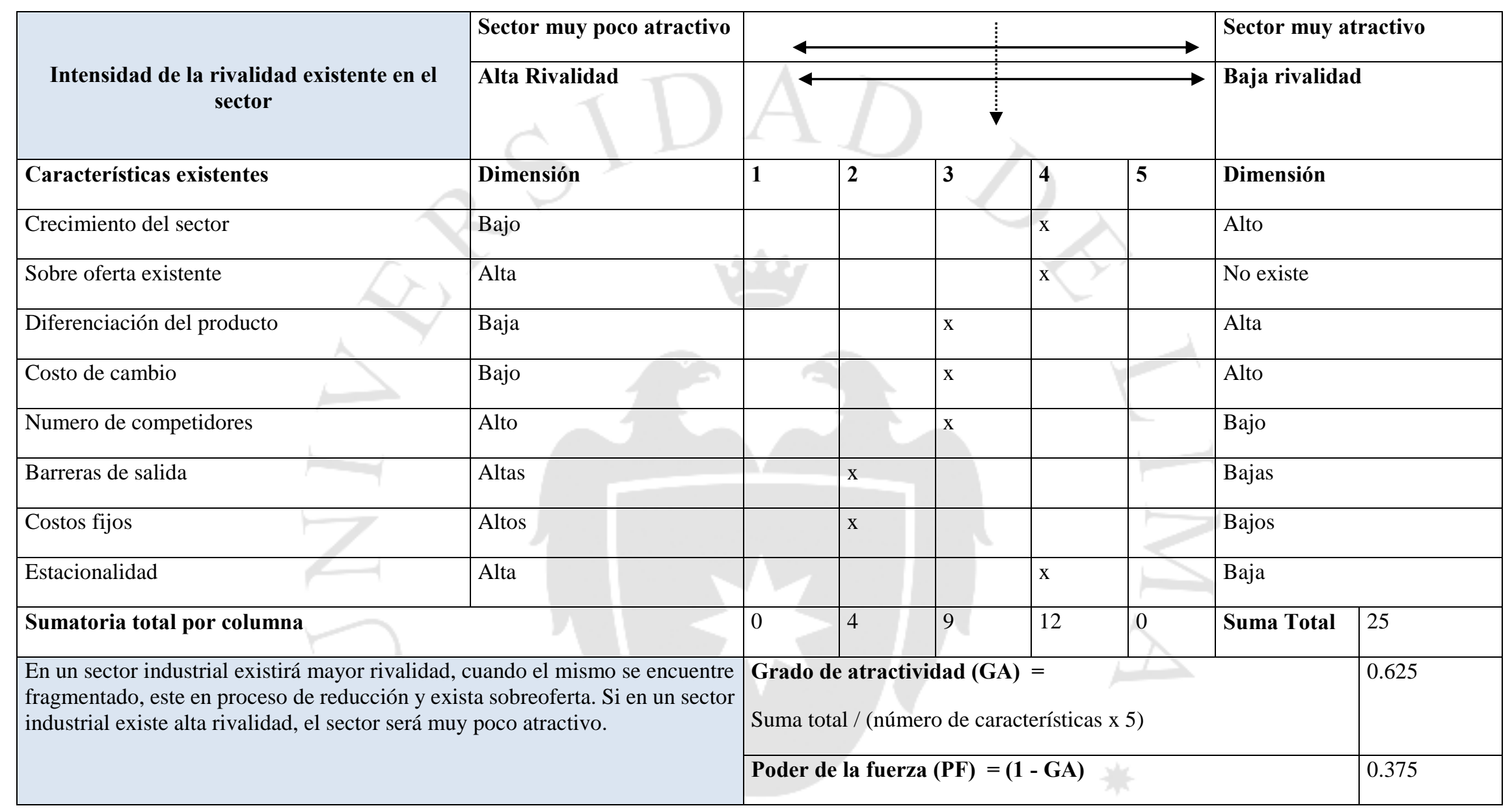




\begin{tabular}{|c|c|c|c|c|c|c|c|c|}
\hline \multirow[b]{2}{*}{$\begin{array}{c}\text { Intensidad de la amenaza de productos } \\
\text { sustitutos }\end{array}$} & Sector muy poco atractivo & & & & & & \multicolumn{2}{|c|}{ Sector muy atractivo } \\
\hline & $\begin{array}{l}\text { Alta amenaza de } \\
\text { sustitución }\end{array}$ & & & & & & \multicolumn{2}{|c|}{$\begin{array}{l}\text { Baja amenaza de } \\
\text { sustitución }\end{array}$} \\
\hline Características existentes & Dimensión & 1 & 2 & 3 & 4 & 5 & \multicolumn{2}{|l|}{ Dimensión } \\
\hline Posibilidad de sustitutos cercanos & Alta & & $\mathrm{x}$ & & & & \multicolumn{2}{|l|}{ Baja } \\
\hline Costo de cambio del usuario & Bajos & +2 & $\mathrm{x}$ & & & & \multicolumn{2}{|l|}{ Altos } \\
\hline Agresividad del producto sustituto & Alta & & $\mathrm{x}$ & & & & \multicolumn{2}{|l|}{ Baja } \\
\hline $\begin{array}{l}\text { Propensión de los consumidores a cambiar de } \\
\text { productos }\end{array}$ & Alta & & $\mathrm{x}$ & & & & \multicolumn{2}{|l|}{ Baja } \\
\hline $\begin{array}{l}\text { Relación valor del producto sustituto / precio } \\
\text { del producto sustituto }\end{array}$ & Alto & & & $\mathrm{x}$ & & & \multicolumn{2}{|l|}{ Bajo } \\
\hline \multicolumn{2}{|l|}{ Sumatoria total por columna } & 0 & 8 & 3 & C & 0 & Suma Total & 11 \\
\hline \multirow{2}{*}{\multicolumn{2}{|c|}{$\begin{array}{l}\text { En un sector industrial existirá mayor Intensidad de amenaza de productos } \\
\text { sustitutos, cuando existan en otros sectores productos que satisfagan muy } \\
\text { cercanamente las necesidades que el producto del sector en cuestión lo haga. Si } \\
\text { en un sector industrial, existe alta Intensidad de la amenaza de productos, el } \\
\text { sector será muy poco atractivo }\end{array}$}} & \multicolumn{6}{|c|}{$\begin{array}{l}\text { Grado de at } \\
\text { Suma total / }\end{array}$} & 0.44 \\
\hline & & \multicolumn{6}{|c|}{ Poder de la fuerza $(\mathrm{PF})=(1$ - GA) } & 0.56 \\
\hline
\end{tabular}




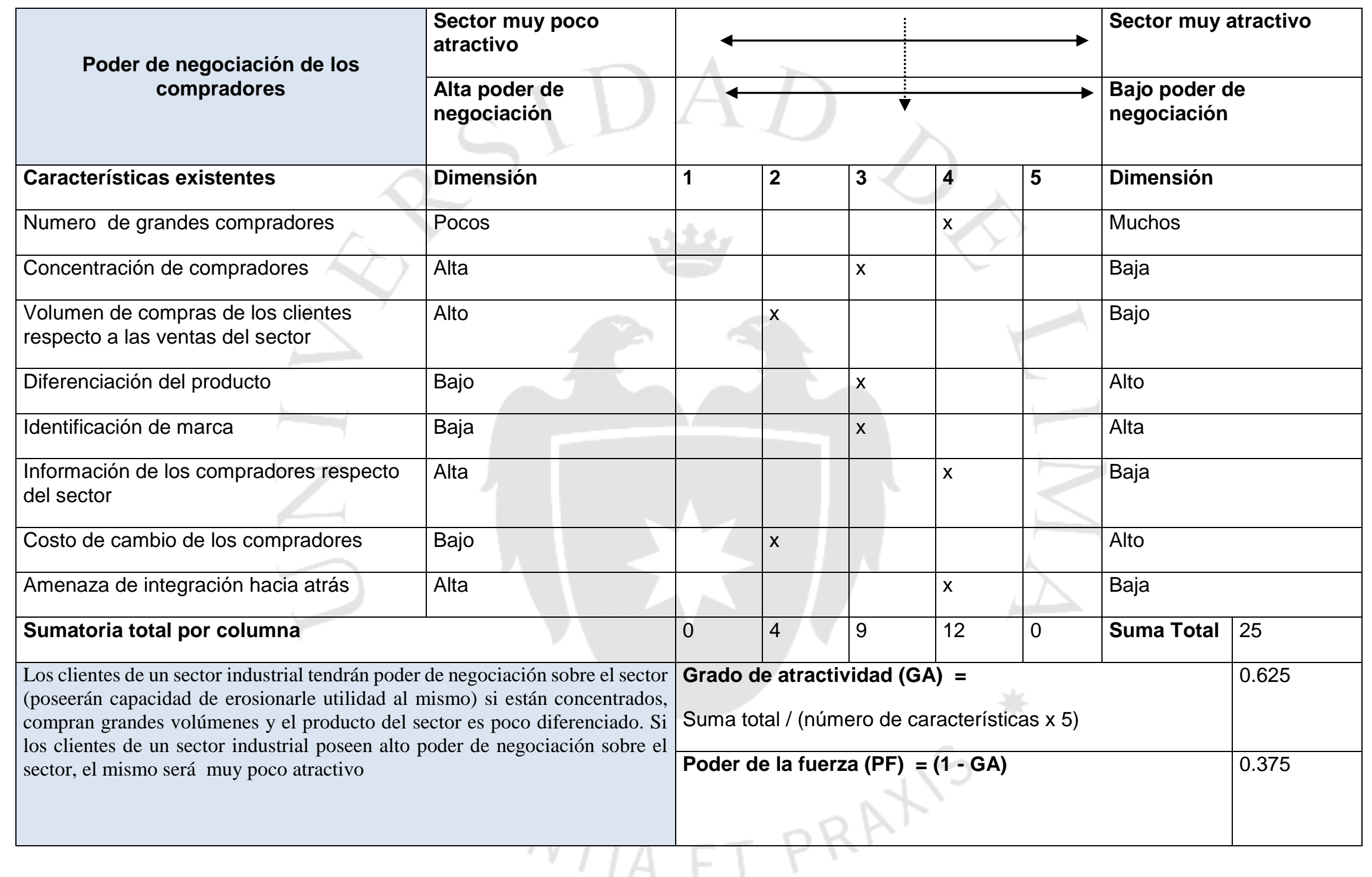




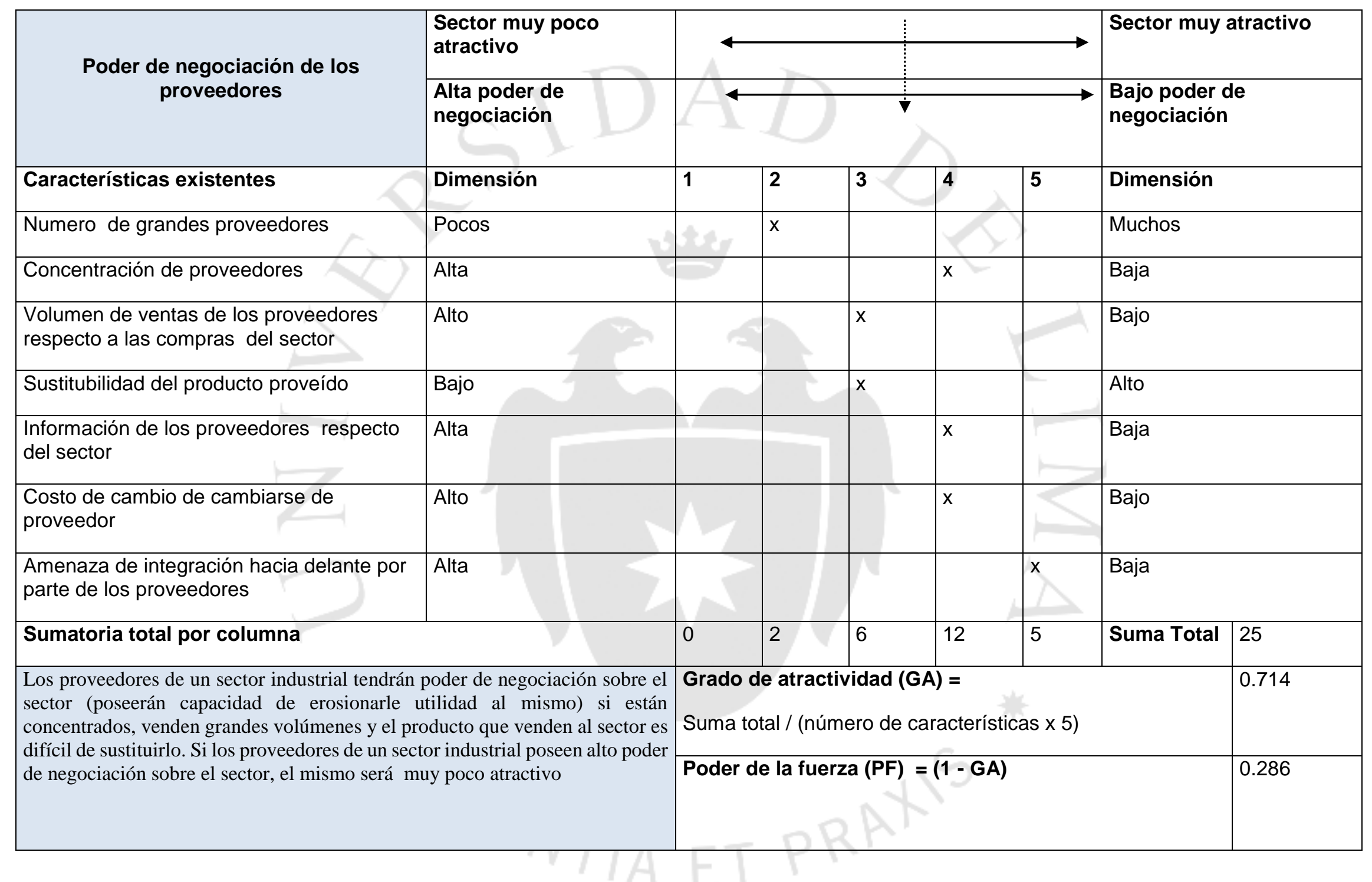




\section{Resultado del análisis estructural del sector industrial}

Ordenar las fuerzas existentes en el sector, de acuerdo a su poder estableciendo, cuál de ellas gobierna el sector, para así poder mejorar la posición competitiva.

\begin{tabular}{|c|c|c|c|c|c|}
\hline \multicolumn{2}{|r|}{$\begin{array}{l}\text { Fuerzas existente en el sector en orden de su poder } \\
\text { de afectación al sector }\end{array}$} & \multicolumn{2}{|c|}{ Valor obtenido en el análisis previo } & \multicolumn{2}{|c|}{$\begin{array}{l}\text { Orden de prioridad para } \\
\text { mejorar la posición con el } \\
\text { fin de obtener V.C. }\end{array}$} \\
\hline & & \multirow{2}{*}{\begin{tabular}{|l|} 
PF \\
0.56
\end{tabular}} & \multirow{2}{*}{\begin{tabular}{|l|} 
GA \\
0.44 \\
\end{tabular}} & & \\
\hline 1 & $\begin{array}{l}\text { Intensidad de la amenaza de productos } \\
\text { sustitutos }\end{array}$ & & & 1 & Primera \\
\hline 2 & Intensidad de la rivalidad existente en el sector & 0.375 & 0.625 & 2 & Segunda \\
\hline 3 & Poder de negociación de los compradores & 0.375 & 0.625 & 3 & Tercera \\
\hline 4 & Ingreso por parte de competidores potenciales & 0.35 & 0.65 & 4 & Cuarta \\
\hline 5 & Poder de negociación de los proveedores & 0.286 & 0.714 & 5 & Quinta \\
\hline
\end{tabular}




\section{ANEXO 2: ANÁLISIS FODA}

En el análisis FODA, se han elegido los principales factores que afectan directa e indirectamente el análisis del negocio, conduciendo a establecer estrategias acorde a las circunstancias:

\section{Matriz FODA}

\begin{tabular}{|c|c|}
\hline Fortalezas & Oportunidades \\
\hline $\begin{array}{l}\text { FO-1: Altos niveles de inversión en la } \\
\text { producción }\end{array}$ & $\begin{array}{l}\text { OP-1:Barreras de ingreso como licencias y } \\
\text { tramites de funcionamiento }\end{array}$ \\
\hline $\begin{array}{l}\text { FO-2: El boom gastronómico amplía el interés } \\
\text { por el consumo de nuevas variedades }\end{array}$ & $\begin{array}{l}\text { OP-2:Crecimiento sostenido con una oferta de } \\
\text { más de } 40 \text { millones de litros }\end{array}$ \\
\hline $\begin{array}{l}\text { FO-3: La frecuencia de compra de vinos es } \\
\text { principalmente en Supermercados }\end{array}$ & OP-3:Crecimiento del rubro en $10 \%$ \\
\hline FO-4: La lealtad a la marca en vinos es $35 \%$ & OP-4:Dinamismo del consumo de Lima \\
\hline FO-5: $55 \%$ compraría otra marca de vinos & OP-5:Expansión de la cadena de distribución \\
\hline $\begin{array}{l}\text { FO-6:Proliferación de marcas en un rango de } \\
\text { precios }\end{array}$ & $\begin{array}{l}\text { OP-6:Posicionamiento en marcas nacionales de } \\
\text { vinos }\end{array}$ \\
\hline $\begin{array}{l}\text { FO-7:Producción y precios estables (bajos } \\
\text { niveles de escases) }\end{array}$ & \\
\hline Debilidades & Amenazas \\
\hline $\begin{array}{l}\text { DE-1:Existe mayor interés por el consumo de } \\
\text { vinos de mayor calidad }\end{array}$ & $\begin{array}{l}\text { AM-1:Competencia trabaja con economías de } \\
\text { escala }\end{array}$ \\
\hline $\begin{array}{l}\text { DE-2:No existe buenas técnicas de sembrío y } \\
\text { cosecha }\end{array}$ & $\begin{array}{l}\text { AM-2:Posicionamiento de marcas internacionales } \\
\text { de licores }\end{array}$ \\
\hline $\begin{array}{l}\text { DE-3:Existen productos sustitutos altamente } \\
\text { competitivos }\end{array}$ & AM-3:Comercio de productos sustitutos del vino \\
\hline $\begin{array}{l}\text { DE-4:Existe marcas nacionales de vinos } \\
\text { altamente competitivos }\end{array}$ & $\begin{array}{l}\text { AM-4:Liberalización de barreras de ingreso a } \\
\text { producción importados }\end{array}$ \\
\hline
\end{tabular}

Elaboración propia

Luego de ello, a través de la herramienta PEYEA se puede elaborar la siguiente estrategia que se diseña en función al FODA encontrado. 
Fuerza Financiera y capacidad de base (FF)

\begin{tabular}{|l|l|l|}
\hline \multicolumn{2}{|l|}{ Fuerza Financiera y Capacidades de Base (FF) } & $\begin{array}{l}\text { Valor } \\
(+)\end{array}$ \\
\hline FO-1 & Altos niveles de inversión en la producción & 6 \\
\hline FO-2 & $\begin{array}{l}\text { El boom gastronómico amplia el interés por el } \\
\text { consumo de nuevas variedades }\end{array}$ & 6 \\
\hline FO-3 & $\begin{array}{l}\text { La frecuencia de compra de vinos es } \\
\text { principalmente en Supermercados }\end{array}$ & 6 \\
\hline FO-4 & La lealtad a la marca en vinos es 35\% & 5 \\
\hline FO-5 & $55 \%$ compraría otra marca de vinos & 5 \\
\hline DE-1 & $\begin{array}{l}\text { Existe mayor interés por el consumo de vinos de } \\
\text { mayor calidad }\end{array}$ & 5 \\
\hline Promedio FF & 5.50 \\
\hline
\end{tabular}

Elaboración propia

Ventaja competitiva (VC)

\begin{tabular}{|l|l|l|}
\hline \multicolumn{2}{|l|}{ Ventaja Competitiva (VC) } & $\begin{array}{l}\text { Valor } \\
(-)\end{array}$ \\
\hline FO-6 & $\begin{array}{l}\text { Proliferación de marcas en un rango de } \\
\text { precios }\end{array}$ & -5 \\
\hline FO-7 & $\begin{array}{l}\text { Producción permanente (bajos niveles de } \\
\text { escases) }\end{array}$ & -6 \\
\hline DE-2 & $\begin{array}{l}\text { No existe buenas técnicas de sembrío y } \\
\text { cosecha }\end{array}$ & -4 \\
\hline DE-3 & $\begin{array}{l}\text { Existen productos sustitutos altamente } \\
\text { competitivos }\end{array}$ & -6 \\
\hline DE-4 & $\begin{array}{l}\text { Existe marcas nacionales de vinos altamente } \\
\text { competitivos }\end{array}$ & -6 \\
\hline Promedio VC & $\mathbf{- 5 . 4 0}$ \\
\hline
\end{tabular}

Elaboración propia 


\section{Estabilidad del ambiente (EA)}

\begin{tabular}{|l|l|l|}
\hline \multicolumn{2}{|l|}{ Estabilidad del Ambiente (EA) } & $\begin{array}{l}\text { Valor } \\
(-)\end{array}$ \\
\hline OP-1 & $\begin{array}{l}\text { Barreras de ingreso como licencias y tramites } \\
\text { de funcionamiento }\end{array}$ & -5 \\
\hline OP-2 & $\begin{array}{l}\text { Crecimiento sostenido con una oferta de más de } \\
40 \text { millones de litros }\end{array}$ & -4 \\
\hline OP-3 & Crecimiento del rubro en 10\% & -5 \\
\hline OP-4 & Dinamismo del consumo de Lima & -6 \\
\hline OP-5 & Expansión de la cadena de distribución & -6 \\
\hline Promedio EA & & $-\mathbf{- 5 . 2 0}$ \\
\hline
\end{tabular}

Elaboración propia

Fuerza de la Industria (FI)

\begin{tabular}{|c|c|c|}
\hline \multicolumn{2}{|c|}{ Fuerza de la Industria (FI) } & $\begin{array}{l}\text { Valor } \\
(+)\end{array}$ \\
\hline OP-6 & $\begin{array}{l}\text { Posicionamiento en marcas nacionales de } \\
\text { vinos }\end{array}$ & 6 \\
\hline AM-1 & Competencia trabaja con economías de escala & 5 \\
\hline AM-2 & $\begin{array}{l}\text { Posicionamiento de marcas internacionales de } \\
\text { licores }\end{array}$ & 6 \\
\hline AM-3 & Comercio de productos sustitutos del vino & 5 \\
\hline AM-4 & $\begin{array}{l}\text { Liberalización de barreras de ingreso a prod. } \\
\text { Importados }\end{array}$ & 6 \\
\hline \multicolumn{2}{|c|}{ Promedio FI } & 5.60 \\
\hline
\end{tabular}

Elaboración propia 


\section{Luego se elabora la matriz PEYEA:}

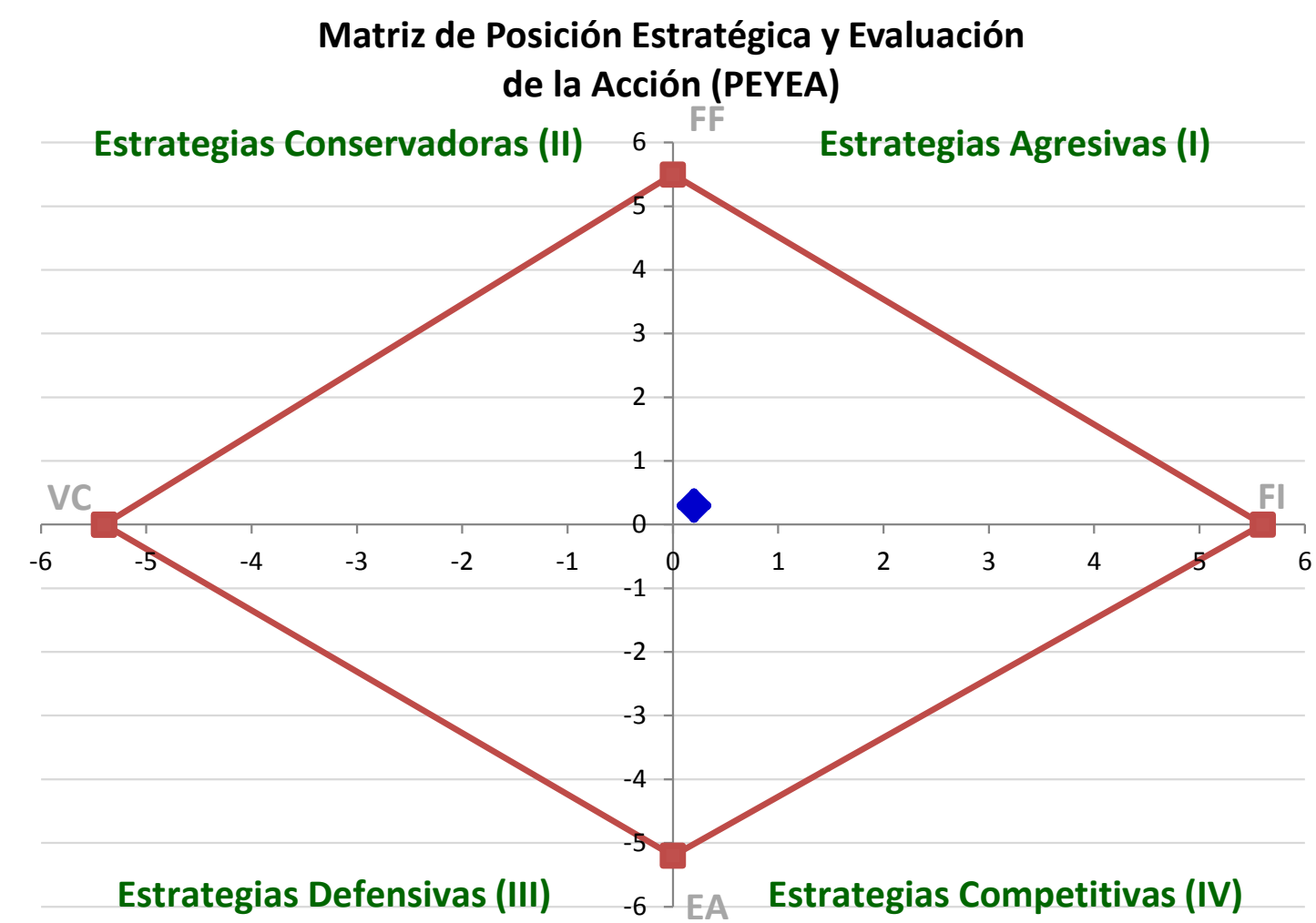

Elaboración propia

En la matriz se observa que la estrategia a usar según la posición de las variables es la agresiva. Considerando, que el ambiente en donde se desarrollan las diferentes actividades del consumo de bebidas alcohólicas, tiene altos niveles de rentabilidad, y demandan altos niveles de inversión tanto en la producción, distribución, venta y marketing, se puede sostener que la estrategia debe ser cuantificable a una industria muy competitiva. 
Estrategias del cuadrante Agresivo

\begin{tabular}{|l|}
\hline Tipos de estrategias \\
\hline Estrategias de crecimiento intensivo \\
\hline Estrategias integrativas \\
\hline Estrategias de diversificación \\
\hline Penetración del mercado \\
\hline Desarrollo del producto \\
\hline Integración vertical \\
\hline Diversificación \\
\hline Elaboración propia
\end{tabular}

Para que el producto que ofrecemos en el mercado sea atractivo al consumidor, se plantea seguir 02 estrategias que pueden ofrecer valor al negocio:

Penetración del mercado: Buscar nichos de mercados, donde el producto sea atractivo y de consumo, considerando las barreras socioeconómicas, etarias y geográficas.

Desarrollo del producto: Se debe buscar mejorar constantemente el sabor del producto, para evitar que su sabor dulce sea una barrera comercial y de consumo, sacar al mercado nuevas presentaciones.

Diversificación: La empresa puede sacar al mercado nuevos productos utilizando como materias primas frutas peruanas. 


\section{ANEXO No 3. CUESTIONARIO DE ESTUDIO DE MERCADO}

Buenos días, mi nombre es Víctor Veliz, y estoy realizando una encuesta para un proyecto de la Universidad de Lima. En esta ocasión la encuesta sobre el consumo de licores, y quisiera que colabore conmigo respondiendo algunas preguntas. i¡MUCHAS GRACIAS!!

SOLO PARA RESIDENTES EN LA CIUDAD DE LIMA METROPOLITANA

MAYORES DE 18 AÑOS

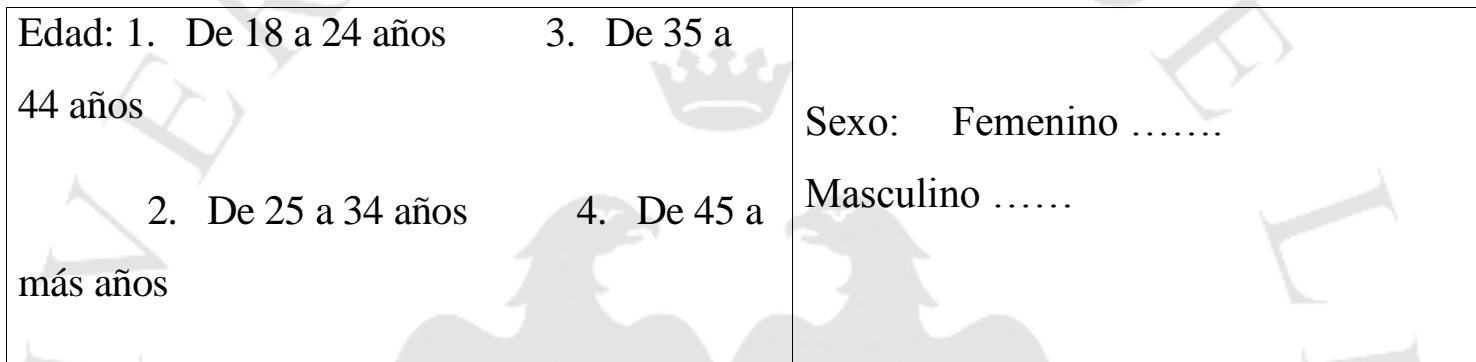

\section{HABITOS DE CONSUMO}

Distrito de procedencia:

¿Consume usted bebidas alcohólicas?

Sí......

No.......

Para los que respondieron $\mathrm{Si}$ :

De la siguiente relación de licores que le voy a leer, ¿Cuáles ha consumido Ud. en los últimos 6 meses? 


\begin{tabular}{|l|l|l|l|l|l|l|}
\hline & Ron & Cerveza & Vino & Pisco & $\begin{array}{l}\text { Vinos } \\
\text { espumantes }\end{array}$ & Otros: \\
\hline P1 & 1 & 2 & 3 & 4 & 5 & 6 \\
\hline
\end{tabular}

¿Con quienes prefiere consumir sus bebidas alcohólicas generalmente?

\begin{tabular}{|l|l|l|l|l|l|}
\hline 1 & 2 & 3 & 4 & 5 & 6 \\
\hline Amigos & Familiares & $\begin{array}{l}\text { Compañeros } \\
\text { de trabajo }\end{array}$ & Solo & $\begin{array}{l}\text { Con } \\
\text { mi } \\
\text { pareja }\end{array}$ & Otros: \\
\hline
\end{tabular}

¿Con que frecuencia acostumbra consumir los siguientes productos alcohólicos?

\begin{tabular}{|l|l|l|l|l|l|}
\hline \multirow{2}{*}{ Frecuencia } & \multicolumn{5}{|l|}{ 6. Por línea de producto } \\
\cline { 2 - 7 } & Cerveza & Vino & Espumantes & Pisco & Ron \\
\hline Semanal & 1 & 1 & 1 & 1 & 1 \\
\hline Quincenal & 2 & 2 & 2 & 2 & 2 \\
\hline Mensual & 3 & 3 & 3 & 3 & 3 \\
\hline $\begin{array}{l}\text { Cada dos } \\
\text { meses }\end{array}$ & 4 & 4 & 4 & 4 & 4 \\
\hline Cada 6 meses & 5 & 5 & 5 & & 5 \\
\hline Una vez al año & 6 & 6 & 6 & 6 & 6 \\
\hline Casi nunca & 7 & 7 & 7 & 7 & 7 \\
\hline
\end{tabular}

¿Ha escuchado o tiene conocimiento de algún licor de higo? 
1 Si 2 No 3 Ns / Nr

\section{PRECIO}

¿Cuál es el precio promedio que acostumbra pagar por alguna bebida alcohólica?

\begin{tabular}{|l|l|l|l|l|l|}
\hline \multirow{2}{*}{} & \multicolumn{4}{|l|}{ 11. Por línea de producto } \\
\cline { 2 - 6 } & Cerveza & Vino & Espumante & Pisco & Ron \\
\hline Precio & & & & & \\
\hline
\end{tabular}

\section{PROMOCIÓN / PLAZA}

¿A través de que canal compra sus bebidas alcohólicas generalmente?

\begin{tabular}{|l|l|l|l|l|l|l|}
\hline 1 & 2 & 3 & 4 & 5 & 6 & 7 \\
\hline Restaurante & $\begin{array}{l}\text { Bares / } \\
\text { Pubs }\end{array}$ & Discotecas & Licorerías & Supermercados & Bodegas & Otros: \\
\hline
\end{tabular}

\section{PRODUCTO}

¿Adquiriría usted un licor de higo con sabor similar a un vino dulce, con olor y sabor característicos al de la fruta?

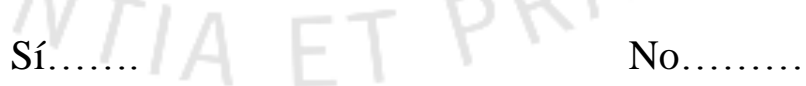

\section{A los que respondieron Si:}

(PRUEBA DE CONCEPTO DE PROBABILIDAD DE ADQUIRIRLA - QUERER)

Si apareciera un nuevo producto de licor de higo donde usted pueda adquirir en autoservicios, restaurantes, bodegas y/o licorerías con un sabor similar al vino dulce ¿Qué tan probable es que Ud. adquiera el producto? 


\begin{tabular}{|l|l|}
\hline Muy probablemente lo adquiriría & 1 \\
\hline Probablemente lo adquiriría & 2 \\
\hline $\begin{array}{l}\text { Ni poco ni mucho probable lo } \\
\text { adquiriría }\end{array}$ & 3 \\
\hline Poco probable lo adquiría & 4 \\
\hline Nada probable lo adquiriría & 5 \\
\hline
\end{tabular}

¿Cuál es el color de la botella que le gustaría que vaya el licor de higo propuesto en el concepto?
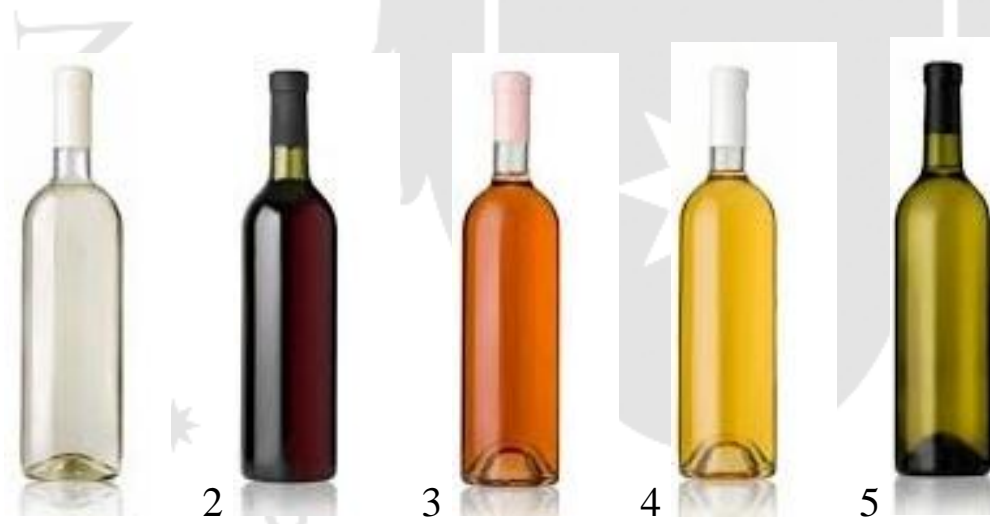


\section{ANEXO No 4. CUESTIONARIO DE ESTUDIO DE MERCADO (CON LOS DATOS OBTENIDOS)}

72 personas respondieron el cuestionario

Edad:

\begin{tabular}{|l|l|}
\hline Rango de edad & Porcentaje \\
\hline De 18 a 24 años & $25 \%$ \\
\hline De 25 a 34 años & $32 \%$ \\
\hline De 35 a 44 años & $17 \%$ \\
\hline De 44 años a más & $26 \%$ \\
\hline Total & $100 \%$ \\
\hline
\end{tabular}

Hábitos de consumo:

1. Distrito de procedencia

\begin{tabular}{|l|l|}
\hline Distrito & Porcentaje \\
\hline Surco & $34,7 \%$ \\
\hline San Borja & $22,2 \%$ \\
\hline La Molina & $19,4 \%$ \\
\hline Miraflores & $8,3 \%$ \\
\hline Los Olivos & $8,3 \%$ \\
\hline San Isidro & $4,2 \%$ \\
\hline Ate & $2,8 \%$ \\
\hline Total & $\mathbf{1 0 0} \%$ \\
\hline
\end{tabular}




\section{Consume usted bebidas alcohólicas}

Si: 70 personas

No: 2 personas

Para los que respondieron Si:

3. De la siguiente relación de licores que le voy a leer, ¿Cuáles ha consumido Ud. en los últimos 6 meses?

\begin{tabular}{|l|l|}
\hline Bebida & Porcentaje \\
\hline Ron & $16,2 \%$ \\
\hline Cerveza & $23,1 \%$ \\
\hline Vino & $20,4 \%$ \\
\hline Pisco & $16,2 \%$ \\
\hline Vino espumoso & $12,5 \%$ \\
\hline Otros & $11,6 \%$ \\
\hline Total & $100 \%$ \\
\hline
\end{tabular}

¿Con quienes prefiere consumir sus bebidas alcohólicas generalmente?

\begin{tabular}{|l|l|}
\hline Compañía & Porcentaje \\
\hline Amigos & $39 \%$ \\
\hline Familiares & $29 \%$ \\
\hline Compañeros de trabajo & $20 \%$ \\
\hline Solo & $9 \%$ \\
\hline Con mi pareja & $3 \%$ \\
\hline Otros & $1 \%$ \\
\hline Total & $\mathbf{1 0 0 \%}$ \\
\hline
\end{tabular}


¿Con que frecuencia acostumbra consumir los siguientes productos alcohólicos?

\begin{tabular}{|l|l|l|l|l|l|}
\hline Frecuencia & Cerveza & Vino & Espumantes & Pisco & Ron \\
\hline Semanal & $16 \%$ & $6 \%$ & $1 \%$ & $6 \%$ & $4 \%$ \\
\hline Quincenal & $23 \%$ & $14 \%$ & $6 \%$ & $16 \%$ & $14 \%$ \\
\hline Mensual & $31 \%$ & $49 \%$ & $14 \%$ & $43 \%$ & $40 \%$ \\
\hline Cada 2 meses & $17 \%$ & $17 \%$ & $53 \%$ & $17 \%$ & $20 \%$ \\
\hline Cada 6 meses & $7 \%$ & $7 \%$ & $17 \%$ & $9 \%$ & $10 \%$ \\
\hline Una vez al año & $6 \%$ & $7 \%$ & $9 \%$ & $10 \%$ & $11 \%$ \\
\hline Total & $\mathbf{1 0 0} \%$ & $\mathbf{1 0 0} \%$ & $\mathbf{1 0 0} \%$ & $\mathbf{1 0 0 \%}$ & $\mathbf{1 0 0 \%}$ \\
\hline
\end{tabular}

¿Ha escuchado o tiene conocimiento de algún licor de higo?

\begin{tabular}{|l|l|}
\hline Si & 18 \\
\hline No & 37 \\
\hline No sabe/ No responde & 15 \\
\hline Total & $\mathbf{7 0}$ \\
\hline
\end{tabular}




\section{PRECIO}

¿Cuál es el precio promedio que acostumbra pagar por alguna bebida alcohólica?

\begin{tabular}{|l|l|l|l|l|l|}
\hline \multirow{2}{*}{} & \multicolumn{5}{|l|}{ Por línea de producto } \\
\cline { 2 - 6 } & Cerveza & Vino & Espumante & Pisco & Ron \\
\hline Precio & S/. 5 & S/. 25.5 & S/. 19 & S/. 35 & S/. 40 \\
\hline
\end{tabular}

\section{PROMOCIÓN / PLAZA}

¿A través de que canal compra sus bebidas alcohólicas generalmente?

\section{PRODUCTO}

\begin{tabular}{|l|l|}
\hline Canal & Total \\
\hline Restaurante & $4 \%$ \\
\hline Bares & $7 \%$ \\
\hline Discotecas & $10 \%$ \\
\hline Licorerías & $26 \%$ \\
\hline Supermercados & $36 \%$ \\
\hline Bodegas & $17 \%$ \\
\hline Total & $\mathbf{1 0 0 \%}$ \\
\hline
\end{tabular}

¿Adquiriría usted un licor de higo con sabor similar a un vino dulce, con olor y sabor característicos al de la fruta?

\begin{tabular}{|l|l|l|}
\hline Respuesta & Personas & Porcentaje \\
\hline Si & 37 & $52,9 \%$ \\
\hline No & 33 & $47,1 \%$ \\
\hline Total & $\mathbf{7 0}$ & $\mathbf{1 0 0} \%$ \\
\hline
\end{tabular}


A los que respondieron $\mathrm{Si}$ :

(PRUEBA DE CONCEPTO DE PROBABILIDAD DE ADQUIRIRLA - QUERER) Si apareciera un nuevo producto de licor de higo donde usted pueda adquirir en autoservicios, restaurantes, bodegas y/o licorerías con un sabor similar al vino dulce ¿Qué tan probable es que Ud. adquiera el producto?

Promedio de la intensidad de compra: $51.7 \%$.

¿Cuál es el color de la botella que le gustaría que vaya el licor de higo propuesto en el concepto?

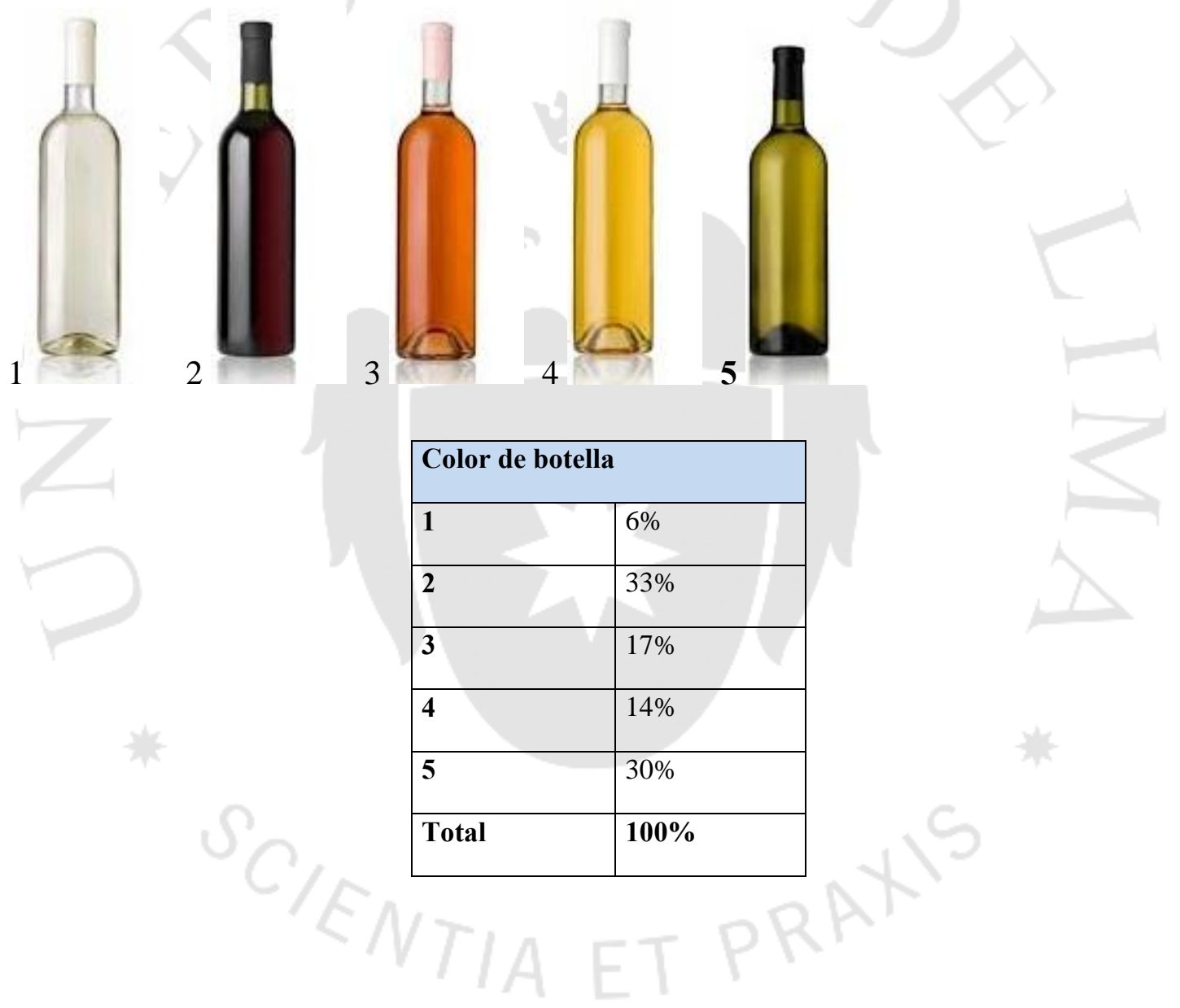




\section{ANEXO 5: PROCESO DE FERMENTACIÓN}

El proceso principal por el cual se transforma el mosto en vino es la fermentación alcohólica:

Consiste en la transformación de los azúcares (glucosa y fructosa) contenidos en la uva en alcohol etílico y anhídrido carbónico.

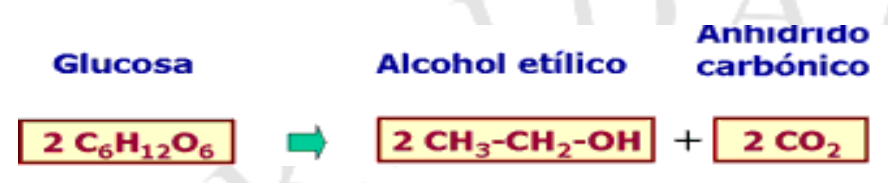

Aproximadamente se produce 1 grado alcohólico por cada 17 gramos de azúcar contenidos en el mosto:

Así, un mosto con 204 gramos/litro dará lugar a un vino con 12 grados de alcohol.

En este proceso se produce también anhídrido carbónico en estado gaseoso, lo que provoca el burbujeo, la ebullición y el aroma característico de una cuba de mosto en fermentación.

Esta formación de carbónico va a ser importante para la extracción de sustancias contenidas en los hollejos y en proporcionar una atmósfera protectora de la oxidación de las frutas que es beneficiosa para la obtención de un licor de calidad.

¿Quién realiza este proceso? Son las levaduras adheridas al hollejo de la uva (mediante una capa cerosa denominada pruina) las que, para satisfacer sus necesidades de crecimiento, favorecen el proceso.

Son levaduras del género Sacharomyces las que suelen desempeñar la parte más importante del proceso. Son las auténticas "obreras del vino."

Es de suma importancia controlar la temperatura de fermentación continuamente durante todo el proceso.

El final del proceso fermentativo es cuando ya se han desdoblado prácticamente todos los azúcares y cesa la ebullición. En bodegas esto se determina con los clásicos pesamostos o densímetros. 


\section{ANEXO 6: ESPECIFICACIONES DE LA MAQUINARIA}

\section{Lavadora de inmersión con aspersión}

\begin{tabular}{|l|l|}
\hline Marca & CITALSA \\
\hline
\end{tabular}

\begin{tabular}{|c|c|c|c|}
\hline Referencia & LIA-1 & & \\
\hline Procedencia & Colombia & & \\
\hline Construcción & $\begin{array}{l}\text { Estructura } 100 \% \text { inox. (piezas comerciales o } \\
\text { accesorios de ensamble del equipo, que no } \\
\text { estén en contacto directo con el alimento, } \\
\text { pueden ser en materiales diferentes). }\end{array}$ & & \\
\hline Acabado & Tipo sandblasting & & \\
\hline 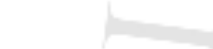 & & & \\
\hline Función & $\begin{array}{l}\text { Se utiliza para lavar frutas y hortalizas de } \\
\text { hasta } 10 \mathrm{~cm} \text {. Utilizando para ello un tanque de }\end{array}$ & & \\
\hline & $\begin{array}{l}\text { inmersión con turbulencia y una ducha de } \\
\text { aspersión plana para terminar el lavado } \\
\text { superficial del producto. }\end{array}$ & Capacidad & $400 \mathrm{~kg} / \mathrm{hr}$ \\
\hline Descripción & $\begin{array}{l}\text { El equipo consta de un tanque donde se } \\
\text { genera la turbulencia, unas duchas de } \\
\text { aspersión plana, una bomba que provee la } \\
\text { recirculación del agua a presión y un elevador } \\
\text { para retirar el producto que ya ha sido lavado, } \\
\text { además posee un tanque de recepción de agua } \\
\text { en el cuál se filtra el agua y se decantan los } \\
\text { sólidos como arena para que no sean } \\
\text { recirculados al equipo. }\end{array}$ & Ventajas & $\begin{array}{l}\text { Lavado eficiente del producto. } \\
\text { Reducción en consumo de agua durante la } \\
\text { operación. } \\
\text { Menor daño del producto y baja } \\
\text { manipulación del mismo. } \\
\text { Economía en tiempo de lavado. } \\
\text { Versatilidad para usarlo en gran variedad } \\
\text { de productos. }\end{array}$ \\
\hline Características & Tanque para almacenar $0.5 \mathrm{~m}^{3}$ de agua. & Dimensiones & Frente: $100 \mathrm{~cm}$. \\
\hline & $\begin{array}{l}\text { Para fruta y hortalizas de máximo } 10 \mathrm{~cm} . \\
\text { Transporte del producto de forma automática. }\end{array}$ & & $\begin{array}{l}\text { Largo: } 220 \mathrm{~cm} \\
\text { Altura: } 170 \mathrm{~cm}\end{array}$ \\
\hline
\end{tabular}




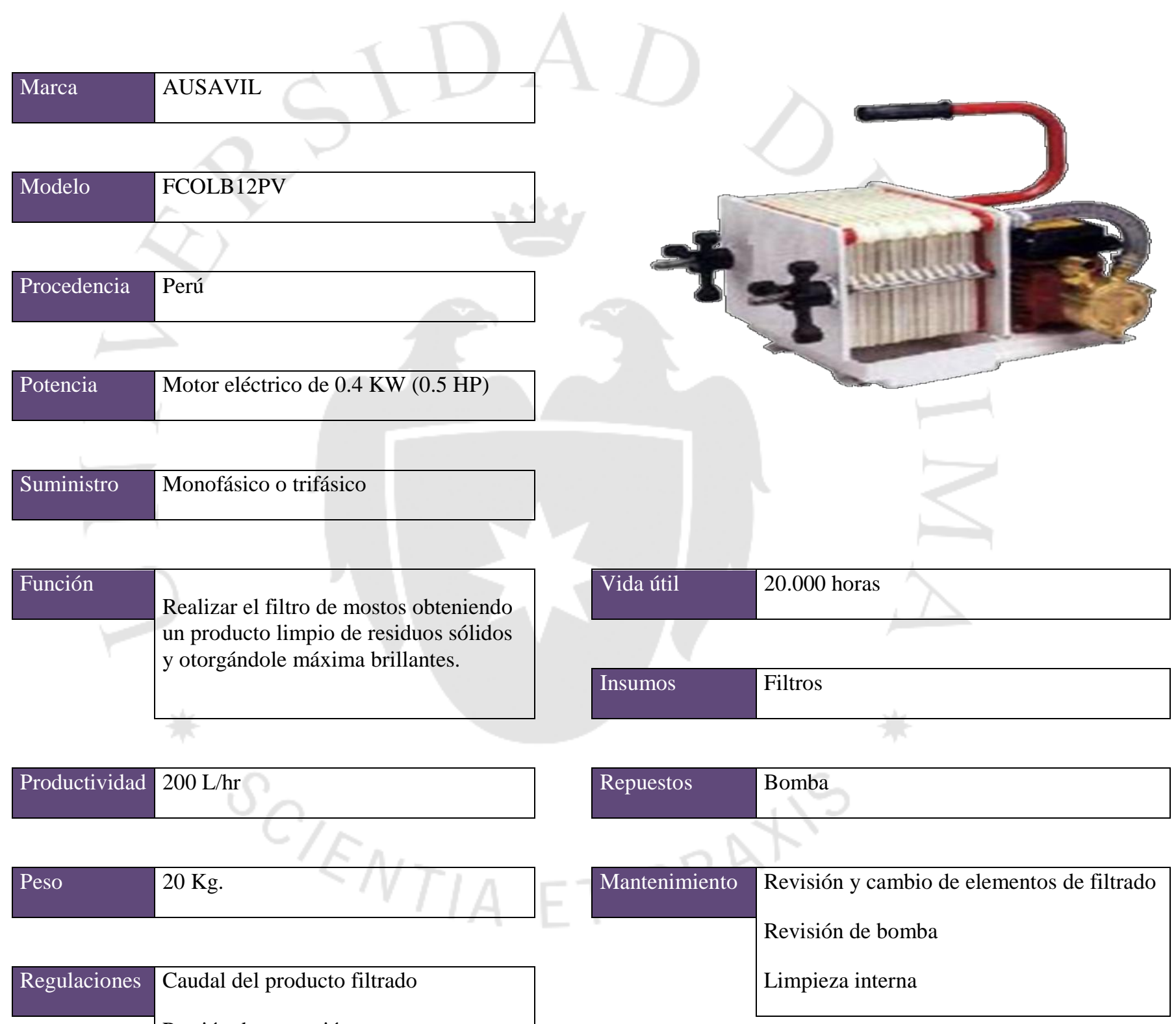




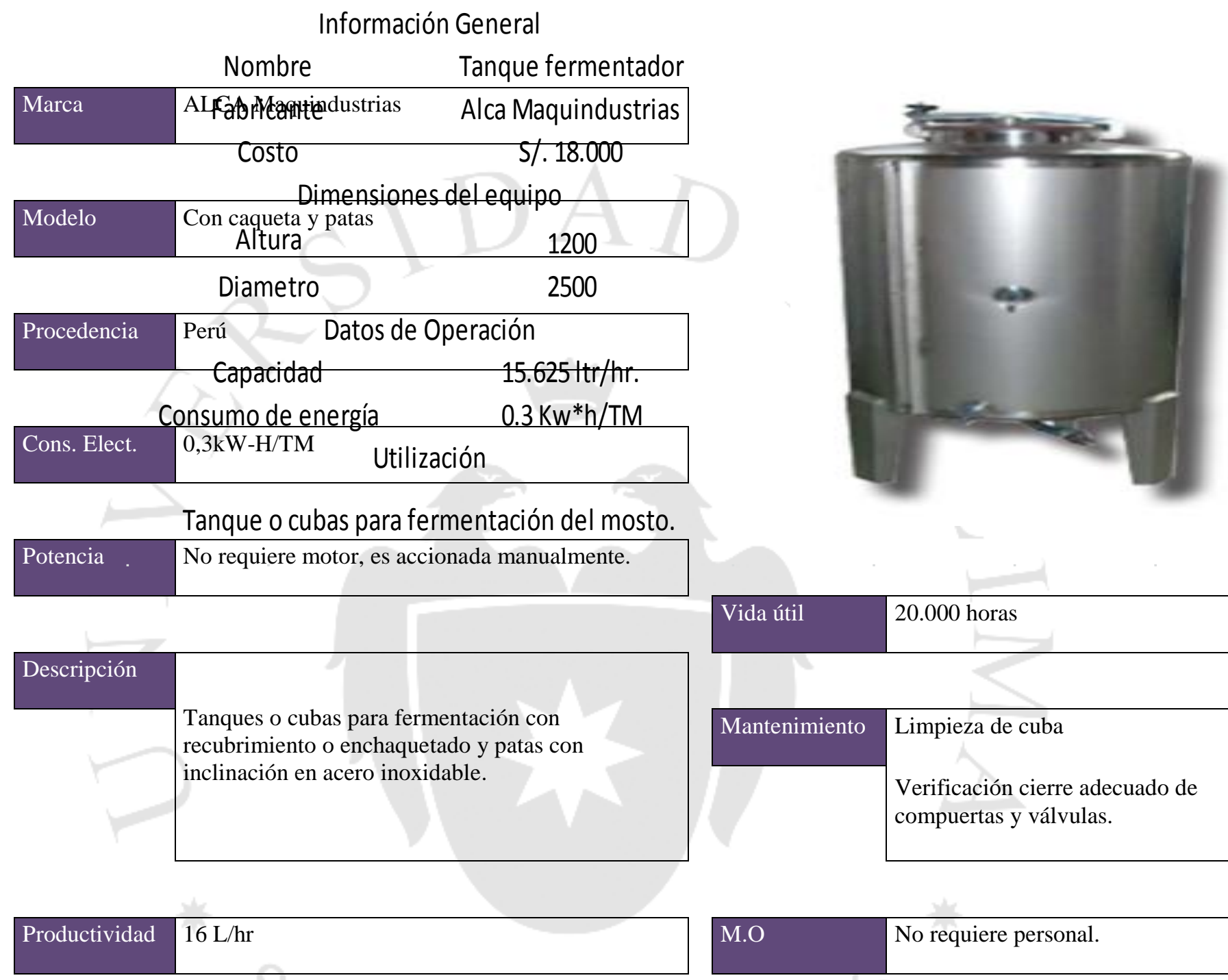



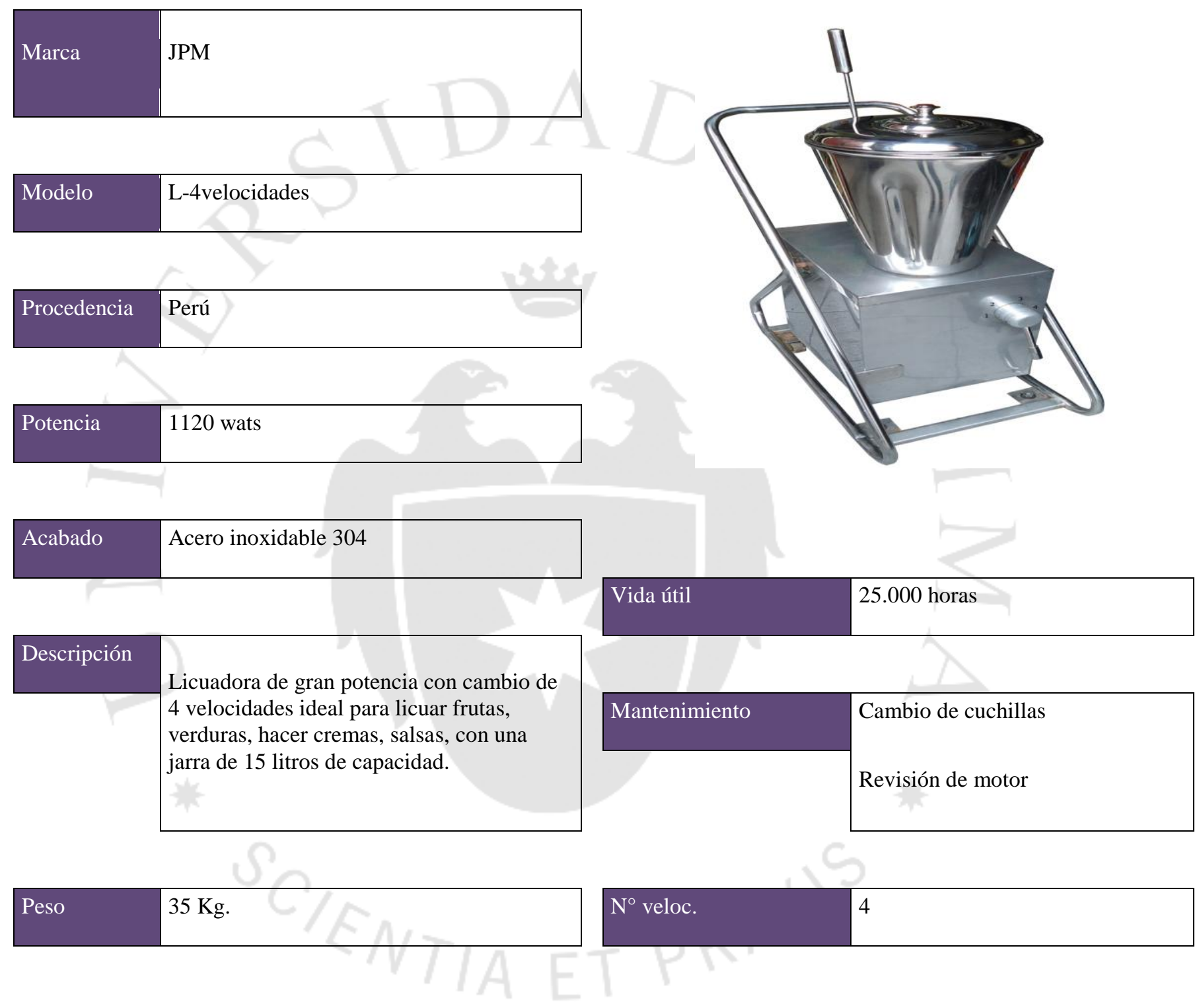


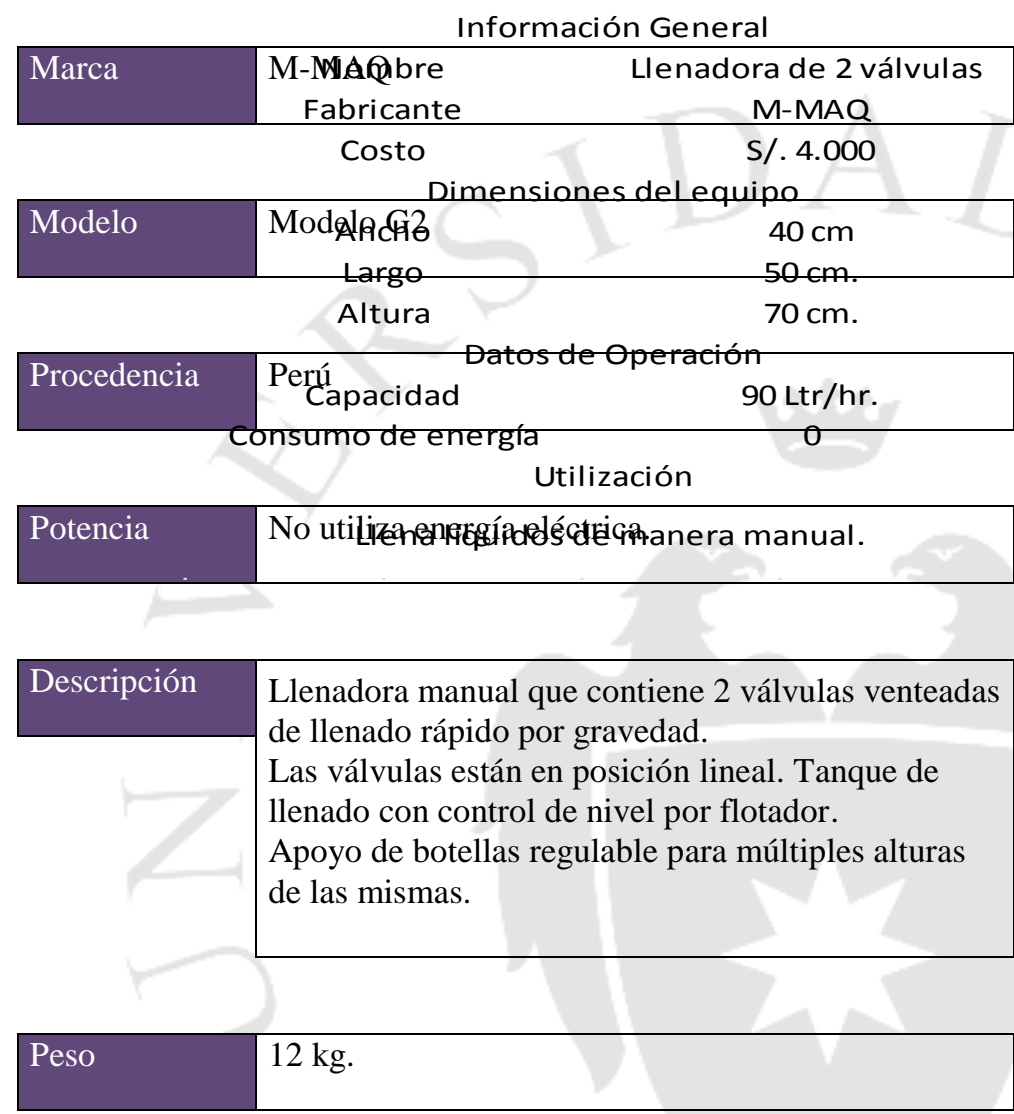

\begin{tabular}{|l|l|}
\hline Regulaciones & $\begin{array}{l}\text { Volumen llenado por botella } \\
\text { Velocidad de llenado }\end{array}$ \\
\hline
\end{tabular}

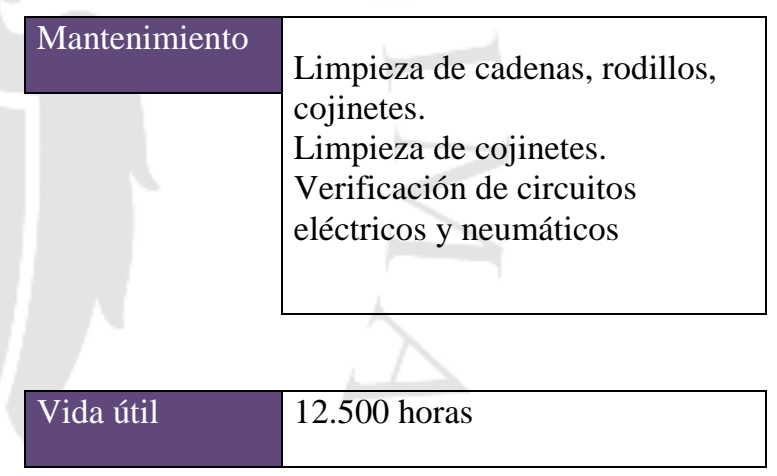

M.O

Requiere de una persona para ser operada. 


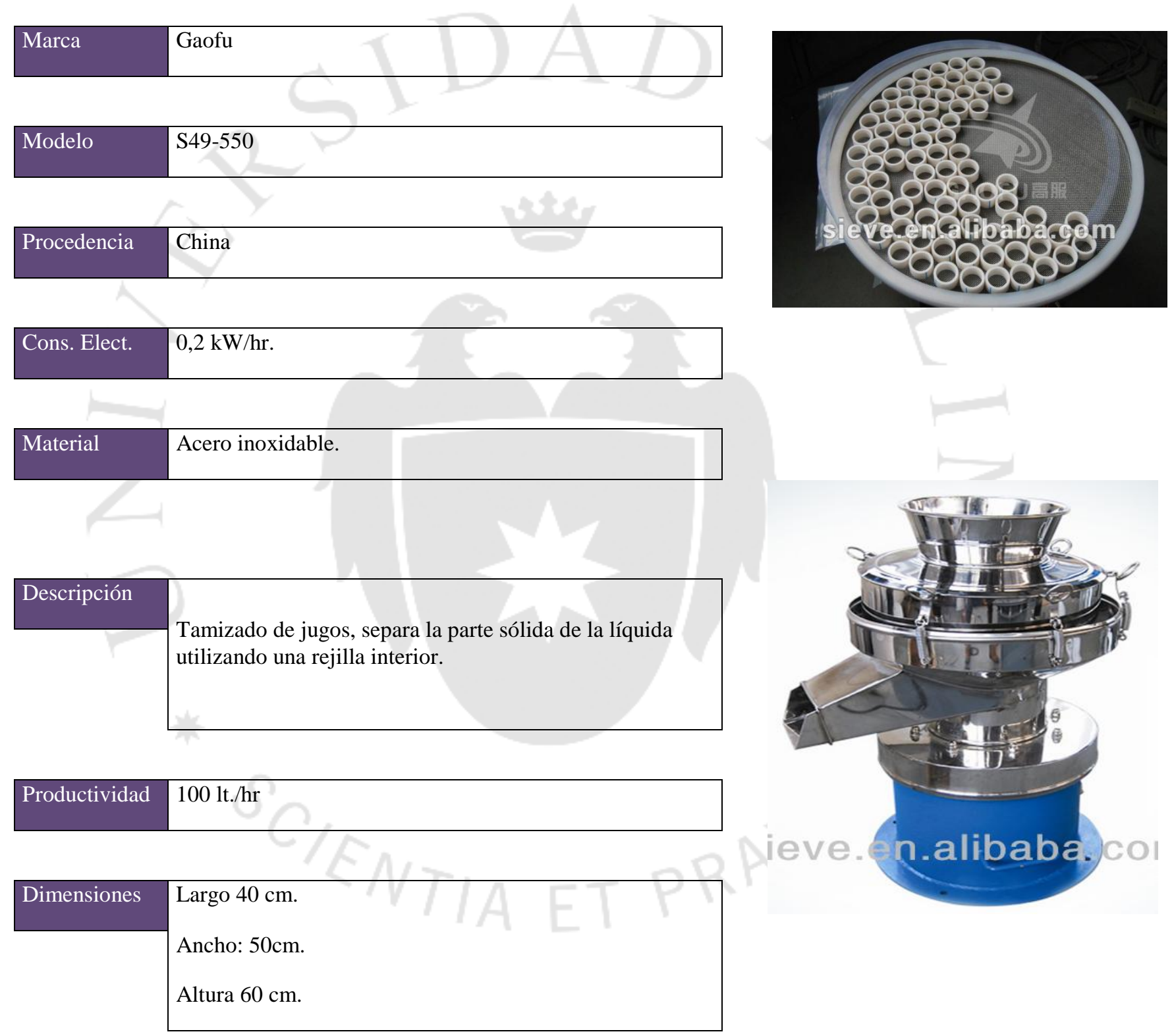



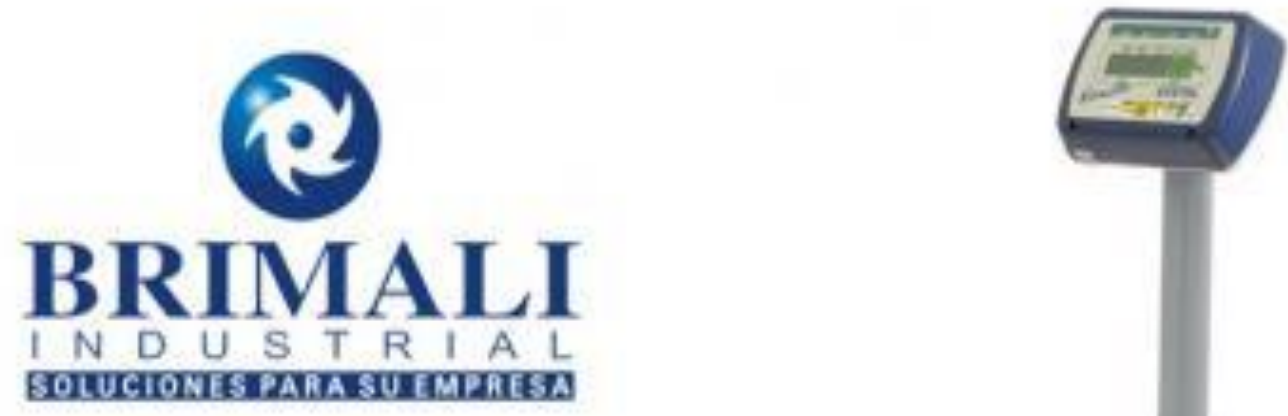

\section{KOMBA 300}

Modelo (SP) Solo Peso

Conexión a PC o impresora

Teclado membrana impermeable

Celda protegida a impactos y sobrepeso

Brazo soporte y bandeja desmontable

Plataforma resistente en acero inoxidable

Función acumulación y desacumulación de peso

Energía AC 110 - 220V. / DC recargable

Capacidad $300 \mathrm{Kg} . \pm 100 \mathrm{~g}$.

Tara ingresable por peso y teclado

\section{Balanza Systel - SP - Conexión PC - Impresora}




\section{Sistema de Osmosis Inversa en Perú de 100GPD - Modelo ROMI 100 - 100GPD}

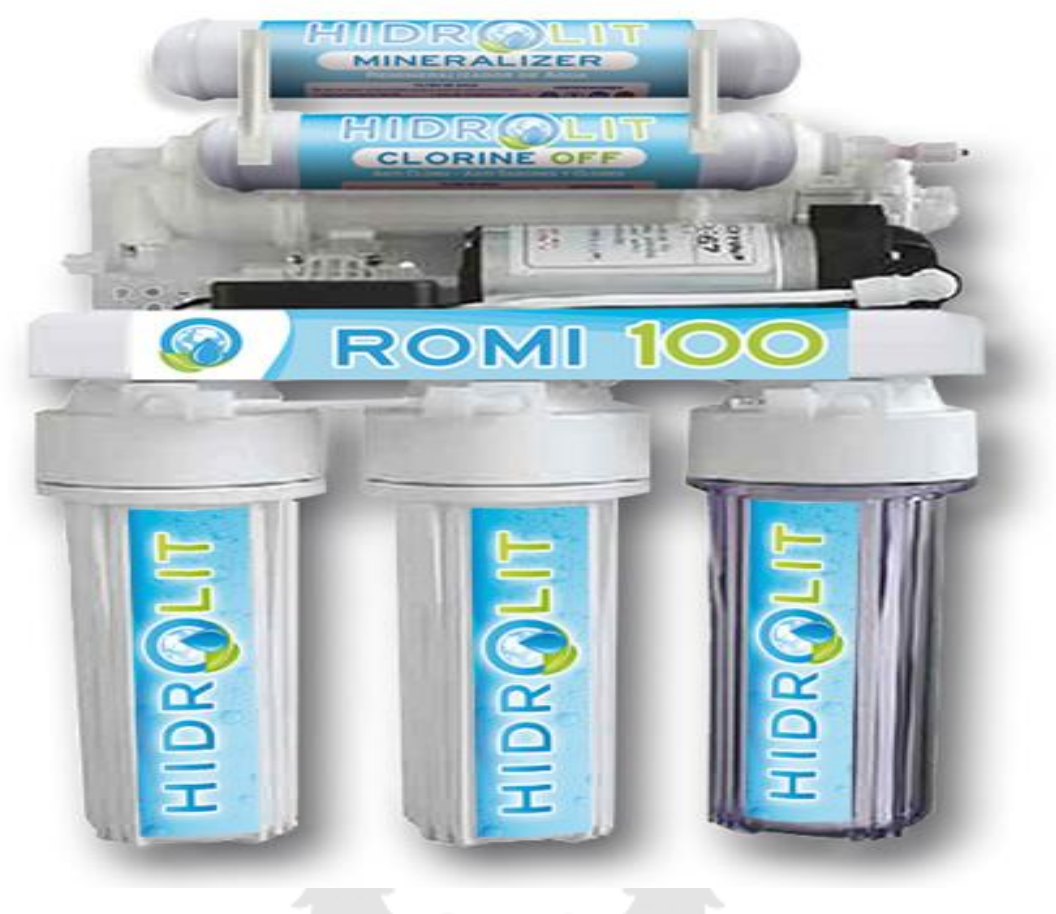

Características:

- Fácil Instalación: Lo instala con el manual de instalación cualquier persona sin conocimientos de plomería en menos de 20 minutos.

- Mantenimiento simple: Anualmente debe cambiar las primeras etapas de filtración, y trienalmente debe cambiar la membrana osmoplasmática.

- Alto rendimiento: 160.000 litros. Luego cambia los cartuchos de filtración como se indica en el punto anterior.

- Calidad del Agua: El sistema de osmosis inversa desmineraliza el agua por completo para luego de obtener casi $\mathrm{H} 2 \mathrm{O}$ pura sin minerales. Luego de ello, pasa por una última etapa de "post mineralización", con lo cual el agua es nanocristalina y óptima para el consumo humano. Aguas embotelladas de esta calidad en el mercado cuestan mucho dinero. El Agua del ROMI 100 cumple con los parámetros de la Organización Mundial de la Salud y la normativa de DIGESA Perú. Avalado por Organismos Internacionales, NSF, Water Quality y Laboratorios de primera línea.

- Dimensiones: $50 \mathrm{~cm}$ altura $\times 49 \mathrm{~cm}$ ancho $\mathrm{x} 40 \mathrm{~cm}$ profundo.

- Presentación del Equipo: El equipo viene ensamblado, listo para instalar, termosellado, con todos sus repuestos y accesorios para instalarlo fácilmente y en su caja institucional.

- Sustancias que retiene con alta efectividad: Bacterias, Arsénico, Mercurio, Cianuro, Zinc, Cobre, Cadmio, Uranio, Selenio, Antimonio, THM's, Cloraminas, Sedimentos, Suciedad, Cloro, Plomo y Cromo. 


\section{ANEXO 7: MATRIZ DE LEOPOLD}

Uno de los métodos a utilizar para medir el impacto ambiental será a partir de la matriz de Leopold.

Los valores a tomar para la calificación serán entre -10 y 10 siendo:

Calificativo de -10 a una actividad que hace un daño extremo al factor ambiental calificado. Calificativo de 10 a una actividad que promueve la preservación ambiental.

\section{Matriz de Leopold}

\begin{tabular}{|c|c|c|c|c|c|c|c|c|c|c|}
\hline Factores ambientales & Físico & químic & & Socic & econón & & & Biológ̨ & $\cos$ & \\
\hline Actividades del proceso & 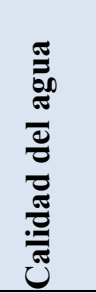 & 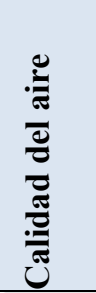 & 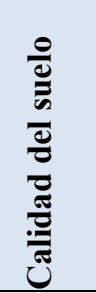 & 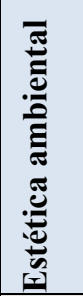 & 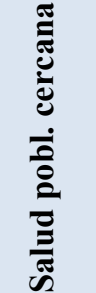 & 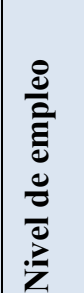 & $\stackrel{\mathscr{e}}{\stackrel{0}{ٍ}}$ & $\frac{\pi}{\frac{\pi}{2}}$ & 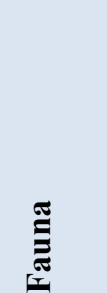 & \\
\hline Selección & 0 & -1 & -1 & 0 & 0 & 2 & 0 & -1 & 0 & $-0,11$ \\
\hline Lavado & -3 & -1 & -1 & 0 & 0 & 2 & -1 & -1 & 0 & $-0,56$ \\
\hline Inmersión & -1 & 0 & -1 & 0 & 0 & 2 & 0 & -1 & 0 & $-0,11$ \\
\hline Secado & -1 & 0 & 0 & 0 & 0 & 2 & -3 & 0 & 0 & $-0,22$ \\
\hline Rehidratado & 0 & 0 & 0 & 0 & 0 & 2 & 0 & 0 & 0 & 0,22 \\
\hline Licuado & -1 & 0 & 0 & 0 & 0 & 2 & -2 & 0 & 0 & $-0,11$ \\
\hline Tamizado & -2 & 0 & 0 & 0 & 0 & 2 & -1 & 0 & 0 & $-0,11$ \\
\hline Fermentado & -1 & -1 & 0 & 0 & -1 & 2 & -1 & 0 & -1 & $-0,33$ \\
\hline Filtrado & -1 & 0 & -1 & 0 & 0 & 2 & -2 & 0 & 0 & $-0,22$ \\
\hline Embotellado & -1 & 0 & 0 & 0 & 0 & 2 & -1 & 0 & 0 & 0,00 \\
\hline Encorchado & 0 & 0 & 0 & 0 & 0 & 2 & 0 & 0 & 0 & 0,22 \\
\hline Etiquetado & 0 & 0 & 0 & 0 & 0 & 2 & 0 & 0 & 0 & 0,22 \\
\hline Promedio & $-0,92$ & $-0,25$ & $-0,33$ & 0,00 & $-0,08$ & 2,00 & $-0,92$ & $-0,25$ & $-0,08$ & $-0,09$ \\
\hline
\end{tabular}

Elaboración propia 
Como se puede apreciar en la producción de licor de higo hay un impacto ambiental negativo que es muy pequeño, esto se da debido al proceso en sí, a las máquinas utilizadas que por ser de pequeñas no generan gran impacto y a la cantidad de higos procesados.

Los impactos ambientales implicados al proceso de producción son:

Producción de polvo que pudiera ocasionar alergias o enfermedades respiratorias.

Ruido que se pueda originar en las diferentes etapas del proceso y transporte.

Consumo de energía

Generación de residuos procedentes de las bolsas, residuos como restos del tamizado.

Como acciones para contrarrestar los impactos ambientales se tiene:

- Emplear correctamente toda la maquinaria y equipos involucrados en el proceso de producción.

- Utilizar el higo en la cantidad necesaria.

- Realizar la adecuada gestión de stock de almacén para evitar que caduquen los productos.

- Optimizar el transporte de productos de un lugar a otro.

- Realizar una buena disposición de los residuos, para reducir sus efectos sobre el medio.

- Buena limpieza de las instalaciones. 
A continuación se mostrará el gráfico del producto con información básica:

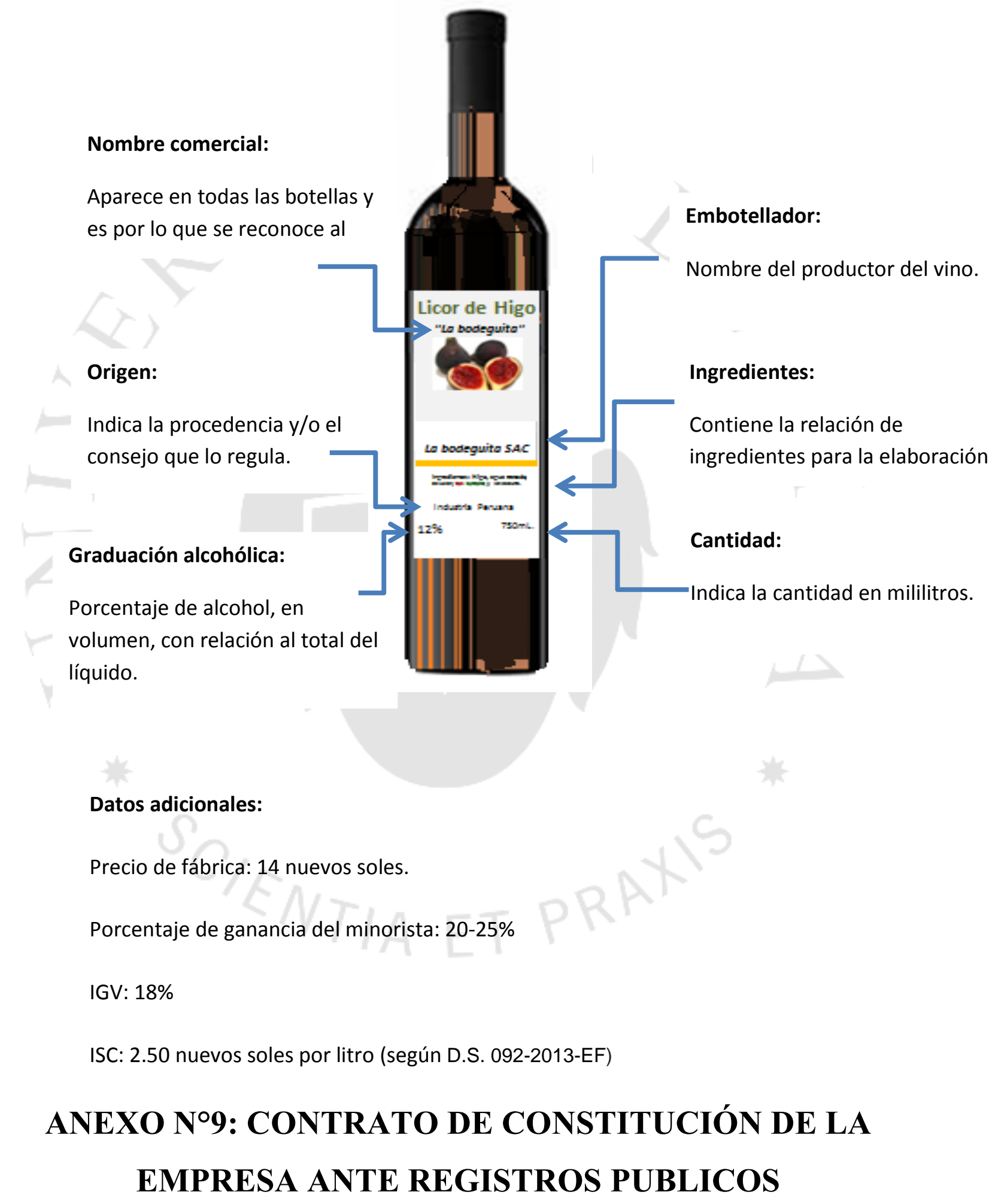


MODELO DE CONSTITUCIÓN PARA UNA EMPRESA ANONIMA CERRADA S.A.C. (CON APORTE EN BIENES DINERARIOS) CONSTITUCIÓN DE EMPRESA SOCIEDAD ANONIMA CERRADA

QUE OTORGA DON:

DE CONFORMIDAD CON EL ARTICULO 58 LITERAL H DE LA LEY 26002 LEY DEL NOTARIADO), SEÑALANDO DOMICILIO PARA EFECTOS DE ESTE INSTRUMENTO EN DISTRITO. PROVINCIA Y DEPARTAMENTO $\mathrm{DE}$ EN LOS TÉRMINOS SIGUIENTES:

PRIMERA.POR

$E L$ PRESENTE, $D O N$ : CONSTITUYE UNA

EMPRESA INDIVIDUAL DE RESPONSABILIDAD LIMITADA

BAJO LA DENOMINACIÓN DE: “ E.I.R.L." CON DOMICILIO EN LA CIUDAD DE. QUE INICIA SUS OPERACIONES A PARTIR DE SU INSCRIPCIÓN EN EL REGISTRO MERCANTIL CON UNA DURACIÓN INDEFINIDA, PUDIENDO ESTABLECER SUCURSALES EN TODO EL TERRITORIO NACIONAL.

SEGUNDA.- EL OBJETO DE LA EMPRESA ES: SE ENTIENDEN INCLUIDOS EN EL OBJETO LOS ACTOS RELACIONADOS CON EL MISMO, QUE COADYUVEN A LA REALIZACION DE SUS FINES EMPRESARIALES. PARA CUMPLIR DICHO OBJETO, PODRÁ REALIZAR TODOS AQUELLOS ACTOS Y CONTRATOS QUE SEAN LÍCITOS, SIN RESTRICCIÓN ALGUNA.

TERCERA.- EL CAPITAL DE LA EMPRESA ES DE $\mathrm{S} /$ CONSTITUIDO POR APORTES DEL

TITULAR.

CUARTA.- SON ÓRGANOS DE LA EMPRESA, EL TITULAR Y LA GERENCIA. EL RÉGIMEN QUE LE CORRESPONDA ESTÁ SEÑALADO EN EL DECRETO LEY № 21621, ARTÍCULOS 39 Y 50 RESPECTIVAMENTE Y DEMÁS NORMAS MODIFICATORIAS Y COMPLEMENTARIAS.

QUINTA.- LA GERENCIA ES EL ÓRGANO QUE TIENE A SU CARGO LA ADMINISTRACIÓN Y REPRESENTACIÓN DE LA EMPRESA. SERÁ DESEMPEÑADA POR UNA O MÁS PERSONAS NATURALES. EL CARGO DE GERENTE ES INDELEGABLE. EN CASO DE QUE EL CARGO DE GERENTE RECAIGA EN EL TITULAR, ÉSTE SE DENOMINARÁ TITULAR GERENTE. 
SEXTA.- LA DESIGNACIÓN DEL GERENTE SERÁ EFECTUADA POR EL TITULAR, LA DURACIÓN DEL CARGO ES INDEFINIDA, AUNQUE PUEDE SER REVOCADO EN CUALQUIER MOMENTO.

SEPTIMA.- CORRESPONDE AL GERENTE:

ORGANIZAR EL RÉGIMEN INTERNO DE LA EMPRESA.

CELEBRAR CONTRATOS INHERENTES AL OBJETO DE LA EMPRESA,

FIJANDO SUS CONDICIONES; SUPERVISAR Y FISCALIZAR EL DESARROLLO DE LAS ACTIVIDADES DE LA EMPRESA.

REPRESENTAR A LA EMPRESA ANTE LOS PODERES DEL ESTADO, INSTITUCIONES NACIONALES Y EXTRANJERAS, GOZANDO DE LAS FACULTADES GENERALES Y ESPECIALES A QUE SE REFIEREN LOS ARTÍCULOS 74, 75, 77 Y 436 DEL CÓDIGO PROCESAL CIVIL. TAMBIÉN GOZA DE LA FACULTAD A QUE SE REFIERE EL ARTÍCULO 10 DE LA LEY GOZA DE LA FACULTAD A QUE SE REFIERE EL ARTíCULO 10 DE LA LEY № 26636, PODRA CELEBRAR CONCILIACIÓN EXTRA JUDICIAL, ADEMAS PODRA CONSTITUIR Y REPRESENTAR A LA ASOCIACION QUE CREA CONVENIENTE Y DEMAS NORMAS COMPLEMENTARIAS.

CUIDAR LOS ACTIVOS DE LA EMPRESA.

ABRIR Y CERRAR CUENTAS CORRIENTES, BANCARIAS, MERCANTILES Y GIRAR CONTRA LAS MISMAS, COBRAR Y ENDOSAR CHEQUES DE LA EMPRESA, ASI COMO ENDOSAR Y DESCONTAR DOCUMNETOS DE CREDITO. SOLICITAR SOBREGIROS, PRÉSTAMOS, CREDITOS O FINANCIACIONES PARA DESARROLLAR EL OBJETO SOCIAL CELEBRANDO LOS CONTRATOS RESPECTIVOS.

SOLICITAR TODA CLASE DE PRESTAMOS CON GARANTIAS HIPOTECARIA, PRENDARIA Y DE CUALQUIER FORMA, ADEMAS CONOCIMIENTO DE EMBARQUE, CARTA DE PODER, CARTA FIANZA, POLIZA, LETRAS DE CAMBIO, PAGARES, FACTURAS CONFORMADAS Y CUALQUIER OTRO TITULO VALOR.

SUSCRIBIR CONTRATOS DE ARRENDAMIENTO Y SUBARRENDAMIENTO.

COMPRAR Y VENDER LOS BIENES SEAN MUEBLES O INMUEBLES DE LA EMPRESA, SUSCRIBIENDO LOS RESPECTIVOS CONTRATOS.

CELEBRAR, SUSCRIBIR LEASING O ARRENDAMIENTO FINANCIERO, CONSORCIO, ASOCIACION EN PARTICIPACION Y CUALQUIER OTRO CONTRATO DE COLABORACION EMPRESARIAL, VINCULADOS AL OBJETO DE LA EMPRESA. 
AUTORIZAR A SOLA FIRMA LA ADQUISICIÓN DE BIENES, CONTRATACIÓN DE OBRAS Y PRESTACIÓN DE SERVICIOS PERSONALES.

NOMBRAR, PROMOVER, SUSPENDER Y DESPEDIR A LOS EMPLEADOS Y SERVIDORES DE LA EMPRESA.

CONCEDER LICENCIA AL PERSONAL DE LA EMPRESA.

CUIDAR DE LA CONTABILIDAD Y FORMULAR EL ESTADO DE PÉRDIDAS Y GANANCIAS, EL BALANCE GENERAL DE LA EMPRESA Y LOS DEMÁS ESTADOS Y ANÁLISIS CONTABLES QUE SOLICITE EL TITULAR.

SOLICITAR, ADQUIRIR, TRANFERIR REGISTROS DE PATENTES, MARCAS, NOMBRES COMERCIALES CONFORME A LEY, SUSCRIBIENDO CUALQUIER CLASE DE DOCUMENTOS VINCULADOS, QUE CONLLEVE A LA REALIZACION DEL OBJETO SOCIAL.

PARTICIAPR EN LICITACIONES, CONCURSOS PUBLICOS Y/O ADJUDICACIONES, SUSCRIBIERON LOS RESPECTIVOS DOCUMENTOS, QUE CONLLEVE A LA REALIZACION DEL OBJETO SOCIAL.

OCTAVA.- PARA TODO LO NO PREVISTO RIGEN LAS DISPOSICIONES CONTENIDAS EN EL D.L. № 21621 Y AQUELLAS QUE LAS MODIFIQUEN O COMPLEMENTEN.

DISPOSICION TRANSITORIA.- DON................., IDENTIFICADO CON DNI №.................... EJERCERA EL CARGO DE TITULAR GERENTE DE LA EMPRESA, PERUANO, CON DOMICILIO SEÑALADO EN LA INTRODUCCION DE LA PRESENTE.

DE. DEL $2 \ldots \ldots$. 